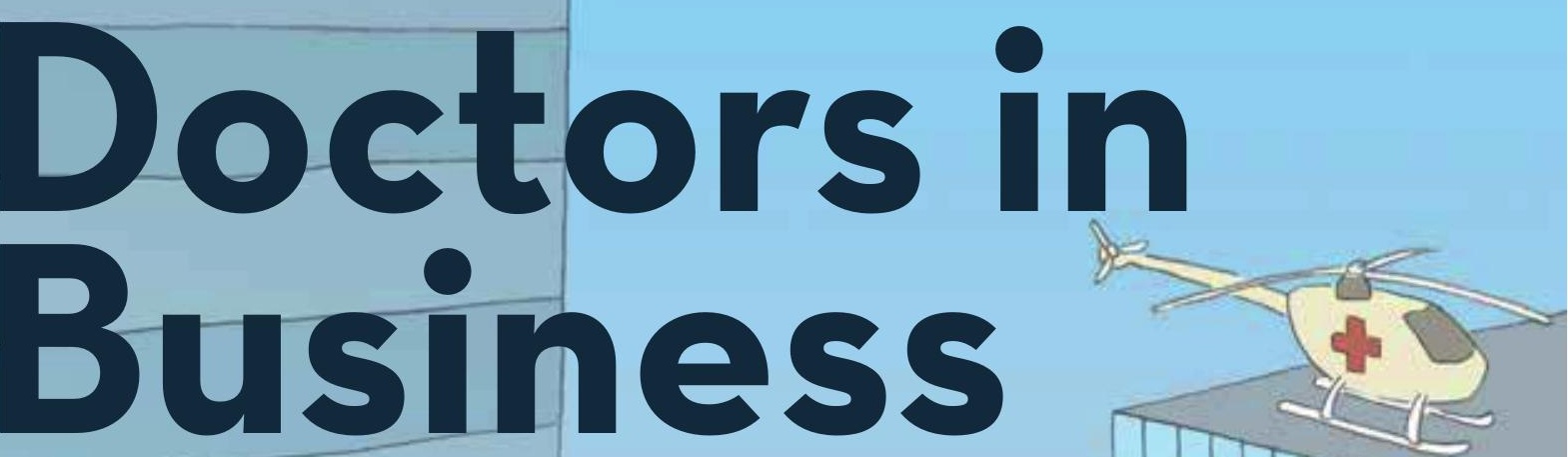

A STUDY INTO WHAT DRIVES 'PHYSICIANS' ENTREPRENEURSHIP 


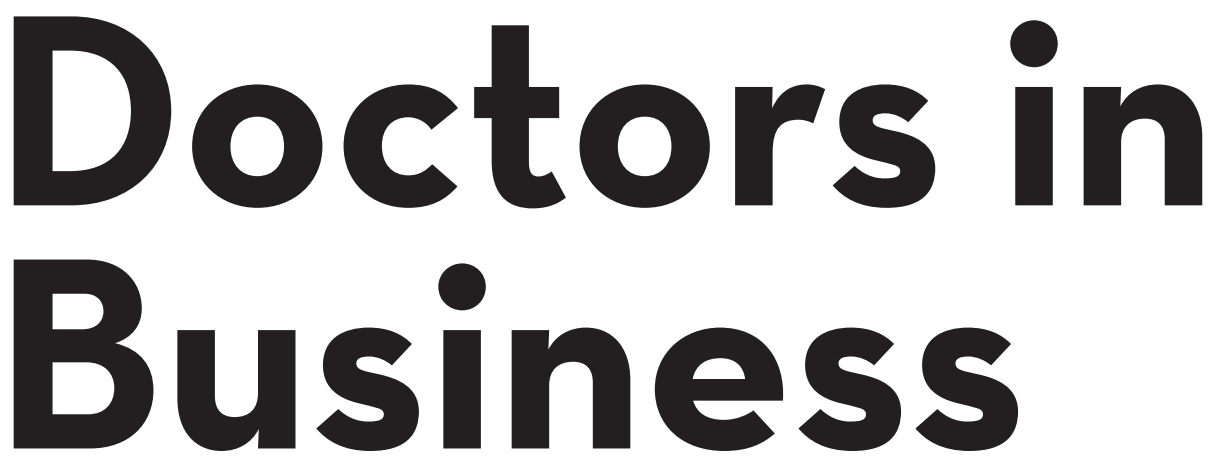

A STUDY INTO WHAT DRIVES

PHYSICIANS' ENTREPRENEURSHIP

WOUT T. KOELEWIJN 
ISBN: 978-90-365-3590-8

(C) 2013, W.T. Koelewijn, Enschede, The Netherlands

All rights reserved. No parts of this publication may be reproduced, stored in a retrieval system of any nature, or transmitted in any form or by any means, electronic, mechanical, photocopying, recording or otherwise, without the prior written permission of the holder of the copyright.

\section{Address of correspondence}

Wout T. Koelewijn

Vlietsingel 84

3831 SV Leusden

The Netherlands

woutkoelewijn@hotmail.com

+31(0)6 - 20584867 


\title{
DOCTORS IN BUSINESS
}

\section{A STUDY INTO WHAT DRIVES PHYSICIANS' ENTREPRENEURSHIP}

\section{PROEFSCHRIFT}

\author{
ter verkrijging van \\ de graad van doctor aan de Universiteit Twente, \\ op gezag van de rector magnificus, \\ prof. dr. H. Brinksma, \\ volgens besluit van het College voor Promoties \\ in het openbaar te verdedigen \\ op vrijdag 28 maart 2014 om 14:45 uur \\ door \\ Wout Theodoor Koelewijn
}

geboren op 28 maart 1976

te Amersfoort 
Dit proefschrift is goedgekeurd door de promotoren:

Prof. dr. W.H. van Harten

Prof. dr. A.J. Groen

en de assistent promotor:

Dr. M.L. Ehrenhard

\section{Promotiecommissie}

\section{Voorzitter/secretaris}

Prof. dr. ir. A.J. Mouthaan

Universiteit Twente

\section{Promotoren}

Prof. dr. W.H. van Harten

Universiteit Twente

Prof. dr. A.J. Groen

Universiteit Twente

\section{Assistent promotor}

Dr. M.L. Ehrenhard

Universiteit Twente

\section{Leden}

Prof. dr. W.A. Dolfsma

Rijksuniversiteit Groningen

Prof. dr. ir. O.A.M. Fisscher

Universiteit Twente

Prof. dr. A. Klink

Vrije Universiteit

Prof. dr. J. Telgen

Universiteit Twente

Prof. dr. L.H.L. Winter

Nyenrode Business Universiteit

\section{Paranimfen}

Henk-Willem Laan

Joanne Leerlooijer 




\section{Contents}

Chapter 1 Introduction

Chapter 2 - a literature review

Intra-organizational dynamics as drivers of entrepreneurship among physicians and managers in hospitals of western countries

Chapter 3 - a qualitative exploratory study

Physician' entrepreneurship explained: intra-organizational dynamics in Dutch hospitals and specialty clinics

Chapter 4 - a quantitative study

Exploring personal interests of physicians in hospitals and specialty clinics

Chapter 5 - a quantitative study

Bridging neo-institutional theory and entrepreneurship theory:

validation in a hospital setting

Chapter 6 - a quantitative study

Motivational needs and self-efficacy as predictors of

entrepreneurial intent of hospital-based physicians

Chapter 7 Discussion

List of respondents

Summary

Samenvatting

Dankwoord 


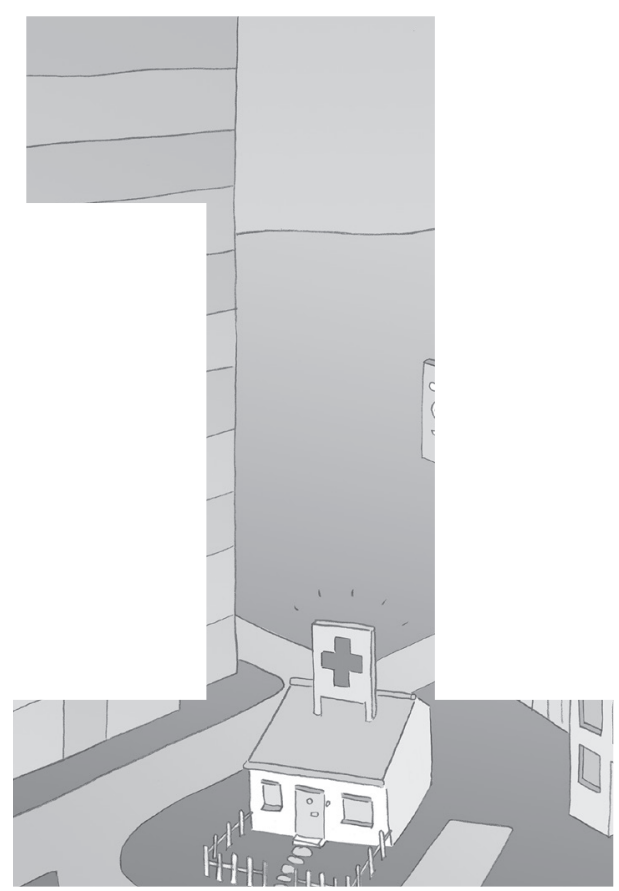

INTRODUCTION 


\section{Introduction}

During the 1990s, physicians' entrepreneurship grew into a powerful force shaping healthcare in many Western countries (Saltman et al., 2002). Deregulations implemented during this period were part of a third consecutive wave of healthcare reforms starting after the Second World War (Cutler, 2002). The first wave started after 1945 and continued until the 1980s; its aim was to ensure access to medical care. Wide accessibility and scientific and technological developments led to rising costs and to limit these costs, the second wave (from the 1980s until the early 1990s) introduced widespread budget and control systems across different nations. To tackle the problem of growing inefficiencies resulting from these budget systems, the third wave introduced incentives and competition among healthcare providers from the early 1990s onward. This resulted in a surge of medical entrepreneurial activities (Cutler, 2002; Ikkersheim \& Koolman, 2013; Saltman \& Figueras, 1997). In this process, the concept of managed competition was introduced. Managed competition relies on a sponsor to manage the market for competing health plans, to establish equitable rules, create price-elastic demand, and avoid uncompensated risk selection. That sponsor could take the form of a health insurance purchasing cooperative, fundholder or health maintenance organization (HMO) (Enthoven, 1993). Different countries adopted elements of managed competition in shaping and optimizing their healthcare systems. In the United States, managed competition was introduced with an emphasis on competition and entrepreneurship. In contrast, European countries, like the United Kingdom and the Netherlands, put the emphasis on regulatory instruments when they implemented managed competition.

In the US, after gaining control of both the Senate and the House in 1995, the Republicans reinforced market mechanisms to contain costs. For-profit Managed Care Organizations (MCOs) were most successful in capitalizing on these developments (Bloche, 2003). During the same period, the number of specialty hospitals in the United States tripled between January 1990 and March 2003 from 29 to 100, and the number of ambulatory surgery centers (ASCs) doubled between 1991 and 2001 (Shactman, 2005). Proponents claimed that because of their specialization, they could achieve higher quality, greater efficiency, and lower costs than general hospitals.

These general hospitals however, contended that specialty facilities drained revenues away from full-service community hospitals, thereby endangering care for the poor and uninsured as well as endangering the provision of unprofitable services. In addition, critics pointed at the fact that most specialty facilities are at least partly owned by physicians, who can benefit financially from referring or not referring patients to their own facilities. In response to this criticism, the federal government essentially banned the building of new specialty 
hospitals by instituting an eighteen-month moratorium on payments for physician services in new hospitals in which physicians have an ownership interest. After this moratorium on the specialty hospitals ended in 2006, the number of these facilities almost tripled, resulting in a new rise in healthcare expenditure (Perry, 2012).

In the UK, the introduction of managed competition entailed general practitioners (primary care physicians) becoming general fundholders who received a budget to purchase services such as elective surgery and outpatient pharmaceuticals. This reportedly led to lower prices paid by fundholders for hospital services relative to non-fundholders (Propper \& Soderlund, 1998). In the late 1990s, healthcare expenditure in the UK rose rapidly. However, with National Health Service (NHS) budget limits strictly imposed, these increases were not caused by growing demand or new entrants, but were rather the outcome of a political process in which Labour chose to raise the NHS budget by $5 \%$ to $7.5 \%$ per annum. As a result, the NHS became a better alternative to independent hospitals, three-quarters of which are for profit. To enable a further increase in provider capacity, the government started to encourage the use of the independent sector by the NHS in 2000. To have access to the NHS, independent hospitals had to alter their business model in order to become a competitive alternative to NHS hospitals, creating a level playing field. As a result, the average cost of outsourced care in the independent sector decreased by 20\% between 2002 and 2006 (Jeurissen, 2010).

In the Netherlands, a system of regulated competition with a mandate for individuals to purchase insurance was introduced in 2006. In addition, reforms containing elements from managed competition were implemented as the former lump-sum financing system was gradually replaced by a fee-for-service system (prestatiebekosting). This, combined with the favorable treatment of specialty clinics, caused an increase in entrepreneurial activities. The number of specialty clinics (many of which were founded by physician-entrepreneurs) rose by 62\% from 149 in 2007 to 241 in 2010, while the total revenue of these clinics tripled to 315 million euros, equaling roughly $2.5 \%$ of the total hospital budget (NZA, 2012). These developments were supported by the Dutch Healthcare Authority, which advocated more specialty clinics because of their substantially lower charges compared to hospitals (NZA, 2012), while in addition, the Dutch Health Care Inspectorate pointed at the positive developments with regard to the quality of care provided by specialty clinics (Health Care Inspectorate, 2010, 2013). In the media as well, specialty clinics were being welcomed as efficient providers, providing fast access to patient-oriented care (Bruinsma, 2010, 2011; Piersma, 2009; Walburg, 2011).

Despite the positive perception of physicians' entrepreneurship as a part of managed competition, it still remained a relatively rare phenomenon as the vast majority of physicians continued to work in hospitals, leaving the start of specialty clinics to the 'entrepreneurial 
few'. At times, the entrepreneurial ambitions of these physicians resulted in fierce conflicts with hospital management who felt surprised by their aspirations (Hopstaken, 2008; Kiers, 2008). This triggered the questions answered in this dissertation: What drives physicians' entrepreneurship and how can latent entrepreneurship in hospitals be identified and developed?

The objective of this dissertation is to study the drivers of physicians' entrepreneurship in the Netherlands. In this dissertation, 'entrepreneurship' is defined as "new entries of actors who discover, evaluate, and exploit opportunities to create future products or services by bearing the risk of profit and loss" (Burgelman, 1983; Hisrich \& Peters, 1992; Shane \& Venkataraman, 2000). In the research model, the construct of entrepreneurial intent (Thompson, 2009) is used as a proxy for entrepreneurship. Hereby entrepreneurial intent is defined as "a self-acknowledged conviction by a person that they intend to set up a new business venture and consciously plan to do so at some point in the future".

In explaining the causes for developing entrepreneurial intent, this study focusses on two perspectives influencing a physician's decision to become an entrepreneur, namely (a) contextual factors, both in the field and at the intra-organizational level, and (b) individual factors, constituted by motivational needs and self-efficacy. The dual focus of this dissertation helps to better understand the drivers of physicians' entrepreneurship.

With respect to the first perspective, we apply institutional theory as it allows for in-depth analysis of the impact of contextual factors like market reforms and institutional regulations on intra-organizational dynamics in hospitals (Carsrud et al., 1987). As part of the third wave of healthcare reforms, principles of business-like healthcare were adopted, including value creation, cost containment, and efficiency, at the expense of the traditional logic of medical professionalism, which emphasizes the need to practice in strict isolation from commercial interests, optimizing the medical quality of procedures. At the organizational level of hospitals, this gave rise to tensions between physicians embedded in the weakening logic of medical professionalism and hospital management embedded in the advancing businesslike healthcare logic (Reay \& Hinings, 2009).

In their model, Greenwood and Hinings (1996) relate these field-level contextual influences brought about by market and institutional actors to intra-organizational dynamics. The basic premise of these dynamics is the concept of interests, as they provide arenas for conflict as groups holding different interests will attempt to promote their own interests through power relations. As a result, intra-organizational dynamics are defined as the interplay between (1) power dependences and interest dissatisfaction, (2) power dependencies and value commitments, (3) interest dissatisfaction and value commitments, and finally (4) 
power dependencies and value commitments and the capacity for action of organizational actors, potentially leading to radical change.

Combining entrepreneurship theory and institutional theory has long been identified as having significant potential, but so far little progress has been made in realizing that potential (Phillips \& Tracey, 2007). Furthermore, efforts to combine the two strands have often failed to adopt an institutional perspective in explaining nascent entrepreneurship at the individual level (Bruton et al., 2010; Greenwood et al., 2011; Smets et al., 2012). This dissertation contributes to the literature by doing exactly these two things: combining institutional and entrepreneurship theory to explain patterns of nascent entrepreneurship among individual actors.

However, as a majority of physicians share similar contextual factors as incorporated in the neo-institutional model while only a minority of physicians turn into entrepreneurs, the research presented in this dissertation includes a second perspective: the personality of the individual physician. Therefore physicians' traits will also be considered (Heckert et al., 2000b; Kets de Vries, 1977; McClelland, 1961). More specifically, focus is placed on the question of what personality-related traits cause physicians to develop entrepreneurial intent. Hereby, two influential personality-related theories will be taken into account: motivational needs theory and self-efficacy theory.

Motivational needs theory has been highly influential in explaining various types of choices and behavior. For example, it suggests that students' motivation to exert effort in the quest to attain academic success is driven by their relative need levels particularly their need to achieve (Atkinson, 1958; Steers \& Braunstein, 1976). Furthermore, in this dissertation the construct of capacity for action included in the original model of Greenwood and Hinings (1996) is replaced by the related and more recent construct of self-efficacy (Bandura, 2002).

This dissertation seeks to rectify the limitations of previous studies, thereby aiming to make two general and five theoretical contributions. With respect to the first general contribution, this dissertation aims to provide additional, quantitatively-based knowledge about physicians' entrepreneurship in the Netherlands to add to the earlier, more qualitative research of Kim Putters (Putters, 2001). The second general contribution is directed towards the development of an instrument for hospital management. Given the growing importance of providing care at lower costs and of higher quality, it becomes increasingly important to identify specialties that can fulfill these demands, either in an intrapreneurial or an extrapreneurial setting. This research aims to provide a forward-looking model that could help identify potential entrepreneurial hotspots in the hospital organization. 
In addition, this dissertation aims to make five contributions to contemporary institutional and entrepreneurship theory, thereby enhancing current understanding about the drivers of physicians' entrepreneurship. It aims to contribute (1) to the conceptualization of intra-organizational dynamics in hospitals and the influence of these dynamics on entrepreneurship, (2a) to the assessment of the intra-organizational dynamics in hospitals that lead to physicians' entrepreneurship, $(2 \mathrm{~b})$ to the understanding of the nature of physicians' entrepreneurship, (3) to the identification of physicians' interests across hospital type or specialties, (4) to the combination of institutional and entrepreneurship theory and their influence on patterns of nascent entrepreneurship among individual actors, and (5) to the identification of physicians' motivational needs and self-efficacy across hospital type or specialties and their influence on entrepreneurial intent. These five topics serve as the leading themes of the five papers included in this dissertation. These themes are summarized and shown in relation to one another in Figure 1.

Figure 1: Research model

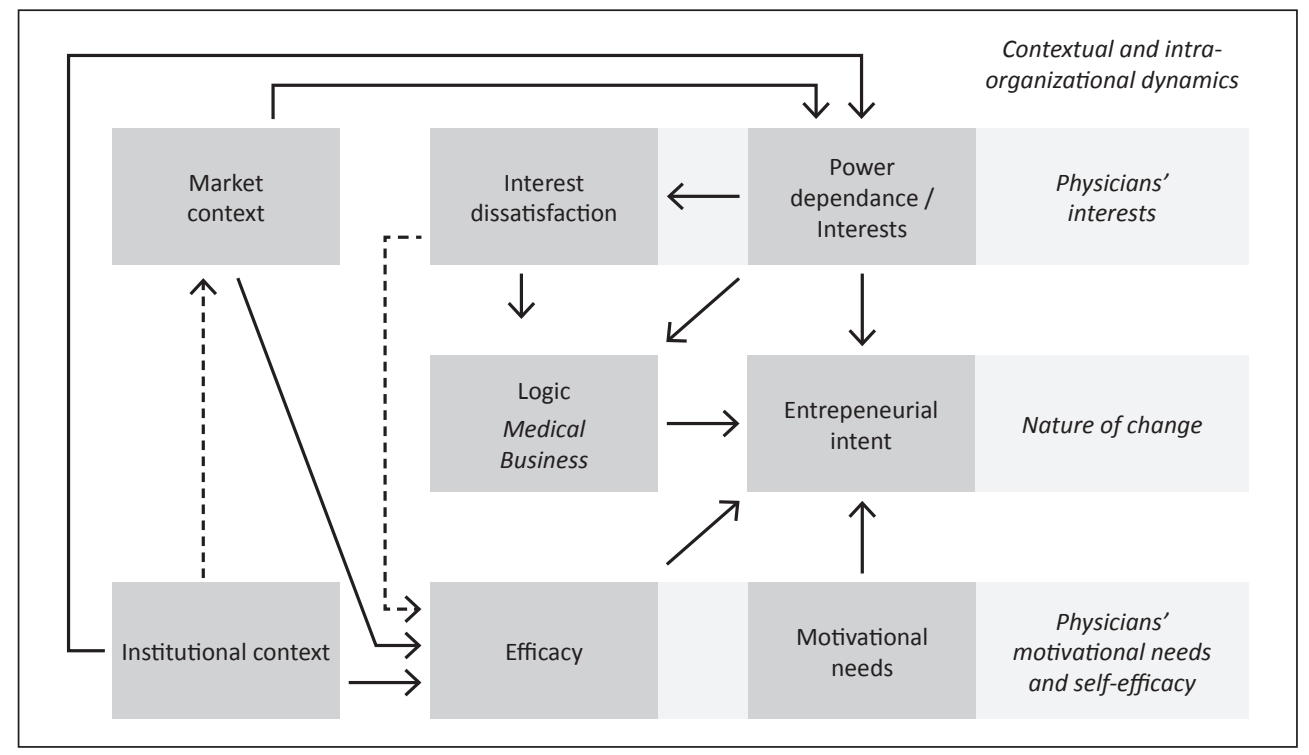

The basic research model is derived from the neo-institutional model of radical organizational change as defined by Greenwood and Hinings (1996).Six adaptations were made to this model. First, although in their model Greenwood and Hinings assumed interests to be fundamental to explaining intra-organizational dynamics, they did not explicate this. In this research model, however, physicians' interests are included as a key component of intra-organizational dynamics. Second, the construct of 'value commitment' was replaced 
by 'logic', as an embeddedness in one logic was assumed to imply a competitive value commitment towards the other logic (Reay \& Hinings, 2009). Third, capacity for action, which was originally defined as "the ability to manage the transition process from one logic or template to another" (Greenwood \& Hinings, 1996: 1039), was replaced by perceived efficacy at three levels: the individual self, the physician group and the organizational level (Zhao et al., 2005). Fourth, although market and institutional contexts are unrelated in the original model of Greenwood and Hinings, in this dissertation a connection between them is proposed (Scott, 2001). Fifth, dissatisfaction by physicians with facilitation received by management in striving to satisfy certain interests is expected to influence the efficacy of the individual, group and organization as perceived by the individual physician. Therefore, a relation between the two constructs is added. Finally, the motivational needs of individual physicians are added to allow for further analyses based on personality differences (Atkinson, 1958; Heckert et al., 2000a; Steers \& Braunstein, 1976).

The research questions and methodology that guided this research for each of the five papers will be specified next.

\section{Research questions and methods}

This dissertation examines the factors driving physicians' entrepreneurship. In particular, it addresses drivers related to:

1. Contextual factors, both at the field level and at the intra-organizational level

2. Individual factors, constituted by motivational needs and self-efficacy

These two perspectives cover a wide, complex domain of institutional, entrepreneurship, and motivational theory and research. Both are explicated further and studied in the five papers.

As the first step in constructing a research model, Paper 1 deals with the conceptualization and understanding of intra-organizational dynamics between physicians and managers in hospitals and their influence on the development of physicians' entrepreneurship. Paper 1 therefore addresses the following question: What is known about the influence of intraorganizational dynamics among hospital managers and physicians on entrepreneurship in hospitals? To answer this question, a literature review was conducted based on a careful search and selection of articles.

In Paper 2, after having established the theoretical model for our research, this model is grounded by a series of case studies. These studies were conducted to answer the following 
question: How do intra-organizational dynamics between physicians and managers induce physicians to become entrepreneurs by starting a specialty clinic? In addition, Paper 2 contains an analysis of the nature of the change brought about by starting a specialty clinic. The question addressed with respect to this issue is: Are specialty clinics founded through physicians' entrepreneurship an example of sedimented change or transformational change? For this exploratory study, a two-step survey was conducted. First, a total of fifteen physicians and eight managers in four hospitals were interviewed. In the second step, twelve physicians and seven managers in twelve specialty clinics were interviewed.

The findings of Papers 1 and 2 show that interests held by organizational members are central in explaining intra-organizational dynamics and organizational responses to institutional pressures (Bidwell, 2012; Greenwood \& Hinings, 1996; Kim et al., 2007; Koelewijn et al., 2012). Therefore, Paper 3 focuses on the identification and analysis of the interests of physicians working in diverse specialties and different types of hospitals by answering this research question: What is the nature and structure of physicians' interests and how do these differ between hospitals and specialties? To answer this question, first a list of ten interests was derived by drawing from both theory and interviews with physicians. This list was included in an online survey for which we sent an invitation by e-mail to a large sample of 7,913 physicians in the Netherlands working in a hospital or specialty clinic. Two reminders were sent to those who had not yet filled out the survey. In total, $18.6 \%$ filled out the questionnaire completely $(n=1,475)$. Next, systematic exploratory and confirmatory factor analyses were applied to produce a structural model of physicians' interests. Finally, univariate and post-hoc analyses of the standardized factor loadings were used to assess differences between specialty groups and types of hospitals.

After designing and grounding the research model and having established both the nature and structure of physicians' interests, the next topic examined, in Paper 4 , is on the contextual pressures and intra-organizational dynamics that contribute to the birth of physicians' entrepreneurial intent. The research question is formulated as: How do contextual factors influence intra-organizational dynamics and how do these dynamics contribute to the development of entrepreneurial intent among physicians? This research question was answered by analyzing data derived from the large-scale survey presented in Paper 3. However for this research, focus is on the 7,762 hospital-based physicians, of whom a total of $18.4 \%$ filled out the questionnaire completely $(n=1,430)$. Structural equation modeling was used for the analyses.

Finally, although the majority of physicians often share quite similar contextual factors, just a small number of them turn into entrepreneurs. Therefore in Paper 5, it is hypothesized that personality-related factors like motivational needs and self-efficacy influence 
entrepreneurial intent. This study aims to clarify the following research question: How do motivational needs and self-efficacy relate to entrepreneurial intent among physicians and how do these differ across hospitals and specialties? This research question was answered by analyzing the data derived from the large-scale survey among 7,913 physicians in the Netherlands, including both hospital-based physicians and physicians working in specialty clinics $(n=1,475)$.

\section{Dissertation outline}

Table 1 summarizes the research questions, the research methods, the chapter that provides the answer to each research question and the constructs that were examined. In Chapter 2 , our research model is established by conducting a literature review. In Chapter 3 this theoretical model is grounded through the use of interviews with physicians and managers, both in hospitals and in specialty clinics. In addition, as physicians' interests are central to the research model, the nature and structure of these interests is investigated in Chapter 4. Chapter 5 presents the results of the empirical testing of the research model. Finally in Chapter 6 , the influence of motivational needs and self-efficacy on physicians' entrepreneurial intent is established for both hospital-based physicians and physicians working in specialty clinics. The conclusions and discussion are presented in Chapter 7. Finally, Chapter 8 contains the summary. 


\section{Table 1: Outline of dissertation}

\begin{tabular}{|c|c|c|c|}
\hline Chapter & Research question & Research method & Constructs \\
\hline 2 & $\begin{array}{l}\text { What is known about the influence } \\
\text { of intra-organizational dynamics } \\
\text { among hospital managers and } \\
\text { physicians on entrepreneurship in } \\
\text { hospitals? }\end{array}$ & Literature review & $\begin{array}{l}\text { Contextual and } \\
\text { intra-organizational } \\
\text { dynamics }\end{array}$ \\
\hline 3 & $\begin{array}{l}\text { - How do intra-organizational } \\
\text { dynamics between physicians } \\
\text { and managers induce physicians } \\
\text { to become entrepreneurs by } \\
\text { starting a specialty clinic? } \\
\text { - Are specialty clinics } \\
\text { founded through physicians' } \\
\text { entrepreneurship an example } \\
\text { of sedimented change or } \\
\text { transformational change? }\end{array}$ & Interviews & $\begin{array}{l}\text { Intra-organizational } \\
\text { dynamics } \\
\text { Nature of change }\end{array}$ \\
\hline 4 & $\begin{array}{l}\text { Are specialty clinics } \\
\text { founded through physicians' } \\
\text { entrepreneurship an example } \\
\text { of sedimented change or } \\
\text { transformational change? }\end{array}$ & $\begin{array}{l}\text { Literature, } \\
\text { interviews, survey }\end{array}$ & Physicians' interests \\
\hline 5 & $\begin{array}{l}\text { How do contextual factors influence } \\
\text { intra-organizational dynamics } \\
\text { and how do these dynamics } \\
\text { contribute to the development } \\
\text { of entrepreneurial intent among } \\
\text { physicians? }\end{array}$ & Survey & $\begin{array}{l}\text { Contextual- and } \\
\text { intra-organizational } \\
\text { dynamics }\end{array}$ \\
\hline 6 & $\begin{array}{l}\text { How do motivational needs and self- } \\
\text { efficacy relate to entrepreneurial } \\
\text { intent among physicians and how } \\
\text { these differ across hospitals and } \\
\text { specialties? }\end{array}$ & Survey & $\begin{array}{l}\text { Motivational needs } \\
\text { and self-efficacy }\end{array}$ \\
\hline
\end{tabular}




\section{References}

Atkinson, J.W. (1958). Motives in fantasy, action, and society: a method of assessment and study. Princeton, N.J.,: Van Nostrand.

Bandura, A. (2002). Self-efficacy, The exercise of control. New York: Freeman and Company.

Bidwell, M.J. (2012). Politics and Firm Boundaries: How Organizational Structure, Group Interests, and

Resources Affect Outsourcing. Organization Science, 23, 1622-1642.

Bloche, M.G. (2003). The Privatization of Health Care Reform: Legal and Regulatory Perspectives: Oxford University Press.

Bruinsma, J. (2010). Zelfstandige kliniek als heipaal onder het ziekenhuis. De Volkskrant, Amsterdam, 2. Bruinsma, J. (2011). Privéklinieken doen nu volledig mee. De Volkskrant, Amsterdam, 1.

Bruton, G.D., Ahlstrom, D., \& Li, H.L. (2010). Institutional Theory and Entrepreneurship: Where Are We Now and Where Do We Need to Move in the Future? Entrepreneurship Theory and Practice, 34, 421-440.

Burgelman, R.A. (1983). A process model of internal corporate venturing in the diversified major firm.

Administrative Science Quarterly, 28, 223-244.

Carsrud, A., Olm, K., \& Eddy, G. (1987). Entrepreneurs-Mentors, networks, and successful new venture development: An exploratory study. American Journal of Small Business, 12, 13-18.

Cutler, D.M. (2002). Equality, efficiency, and market fundamentals: The dynamics of international medicalcare reform. Journal of Economic Literature, 40, 881-906.

Elsen van den, W. (2013). Zelfstandige Klinieken luiden Noodklok. Zorgvisie.

Enthoven, A.C. (1993). The History and Principles of Managed Competition. Health Affairs, 12, 24-48.

Greenwood, R., \& Hinings, C.R. (1996). Understanding radical organizational change: Bringing together the old and the new institutionalism. Academy of Management Review, 21, 1022-1054.

Greenwood, R., Raynard, M., Kodeih, F., Micelotta, E.R., \& Lounsbury, M. (2011). Institutional Complexity and Organizational Responses. Academy of Management Annals, 5, 317-371.

Health Care Inspectorate, I.G.Z. (2010). Het resultaat telt - particuliere klinieken 2009. Utrecht.

Health Care Inspectorate, I.G.Z. (2013). Het resultaat telt - Particuliere Klinieken 2012. Utrecht.

Heckert, T.M., Cuneio, G., Hannah, A.P., Adams, P.J., Droste, H.E., Mueller, M.A., et al. (2000a). Creation of a new needs assessment questionnaire. Journal of Social Behavior and Personality, 15, 121-136.

Heckert, T.M., Cuneio, G., Hannah, A.P., Adams, P.J., Droste, H.E., Mueller, M.A., et al. (2000b). Creation of a New Needs Assessment Questionnaire. Journal of Social Behavior \& Personality, 15, 121-136.

Hisrich, R.D., \& Peters, M.P. (1992). Entrepreneurship: Starting, developing, and managing a new enterprise.: McGraw-Hill/Irwin.

Hopstaken, L. (2008). Ongericht ondernemen, ziekenhuizen in verwarring. Zorgvisie, 38.

Ikkersheim, D.E., \& Koolman, X. (2013). The first effects of Dutch health care reform on hospitals. Proefschrift (p. 10). Amsterdam: Vrije Universiteit.

Jeurissen, P.P.T. (2010). For-profit hospitals: A comparative and longitudinal study of the for-profit hospital sector in four Western countries. iBMG. Rotterdam: Erasmus University Rotterdam.

Kets de Vries, M.F.R. (1977). The entrepreneurial personality: A person at the crossroads. Journal of Management Studies, 14, 34-58.

Kiers, B. (2008). Ziekenhuizen en artsen Assen ruziën door. Zorgvisie, 38.

Kim, T.Y., Shin, D., Oh, H., \& Jeong, Y.C. (2007). Inside the iron cage: Organizational political dynamics and institutional changes in presidential selection systems in Korean universities, 1985-2002. Administrative Science Quarterly, 52, 286-323.

Koelewijn, W.T., Ehrenhard, M.L., Groen, A.J., \& van Harten, W.H. (2012). Intra-organizational dynamics as 
drivers of entrepreneurship among physicians and managers in hospitals of western countries. Social Science \& Medicine, 75, 795-800.

McClelland, D.C. (1961). The achieving society. Princeton, N.J.,: Van Nostrand.

Mous, K. (2013). Beleid CZ in strijd met Zorgverzekeringswet. Het Financieele Dagblad, Amsterdam.

NZA (2012). ZBC Monitor - Een kwalitatieve en kwantitatieve analyse. Utrecht: Dutch Healthcare Authority.

Olsthoorn, S. (2013). Klein en niet vernieuwend? Dan geen contract meer met Achmea. Het Financieele Dagblad. Amsterdam.

Perry, J.E. (2012). Physician-Owned Specialty Hospitals and the Patient Protection and Affordable Care Act: Health Care Reform at the Intersection of Law and Ethics. American Business Law Journal, 49, 369-417.

Phillips, N., \& Tracey, P. (2007). Opportunity recognition, entrepreneurial capabilities and bricolage:

connecting institutional theory and entrepreneurship in strategic organization. Strategic Organization, 5, 313.

Piersma, J. (2009). Privékliniek komt snel uit de marge van de zorgmarkt. Het Financieele Dagblad (p. 1). Amsterdam.

Propper, C., \& Soderlund, N. (1998). Competition in the NHS internal market: An overview of its effects on hospital prices and costs. Health Economics, 7, 187-197.

Putters, K. (2001). Geboeid ondernemen: een studie naar het management in de Nederlandse ziekenhuiszorg. Rotterdam: Erasmus Universiteit Rotterdam.

Reay, T., \& Hinings, C.R. (2009). Managing the Rivalry of Competing Institutional Logics. Organization Studies, 30, 629-652.

Saltman, R.B., Busse, R., \& Mossialos, E. (2002). Regulating entrepreneurial behaviour in European health care systems. Philadelphia: Open University Press Buckingham.

Saltman, R.B., \& Figueras, J. (1997). European healthcare reform: Analysis of current strategies. WHO Regional Publications. Copenhagen: WHO Regional Office for Europe.

Scott, W.R. (2001). Institutions and Organizations. Thousand Oaks: Sage Publications.

Shactman, D. (2005). Specialty hospitals, ambulatory surgery centers, and general hospitals: Charting a wise public policy course. Health Affairs, 24, 868-873.

Shane, S., \& Venkataraman, S. (2000). The Promise of Entrepreneurship As a Field of Research. The Academy of Management review, 25, 217-226.

Smets, M., Morris, T., \& Greenwood, R. (2012). From practice to field: A multilevel model of practice-driven institutional change. Academy of Management Journal, 55, 877-904.

Steers, R.M., \& Braunstein, D.N. (1976). Behaviorally-Based Measure of Manifest Needs in Work Settings. Journal of Vocational Behavior, 9, 251-266.

Thompson, E.R. (2009). Individual Entrepreneurial Intent: Construct Clarification and Development of an Internationally Reliable Metric. Entrepreneurship Theory and Practice, 33, 669-694.

Walburg, L. (2011). Lijfarts. Het Financieele Dagblad (p. 4). Amsterdam.

Zhao, H., Seibert, S.E., \& Hills, G.E. (2005). The mediating role of self-efficacy in the development of entrepreneurial intentions. Journal of Applied Psychology, 90, 1265-1272. 



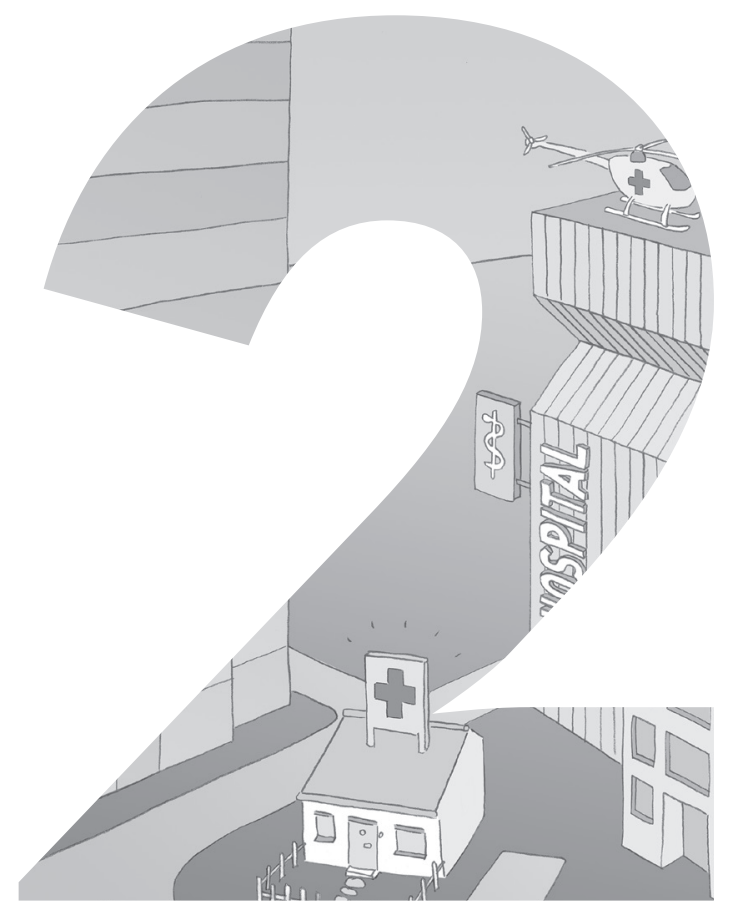

review

INTRA-ORGANIZATIONAL DYNAMICS AS DRIVERS OF ENTREPRENEURSHIP AMONG PHYSICIANS AND MANAGERS IN HOSPITALS OF WESTERN COUNTRIES

Wout T. Koelewijn Michel L. Ehrenhard Aard J. Groen Wim H. van Harten 


\begin{abstract}
During the past decade, entrepreneurship in the healthcare sector has become increasingly important. The aging society, the continuous stream of innovative technologies and the growth of chronic illnesses are jeopardizing the sustainability of healthcare systems. In response, many European governments started to reform healthcare during the 1990s, replacing the traditional logic of medical professionalism with business-like logics. This trend is expected to continue as many governments will have to reduce their healthcare spending in response to the current growing budget deficits. In the process, entrepreneurship is being stimulated, yet little is known about intra-hospital dynamics leading to entrepreneurial behavior.
\end{abstract}

The purpose of this article is to review existing literature concerning the influence of intraorganizational dynamics on entrepreneurship among physicians and managers in hospitals of Western countries. Therefore, we conducted a theory-led, systematic review of how intra-organizational dynamics among hospital managers and physicians can influence entrepreneurship. We designed our review using the neo-institutional framework of Greenwood and Hinings (1996). We analyze these dynamics in terms of power dependencies, interest dissatisfaction and value commitments.

Our search revealed that physicians' dependence on hospital management has increased along with healthcare reforms and the resulting emphasis on business logics. This has induced various types of responses by physicians. Physicians can be pushed to adopt an entrepreneurial attitude as part of a defensive value commitment toward the businesslike healthcare logic, to defend their traditionally dominant position and professional autonomy. In contrast, physicians holding a transformative attitude toward traditional medical professionalism seem more prone to adopt the entrepreneurial elements of business-like healthcare, encouraged by the prospect of increased autonomy and income. Interest dissatisfaction and competing value commitments can also stimulate physicians' entrepreneurship and, depending on their relative importance, determine whether it is necessity-based or opportunity-driven.

\title{
Introduction
}

Entrepreneurship among physicians and hospital managers is gaining renewed interest. Already during the 1990s, many European governments started to deregulate their healthcare systems, induced by trends like the aging society, the progress of innovation, the introduction of new technologies and the growth of chronic illnesses that were 
pushing healthcare to its limits (Saltman, Busse, \& Mossialos, 2002). In explicitly adopting principles of the new logic of business-like healthcare, more weight was being given to value creation, cost containment and efficiency at the expense of the traditional logic of medical professionalism, which emphasizes the need to practice in strict isolation from commercial interests, optimizing the medical quality of procedures. At the organizational level, this gave rise to tensions between physicians embedded in the weakening logic of medical professionalism and hospital management embedded in the advancing business-like healthcare logic (Reay \& Hinings, 2009). In addition, the growing reliance on the businesslike healthcare logic resulted in a surge of medical entrepreneurial activities in countries across Europe (Saltman \& Figueras, 1997).

The debt crisis and the current economic downturn will place additional pressure on governments of many Western countries to consider budget cuts and healthcare deregulations (OECD, 2011). Based on the outcomes during the 1990s, intra-organizational dynamics between physicians and managers are expected to cause tension in addition to leading to a growing number of medical entrepreneurial initiatives. Still, little is known about how these dynamics lead to entrepreneurship.

To improve our understanding, we conducted a systematic literature review. We used neoinstitutional theory to provide a structure for the intra-organization dynamics that may be driving entrepreneurship. This approach fits well with the recent interest in making connections with organization studies in the analysis of health policy and management, as was shown in the recent Social Science \& Medicine Special Issue "Organization studies and the analysis of health systems" (Currie, Dingwall, Kitchener, \& Waring, 2012).

We formulated our review question as follows:

What is known about the influence of intra-organizational dynamics among hospital managers and physicians on entrepreneurship in hospitals?

We define entrepreneurship in a hospital context as 'new entries by physicians and hospital managers who discover, evaluate and exploit opportunities to create future health services by bearing the risk of profit and loss' (Burgelman, 1983; Hisrich \& Peters, 1992; Shane \& Venkataraman, 2000). Hereby, our definition of physicians includes registrars, specialists and all other doctors working in a hospital. In addition, mistakes are viewed less forgivingly in the healthcare sector compared to the commercial sector, increasing the need for entrepreneurial risks to be calculated (Currie, Humpreys, Ucbasaran, \& McManus, 2008). As the business-like healthcare logic emphasizes entrepreneurial values, practices and processes, we include entrepreneurial orientation as defined by Lumpkin and Dess (1996). It comprises the constructs of autonomy, innovativeness, risk taking, proactiveness and 
competitive aggressiveness (Lumpkin \& Dess, 1996; Miller \& Friesen, 1983). Based on the work of these authors, we reason that a minimum level of entrepreneurial orientation among organizational members or groups will be critical in explaining entrepreneurial initiatives (Krauss \& Frese,2005).

We structure our review according to the neo-institutional model of Greenwood and Hinings (1996). As this frequently cited and highly relevant model has not been applied in a hospital setting before, we aim to fill this gap in literature. Greenwood and Hinings define intraorganizational dynamics in terms of the interplay between (1) power dependences and interest dissatisfaction, (2) power dependencies and value commitments, and (3) interest dissatisfaction and value commitments. In our review we will focus on intra-organizational dynamics depicted in the shaded area of Fig. 1, as potential drivers of entrepreneurship. We combine these three elements with the concept of entrepreneurial orientation and formulate three subsidiary research questions:

1. In what ways do power interdependencies between physicians and managers lead to interest dissatisfaction in hospitals?

2. How are power dependencies related to value commitments and to an entrepreneurial orientation in hospitals?

3. How do interest dissatisfaction, competitive commitment and entrepreneurial orientation interact in hospitals?

\section{Review method}

The databases of Scopus, ISI and Pubmed were searched for relevant studies in English language journals. The searches were conducted in OctobereNovember (weeks 43e45) 2009. The definition of search items and the selection criteria were based on the three research questions. The retrieved articles were manually searched for other relevant references. In total, 34 publications were included in this review. More information on the search terms and selection process can be found in the attached web-accessible file (Appendix A).

We present the main findings and finish with a summary per research question. In addition, we contextualize the findings by adding quotations from interviews held in 2010e2011 with physicians in the Netherlands to verify the applicability of the neo-institutional model of Greenwood and Hinings (1996) in a hospital setting. 
Figure 1: Review model of intra-organizational dynamics as drivers of entrepreneurship

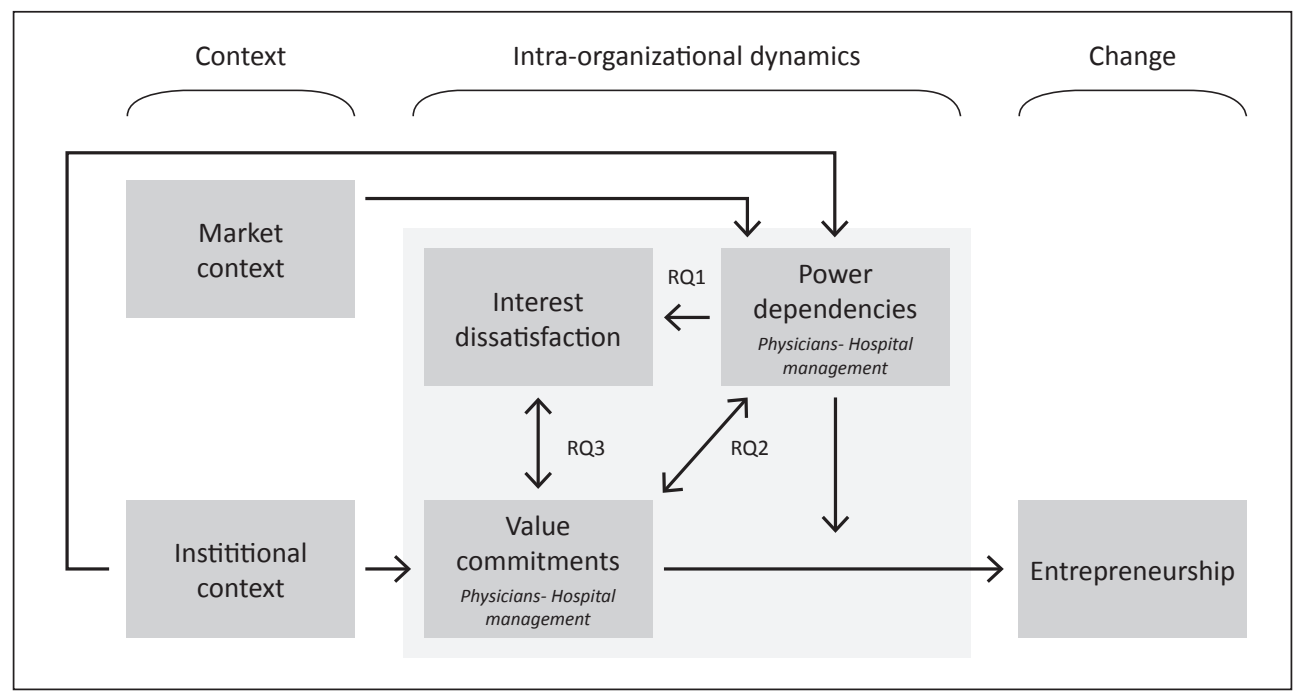

\title{
Power dependencies and interest dissatisfaction in hospitals
}

\begin{abstract}
"I started my own clinic as I did not like the prospect of having to keep working in the hospital, having to put patients in need of a simple treatment on a waiting list just to fit the schedules of management." Quotation from interview with an ophthalmologist, the Netherlands, January 2010
\end{abstract}

We found twenty-two papers dealing with the influence of power dependencies on interest dissatisfaction in hospitals. An overview of the review results can be found in Table 1, which is obtainable through a web-accessible file (Appendix A).

Many papers were found on the increased interdependence between physicians and managers resulting from the increased dominance of the business-like healthcare logic (Castellani \& Wear, 2000; Degeling et al., 2006; Kaissi, 2005; Lega \& Depietro, 2005; Som, 2005; Sutherland \& Dawson, 1998; Warwicker, 1998). Although medical dominance is reported to remain strong in key areas of technical and clinical autonomy (Abernethy, 2004; Currie, Humpreys, Waring, \& Rowley, 2009; Fitzgerald \& Ferlie, 2000; Klopper-Kes, Meerdink, van Harten, \& Wilderom, 2009; McDonald, Waring, \& Harrison, 2006; Succi, Lee, \& Alexander, 1998), it is a source of strain and interest dissatisfaction among physicians (Thorne, 2002). Based on a survey among 8108 physicians in the US, Paul Leigh (2002) points to the high proportion of dissatisfied physicians among surgical specialties, whereas their colleagues 
practicing medical specialties are unlikely to be dissatisfied. In addition to current explanations, we reason that the degree of tacit versus explicit knowledge applied by physicians may partly explain the level of interest dissatisfaction among physicians. Generally, physicians working in medical specialties tend to apply higher levels of tacit knowledge compared to physicians working in surgical specialties. As the application of tacit knowledge is more difficult to bring within a management-driven performance framework than the application of explicit knowledge, physicians working in other medical specialties are more successful in retaining their power and more satisfied compared to their colleagues working in surgical specialties.

Also, physicians outside clinical areas have not uniformly lost power as some have gained considerably. Based on their longitu dinal study of 31 physicians with managerial responsibilities, Fitzgerald and Ferlie (2000) conclude that many physicians who have assumed hybrid roles have gained political power and autonomy. Some of these physicians are motivated by the desire to improve the quality of care, some are defensively motivated, using their role as a custodial strategy to prevent managers from gaining influence, while others are self-interested and looking for power.

Despite these reports of physicians being successful in retaining power, physicians are more pessimistic than managers about their relationship, as Rundall and Kaiser (2004) conclude on the basis of their survey among 1092 physicians and managers in the UK and US. This is attributed to the pervasive nature of the change brought by the introduction of the businesslike healthcare logic. Another explanation provided by various studies is that both physicians and managers believe the other group has more power than they attribute to their own group (Braithwaite \& Westbrook, 2004; Salvadores, Schneider, \& Zubero, 2001). This observation is of particular importance as the perceived power and influence of a group may be tied to its willingness to participate in decision-making and the implementation of policies (Daake \& Anthony, 2000). This may result in a possible lack of support for new policies if physicians perceive them as management-led without adequate consultations (Som, 2005). According to Rivers and Woodard (1997), conflicts between hospital management and physicians can be prevented or resolved by avoiding controversial decisions that may threaten the interests and autonomy of either group and by agreeing to decisions that hold something for everyone. In addition, the influence of power dependency on interest dissatisfaction might be mitigated by the use of common goals and objectives to stimulate collaboration (Klopper-Kes et al., 2009).

Summarizing, although no studies were found dealing with interest dissatisfaction among hospital managers, convincing data on the relation between power dependency and interest dissatisfaction among physicians was found in the surveys of Degeling (2006) and Paul Leigh (2002), and the case studies described by Cohn (2005) and Som (2005). In general, 
these studies conclude that the growing dominance of the business-like healthcare logic has severely altered the relationship between managers and physicians in hospitals. Power dependencies have shifted and intensified in favor of hospital managers. The diminished economic autonomy of physicians and continuous efforts to bring clinical care within a management framework are associated with interest dissatisfaction among physicians. Their level of dissatisfaction is dependent on the extent of their subordination to management and the use of structural power to control their clinical practice. Sensitivity to controversial decisions and super-ordinate goals stimulating collaboration between physicians and managers may mitigate the influence of power dependency on interest dissatisfaction. In the following sections we will relate these concepts of power dependency and interest dissatisfaction to value commitments and entrepreneurial orientation.

\section{Power dependencies, value commitments and entrepreneurial orientation in hospitals}

"I always aimed to provide the highest quality of care. However, hospital management made it hard for me to do so. Now, in my own clinic, I have the freedom to work according to the highest standards." Quotation from interview with a surgeon, the Netherlands, November 2011

Nine papers were found dealing with the relation between power dependencies and value commitments in hospitals. An overview of the review results is included in Table 2, which is available as a web-accessible file (Appendix A).

Based on their survey among 1221 physicians, Floyd, Kramer, and Born (2005) suggest that physicians driven by a defensive value commitment are more willing to leave their profession than to change the way they practice. In reality however, physicians may even turn into clinical directors participating in hospital management despite their defensive value commitment, as Buchanan (1997) reports on the basis of in-depth interviews with six clinical directors and nineteen hospital managers.

Ong and Schepers (1998) report that physicians who continue in their medical profession despite the changes brought about by the business-like healthcare logic may choose to leverage their position as sole supplier of essential knowledge and skills to protect their interests. A more explicit strategy driven by a defensive value commitment is to invoke the help of the board of trustees or to start lawsuits to stop hospital management adopting principles of the business-like healthcare logic (Feinstein, 2003). 
Thorne (2002) provides examples in her in-depth case study of the struggle for power between physicians and managers in the British National Health Service, showing how physicians are pushed to explicitly adopt elements of the business-like healthcare logic they intended to resist to maintain their professional autonomy. As a result, these physicians may attend business schools to acquaint themselves with the concepts of business-like healthcare or establish their own clinics or healthcare system based to some extent on the logic of medical professionalism (Feinstein, 2003). By integrating managerial functions in their own set of responsibilities, physicians' dependence on the managerial power of others decreases.

Finally, as Berenson, Bodenheimer, and Pham, (2006) and Fletcher (2005) point out, physicians can have a transformative commitment to their traditionally dominant logic of medical professionalism. Attracted by the prospect of additional sources of income and autonomy over working conditions, many physicians in the US, chose to become medical entrepreneurs. Fletcher (2005) reports how physicians invest in enterprises delivering ancillary medical services while Berenson et al. (2006) provides examples of physicians investing in specialty clinics or outpatient centers that compete with hospitals. This increases the need for the adoption of entrepreneurial values. However, as cross-sectional research by Bhuian, Menguc, and Bell (2005) among 231 US hospitals shows, both hospital managers and physicians should consider the implications. As overly strong and explicit entrepreneurial values are associated with lower hospital performance, moderate entrepreneurship may provide the best results.

Unfortunately, we did not find studies on joint entrepreneurial activities by both physicians and managers in addition to the influence of value commitments on entrepreneurship by physicians. Neither did we encounter studies concerning the drivers and entrepreneurial orientation that cause hospital managers to engage in entrepreneurship.

Although our review uncovered only limited empirical material concerning the influence of power dependencies on the transformative commitment of physicians, the most convincing studies we found were the survey by Berenson et al. (2006), and the case study by Thorne (2002). Increased power dependence on hospital managers has heightened both transformative and defensive value commitments among physicians. As part of a transformative value commitment, physicians may be drawn to become medical entrepreneurs and open specialty clinics by the prospect of additional income and autonomy. As part of a defensive value commitment, physicians are pushed to embrace certain elements of the businesslike healthcare logic to effectively protect their professional autonomy. This last finding relates well to the notion of custodial strategy (Ackroyd, Hughes, \& Soothill, 1989) in which managerial practice is embraced by professional interests to maintain the status quo as defined by the professional community. 


\title{
Relation between interest dissatisfaction, value commitments and entrepreneurial orientation in hospitals
}

\author{
"The raison d'être of management is to facilitate physicians. However, they \\ expected me to facilitate them, a situation that became unbearable. Since I \\ believed I could do better at organizing things than managers, I started my own \\ clinic." Quotation from interview with a dermatologist, the Netherlands, August 2011
}

We found six papers that dealt with the relation between interest dissatisfaction and a transformative value commitment in hospitals. An overview of the review results is presented in Table 3, which is available as a web-accessible file (Appendix A).

According to the reviewed articles, there seems to be a positive relation between the presence of two rival logics, interest dissatisfaction and a transformative commitment. Based on their extensive research, Reay and Hinings (2009) conclude that separate identities embedded in different logics may be maintained "through pragmatic collaborations" while executing tasks and responsibilities. In addition, Hoogland and Jochemsen (2000) indicate that despite pragmatic collaborations, organizational members who continuously experience the presence of a rival logic will focus their interest dissatisfaction on the other group, which is held responsible for diminished autonomy or the unfavorable distribution of resources.

Research by Pham (2004) among 90 physicians being exposed to managed care reveals that in the course of the process in which health plans began imposing restrictions on their clinical autonomy, physicians increasingly found themselves dissatisfied with the role of "double agents", with potentially conflicting responsibilities to patients and insurers. Over time, their interest dissatisfaction channeled into both a defensive value commitment toward the business-like healthcare logic and a transformative commitment among physicians toward the traditional logic of medical professionalism. Both resulted in practices based on a hybrid logic of medical professionalism combined with entrepreneurship derived from the business-like healthcare logic (Pham, Devers, May, \& Berenson, 2004; Stone, 1997; Volz, 1999).

Hospital performance benefits from the ability of management to relate to the individual interests and value commitments of physicians. Wood, Bhuian, and Kiecker (2000) reports on the basis of a cross-sectional survey among 237 US hospital managers that senior management's ability to develop an organization-wide market orientation and entrepreneurship positively influences performance: “Organizational entrepreneurship must be supported by actively encouraging new product idea generation, implementation of new methods and techniques in the delivery of health-care services" (p.222). This 
allows physicians holding different value commitments to participate in hospital-wide entrepreneurial initiatives.

Summarizing, our review yielded limited results concerning the relation between interest dissatisfaction and value commitments. No results were found on the relation between interest dissatisfaction and entrepreneurial orientation. Still, Volz (1999) provides insights on the relation between interest dissatisfaction and defensive or transformative value commitments. Interest dissatisfaction can stimulate entrepreneurial activities among physicians holding a defensive or transformative value commitment. In this respect we reason that the type of value commitment determines whether entrepreneurship is need-based or opportunity-driven. This represents a novel observation as need-based entrepreneurship is generally associated with low incomes and unemployment (Ritsilä \& Tervo, 2002).

Finally, physicians' involvement in the entrepreneurial activities of hospitals is important as research suggests that active development by hospital management of both a hospital-wide market orientation and entrepreneurship is related to higher performance.

\section{Discussion}

We investigated the influence of intra-organizational dynamics among managers and physicians on entrepreneurial behavior in a hospital setting. Based on the neo-institutional model of Greenwood and Hinings (1996) we derived three research questions, and we will summarize the results accordingly. Finally, we will provide suggestions for further research. First, we found that contextual changes have considerably altered the relation between managers and physicians in hospitals as dependencies have shifted and intensified. Physicians' economic autonomy has been diminished while there have been continuous efforts to bring clinical care within a management framework. This is associated with interest dissatisfaction among physicians.

Second, our review indicates that growing power dependence on hospital managers has heightened both defensive and transformative value commitments among physicians. As part of a defensive value commitment, physicians can be pushed to defend their position and autonomy by adopting the entrepreneurship entailed by the business-like healthcare logic to protect their position and autonomy effectively. As part of a transformative value commitment toward their traditional logic of medical professionalism, physicians can be attracted to entrepreneurship by the prospect of increased autonomy and income. Both commitments can apparently lead to the same outcome, although the physician holding a defensive commitment might be confronted with the very business logic he wanted to escape 
in the first place. This is supported by the work of Lega and Depietro (2005), describing how hospitals over time, seemingly inevitably, assume the form of professional bureaucracies.

Third, literature reveals that besides power dependence, interest dissatisfaction can also stimulate entrepreneurial activities among physicians holding a defensive or transformative value commitment. In addition, literature suggests that management can improve hospital performance by developing an organization-wide market orientation and actively seeking the involvement of physicians in the entrepreneurial process, from idea generation to the implementation of new health services.

Finally, we contribute to current literature by adding intra-organizational factors as drivers of necessity-based entrepreneurship. Until now, necessity-based entrepreneurs were mainly associated with low wages and unemployment.

Our approach has resulted in a unique and integrative contribution to the current literature on entrepreneurship of physicians and hospital managers, despite rendering limited results. Still, only initial support was established for the hypotheses derived from the model of Greenwood and Hinings, and this should be considered as a starting point for further methodological testing. Therefore, we propose to operationalize interest dissatisfaction, power dependence and value commitments and to test them in larger descriptive studies, preferably longitudinally in a hospital setting.

Finally, we know little about the exact sequence of activities in the process resulting in physicians' entrepreneurship, including interactions and decision-making processes of physicians and managers to realize entrepreneurial initiatives. Qualitative research addressing these questions would provide important additional insights into the question as to how and when entrepreneurship takes place in a hospital setting. 


\section{References}

Abernethy, M. A., \& Vagnoni, E. (2004). Power, organization design and managerial behaviour. Accounting, Organizations and Society, 29(3-4), 207-225.

Ackroyd, S., Hughes, J. A., \& Soothill, K. (1989). Public-sector services and their management. Journal of Management Studies, 26(6), 603-619.

Berenson, R. A., Bodenheimer, T., \& Pham, H. H. (2006). Specialty-service lines: salvos in the new medical arms race. Health Affairs, 25(5).

Bhuian, S. N., Menguc, B., \& Bell, S. J. (2005). Just entrepreneurial enough: The moderating effect of entrepreneurship on the relationship between market orientation and performance. Journal of Business Research, 58(1), 9-17.

Braithwaite, J., \& Westbrook, M. T. (2004). A survey of staff attitudes and comparative managerial and nonmanagerial views in a clinical directorate. Health Services Management Research, 17(3), 141-166.

Buchanan, D., Jordan, S., et al. (1997). Doctor in the process. The engagement of clinical directors in hospital management. Journal of Management in Medicine,11(2-3), 132-156.

Burgelman, R. A. (1983). A process model of internal corporate venturing in the diversified major firm. Administrative Science Quarterly, 28(2), 223-244.

Castellani, B., \& Wear, D. (2000). Physician views on practicing professionalism in the corporate age. Qualitative Health Research, 10(4), 490-506.

Cohn, K. H., Gill, S. L., \& Schwartz, R. W. (2005). Gaining hospital administrators' attention: ways to improve physician-hospital management dialogue. Surgery,137(2), 132-140.

Currie, G., Dingwall, R., Kitchener, M. J., \& Waring, J. (2012). Let's dance: organization studies, medical sociology and health policy. Social Science \& Medicine, 74 (3), 273-280.

Currie, G., Humpreys, M., Ucbasaran, D., \& McManus, S. (2008). Entrepreneurial leadership in the English public sector: paradox or possibility? Public Administration, 86(4), 987-1008.

Currie, G., Humpreys, M., Waring, J., \& Rowley, E. (2009). Narratives of professional regulation and patient safety: the case of medical devices in anaesthetics. Health, Risk and Society, 11(2), 117-135.

Daake, D., \& Anthony, W. P. (2000). Understanding stakeholder power and influence gaps in a health care organization: an empirical study. Health Care Management Review, 25(3), 94-107.

Degeling, P., Zhang, K., Coyle, B., Xu, L., Meng, Q., Qu, J., et al. (20 06). Clinicians and the governance of hospitals: a cross-cultural perspective on relations between profession and management. Social Science \& Medicine, 63(3), 757-775.

Feinstein, A. R. (2003). Scholars, investigators, and entrepreneurs: the metamorphosis of American medicine. Perspectives in Biology and Medicine, 46(2), 234-253.

Fitzgerald, L., \& Ferlie, E. (2000). Professionals: back to the future? Human Relations, 53(5), 713-739.

Fletcher, T. (20 05). The impact of physician entrepreneurship on escalating health care costs. JACR Journal of the American College of Radiology, 2(5), 411-414.

Floyd, S. W., Kramer, J. A., \& Born, P. H. (2005). Institutional forces in the acceptance of managed care practices by physicians. Health Care Management Review, 30(3), 237-250.

Greenwood, R., \& Hinings, C. R. (1996). Understanding radical organizational change: bringing together the old and the new institutionalism. The Academy of Management Review, 1022-1054.

Hisrich, R. D., \& Peters, M. P. (1992). Entrepreneurship: Starting, developing, and managing a new enterprise.

McGraw-Hill/Irwin. Hoogland, J., \& Jochemsen, H. (2000). Professional autonomy and the normative structure of medical practice. Theoretical Medicine and Bioethics, 21(5), 457-475. 


\section{2 - Intra-organizational dynamics as drivers of entrepreneurship among physicians and managers in hospitals of western countries}

Kaissi, A. (2005). Manager-physician relationships: an organizational theory perspective. The Health Care Manager, 24(2), 165-176.

Klopper-Kes, A., Meerdink, N., van Harten, W., \& Wilderom, C. (2009). Stereotypical images between physicians and managers in hospitals. Journal of Health Organisation and Management, 23.

Krauss, S. I., Frese, M., Friedrich, C., \& Unger, J. M. (2005). Entrepreneurial orientation: a psychological model of success among southern African small business owners. European Journal of Work and Organizational Psychology, 14(3),315-344.

Lega, F., \& Depietro, C. (2005). Converging patterns in hospital organization: beyond the professional bureaucracy. Health Policy, 74, 261-281.

Lumpkin, G. T., \& Dess, G. G. (1996). Clarifying the entrepreneurial orientation construct and linking it to performance. The Academy of Management Review, 21, 135-172.

McDonald, R., Waring, J., \& Harrison, S. (2006). Rules, safety and the narrativisation of identity: a hospital operating theatre case study. Sociology of Health and Illness, 28(2), 178-202.

Miller, D., \& Friesen, P. H. (1983). Strategy-making and environment: the third link. Strategic Management Journal, 4(3), 221-235.

OECD. (2011). Health: Spending continues to outpace economic growth in most OECD Countries. OECD Health Data 2011.

Ong, B. N., \& Schepers, R. (1998). Comparative perspectives on doctors in management in the UK and The Netherlands. Journal of Management in Medicine, 12(6), 378-390, 322.

Paul Leigh, J., Kravitz, R. L., Schembri, M., Samuels, S. J., \& Mobley, S. (2002). Physician career satisfaction across specialties. Archives of Internal Medicine, 162(14), 1577-1584.

Pham, H. H., Devers, K. J., May, J. H., \& Berenson, R. (2004). Financial pressures spur physician entrepreneurialism. Health Affairs, 23(2), 70-81.

Reay, T., \& Hinings, C. R. (2009). Managing the rivalry of competing institutional logics. Organization Studies, 30(6), 629-652.

Ritsilä, J., \& Tervo, H. (2002). Effects of unemployment on new firm formation: micro-level panel data evidence from Finland. Small Business Economics, 19(1), 31-40.

Rivers, P. A., \& Woodard, B. (1997). Organizational power and conflict regarding the hospital-physician relationship: symbolic or substantive? Health Services Management Research, 10(2), 91-106.

Rundall, T. G., Kaiser, H. J., Davies, H. T. O., \& Hodges, C. L. (2004). Doctor-manager relationships in the United States and the United Kingdom. Journal of Healthcare Management, 49(4), 251-268.

Saltman, R. B., Busse, R., \& Mossialos, E. (2002). Regulating entrepreneurial behaviour in European health care systems. Philadelphia/Buckingham: Open University Press.

Saltman, R. B., \& Figueras, J. (1997). European healthcare reform: Analysis of current strategies. WHO Regional Publications, European Series No. 72. Copenhagen: WHO Regional Office for Europe.

Salvadores, P., Schneider, J., \& Zubero, I. (2001). Theoretical and perceived balance of power inside Spanish public hospitals. BMC Health Services Research [electronic resource], 1(1), 9.

Shane, S., \& Venkataraman, S. (2000). The promise of entrepreneurship as a field of research. The Academy of Management Review, 25(1), 217-226.

Som, C. V. (2005). Nothing seems to have changed, nothing seems to be changing and perhaps nothing will change in the NHS. International Journal of Public Sector Management, 18(5), 463-477.

Stone, D. A. (1997). The doctor as businessman: the changing politics of a cultural icon. Journal of Health Politics, Policy and Law, 22(2), 533-556.

Succi, M. J., Lee, S. Y. D., \& Alexander, J. A. (1998). Trust between managers and physicians in community hospitals. Journal of Healthcare Management, 43(5), 397-415. 


\section{Doctors in Business}

Sutherland, K., \& Dawson, S. (1998). Power and quality improvement in the new NHS: the roles of doctors and managers. Quality in Health Care, 7(Suppl.), S16-S23.

Thorne, M. L. (2002). Colonizing the new world of NHS management: the shifting power of professionals. Health

Services Management Research, 15(1), 14-26.

Volz, D. (1999). How physician networks are selling themselves. Marketing health services, 19(1), 30-33.

Warwicker, T. (1998). Managerialism and the British GP: the GP as manager and as managed. International Journal of Public Sector Management, 11(2-3),201-218.

Wood, V. R., Bhuian, S., \& Kiecker, P. (2000). Market orientation and organizational performance in not-forprofit hospitals. Journal of Business Research, 48(3), 213-224. 


\section{Appendix A: Review method and results}

\section{Data sources and searches}

The databases of Scopus, ISI and Pubmed were searched for relevant studies. The searches were conducted in October-November (weeks 43-45) 2009. The retrieved articles were manually searched for other relevant references. The following search terms were used:

\section{Search 1: Terms related to the first research question :}

In what ways do power interdependencies between physicians and managers lead to interest dissatisfaction in hospitals?

- ((physician OR doctor) AND (manager OR administrator) AND dissatisfaction)

- ((physician OR doctor) AND (manager OR administrator) AND power NOT nurse)

- ((physician OR doctor) AND (manager OR administrator) AND (power OR interest) AND (hospital OR clinic) NOT nurse)

\section{Search 2: Terms related to the second research question:}

How are power dependencies related to competitive and transformative value commitments and to an entrepreneurial orientation in hospitals?

- ((physician OR doctor) AND (manager OR administrator) AND (power OR values) AND ("entrepreneurial orientation" OR autonomy OR innovativeness OR "risk taking" OR pro-activeness))

Search 3: Terms related to the third research question:

- How do interest dissatisfaction, competitive commitment, and entrepreneurial orientation interact in hospitals?

- (interests AND values AND ('entrepreneurial orientation' OR autonomy OR innovativeness $O R$ 'risk taking' OR proactiveness) AND (initiative OR 'new entry' $O R$ 'new business' OR startup OR 'venture founding' OR entrepreneurship))

\section{Study selection}

Studies were included if they complied with all of the following criteria:

- Written in English

- Published between 1996 and 2009 to capture any relevant material resulting from the publication of the article of Greenwood \& Hinings (1996).

- Commentaries were excluded

- Dealing with the influence of competing logics on intra-organizational dynamics and/ or the influence of intra-organizational dynamics on entrepreneurial initiatives and/or explanations for entrepreneurial behavior by physicians and managers in hospitals of Western countries. 


\section{Data extraction}

Study inclusion was determined in a two-step procedure. First, the abstracts of retrieved studies were evaluated for concordance with the formal inclusion rules by one reviewer. The remaining studies were selected for full text appraisal. In this second step, all full texts were checked against the criteria, and excluded if violating any one of them. Two of the other authors verified this selection through an independent review of a randomly selected sample of papers and this did not result in additional hits. The resulting set of articles are presented and discussed in detail.

\section{Findings}

The literature search initially identified 1110 candidate articles, of which 117 were selected for full text retrieval (Figure 2). Seven articles (Volz, 1999; Feinstein, 2003; Fletcher, 2005; Pham, 2004; Wood, 2000; Bhuian, 2005; Reay \& Hinings, 2009) were included based on referrals by academic experts on the relation between physicians and hospital managers. In all, 34 publications satisfied all criteria and are included in this review. These were 23 quantitative and qualitative studies, and 11 theoretical papers. Only three articles are used for two different research questions (Stone, 1997; Ong \& Schepers; 1998 Thorne, 2002).The review process is depicted in figure 1.

Figure 1: Schematic representation of the review process

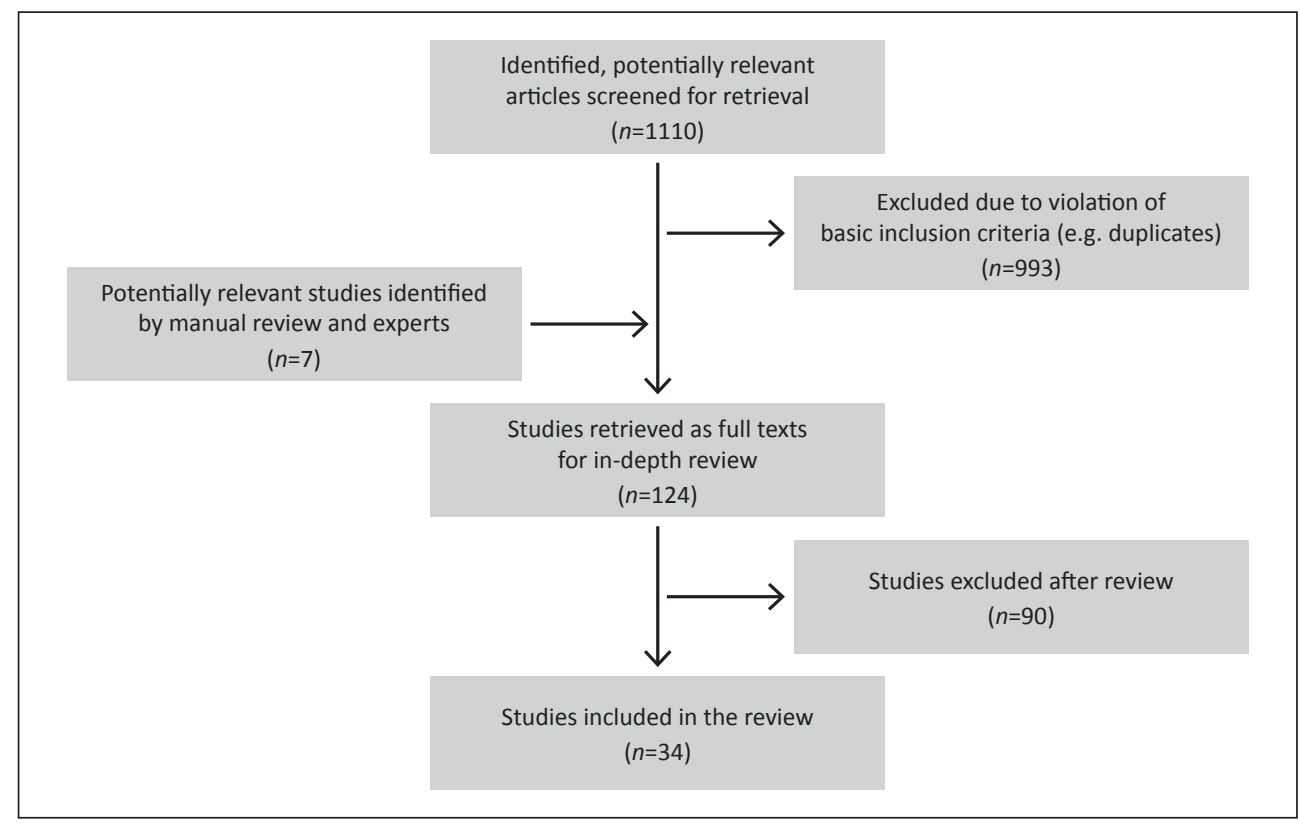




\begin{tabular}{|c|c|c|c|c|c|c|c|}
\hline 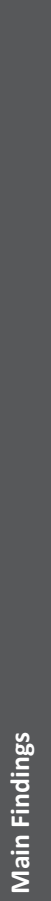 & 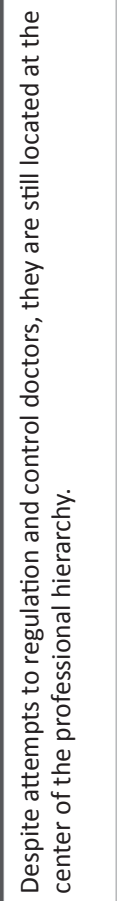 & 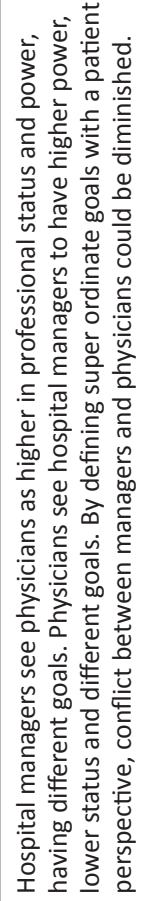 & 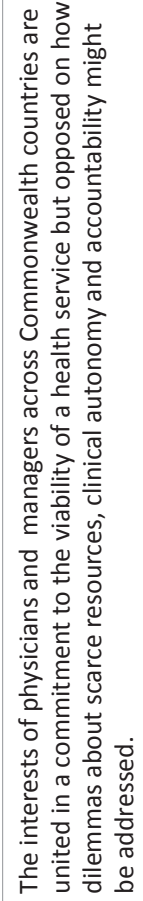 & 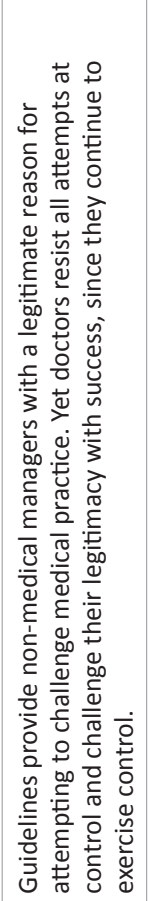 & 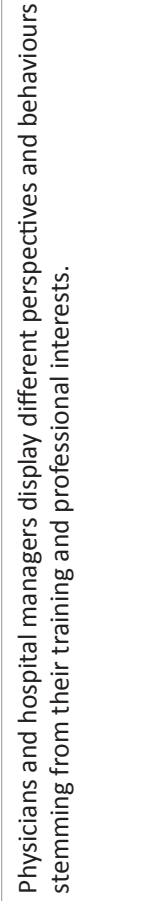 & 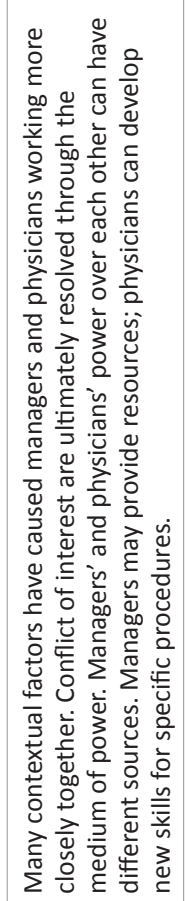 & 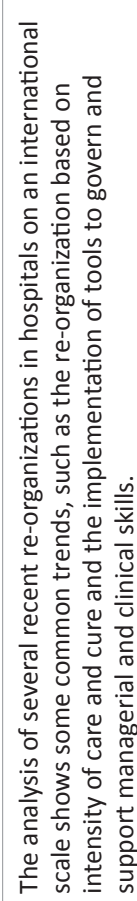 \\
\hline 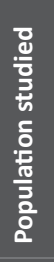 & 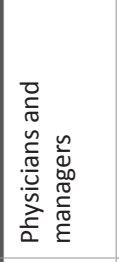 & 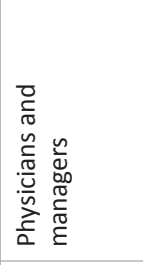 & 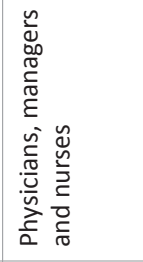 & 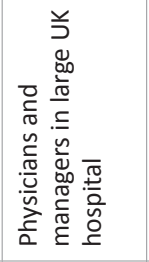 & 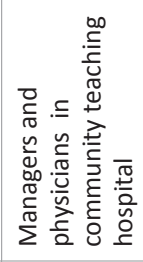 & 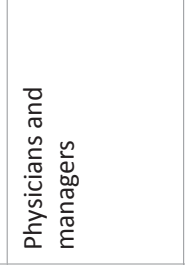 & 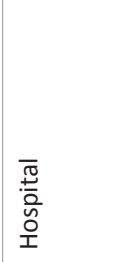 \\
\hline & 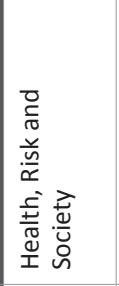 & 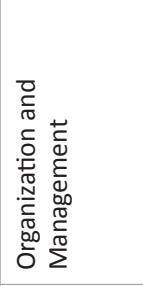 & 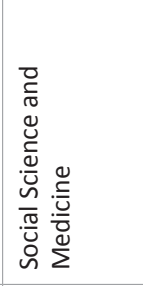 & 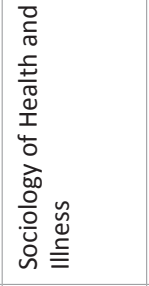 & 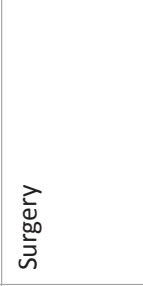 & 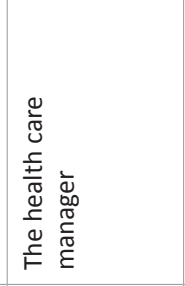 & 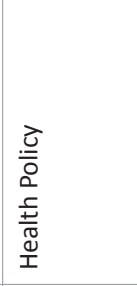 \\
\hline 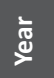 & ஜ્̀ & ஜे & ષั & ષ્ & 농 & ֻัญ & ํํㅇ \\
\hline 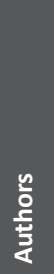 & 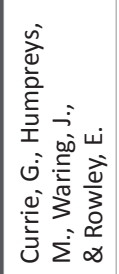 & 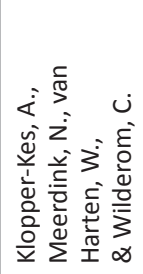 & 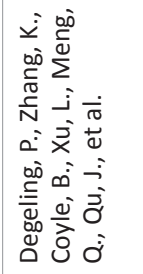 & 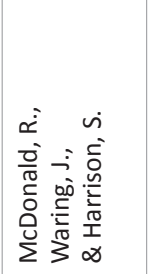 & 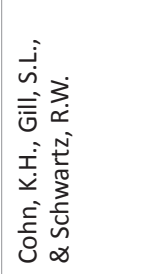 & 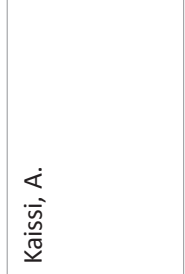 & 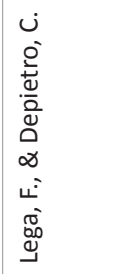 \\
\hline
\end{tabular}




\begin{tabular}{|c|c|c|c|c|c|c|c|}
\hline 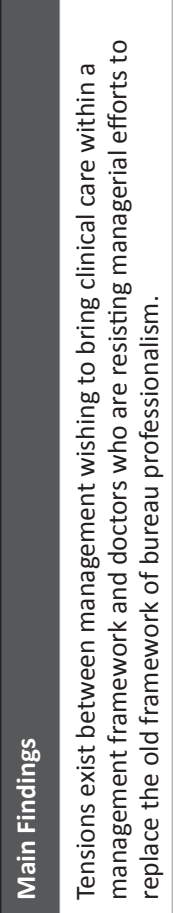 & 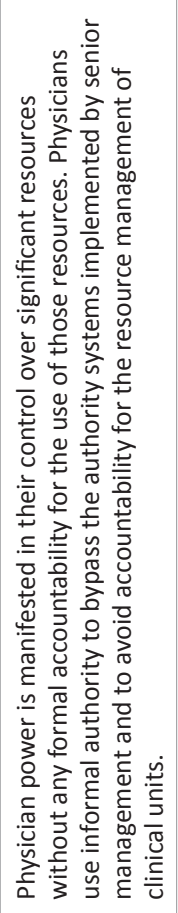 & 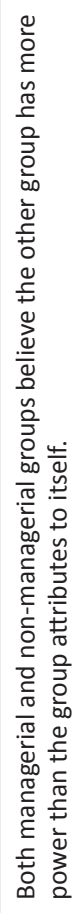 & 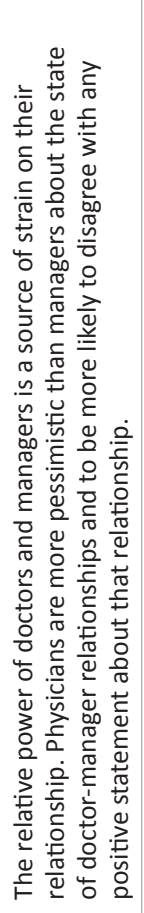 & 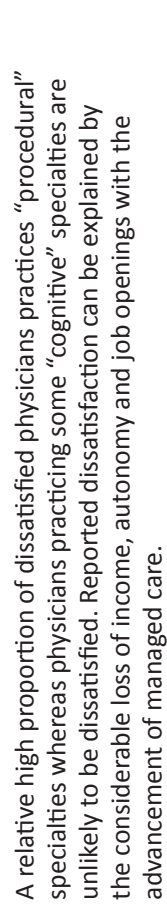 & 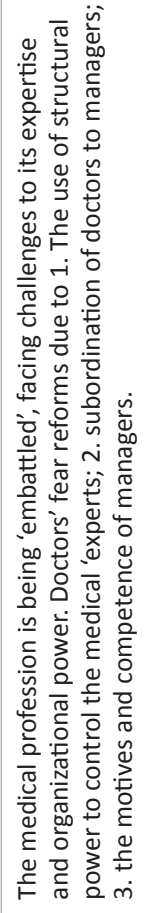 & 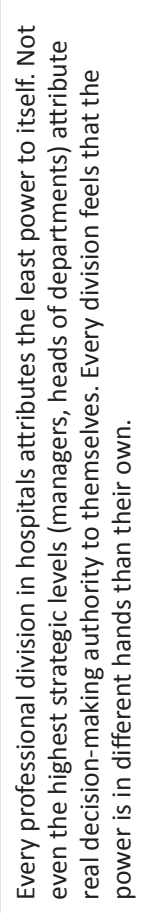 & 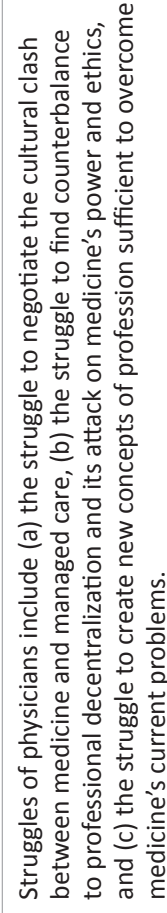 \\
\hline 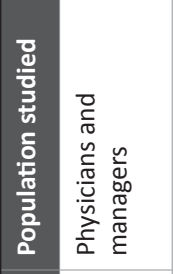 & 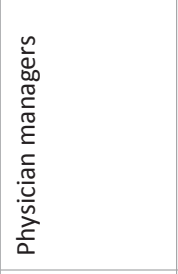 & 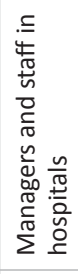 & 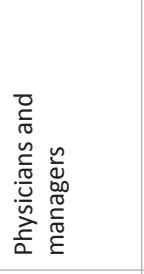 & 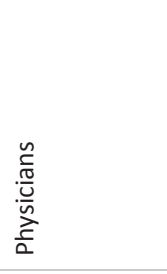 & 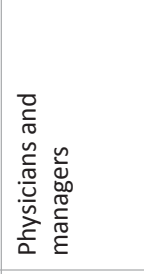 & 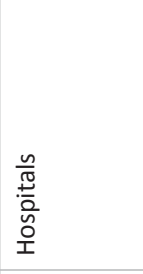 & 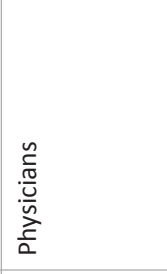 \\
\hline 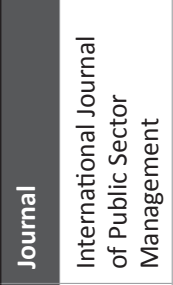 & 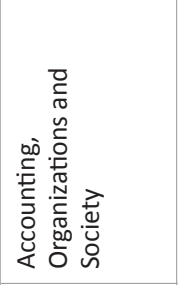 & 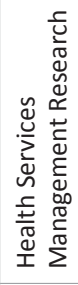 & 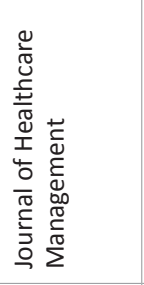 & 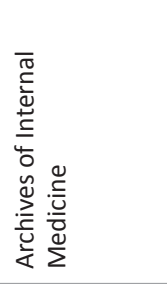 & 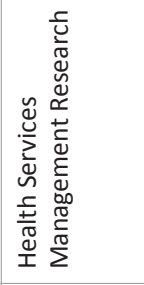 & 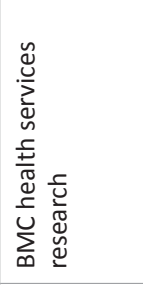 & 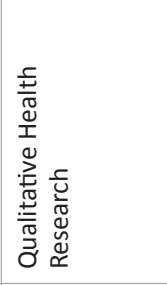 \\
\hline ֻัڤ & ఫ্ণ & ఫ্ & ర্ণ & ర్రి & ఫ్ & ઠి & ঃ \\
\hline $\begin{array}{l}\text { نे } \\
\text { हे } \\
\text { ڤn }\end{array}$ & 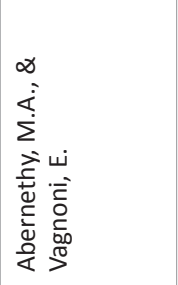 & 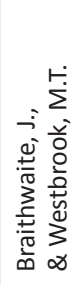 & 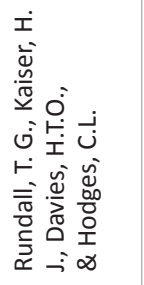 & 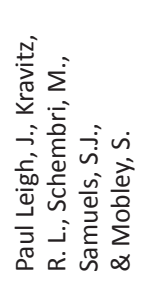 & $\begin{array}{l}\dot{j} \\
\dot{\sum} \\
0 \\
\stackrel{0}{ \pm} \\
\dot{0} \\
\stackrel{1}{F}\end{array}$ & 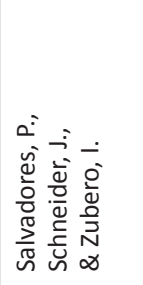 & 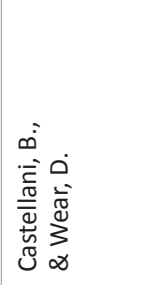 \\
\hline
\end{tabular}




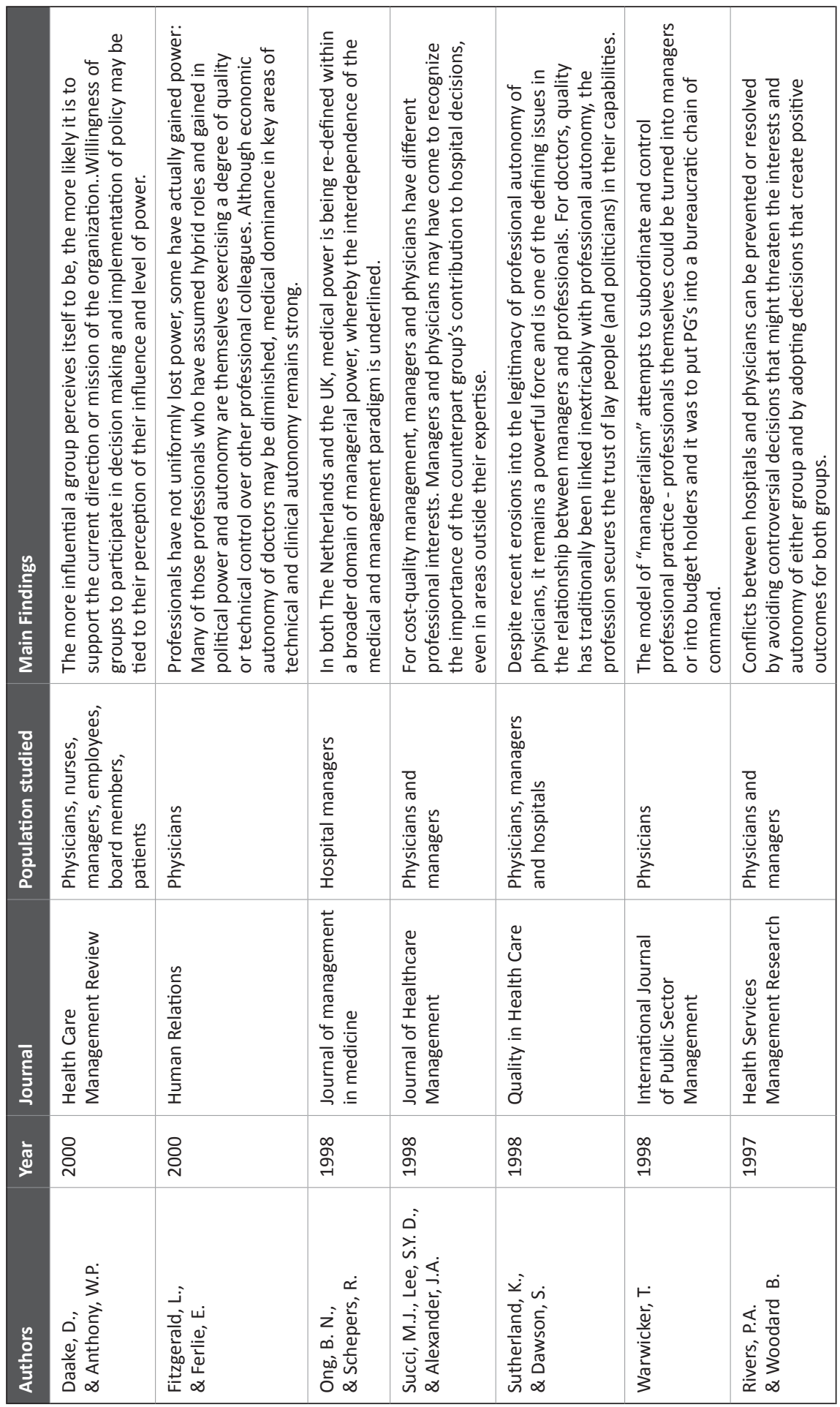




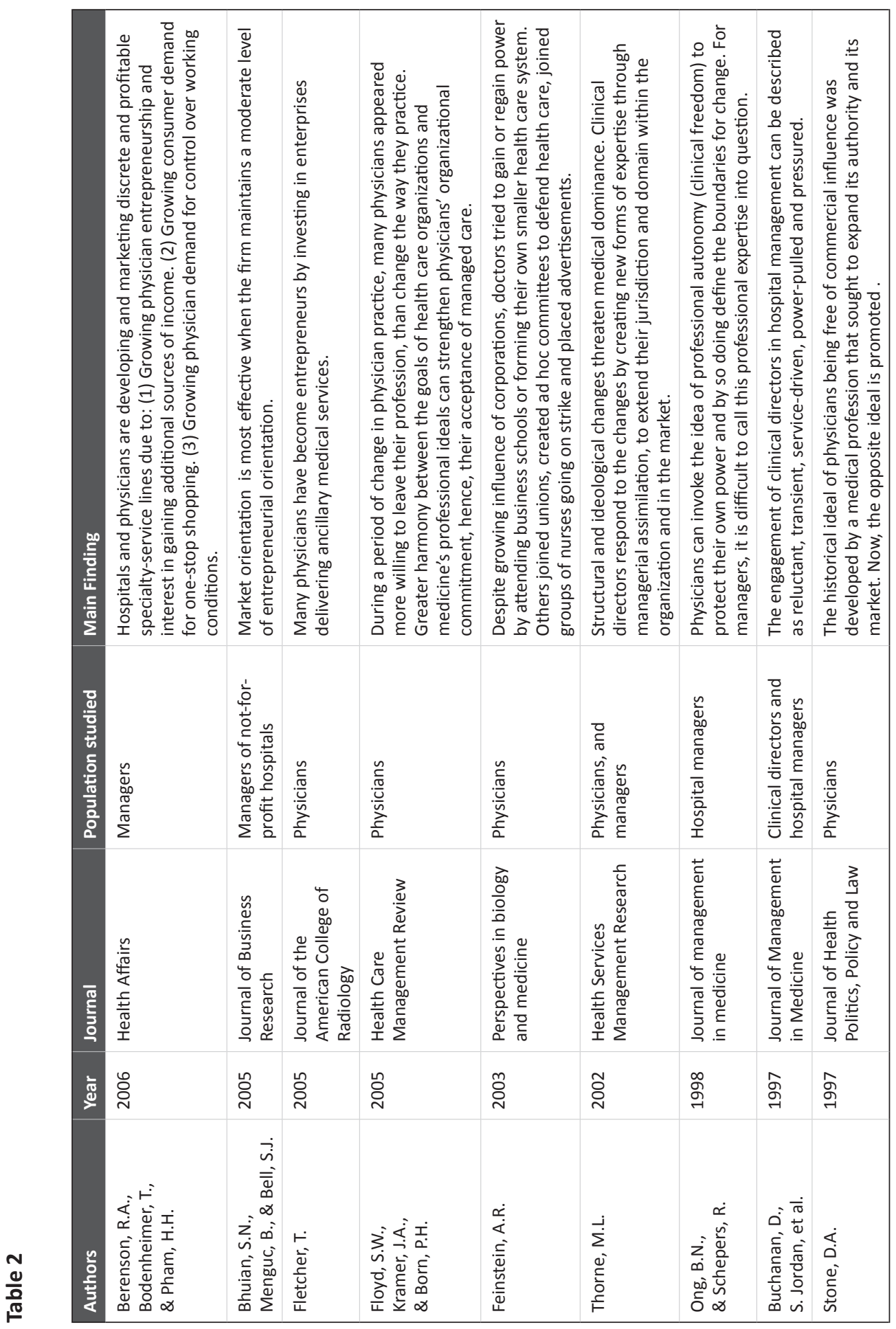




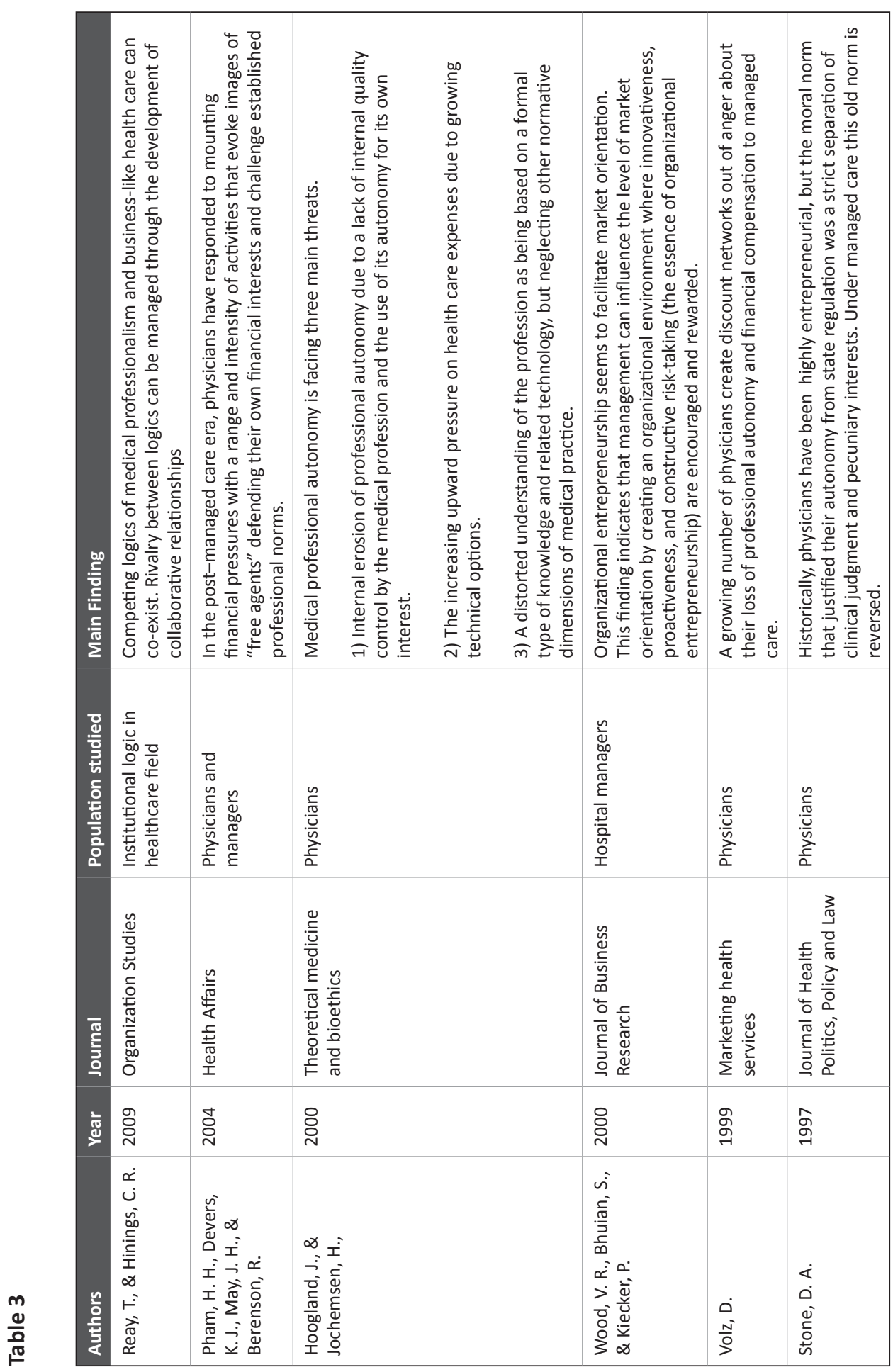





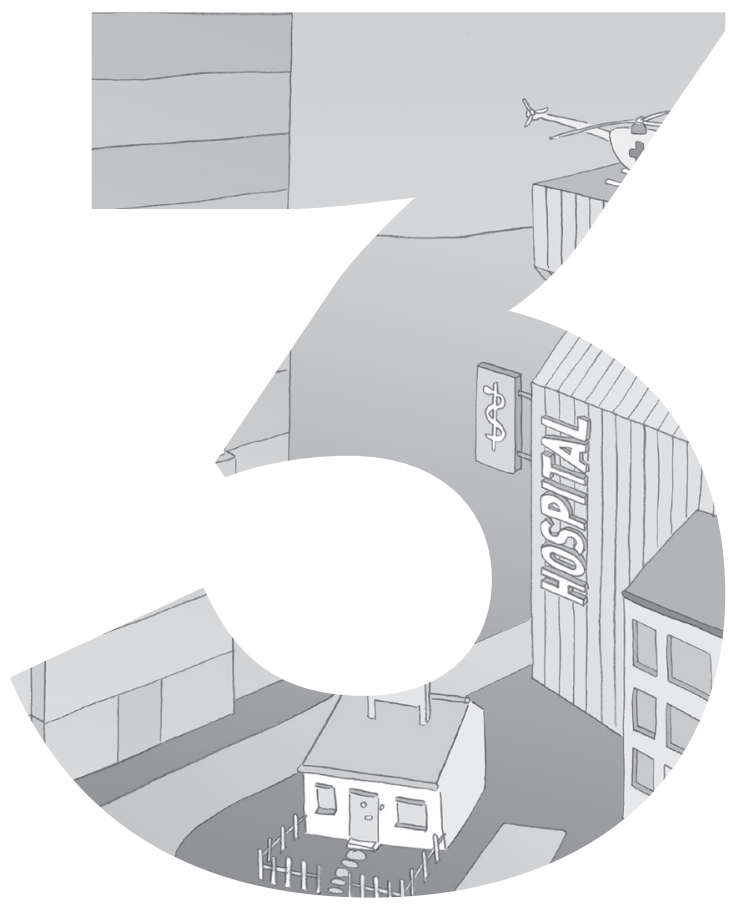

case study

PHYSICIAN' ENTREPRENEURSHIP

EXPLAINED: INTRA-ORGANIZATIONAL

DYNAMICS IN DUTCH HOSPITALS AND

SPECIALTY CLINICS

Wout T. Koelewijn

Matthijs de Rover

Wim H. van Harten

REVISED SUBMISSION 


\begin{abstract}
Background

Challenges brought about by developments such as continuing market reforms and budget reductions have strained the relation between managers and physicians in hospitals. By applying neo-institutional theory, we explore how intra-organizational dynamics between physicians and managers induce physicians to become entrepreneurs by starting a specialty clinic. In addition, we determine the nature of this change by analyzing the intraorganizational dynamics in both hospitals and clinics.
\end{abstract}

\title{
Methods
}

For our exploratory research, we conducted a two-step study. First, we interviewed a total of fifteen physicians and eight managers in four hospitals. As our second step, we interviewed twelve physicians and seven managers in twelve specialty clinics; all completed a questionnaire on physicians' interests.

\section{Results}

We found evidence that in becoming entrepreneurs, physicians are influenced by intraorganizational dynamics, including power dependence, interest dissatisfaction, and value commitments, between physicians and managers as well as among physicians' groups. The precise motivation for starting a new clinic can vary depending on the medical or business logic in which the entrepreneurs are embedded.

\section{Conclusions}

We conclude that the entrepreneurial process of starting a specialty clinic is a process of sedimented change in which elements of the business logic are added to the existing logic of medical professionalism, leading to a hybrid logic. These findings have implications for policy at both the national level and the hospital level. Shared ownership and aligned incentives may provide the additional cement in which the developing entrepreneurial values are "glued" to the central medical logic. 


\section{Background}

Managing health care organizations has become increasingly difficult (Bode, 2012; Kaissi, 2005; Shortell et al., 2004). The rising demand for care, the continuous stream of technological innovations and healthcare reforms, reinforced by the financial crisis, have strained the relationship between physicians and managers in many hospitals (Kuhlmann et al., 2011; Saltman et al., 2002). This relationship, however, embodies "a critical determinant of the success of healthcare organizations" (Cohn et al., 2005; Kaissi, 2005; Klopper-Kes et al., 2010b; OECD, 2011; Ranawat et al., 2009).

On a more fundamental level, the relationship between physicians and managers is influenced by institutional logics (Reay \& Hinings, 2009), consisting of "taken-for-granted rules"; these are influential in shaping both organizational fields, such as healthcare, and the behavior of organizations, groups, and individuals working in these fields (Scott, 2001). In general, physicians are embedded in the traditional logic of medical professionalism, which includes values like external orientation and physicians' autonomy. In contrast, hospital managers are embedded in the logic of business-like healthcare (Witman et al., 2011), focusing on efficiency, and performance indicators and quality indicators (Reay \& Hinings, 2009). These different logics are competing for dominance and lead to rivalry between the two groups. (Andrews, 2010; Bode, 2012; Degeling et al., 2006; Kaissi, 2005; Reay \& Hinings, 2009; Witman et al., 2011).

Neo-institutional theory allows for further analysis of these rivalries between groups within organizations. According to Greenwood and Hinings (Greenwood \& Hinings, 1996) intraorganizational dynamics are composed of power dependence, interest dissatisfaction, value commitments, and potentially radical change. Before applying this model as illustrated in Figure 1 to hospitals and specialty clinics, we will briefly explain each construct.

The growing dominance of business-like healthcare at the expense of their traditional logic of medical professionalism has altered physicians' perceived power dependence on management. It has diminished physicians' autonomy and their ability to satisfy their interests while simultaneously contributing to a more business-like way of managing hospitals through the use of facts, quality parameters, and input from patients. Depending on the value commitment of the individual physician, this may have given rise to interest dissatisfaction. 
Interest dissatisfaction is defined by Greenwood and Hinings (Greenwood \& Hinings, 1996) as "the degree of dissatisfaction of groups and individuals with the existing distribution of resources and their motivation to enhance or sustain their shares of scarce and valued resources". As physicians have slowly shifted towards unfavorable positions of power within hospital organizations, this may have caused interest dissatisfaction especially among physicians embedded in the logic of medical professionalism thereby influencing their value commitment.

As part of the construct of value commitments, Greenwood and Hinings distinguish between four different generic patterns, varying according to their embeddedness in a certain logic:

- "status-quo commitment" in which organizational groups adhere to the status quo;

- "indifferent commitment" in which organizational groups are indifferent about which logic is dominant;

- "competitive commitment" in which one group challenges the dominance of the logic held by another group;

- "reformative commitment" in which all organizational groups agree a change of logic is necessary.

A competitive value commitment may be either transformative or defensive in orientation (Koelewijn et al. (2012)). In the hospital context, physicians holding a transformatively oriented competitive value favor the newly dominant business logic over the traditionally dominant medical logic. This contrasts with the opposite situation of physicians holding a defensively oriented competitive value commitment.

The interplay of power dependence, interest dissatisfaction, and value commitments can result in "radical change", which involves abandoning the current dominant logic rather than fine-tuning it. In the context of our research, we assume entrepreneurship to be an example of radical change by physicians who abandon the current logic of business-like healthcare in an effort to regain autonomy. Hereby, entrepreneurship is defined as "new entries by physicians and hospital managers who discover, evaluate, and exploit opportunities to create future health services by bearing the risk of profit and loss"(Burgelman, 1983; Hisrich \& Peters, 1992; Shane \& Venkataraman, 2000). 
Finally, in analyzing the nature of entrepreneurial radical change, we distinguish between transformational change and sedimented change (Cooper et al., 1996). Whereas transformational change entails the creation of an entirely new logic, sedimentation suggests that elements from another, sometimes conflicting, logic may be added to the present logic. As a result, this type of change remains incomplete and reversible (Pinnington \& Morris, 2003). Examples of sedimented change are provided by e.g. Kitchener (1998), who applied Greenwood and Hinings' (1988) model in explaining the introduction of a quasi-market in the UK. He concluded that this did not lead to a transformational change in the logics of its actors, but instead a "co-existence of new structures and systems". This was supported by Addicott and Furlie (2006) who concluded that in managed clinical networks for cancer in London "a hybrid interpretive scheme has prevailed, whereby the characteristics of a range of conflicting archetypes coexist".

\section{Methods}

In preparing our questionnaire, we made two adaptations to the original model of Greenwood and Hinings. First, we included physicians' interests in the model. Hereby, we built on previous work in identifying physicians' interests to produce a measure of eight interests applicable to physicians across many specialty groups and types of hospitals (Berkowitz et al., 1987; McMurray et al., 1997; Williams et al., 1999; Zazzali et al., 2007). Second, as both the dominant logic and the alternative logic are well defined in our study (business-like healthcare and medical professionalism respectively), we focus on both the physicians' relative position with respect to the two logics and on defining their value commitment towards the other group. For this purpose, the description of the medical logic and business-like logic as developed by Reay and Hinings (2009) was used. Respondents were assigned to one of the two logics based on their responses to the questions, which contained statements referring to values of both the medical logic and the business logic. Respondents who embraced values of both logics were assigned to the hybrid logic. The resulting research model is shown in Figure 1. 
Figure 1: Neo-institutional dynamics model based on Greenwood \& Hinings [15]

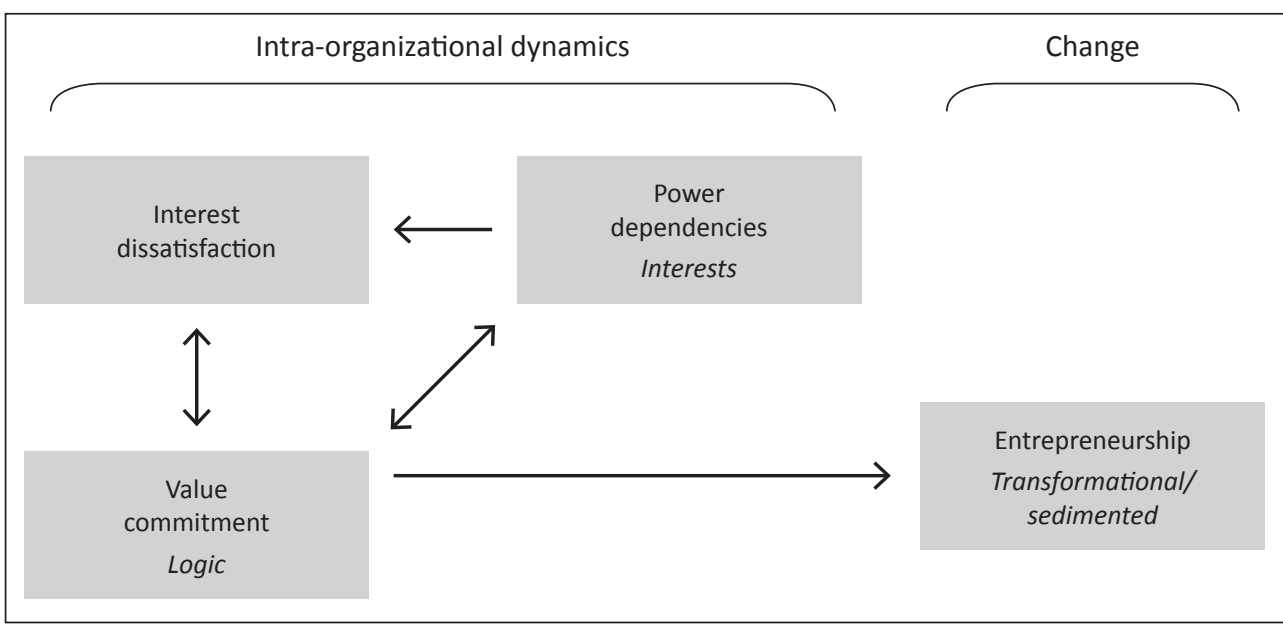

Based on our research model and questionnaire, we conducted a two-step study among both physicians and managers in hospitals and specialty clinics.

In step 1, we conducted semi-structured interviews in four Dutch hospitals with in total fifteen physicians and eight managers, to determine the intra-organizational dynamics in hospitals and their contribution to the absence or presence of entrepreneurship. Additionally, we asked specifically about the interests of the physicians and combined their responses with the initial list of eight interests.

In step 2, we interviewed a total of twelve physicians and seven managers in twelve Dutch entrepreneurial specialty clinics to establish whether physicians' entrepreneurship is an example of transformational change or sedimented change. To assess this, we analyzed the intra-organizational dynamics in specialty clinics in comparison to hospitals. In addition, respondents were asked to indicate the importance they attached to each interest on a scale from 1 (totally unimportant) to 5 (very important).

As indicated in Table 1, the four hospitals and twelve specialty clinics ranged in size and specialty, thereby constituting a representative sample of hospitals and specialty clinics in the Netherlands. 
Table 1: Specialties and size of clinics included in sample

\begin{tabular}{|c|c|c|c|c|c|c|}
\hline & \multicolumn{4}{|c|}{ Hospitals (\# beds) } & \multicolumn{2}{|c|}{ Clinics (\# physicians) } \\
\hline & $<300$ & $400-700$ & $400-700$ & $>700$ & $\leq 10$ & $>10$ \\
\hline Cardiology & & & 1 & & & \\
\hline Dermatology & 1 & & & & 2 & 1 \\
\hline Geriatrics & & & 1 & & & \\
\hline Gynecology & & 1 & & 1 & & \\
\hline Internal medicine & 1 & 1 & & & & \\
\hline Ophthalmology & 1 & 1 & & 1 & & 1 \\
\hline Orthopedics & & & & & 2 & 2 \\
\hline ENT & & & & & & 1 \\
\hline Pediatrics & & & & 1 & & 1 \\
\hline Plastic surgery & & 1 & 1 & & 1 & \\
\hline Radiology & & & & & & 1 \\
\hline Surgery & 1 & & 1 & & & \\
\hline Total & 4 & 4 & 4 & 3 & 5 & 7 \\
\hline
\end{tabular}

In the interviews, respondents were first informed about the aim and method of the study. In order to avoid socially desirable answers as much as possible, they were explicitly asked to reflect on their actual experiences in their present situation in the hospital or specialty clinic. The interviews were recorded, coded, and analyzed anonymously.

\section{Data analysis}

The interviews were recorded, transcribed, and coded with the help of Atlas.ti 6.2. The code list was based the constructs included in our research model (Figure 1). New elements that were mentioned as influencing intra-organizational dynamics, such as organizational size and personal characteristics, were also included in the list.

In order to prevent bias, a second coder reviewed the recorded interviews as well. This resulted in a kappa of 0.73 , showing a relatively high inter-coder reliability. When differences arose, these were discussed; agreement was reached on all items. 
Finally, the quotations included in this article were translated from Dutch into English.

In presenting our findings we will first establish the interests held by hospital-based physicians and the nature of intra-organizational dynamics in hospitals. In addition, we will analyze the influence of management's philosophy concerning physicians' entrepreneurship. Second, we will establish the nature of intra-organizational dynamics in clinics and the importance attached to the interests identified in step 1.

In the discussion section, we will compare our findings in hospitals with our findings in specialty clinics to determine whether entrepreneurship constitutes transformational or sedimented change, and we will present two refined models explaining physicians' entrepreneurship.

\section{Case studies 1}

\section{Intra-hospital dynamics driving physicians' entrepreneurship}

Based on literature (Berkowitz et al., 1987; McMurray et al., 1997; Williams et al., 1999; Zazzali et al., 2007), we generated a list of eight physicians' interests, indicated with an asterisk in Table 2. The interviews with hospital-based physicians resulted in four additional interests. First, "a nice working climate" was mentioned; however, it was explicitly linked to the interest "determining which employees to work with", in which colleagues are included. Therefore we decided not to include "a nice working climate" in the final list of interests. Second, as "opportunism" was mentioned as an interest held by other physicians and not by the interviewee physicians themselves, we decided not to include it. Finally, "specializing further" and "deciding for myself which employees work for me" were added to the final list shown in Table 2. 
Table 2: Interests held by hospital-based physicians $(n=15)$

\begin{tabular}{|l|c|}
\hline Interests among physicians in hospitals ( $\mathbf{n = 1 5 )}$ & $\begin{array}{c}\text { Number of } \\
\text { times cited }\end{array}$ \\
\hline 1. Helping patients as well as possible* & 12 \\
\hline 2. A good income* & 8 \\
\hline 3. Being able to do my work autonomously* & 7 \\
\hline 4. Variety in my work as a physician* & 6 \\
\hline 5. Having a say in hospital policy* & 5 \\
\hline 6. Specializing further & 4 \\
\hline 7. Working with the best facilities* & 3 \\
\hline 8. Deciding for myself which employees work for me & 2 \\
\hline 9. A good work-life balance* & 2 \\
\hline 10. Doing research* & 1 \\
\hline
\end{tabular}

* Interests identified on the basis of a literature review(Berkowitz, Fraser et al. 1987; McMurray, Kirk van et al. 1997; Williams, Konrad et al. 1999; Zazzali, Alexander et al. 2007

\section{Power dependence}

In identifying the presence and cause of perceived power dependence, we found that all physicians reported experiencing power dependencies and interest dissatisfaction with management or colleagues. A factor frequently mentioned as causing interest dissatisfaction with management is the perceived high level of bureaucracy and the associated lack of opportunity physicians experience to have a say in hospital policy. With respect to this perceived level of involvement in decision-making, we found differences depending on both the size and the organizational culture of the hospital and the management style. For example, physicians working in the smallest hospital included in our sample mention the culture of facilitating physicians. In the three other hospitals, the executive managers deal with matters differently, using formal and sometimes bureaucratic decision-making processes. In hospital C, formal processes are perceived as dominating:

"But you do see consultants saying that things aren't possible and it all costs so much time and money. It's quite swimming through treacle here - everything really takes a long time. And then I'll suggest something and nothing gets done with it, you're one month further and you think, oh I never heard anything more about that. That makes it even more of an uphill struggle, and that's a shame." [Manager, hospital C] 
In contrast, the management of hospital B is more welcoming towards physicians' initiatives as the executive manager takes a very open, pragmatic approach towards entrepreneurial initiatives by physicians, resulting in a relatively high number of initiatives executed in partnership with the hospital:

"As a rule, the medical specialists are more entrepreneurial than the managers. Managers think more in terms of limitations than physicians do. But if that's your attitude then it'll take you a while, because then everything is linked to everything else. No, then you're literally not able to start something until you have a project assignment. Well, no Dutch businessman ever sits and waits for a project assignment. They see an opportunity in the market." [Executive, hospital B]

Finally, the executive manager of the largest hospital (hospital D) included in our sample created a parallel informal process next to the standard bureaucratic process to allow for more direct input by physicians:

"One of the nice things we do - because l've completely finished with corporate plans and PDCA cycles - is that once every two years the entire Executive Board and directors and all the medical staff withdraw somewhere to brainstorm about a number of topics. That works much better than all that paperwork and it generates renewed dynamism. And that is really the basis for the hospital's longterm development." [Executive, hospital D]

This parallel policy-making process helps physicians fulfill their interests. As a result, physicians' interest dissatisfaction is relatively low. In addition, in the Netherlands most physicians work in physician' partnerships within a hospital instead on an employment basis. In fact, most of these physicians regard an employment relationship with the hospital as detrimental to their autonomy, causing a higher level of power dependence compared to an independent relationship:

"I've seen several employment relationships go bad in the hospital because people came up against the problem that good plans weren't getting through because so and so - the directors - first said yes, but then no, we mustn't do this after all. And that leads to conflicts and in the end the director says, hang on a minute, I'm the boss here, remember?" [Physician, hospital D] 
Summarizing, all physicians experienced power dependence to some extent. Bureaucracy and a lack of perceived influence in the decision-making processes of management are highly influential factors. These factors in turn are dependent on both hospital size and culture as well as the managerial style of the executive manager. Hereby, more openness by management and greater facilitation of physicians are seen as ways of diminishing physicians' perceived power dependence. Finally, an employment relationship between physicians and a hospital is regarded as causing greater power dependence.

\section{Interest dissatisfaction}

We found mixed results for the causes and extent of interest dissatisfaction among physicians. The causes of interest dissatisfaction related to hospital management include perceived insufficient autonomy, a lack of innovation, and insufficient facilitation for providing the best possible care to patients. In addition, an absence of leadership and too much internal competition among physicians were also mentioned as causes of dissatisfaction.

The causes of interest dissatisfaction with hospital management are often related to the perceived degree of red tape in decision-making. Some managers frankly acknowledge this:

"I often still need to work on creating the basic organization, so you don't even get round to entrepreneurial activities, you're too busy managing. So the entrepreneurial activities are very limited whereas many of the specialist fields would like to see them expand a lot. Take the plastic surgeons: they made their own analysis and said they could recoup the costs, then they just started up and now they're running a good business. They can't do that here." [Manager, hospital C] 
A physician in Hospital C explains his experiences with management:

"I've suggested a couple of really interesting opportunities to the hospital. But you never hear anything more about them. You suggest it, submit it, but never hear anything more about it. And you know what, I don't understand this, I don't get it. Perhaps it's a limitation in me but I can't understand from a rational viewpoint why a hospital doesn't seize those opportunities." [Physician, hospital C]

Good facilitation by management, on the other hand, was found to limit interest dissatisfaction among physicians, as illustrated by one physician:

"I would say the answer to the question why I don't undertake entrepreneurial activities outside the hospital is that we basically have a good outpatient clinic and I'm satisfied with that." [Physician, hospital A]

Besides hospital management, interest dissatisfaction may also be caused by colleagues, depending on the relative power dependence experienced with regard to either hospital management or other physicians. As most hospital-based physicians work in a partnership with other physicians, these partners are very important. Difficulties in this relationship can easily lead to conflicts and may result in entrepreneurship by the departing physician, as explained by a physician who was in the process of starting his own clinic after having left the hospital:

"If there comes a point that it's blindingly obvious they want to get rid of you but don't actually say so, but you aren't performing properly and are doing nothing right, what you do is worthless, if that's the general direction, then I get the message that they just don't want to continue. And then I'm not inclined either to say well, I'll just stay put. I can't function if that kind of thing is going on."

In addition to issues within a partnership, the position of a specialty group within the hierarchy of specialties is also of importance, as illustrated by a physician:

"Our partnership covers about ten per cent of the hospital's entire medical staff. That does put you in a stronger position. And then you can approach the Executive Board or other colleagues with the support of that partnership, in the sense of saying we need to make this or that arrangement. So that was what motivated me at any rate to do this. It's easier for you to arrange things if you have those sixteen fellow physicians supporting you in your partnership." [Physician, hospital C]

Summarizing, we found mixed results on the causes and origins of interest dissatisfaction. The power dependence of hospital-based physicians was related to the hospital's bureaucracy and the resulting perception of powerlessness. In addition, we also found an example of one physician with a high degree of perceived power dependence with regard to his colleagues. 
Due to the problematic relationship, this resulted in interest dissatisfaction with members of his own physician group, rather than with management.

\section{Value commitment}

In exploring how value commitments influence both power dependencies and the perceived cause of interest dissatisfaction, we found a relationship between physicians' embeddedness in either the business-like or hybrid logic or the logic of medical professionalism and their value commitment.

Physicians embedded in the business-like logic or hybrid logic (containing elements from both the medical and business logic) experienced interest dissatisfaction with fellow physicians exhibiting prima donna behavior rather than with hospital management. This results in a transformatively oriented competitive value commitment, aiming to change the traditionally dominant logic of the own group. A physician embedded in a hybrid logic illustrates this:

"I try to communicate in their (managers') language and not retreat into my medical ivory tower, but I try to translate things into management items, parameters, something they can work with. I should say I see that as my challenge; it's essential for getting projects to succeed." "At the same time there are an awful lot of doctors with really unreasonable demands. If someone like that cries out, 'Good gracious, I'm the doctor here, what on earth are you thinking of?'. If you do that just once, you've lost your commitment for the next five years." [Physician, hospital A]

For physicians embedded in the medical logic however, interest dissatisfaction is related to their perceived high power dependence on hospital management. Their decision to engage in entrepreneurship is based on a defensively oriented competitive value commitment aimed at upholding values derived from medical professionalism. As one physician states:

"I didn't want to have to say 'no' to patients who needed a simple operation just because that operation didn't fit in with the management's ideas." [Physician, hospital B]

Summarizing, an embeddedness in the medical logic is associated with interest dissatisfaction with hospital management, while an embedded in a hybrid or business logic is associated with interest dissatisfaction with fellow physicians.

\section{Entrepreneurship}

Based on our research model, we found two ways in which intra-organizational dynamics in hospitals contribute to physicians' entrepreneurship. First, physicians embedded in the medical logic experience power dependencies and interest dissatisfaction with regard to 
management, which induces them to leave the hospital. Second, physicians embedded in the business logic experience power dependencies and interest dissatisfaction with regard to other physicians. However, we did not find examples of physicians embedded in the business-like healthcare logic whose decision to turn into an entrepreneur was induced solely by intra-organizational dynamics. Instead, we found other factors influencing physicians' entrepreneurship. Coming from an entrepreneurial family facilitates the transition, as explained by a plastic surgeon embedded in the business logic:

"Ever since I was a child I've been brought up in an entrepreneurial environment: this is how you run your own business, this is how you deal with your staff, these are your accounts and the whole shebang. And then I started thinking: well, we could do that here in this hospital as well; set up our own business and deliver care privately ourselves." [Physician, hospital B]

Another deciding factor for entrepreneurship is the presence of entrepreneurial traits, as described by a physician embedded in the business logic:

"I turned from being a doctor into an entrepreneur because it's in my blood, so it happened of its own accord. So there was no active mechanism in my case; it was just a question of acting according to your nature and doing what you think best and just sticking to your intuition." [Physician, clinic \#9]

And as perceived by an executive hospital manager:

"What you see is that this grumbling, which can be highly justified, often leads to dissatisfaction and criticisms of the senior management, the Executive Board, confidence issues and all sorts of things - that can be one of the reasons for starting entrepreneurial activities. But you need to be a genuine entrepreneur to actually be able to take that step." [Manager, Hospital B]

\section{Additional findings}

An important factor influencing the shape of physicians' entrepreneurship in hospitals is management's basic attitude towards physicians' entrepreneurship and management's willingness to facilitate entrepreneurial initiatives. The management of three of the hospitals included in our sample only allows physicians' entrepreneurship under certain conditions. Examples of these conditions include the requirement that the new clinic be located at a minimum distance from the hospital, and shared ownership, often with a majority stake for the hospital. For physicians who are dissatisfied with the facilitation provided by hospital management, this stance provides additional "evidence" reinforcing this dissatisfaction.

The management of the fourth hospital included in our sample was prompted by a perceived threat from a new large-scale competitor in the neighborhood to create an entrepreneurial vehicle as part of the hospital's holding company structure. This vehicle was able to facilitate 
physicians attracted by the prospect of starting an entrepreneurial entity. As part of the arrangement, the hospital would hold a majority stake in every newly created entity.

"If you see what the specialists do with this, it's not that much here. But what it has done is to send a message to the staff that we appreciate our people and we also give them the freedom to be entrepreneurs. What you also see is that some specialists are so entrepreneurial that they say: I'm just going to start up my own businesses." [Manager, Hospital B]

Indeed, the facilitation provided for entrepreneurial initiatives has been no panacea preventing physicians from leaving this particular hospital, as one physician explains:

"I wasn't interested in fitting in with a hospital hierarchy where ophthalmologists are somewhere near the bottom. It was time for something different, so I changed direction completely." [Physician, hospital B]

Summarizing, we found most management teams de facto discourage physicians' entrepreneurship by setting conditions. For physicians who are already dissatisfied, this increases their dissatisfaction with hospital management. In contrast, creating an entrepreneurial vehicle as part of the hospital may facilitate physicians in carrying out their initiatives. This, however, is no panacea preventing entrepreneurial physicians from leaving the hospital.

Finally, we summarize the characteristics of intra-organizational dynamics and management's attitudes towards entrepreneurship in Table 3. The facilitative attitude of the management of hospital B resulted in five recent entrepreneurial initiatives within the hospital's holding structure. Furthermore, whereas $C$ is the second largest hospital, it has the highest level of perceived bureaucracy, leading towards entrepreneurship outside the hospital. Both findings point to the influential role of hospital management in either positively or negatively influencing the number of entrepreneurial initiatives as well as the intrapreneurial or extrapreneurial character of these initiatives. 


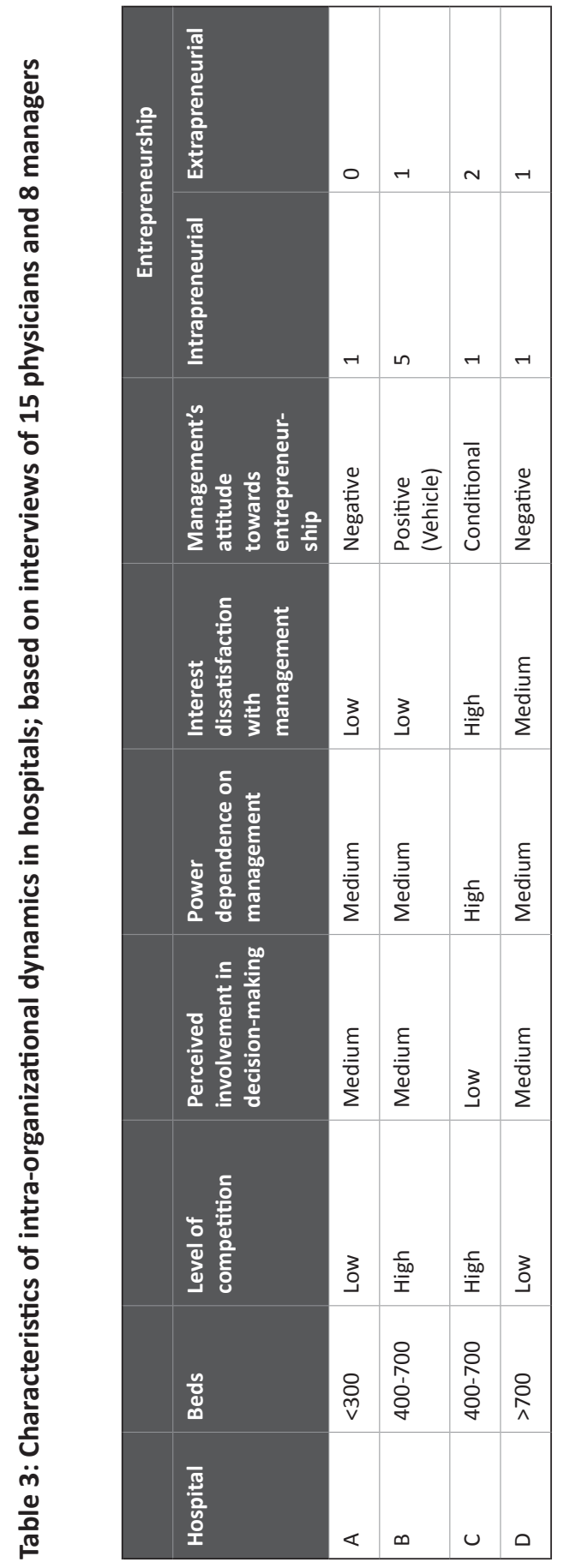




\section{Case studies 2 \\ Intra-organizational dynamics in Dutch specialty clinics}

\section{Interests}

The relative importance of the ten interests identified during the interviews conducted as part of step 1 are presented in Table 4. Since we now focused on both the applicability as well as the relative importance of these interests instead of their identification, we used a Likert scale varying from totally unimportant (1) to very important (5). Although the number of respondents is limited $(n=15)$, we found that helping patients as well as possible is a primary motive for all physicians. Secondly, physicians highly value working with the best facilities, while autonomy, having a say in the clinic's policy and a good work-life balance are rated joint third in importance. Clearly, physicians desire to be facilitated and to be able to influence their work setting. We found the ability, or otherwise, to do this had an effect on intra-organizational dynamics.

Table 4: Indicative survey results for interests among specialty clinic physicians

\begin{tabular}{|l|l|}
\hline Interests among physicians in specialty clinics ( $\mathrm{n}=12)$ & Mean score \\
\hline 1. Helping patients as well as possible & 4.9 \\
\hline 2. Working with the best facilities & 4.4 \\
\hline 3. Being able to do my work autonomously & 4.1 \\
\hline 4. Having a say in the clinic's policy & 4.1 \\
\hline 5. A good work-life balance & 4.1 \\
\hline 6. A good income & 3.7 \\
\hline 7. Variety in my work as a physician & 3.7 \\
\hline 8. Deciding for myself which employees work for me & 3.7 \\
\hline 9. A Specializing further & 3.6 \\
\hline 10. Doing research & 2.9 \\
\hline
\end{tabular}

Scores vary from 1 (not important) to 5 (very important)

\section{Power dependence}

As in step 1, we researched the presence and cause of perceived power dependence among physicians. We found that in specialty clinics, physicians who were involved in the entrepreneurial process and now have a position in the clinic's governance perceive the facilitation provided by management as good. A general manager of a specialty clinic explains his facilitation of physicians as follows: 
"We set up everything to make it as easy as possible for the physicians to do their job. Indeed, they're the boss. In that sense they're not being ordered around by a manager. So they have an awful lot of say in how they can optimize their work and arrangements." [Manager, clinic \#3]

Organizational size appears to be positively related to the degree of perceived power dependence as perceived power dependence is mentioned more frequently by physicians working in larger clinics. In contrast, respondents from smaller clinics experience more direct collaboration by being more centrally positioned within the organization. A manager of the largest clinic reports the downside of a large span of control:

"People always complain a lot. And the complaints are mainly about how remote the directors are - not me, but the directors: people think they are too distant." [Manager, clinic \#2]

In addition to organizational size, the single focus in most clinics on one specialty improved the perceived influence on organizational decision-making. As a result, internal competition with other specialties is limited or absent. This focused character contributes to a lower perceived power dependence.

Perceived power dependence is also reduced by the financial incentives provided by specialty clinics. These incentives are related to the overall performance, thereby fostering a shared interest among physicians and managers alike. As a physician explains:

"We set up the clinic to give everyone a share in the profits. That makes you slightly more motivated to make sure things work out in your own outfit because it's in your own interests." [Physician, clinic \#4]

With regard to physicians who were not involved in the entrepreneurial process of starting up the clinic and who are not included in the clinic's governance, our results indicate that they still perceive high power dependence on management. In contrast, physicians who were involved in the startup phase and who are part of the governance structure of the specialty clinic perceive themselves to be more influential as well as seeing functional interdependence with - rather than dependence on - management. This mutual interdependence is perceived as a positive and vital characteristic of their organization, as a physician involved in the entrepreneurial process notes:

"Yes, I feel I'm dependent on management. But not in a negative way. I just mean that if they weren't there, we wouldn't be able to do our job." [Physician, clinic \#3] 
Summarizing, specific organizational characteristics of specialty clinics stimulate the development of shared interests and collaboration. For example small specialty clinics without much bureaucracy can be more flexible with regard to physicians' interests due to a smaller span of control for the clinics' management and a decision-making process that involves a single specialty. In addition, many specialty clinics offer shared financial incentives, thereby aligning the interests of physicians and managers. Finally, physicians who have been involved in the founding of the clinic and who have a position in the clinic's governance experience low levels of power dependence. Both physicians and managers are aware of their interdependence, which produces a context where physicians are facilitated in practicing their medical profession as autonomously as possible.

\section{Interest dissatisfaction}

With respect to the causes and extent of interest dissatisfaction, ten out of twelve physicians said they were satisfied with the facilitation provided by their management as they are able to satisfy their interests and practice their medical profession while safeguarding their medical autonomy.

One physician, who did not participate in either the entrepreneurial process or the governance of his clinic, reported experiencing interest dissatisfaction with management. However, physicians who were involved in the founding and governance of their specialty clinic reported being able to align their clinic with their own interests (Table 3). A general manager describes how physicians' interests are facilitated:

"The physician-entrepreneurs want short lines of communication, a focus on patients, a personal business, not too big, fast, no waiting, not being constantly shunted from pillar to post, high-quality service, i.e. not a trainee doctor or a general doctor who does a bit of everything. And the facilities for that are what we've essentially organized. It's the doctors who provided the input." [Manager, clinic \#4]

The interests of physicians and managers are found to be highly aligned, thereby preventing interest dissatisfaction and competing interests. Instead, shared interests focus on achieving high patient satisfaction, and the best possible care is realized through shared ownership or financial incentives to optimize the clinic's overall performance. A general manager described the importance of having shared interests:

"In fact, you need to make sure the interests of the doctors and the clinic are aligned. If the interests aren't aligned, they will inevitably end up in a conflict." [Manager, clinic \#3] 
It is noticeable, however, that as clinics grow, physicians and managers report experiencing a similar divergence of interests to managers and physicians working in hospitals. One physician who worked on an employment basis for a specialty clinic explains his difficult relationship with a manager:

"There comes a point where the management tells you, the doctor, how you should be doing your job and I could see that was in the offing. I've always seen this as a big threat and then you gradually get into disagreements with management." [Physician, clinic \#7]

Summarizing, physicians who participate in the founding and governance of the clinic are able to practice their medical profession while satisfying most of their interests; they experience low levels of interest dissatisfaction. Physicians' interests are aligned with clinics' overall performance through shared ownership or additional financial incentives. As clinics grow, however, the interests of managers and physicians start to diverge, thereby creating similar tensions as in hospitals.

\section{Value commitment}

With respect to the influence of logics on power dependencies and interest dissatisfaction, we found a tendency for the development and maintenance of a shared hybrid logic held by both physicians and managers as part of the entrepreneurial process. The basic premise of this hybrid logic entails both groups adopting elements of the logic traditionally held by the other group. As a physician describes it:

"Just as managers need to learn to think a bit like a doctor - they need to be able to empathize with how doctors think - in the same way, doctors need to be able to empathize with how managers think." [Physician, clinic \#6]

One physician who held a medical logic, did not participate in the entrepreneurial process of starting up the clinic and was not involved in the clinic's governance collided with the hybrid logic and eventually left the specialty clinic.

"I had an office manager there. [...] I said: you need to facilitate me. And at a certain point, it was something really simple, I said that I wanted to arrange my consultation hours like this. 'Yes, but we don't agree.' Sorry, but if so then we have a misunderstanding." [Physician-manager, clinic \#7] 
In addition, the relatively small size of specialty clinics helps in building and maintaining a shared hybrid logic as communication can be quick and direct, as explained by a manager:

"We regularly discuss the set of instruments doctors need, agreeing on communication with patients and how we should arrange procedures and protocols. Also, the doctors come in here saying this didn't go well, how should we deal with that, then we try to tackle it at once." [Manager, clinic \#5]

Finally, as the clinic expands, the business logic of management becomes more dominant at the expense of the hybrid logic, potentially giving rise to a defensively oriented competitive value commitment. A physician embedded in the hybrid logic described his feelings about the growth of his clinic:

"But you see that specialty clinics [ZBCs] are getting bigger and bigger, you see that here too, you're getting more and more hierarchical layers. But you have to keep that within limits. And if they get big enough, you automatically get the same organizational problems in the specialty clinics as in the hospitals." [Physician, clinic \#4]

Likewise, the executive manager of Hospital B comments on the dangers of the entrepreneurial entity becoming more bureaucratic:

"So what you need to watch out for is that you don't get the same bureaucracy because you're still doing things in a certain hospital context. Because the management side has a tendency to make things more bureaucratic, they add a layer of bureaucracy to the opportunity and if you do that thoroughly then you inevitably find the opportunity has gone again. Or the staff have lost their enthusiasm." [Executive Manager, hospital B]

Summarizing, at most of the specialty clinics included in our sample, physicians and managers are embedded in a shared hybrid logic. As physicians perceive their interests to be properly facilitated, their value commitment is directed towards maintaining this status quo. One physician who did not participate in the entrepreneurial process or the governance of the clinic collided with the dominant hybrid logic, thereby developing a defensively oriented competitive value commitment. Finally, we found that as clinics grow, so does the dominance of the business logic. 


\section{Entrepreneurship}

Whereas in step 1 we found two mechanisms prompting hospital-based physicians to engage in entrepreneurship, we only encountered one such mechanism for physicians already working in entrepreneurial specialty clinics. This concerned one physician embedded in the medical logic who did not participate in the entrepreneurial process or in the clinic's governance, who therefore experienced power dependencies and interest dissatisfaction with regard to management, inducing him to leave the specialty clinic to start his own business.

We did not find evidence for high levels of power dependencies and interest dissatisfaction with the clinic's management among physicians who did partake in the entrepreneurial process and governance of the clinic. Neither did we encounter similar phenomena with respect to other physicians. Still, growing bureaucratization is mentioned as a potential danger to this stable situation as this may induce growing dependence on the clinic's management, therefore resulting in interest dissatisfaction.

\section{Discussion}

We explored the nature of intra-organizational dynamics between physicians and managers in both hospitals and specialty clinics. In addition, we assessed whether the change whereby a physician turns into an entrepreneur is largely transformational or sedimented. Finally, we formulated suggestions for policymakers at the national and hospital level concerning shared values and aligned stimuli for entrepreneurship.

In literature we found ten interests held by physicians that were confirmed in this research. Although our sample size is relatively small ( $n=15$ hospital and 12 for clinics), we found some interesting differences between the number of times an interest was mentioned by hospital-based physicians, and the importance attached to these interests by physicians working in specialty clinics. The interests of working with the best facilities and a good worklife balance were valued more highly by physicians working in specialty clinics compared to physicians working in hospitals. In addition, a good income, varied work, and further specialization were valued more highly by hospital-based physicians compared to physicians working in specialty clinics.

We found that these interests were reported to influence perceived power dependence and interest dissatisfaction. In particular, a perceived high level of bureaucracy and the associated lack of opportunities for physicians to have a say on hospital policy were found to cause both perceived power dependence and interest dissatisfaction. 
In addition to the focus by Greenwood and Hinings (1996) on intra-organizational dynamics between functionally different groups leading to radical change, we also found evidence that intra-group dynamics may result in radical change, turning physicians into entrepreneurs as well. The initial embeddedness in a certain logic seems to determine their value commitment and related primary focus of perceived power dependence and interest dissatisfaction. Physicians embedded in the traditional logic of medical professionalism perceive high levels of bureaucracy and related power dependence on and interest dissatisfaction with hospital management, resulting in a defensively oriented competitive value commitment. Moreover, intra-organizational dynamics constitute the main incentive for change, which takes the shape of entrepreneurship. Simultaneously, management's attitudes to these types of initiatives by physicians influence how they will be implemented. If a hospital's management explicitly discourages entrepreneurial initiatives, physicians face no alternative than to execute their entrepreneurial initiative outside the hospital (extrapreneurship), while if management is more facilitating, physicians will prefer to collaborate with the hospital organization (intrapreneurship).

As a result, we conclude that our research model holds for physicians embedded in the logic of medical professionalism thereby developing a defensively oriented competitive value commitment as depicted in Figure 2. This confirms earlier findings of Maquis and Lounsburry (2007), who found entrepreneurship to be stimulated by conflicting logics.

The physicians embedded in the dominant logic of business-like healthcare, however, reported that interest dissatisfaction is primarily caused by the prima donna behavior of fellow physicians embedded in the logic of medical professionalism unwilling to adapt to hospital policies. Thereby, a transformatively oriented competitive value commitment is developed towards the traditionally dominant logic of physicians. Although we found intra-organizational dynamics encouraged entrepreneurship to take place, personal factors in particular, such as personality traits and coming from an entrepreneurial family, were mentioned as the main incentive for the entrepreneurship of these physicians. Simultaneously, management's attitude towards entrepreneurship is not mentioned as being of importance in determining whether the initiative takes place within or outside the hospital. Therefore, we adapted our research model, as depicted in Figure 2. 


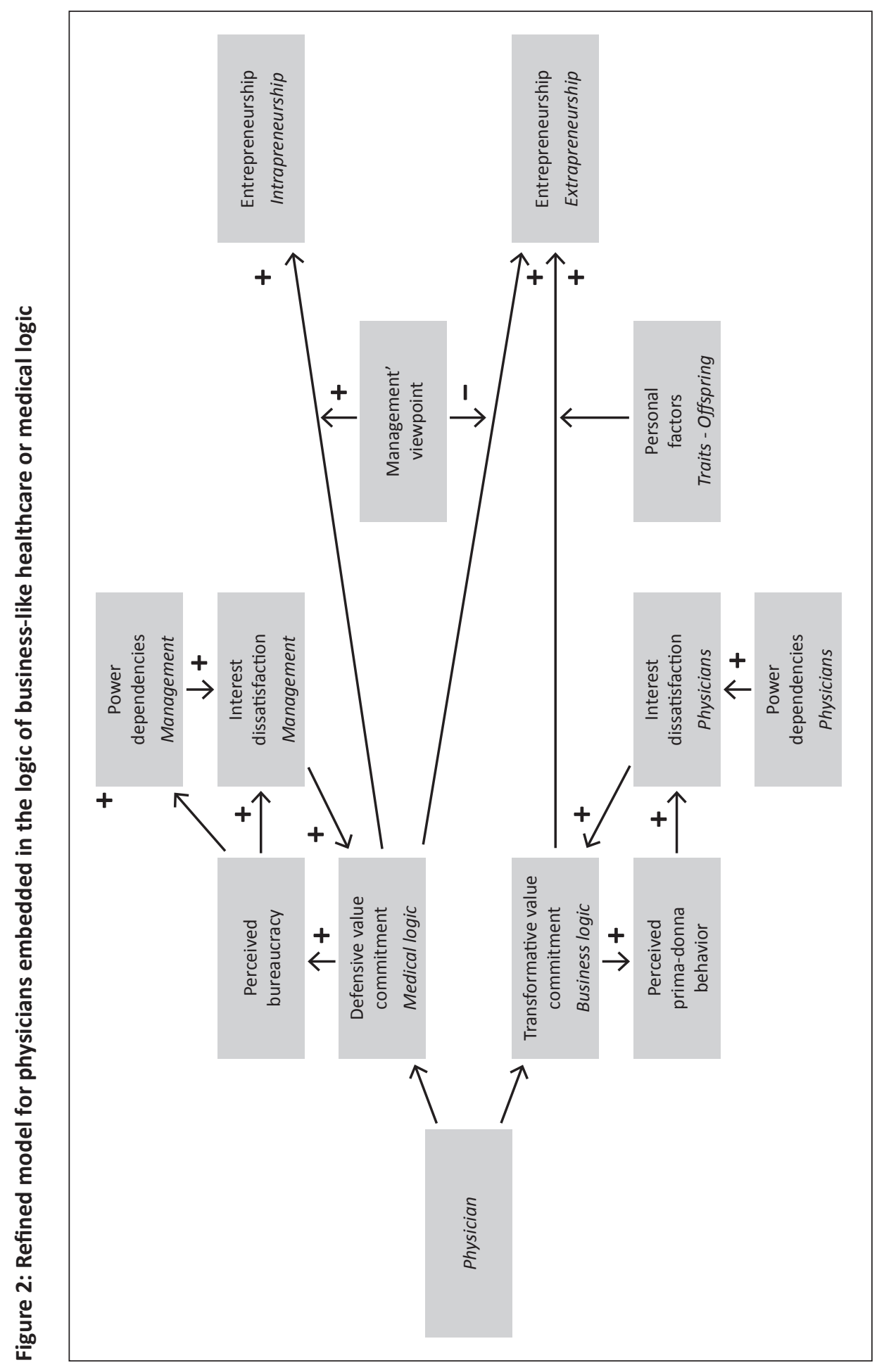


Next, to assess whether the change to entrepreneurship was transformational or sedimented, we analyzed intra-organizational dynamics in specialty clinics. We found that physicians and managers who jointly started a specialty clinic developed a hybrid logic during the startup phase. This hybrid logic subsequently supports their collaboration as it becomes the dominant logic once the clinic is operational. Interestingly, physicians who are not involved in either the startup or governance of the specialty clinic still report high perceived power dependence on, and interest dissatisfaction with, clinic management. Instead of adopting the dominant hybrid logic, these physicians remain embedded in their traditional medical logic, thereby developing a defensively oriented competitive value commitment towards the hybrid logic. This finding suggests that involvement in the startup phase and governance itself comprises a sedimentation process, allowing physicians traditionally embedded in the logic of medical professionalism to adopt elements of the business-like healthcare logic, thereby developing a hybrid logic shared with management. The nature of intraorganizational dynamics in both hospitals and specialty clinics is summarized in Table 5.

Table 5: Intra-organizational dynamics in specialty clinics as compared with hospitals

\begin{tabular}{|c|c|c|c|c|}
\hline & \multicolumn{2}{|l|}{ Hospital } & \multicolumn{2}{|l|}{ Specialty clinic } \\
\hline & \multicolumn{2}{|l|}{ Physicians (n=15) } & \multicolumn{2}{|l|}{ Physicians ( $n=12$ ) } \\
\hline Logic & Medical (6) & $\begin{array}{l}\text { Hybrid (1) } \\
\text { Business (8) }\end{array}$ & Medical (1) & $\begin{array}{l}\text { Hybrid (6) } \\
\text { Business (5) }\end{array}$ \\
\hline $\begin{array}{l}\text { Participated in } \\
\text { startup } \\
\text { In governance }\end{array}$ & & & $\begin{array}{l}\text { No } \\
\text { No }\end{array}$ & $\begin{array}{l}\text { Yes } \\
\text { Yes }\end{array}$ \\
\hline $\begin{array}{l}\text { Perceived power } \\
\text { dependencies* }\end{array}$ & High & Medium & High & Low \\
\hline $\begin{array}{l}\text { Prime subject } \\
\text { of power } \\
\text { dependencies }\end{array}$ & Management & $\begin{array}{l}\text { Fellow } \\
\text { physicians/ } \\
\text { Management }\end{array}$ & Management & - \\
\hline $\begin{array}{l}\text { Perceived } \\
\text { interest } \\
\text { dissatisfaction* }\end{array}$ & High & Medium & High & Low \\
\hline $\begin{array}{l}\text { Perceived value } \\
\text { commitment }\end{array}$ & $\begin{array}{l}\text { Competitive; } \\
\text { defensive } \\
\text { towards business }\end{array}$ & $\begin{array}{l}\text { Competitive; } \\
\text { transformative } \\
\text { towards medical }\end{array}$ & $\begin{array}{l}\text { Competitive; } \\
\text { defensive } \\
\text { towards business }\end{array}$ & Status quo \\
\hline
\end{tabular}

* 'Low' when no example regarding perceived interest dissatisfaction or power dependencies is given, 'medium' when one or two examples are given, and 'high' when more than two examples are given.

We found two indications for the change being sedimented rather than transformational. As part of the medical logic, physicians are supposed to be centrally positioned in the organization allowing them to be both influential as well as autonomous (Reay \& Hinings, 
2009). Being involved in the startup process and governance of the specialty clinic and subsequently having direct influence on clinics' policies not only diminishes the likelihood of interest dissatisfaction developing but also fits well with the initial medical logic in which most entrepreneurial physicians were initially embedded. This is supported by a growing body of literature pointing to the added value of involving physicians in governance (Abernethy \& Vagnoni, 2004; Edwards, 2003; Goodall, 2011; Klopper-Kes et al., 2010a; Scholten \& Van der Grinten, 2002; Walston \& Chou, 2006; Witman et al., 2011). In sum, physicians' satisfaction in specialty clinics is not a result of a newly created logic resulting from transformational change but rather the outcome of a good fit with the medical logic in which the physician was formerly embedded and which prevailed during the entrepreneurial process.

As noted by Pinnington and Morris (2003), whereas transformational change is permanent, sedimented change is temporary and can be reversed. We found this to be the case with respect to the hybrid logic of small, focused specialty clinics. As illustrated by Mintzberg and more recently by Maquis en Lounsbur (2007), small organizations tend to turn into bureaucracies as they grow, thereby providing the conditions for an increasingly dominant business logic. As organizational growth requires more coordination, the business logic increasingly becomes dominant, thereby resembling the very organizations entrepreneurial physicians left in the first place. As a result, organizational members with a strong need for autonomy may leave the specialty clinic (Stuart \& Sorenson, 2003).

Finally, in specialty clinics physicians' and managers' interests are aligned by providing incentives. Shared interests have been shown to positively affect organizational performance and collaboration (Andrews, 2010; Calciolari et al., 2011; Edwards, 2003; Klopper-Kes et al., 2010a; Mache et al., 2012; Ommen et al., 2009; Purdy \& Gray, 2009). In fact, these incentives constitute additional cement to the sediment in which entrepreneurial values are "glued" onto the central medical logic of physicians. This glue may also improve the fit between managers and physicians in other settings, like hospitals.

\section{Study limitations and further research}

Although this was a qualitative study exploring aspects of intra-institutional dynamics, the responding selection of physicians and managers may have biased our findings. Given our relatively limited sample, a large-scale quantitative follow-up study is needed to confirm our qualitative findings. It is remains unclear how the entrepreneurial process actually induces physicians to adopt elements from the business logic and how management is induced to adopt elements from the medical logic, thereby creating a hybrid logic. A follow-up longitudinal study should focus on this process of sedimentation and shed more clarity on the mechanisms involved. 


\section{Conclusion}

The main theoretical contribution of our paper lies in the conceptualization of our findings into a theory of entrepreneurial change in the healthcare sector. We drew from the neoinstitutional theory developed by Greenwood and Hinings (1996), which also assumed that organizations move to a coherent logic with a consistent set of structures and systems. Our analysis demonstrates that the hybrid entrepreneurial logic can be partially overlapping, consisting of different, and sometimes conflicting, layers from both the medical and business logic. As organizations grow, these layers may shift, thereby providing the impetus for a new cycle of change.

Rather than representing transformational change, our findings show that physicians' entrepreneurship demonstrates the existence of sedimented change in which a hybrid logic held by both managers and physicians allows for a collaborative health framework in specialty clinics.

Our findings have implications for policymakers both at the national level and the hospital level. At the national level, budget cuts resulting from the enduring economic downturn in Western countries have provided an impetus for new and additional healthcare reforms relying heavily on the logic of business-like healthcare. However in order to be effective, the deep involvement of physicians, decentralized decision-making and common ground with stakeholders embedded in the medical logic is needed, allowing for a hybrid logic to develop. At the hospital level, policymakers could learn from the mechanisms employed in specialty clinics. For example, by closely aligning organizational entities with medical specialties, management can be more focused and direct, simultaneously allowing for the greater influence and involvement of physicians. In addition, we found shared incentives for both management and physicians, based on both quality indicators and financial indicators of the entity's performance, to be useful in providing additional cement to the sedimented hybrid logic. 


\section{References}

Abernethy, M.A., \& Vagnoni, E. (2004). Power, organization design and managerial behaviour. Accounting, Organizations and Society, 29, 207-225.

Addicott, R., \& Furlie, E. (2006). Sedimented archetype change in public sector organisations the example of managed clinical networks for cancer. Lindfield, NSW: Australian and New Zealand Academy of Management.

Andrews, R. (2010). Organizational social capital, structure and performance. Human Relations, 63, 583-608.

Berkowitz, L., Fraser, C., Treasure, F.P., \& Cochran, S. (1987). Pay, equity, job gratification, and comparisons in pay satisfaction. Journal of Applied Psychology, 72, 544-551.

Bode, I. (2012). Processing Institutional Change in Public Service Provision. Public Organization Review, 1-17.

Burgelman, R.A. (1983). A process model of internal corporate venturing in the diversified major firm. Administrative Science Quarterly, 28, 223-244.

Calciolari, S., Cantu, E., \& Fattore, G. (2011). Performance management and goal ambiguity: Managerial implications in a single payer system. Health Care Management Review, 36, 164-174.

Cohn, K.H., Gill, S.L., \& Schwartz, R.W. (2005). Gaining hospital administrators' attention: Ways to improve physician-hospital management dialogue. Surgery, 137, 132-140.

Cooper, D.J., Hinings, B., Greenwood, R., \& Brown, J.L. (1996). Sedimentation and transformation in organizational change: The case of Canadian law firms. Organization Studies, 17, 623-647.

Degeling, P., Zhang, K., Coyle, B., Xu, L., Meng, Q., Qu, J., et al. (2006). Clinicians and the governance of hospitals: A cross-cultural perspective on relations between profession and management. Social Science \& Medicine, 63, 757-775.

Edwards, N. (2003). Doctors and managers: poor relationships may be damaging patients - what can be done? Quality and Safety in Health Care, 12, i21-i24.

Goodall, A.H. (2011). Physician-leaders and hospital performance: Is there an association? Social Science \& Medicine, 73, 535-539.

Greenwood, R., \& Hinings, C.R. (1996). Understanding radical organizational change: Bringing together the old and the new institutionalism. Academy of Management Review, 21, 1022-1054.

Hisrich, R.D., \& Peters, M.P. (1992). Entrepreneurship: Starting, developing, and managing a new enterprise.: McGraw-Hill/Irwin.

Kaissi, A. (2005). Manager-Physician Relationships: An Organizational Theory Perspective. The health care manager, 24, 165-176.

Kitchener, M. (1998). Quasi-market transformation: An institutionalist approach to change in UK hospitals. Public Administration, 76, 73-95.

Klopper-Kes, A.H.J., Meerdink, N., Wilderom, C.P.M., \& Van Harten, W.H. (2010a). Effective cooperation influencing performance: a study in Dutch hospitals. International Journal for Quality in Health Care, 23, 94-99.

Klopper-Kes, A.H.J., Siesling, S., Meerdink, N., Wilderom, C.P.M., \& van Harten, W.H. (2010b). Quantifying culture gaps between physicians and managers in Dutch hospitals: a survey. BMC Health Services Research, 10.

Koelewijn, W.T., Ehrenhard, M.L., Groen, A.J., \& van Harten, W.H. (2012). Intra-organizational dynamics as drivers of entrepreneurship among physicians and managers in hospitals of western countries. Social Science \& Medicine, 75, 795-800. 
Kuhlmann, E., Burau, V., Larsen, C., Lewandowski, R., Lionis, C., \& Repullo, J. (2011). Medicine and management in European healthcare systems: how do they matter in the control of clinical practice? International Journal of Clinical Practice, 65, 722-724.

Mache, S., Vitzthum, K., Klapp, B.F., \& Groneberg, D.A. (2012). Improving quality of medical treatment and care: are surgeons' working conditions and job satisfaction associated to patient satisfaction? Langenbecks Archives of Surgery, 397, 973-982.

Marquis, C., \& Lounsbury, M. (2007). Vive la résistance: competing logics and the consolidation of US community banking. Academy of Management Journal, 50, 799-820.

McMurray, J.E., Kirk van, J., \& Linzer, M. (1997). Physician Job Satisfaction, Developing a Model Using Qualitative Data. Journal of General Internal Medicine, 12, 711-714.

OECD (2011). Health: Spending continues to outpace economic growth in most OECD Countries. OECD Health Data.

Ommen, O., Driller, E., Koehler, T., Kowalski, C., Ernstmann, N., Neumann, M., et al. (2009). The Relationship between Social Capital in Hospitals and Physician Job Satisfaction. BMC Health Services Research, 9.

Pinnington, A., \& Morris, T. (2003). Archetype change in professional organizations: Survey evidence from large law firms. British Journal of Management, 14, 85-99.

Purdy, J.M., \& Gray, B. (2009). Conflicting logics, mechanisms of diffusion, and multilevel dynamics in emerging institutional fields. Academy of Management Journal, 52, 355-380.

Ranawat, A.S., Koenig, J.H., Thomas, A.J., Krna, C.D., \& Shapiro, L.A. (2009). Aligning Physician and Hospital Incentives: The Approach at Hospital for Special Surgery. Clinical Orthopaedics and Related Research, 467, 2535-2541.

Reay, T., \& Hinings, C.R. (2009). Managing the Rivalry of Competing Institutional Logics. Organization Studies, 30, 629-652.

Saltman, R.B., Busse, R., \& Mossialos, E. (2002). Regulating entrepreneurial behaviour in European health care systems: Open University Press Philadelphia, PA.

Scholten, G., \& Van der Grinten, T. (2002). Integrating medical specialists and hospitals. The growing relevance of collective organisation of medical specialists for Dutch hospital governance. Health Policy, 62, 131-139.

Scott, W.R. (2001). Institutions and Organizations. Thousand Oaks: Sage Publications.

Shane, S., \& Venkataraman, S. (2000). The Promise of Entrepreneurship As a Field of Research. The Academy of Management review, 25, 217-226.

Shortell, S.M., Marsteller, J.A., Lin, M., Pearson, M.L., Wu, S.-Y., Mendel, P., et al. (2004). The role of perceived team effectiveness in improving chronic illness care. Medical Care, 42, 1040-1048.

Stuart, T.E., \& Sorenson, O. (2003). Liquidity events and the geographic distribution of entrepreneurial activity. Administrative Science Quarterly, 175-201.

Walston, S.L., \& Chou, A.F. (2006). Healthcare restructuring and hierarchical alignment - Why do staff and managers perceive change outcomes differently? Medical Care, 44, 879-889.

Williams, E.S., Konrad, T.R., Linzer, M., McMurray, J., Pathman, D.E., Gerrity, M., et al. (1999). Refining the Measurement of Physician Job Satisfaction: Results From the Physician Worklife Survey. Medical Care, 37, 1140-1154.

Witman, Y., Smid, G.A.C., Meurs, P.L., \& Willems, D.L. (2011). Doctor in the lead: balancing between two worlds. Organization, 18, 477-495.

Zazzali, J.L., Alexander, J.A., Shortell, S.M., \& Burns, L.R. (2007). Organizational culture and physician satisfaction with dimensions of group practice. Health Services Research, 42, 1150-1176. 



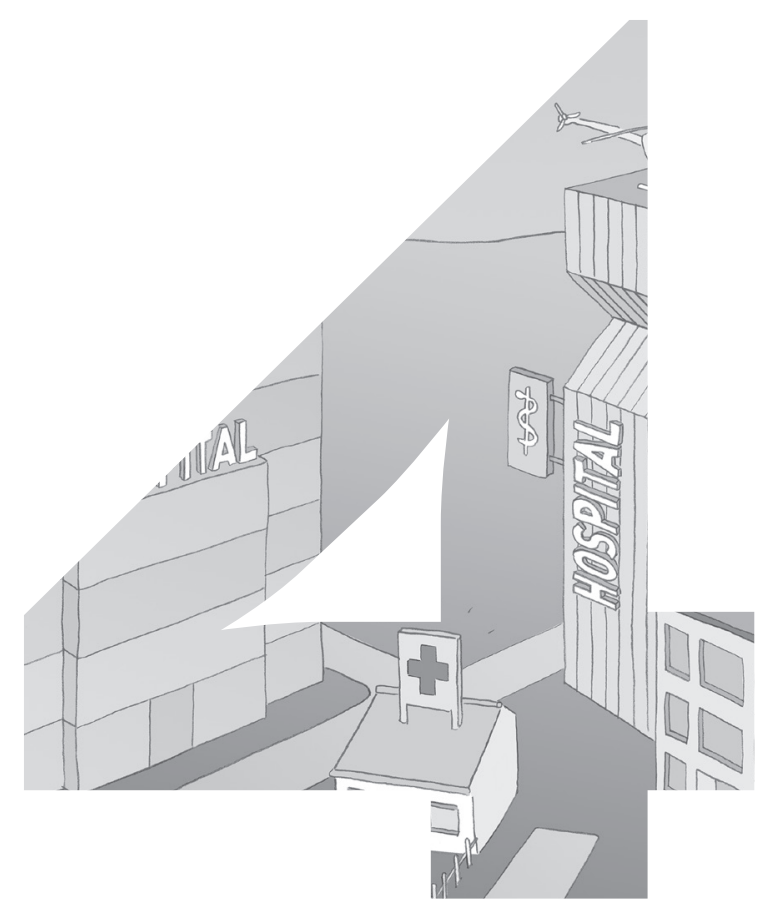

\section{EXPLORING PERSONAL INTERESTS OF PHYSICIANS IN HOSPITALS AND SPECIALITY CLINICS}

Wout T. Koelewijn

Michel L. Ehrenhard

Aard J. Groen

Wim H. van Harten 


\begin{abstract}
Physicians' interests substantially influence intra-organizational dynamics in hospitals, though little is known about the actual content and structure of these interests. The objective of this study was to both identify and build a structured model of physicians' interests. Based on literature and 27 semi-structured interviews with physicians, a questionnaire containing 10 interests was developed. Next, 1,475 physicians in the Netherlands filled out an online survey. Analyses of the data revealed a distinction between the primary interest of 'helping patients as well as possible' and nine secondary interests. Factor analysis identified the main secondary interest dimensions as work-related, setting-related, and life-related. Value attached to interests differs between specialties and types of hospitals. The influence of hospital type on the value attached to interests is stronger than the influence of specialty group on the value attached to interests. Insight in the relative importance of different interests may help policy-makers make decisions that foster shared interests.
\end{abstract}

\title{
Introduction
}

The significance of interests held by organizational members (Bidwell, 2012) in shaping intra-organizational dynamics and organizational responses to institutional pressures for change cannot be overemphasized. (Greenwood \& Hinings, 1996; Kim et al., 2007; Koelewijn et al., 2012)

According to Greenwood and Hinings (1996), interests will provide arenas for conflict as groups holding different interests will attempt to promote their own interests through power relations. Although Kikulus et al. (1995) have argued that this interaction deserves special attention, the extent and implications of the role of organizational members' interests in shaping responses to conflicting institutional pressures remains poorly understood (Jarzabkowski et al., 2009; Kraatz \& Block, 2008; Kraatz \& Moore, 2002).

In addition to the presumed influence of interests, the exploration of the concept of interests itself has not received a great deal of attention from an intra-organizational perspective either. Instead, the few studies covering interest-related issues in health care focus on the causes and consequences of conflicts of interest from an inter-organizational or even interindustry perspective (Brennan et al., 2006; Rodwin, 1993). As a result, the influence of interests from an intra-organizational perspective remains unclear.

In our effort to define interests from an intra-organizational perspective, we adopt the neoinstitutional framework of organizational change as developed by Greenwood \& Hinings 
(1996). They define the concept of interests in terms of organizational members' orientation and their motivation to maintain and enhance their sectional claims. Sartori (1970) acknowledges the political struggle resulting from the competing interests of organizational members and defines these interests as what an actor values in terms of ultimate outcomes. In addition, Thompson (1993), distinguishes between primary interests, which for physicians imply the health of patients, and secondary interests, which may include financial gains or a desire for power. Hall et al. (2001) define secondary interests that include economic, professional, and personal interests. In conclusion, we define interests as primary or secondary outcomes valued by organizations, groups or individuals.

Summarizing, as interests are considered to be highly influential in shaping intra-hospital dynamics (Covaleski \& Dirsmith, 1988; Powell \& DiMaggio, 1991), we focus our study on the identification and analysis of the interests of physicians working in diverse specialties and different types of hospitals. We aim to contribute to the understanding of scholars, hospital managers, and physicians about both the nature and the structure of physicians' interests. This will provide a framework that can improve decision-making processes in both hospitals and specialty clinics. To achieve this, we first derived a list of 10 interests by drawing from both theory and interviews with physicians. Next, we applied systematic exploratory and confirmatory factor analyses to produce a structural model of physicians' interests. Finally, we used univariate and post-hoc analyses of the standardized factor loadings to assess differences between specialty groups and types of hospitals.

\section{Methods}

\section{Study design}

We first refined and extended previous work (Berkowitz et al., 1987; McMurray et al., 1997; Williams et al., 1999; Zazzali et al., 2007) to produce a measure of eight interests indicated by an asterix applicable to physicians across many specialty groups and types of hospitals.

Next, we tested this initial list of eight interests during semi-structured interviews held to elicit the interests of the participating physicians. In total 27 physicians participated, of whom 15 were working in hospitals and 12 in specialty clinics. During the interviews, we first asked our respondents for their present interests to avoid leading them in a particular direction. Next, we combined their responses with the initial list of eight interests, which resulted in a list of in total 12 interests held by physicians in hospitals. However, we decided to remove two of these interests from the final list: First, 'a nice working climate' was mentioned though explicitly linked to the interest 'deciding for myself which employees 
work for me' in which colleagues are included. Second, as 'opportunism' was mentioned as an interest held by other physicians and not by physicians themselves, we decided to exclude it. Finally, 'specializing further' and 'deciding for myself which employees work for me' were added to the final list depicted below:

- Helping patients as well as possible*

- A good income*

- Variety in my work as a physician*

- Specializing further

- Deciding for myself which employees work for me

- Working with the best facilities*

- Being able to do my work autonomously*

- Having a say in hospital policy*

- Doing research*

- A good work-life balance*

Respondents received a personalized invitation by e-mail to increase the response rate. As part of the questionnaire, we explained that these interests were derived both from literature and previous interviews with medical specialists. In addition, we mentioned that questions regarding these interests focused on their current preference given their present situation and experienced dependencies. Finally, respondents were promised strict confidentiality to prevent a potential bias caused by socially desirable answers.

For the purpose of our study, we applied a self-explicated method similar to that used by Chen, Ali and Veeman (2002). Accordingly, we developed two specific tests of the concordance of interests, one focusing on the ordinal aspect of the value attached to an interest, and one comparing the cardinal aspect of the value attached to an interest.

For the cardinal ranking method, all participants were asked to first rank a single interest in relation to the other nine interests, from most important to least important thereby reflecting their current preference. Then participants were asked to rate the importance of each interest in their present situation on a 5-point Likert scale ranging from "very unimportant" (1) to "very important" (5). Three measures of value were derived from these data: a ranking measure rated from most important (10) to least important (1); a rating measure ranging from very unimportant to very important; and a self-explicated measure which we used in our analyses, given by the product of the rating and ranking measures and consequently ranging from 1 to 50 .

Before using the list in a survey among a large sample of physicians in the Netherlands, we first performed a psychometrical test including analyses of skewness, non-response and 
correlation, among 30 physicians in a general hospital to ensure the validity of our results. After this validation we started the large-scale survey across hospital types and specialty groups.

With respect to hospitals we distinguish between general hospitals, large teaching hospitals, academic hospitals, specialist hospitals and specialty clinics. General hospitals offer a broad range of basis care sometimes added with a few of top-reference clinical functions. Large teaching hospitals offer next to basis care also a broad range of top-reference care, in addition to providing education to students of medicine in which the function as satellites of academic hospitals. Academic hospitals provide next to basis to top-reference care, a 'last resort' function for patients with complex healthcare issues. In addition they bear responsibility for providing basic medical training and play a major role in the continuing education of medical specialists. Finally, specialty clinics offer basic care, mostly centered around one or two specialties.

In terms of specialty groups we distinguish between support specialties including microbiology, pathology and anesthesia, surgical specialties including orthopedics and cardio surgery and medical specialties including amongst others; internal medicine and pediatrics.

\section{Data obtained from the questionnaire}

The data collection was undertaken from June to mid-July 2012. For the large-scale survey, we sent an invitation by e-mail to a large sample of 7,913 physicians in the Netherlands working in a hospital or specialty clinic, inviting them to fill out our online survey. Two reminders were sent to those who had not yet filled out the survey. In total, $18.6 \%$ filled out the questionnaire completely $(n=1,475)$, which is a somewhat higher response compared to earlier surveys by Kruijthof (2005) and Klopper et al. (2011).

\section{Ethics approval}

For our research no ethics approval was required. In The Netherlands, ethics approval of research is necessary under the Medical Research Involving Human Subjects Act and/or the Embryos Act (WMO) when it concerns clinical trials in which persons are subjected to treatment or are required to behave in a certain manner.

\section{Descriptive statistics and assessment of the model}

First, as part of our descriptive analysis, a correlation matrix was created, showing the descriptive associations between interests as an indication of covariance and the interdependence of individual interests. 
Next, the associations between the different interest dimensions were assessed. To do this, we applied a systematic procedure in which each step built on the previous steps, using progressively more sophisticated statistical methods. This enabled us to test a structural model while assuring good validity and reliability (Asparouhov \& Muthen, 2009; Donabedian, 1988; Marsh et al., 2009). The software programs of Mplus 6.12 and SPSS 20.0 were used for these analyses.

After controlling for multicollinearity and univariate normality described in Appendix A [INSERT LINK TO ONLINE FILE], an exploratory factor analysis (EFA) was conducted on a subset of $50 \%$ of the respondents to identify the optimal loading of interests on increasing number of factors and remove variables that did not load significantly onto their intended factor (loading < 0.300, $\alpha=0.05$ ). A four-factor model gave an optimal model fit between the interests and the number of factors. A description of our exploratory factor analysis (EFA) can be found in Appendix A.

Finally, a confirmatory factor analysis (CFA) was conducted on the full dataset, containing all respondents, to analyze whether the variables reflected their intended factors and whether the factors could be separated from one other. In CFA, variables are only allowed to load onto the factors specified by the researcher, based on the earlier exploratory factor analysis (EFA).

We checked the model fit indicators when assessing both the EFA and CFA. A good model fit is indicated by a low root mean square error of approximation (RMSEA $<0.08$ ) combined with a non-significant $p$-value ( $p>0.05$ ), and by a high comparative fit index (CFI) and TuckerLewis index (TLI) both close to 1.00 (Kline, 2011). A good model fit means that the model predictions and the data set do not differ significantly (Hair, 2010).

Finally, the resulting model was analyzed to assess differences between groups of specialties and types of hospital. In the Results section, we will present the findings of the analyses.

\section{Results}

In total, 1,472 respondents filled out the questions regarding their interests. Their characteristics are summarized in Table 1. We compared our sample in terms of the number of physicians per specialty group, age, and sex with population data available from the official individual registration of healthcare professionals in The Netherlands (in Dutch: BIG-register). Based on these analyses, we concluded there were no significant differences between the population statistics for physicians in the Netherlands, and the sample statistics for our survey. 
Table 1: Respondents' characteristics

\begin{tabular}{|c|c|}
\hline & Percentage \\
\hline \multicolumn{2}{|l|}{ Gender } \\
\hline Men & $71 \%$ \\
\hline Women & $29 \%$ \\
\hline \multicolumn{2}{|l|}{ Age Distribution } \\
\hline$<35$ & $10 \%$ \\
\hline $35-39$ & $16 \%$ \\
\hline $40-44$ & $13 \%$ \\
\hline $45-49$ & $13 \%$ \\
\hline $50-54$ & $19 \%$ \\
\hline $55-59$ & $17 \%$ \\
\hline $60-65$ & $12 \%$ \\
\hline \multicolumn{2}{|l|}{ Specialty Group } \\
\hline Medical specialties & $49 \%$ \\
\hline Surgical specialties & $29 \%$ \\
\hline Support specialties & $22 \%$ \\
\hline \multicolumn{2}{|l|}{ Hospital Type } \\
\hline General hospitals & $29 \%$ \\
\hline Large teaching hospitals & $43 \%$ \\
\hline Academic hospitals & $22 \%$ \\
\hline Specialist hospitals & $2 \%$ \\
\hline Specialty clinic & $3 \%$ \\
\hline
\end{tabular}

\section{Descriptive presentation of interest scores}

First, we analyzed the outcomes using descriptive statistics. Table 2 shows the means, standard deviations and correlations of physicians' interests. 'Helping patients as well as possible', 'a good work-life balance' and 'a variety in my work as a physician' are considered most important. 'Doing research', 'deciding for myself which employees work for me' and 'specializing further' are considered least important.

The correlations between interests varies from close to zero between 'helping patients as well as possible'and 'doing research' ( $r=.002$, n.s.) to a medium-sized correlation between' deciding for myself which employees work for me' and 'having a say in hospital policy' $(r=.507, p<.01)$. A significant negative relationship was found between 'a good income' and 'doing research' $(r=-.102, p<.01)$, and between 'a good work-life balance' and 'doing research' $(r=-.055, p<.05)$. 


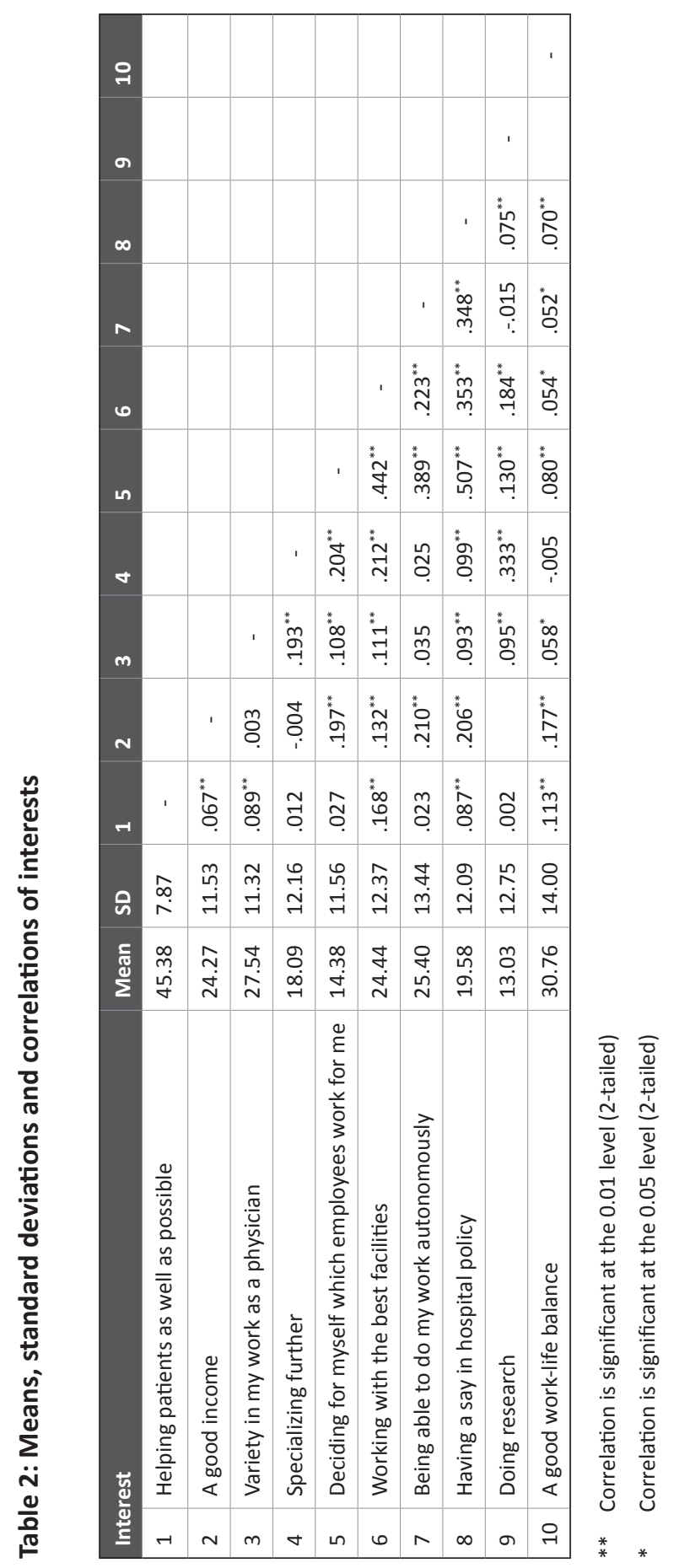




\section{Confirmatory factor analysis (CFA)}

After the EFA based on $50 \%$ of the respondents, we analyzed both the four-factor model and a three-factor model containing only the secondary interests by performing a confirmatory factor analysis on the full dataset.

The four clusters of interests that are derived from this analysis are labeled as follows: Mission, a primary interest, based upon a single item, helping patients as well as possible.

Next, three secondary interest dimensions are distinguished:

1. A work dimension: a secondary interest that is a combination of 'variety in my work as a physician', 'specializing further' and 'doing research';

2. A setting dimension: a secondary interest that covers 'deciding for myself which employees work for me', 'working with the best facilities', 'being able to do my work autonomously' and 'having a say in hospital policy'.

3. A life dimension: a secondary interest consisting of 'a good income' and 'a good worklife balance'.

Based on the robust maximum likelihood estimator (MLM), the four-factor model containing both primary and secondary interests gives a mediocre fit to the data: $N=1,780, \chi 2$ (df) = $225.208(33), p=.0000, \mathrm{RMSEA}=.057, \mathrm{CFI}=.901, \mathrm{TLI}=.865$. This is caused by the presence of a single observed item of the primary interest being treated as a latent variable. As two items per factor is considered the minimum for identification (Kline, 2011), we will exclude 'Mission' as it consists of a single item.

The fit for the three-factor model containing secondary interests and excluding 'Mission' is better than for the four-factor model: $\mathrm{N}=1,780, \chi 2(\mathrm{df})=127.139(24), \mathrm{p}=.0000$, RMSEA $=$ $.049, \mathrm{CFI}=.944, \mathrm{TLI}=.916$.

Concluding, the confirmatory structural equation modeling analysis confirmed the earlier EFA while grouping interests in both primary and secondary interests.

\section{Principal interests of specialty groups and types of hospital}

Next, we assessed the overall scores for the different interest orientations across specialty groups and hospital types as depicted in Table 3.

Mission is valued highest, which corresponds with its position as primary interest. Among the secondary interests, work-related interests are valued higher than life and setting interests. 
Table 3: Estimates, standard error and p-value for the observed variable (mission) and latent variables (work, setting, life)

\begin{tabular}{|l|r|r|r|r|}
\hline \multicolumn{1}{|c|}{ Estimate } & \multicolumn{1}{c|}{ SE } & \multicolumn{1}{c|}{ Est/SE } & \multicolumn{1}{c|}{ P-value } \\
\hline Primary interest & \multicolumn{3}{|c|}{} \\
\hline Mission & 45.431 & 0.186 & 244.843 & 0.000 \\
\hline Secondary interests & \multicolumn{3}{|c|}{} \\
\hline Work & 27.551 & 0.269 & 102.369 & 0.000 \\
\hline Setting & 14.343 & 0.275 & 52.219 & 0.000 \\
\hline Life & 24.257 & 0.273 & 88.786 & 0.000 \\
\hline
\end{tabular}

To assess the differences between specialties and types of hospital, we performed separate univariate analyses (ANOVAs) for both the primary and secondary interests. In addition, we compared the means or mean standardized factor loadings in SPSS by applying the Games-Howell post-hoc test. This test was used because of large differences in sample size between hospital types and in variances across factors (Field, 2009).

For the primary interest of helping patients, we analyzed the mean scores for the different specialties and types of hospital as presented in Table 4. Interestingly, helping patients was valued least by physicians in support specialties and most in surgical specialties to medical specialties. Although we found no significant differences in the value attached to helping patients between types of hospital, the scores suggest that physicians working in specialty clinics may attach lower value to this interest compared to physicians working in large teaching hospitals. 
Table 4: ANOVA and post-hoc test for primary interest by specialty group and hospital type

\begin{tabular}{|l|l|l|l|}
\hline \multicolumn{2}{|l|}{ Variables } & \multicolumn{1}{|l|}{ X } & (SD) \\
\hline & Mission & & \\
\hline \multicolumn{2}{|l|}{ Specialty group } & & \\
\hline & Medical & & $(7.7)$ \\
\hline & Support & 45.52 & $(9.4)$ \\
\hline & Surgical & 44.013 & $(6.6)$ \\
\hline & P value & 46.22 & \\
\hline & & $<0.00$ & $(7.6)$ \\
\hline & Gospital type & & \\
\hline & General hospitals & 45.7 & $(7.3)$ \\
\hline & $\begin{array}{l}\text { Large teaching hos- } \\
\text { pitals }\end{array}$ & 45.8 & $(9.0)$ \\
\hline & Academic hospitals & 44.5 & \\
\hline & Specialist hospitals & 45.0 & $(7.5)$ \\
\hline & Specialty clinic & 43.5 & $(9.3)$ \\
\hline & P value & & \\
\hline
\end{tabular}

1,2, 3 Significantly different from group mentioned

\section{Secondary interests}

To determine differences in scores between specialty group and type of hospital, we calculated the weighted sum scores in Mplus (DiStefano et al., 2009). Mplus uses regression analysis to determine the contribution of each factor score to factor loadings. Here, factor scores were fixed at 0 and variance was fixed at 1 to obtain a standard normal distribution, allowing comparison between the factor loadings of specialty groups or type of hospital. The results are shown in Table 5.

Reviewing the results, a work orientation and setting are significantly more important to physicians working in support specialties than to physicians working in medical and surgical specialties. In addition, life-related interests are valued more by surgeons and physicians practicing supportive specialties than by physicians practicing medical specialties. 


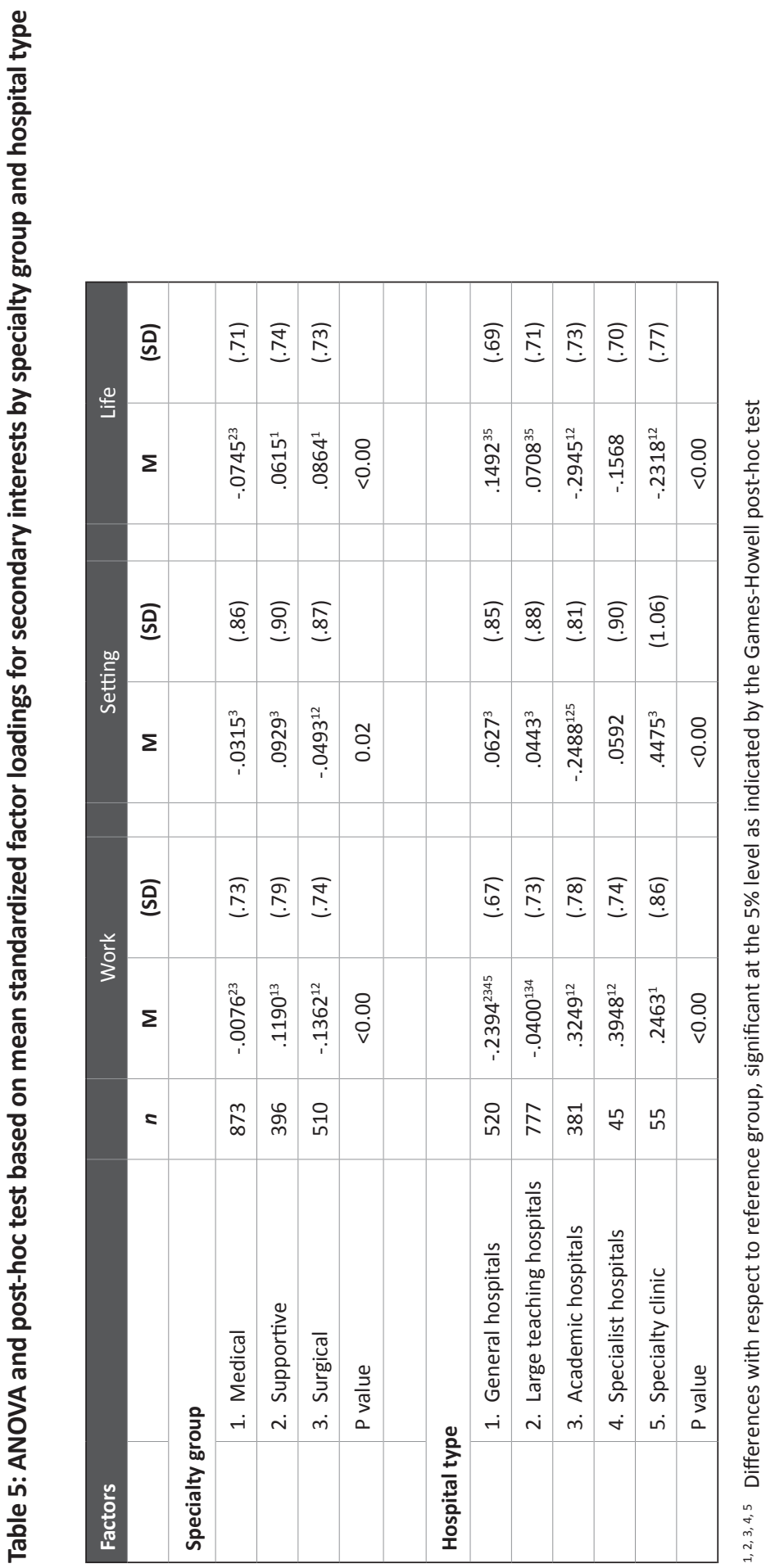


Physicians working in general hospitals score significantly lower on work-related interests compared to physicians working in other hospital types. Setting-related interests are valued least by physicians working in academic hospitals, and most by physicians working in specialty clinics. Finally, life-related interests are valued most by physicians working in general hospitals and least by physicians working in specialty clinics.

\section{Standardized model}

Additional evidence for differences in the value attached to different interests is provided by regressing the latent factors on both the type of hospital and type of specialty. The results are depicted in Table 6. A significant difference in work-related interests is found for type of hospital. Significant differences in life-related interests are found for type of hospital as well as type of specialty.

The fit indices for each background variable containing the three latent constructs are acceptable.

Specialty group: $\mathrm{N}=1,780, \chi 2(\mathrm{df})=188.874(30), \mathrm{p}=.0000, \mathrm{RMSEA}=.055, \mathrm{CFI}=.918, \mathrm{TLI}=.877$. Hospital type: $\mathrm{N}=1,779, \chi 2(\mathrm{df})=186.162(30), \mathrm{p}=.0000, \mathrm{RMSEA}=.054, \mathrm{CFI}=.926, \mathrm{TLI}=.889$.

Table 6: Standardized results for secondary interests

\begin{tabular}{|l|c|c|c|c|}
\hline & Estimate & SE & Est./SE & $\begin{array}{c}\text { Two-tailed } \\
\text { P-value }\end{array}$ \\
\hline Work & & & & \\
\hline Specialty Group & 0.098 & 0.031 & 3.172 & 0.002 \\
\hline Hospital Type & 0.435 & 0.033 & 13.021 & 0.000 \\
\hline Setting & & & & \\
\hline Specialty Group & & & & \\
\hline Hospital Type & 0.051 & 0.027 & -1.583 & 0.116 \\
\hline & -0.048 & 0.030 & & \\
\hline Life & & & -6.353 & 0.000 \\
\hline Specialty Group & -0.269 & 0.042 & & \\
\hline Hospital Type & & & & \\
\hline
\end{tabular}

For the work orientation, the type of hospital has a stronger effect than the specialty group. For the setting orientation, the relationship with both specialty group and hospital type is 
non-significant, while for the life orientation, the hospital type has a bigger effect than the specialty group. Overall, the influence of hospital type is stronger than specialty group.

\section{Discussion}

The results of our study provide a better understanding of both the content and the structure of interests held by physicians. More specifically, the value attached to these interests is not uniform across physicians in different specialties and hospitals.

Our empirical results support the distinction hypothesized by Thompson (1993) between primary and secondary interests. Physicians perceive helping patients as their primary interest. By applying factor analysis we managed to identify three clusters, or dimensions, of secondary interests: work, setting and life. The factor loadings and correlations between latent factors of secondary interests are depicted in Figure 1. 
Figure 1

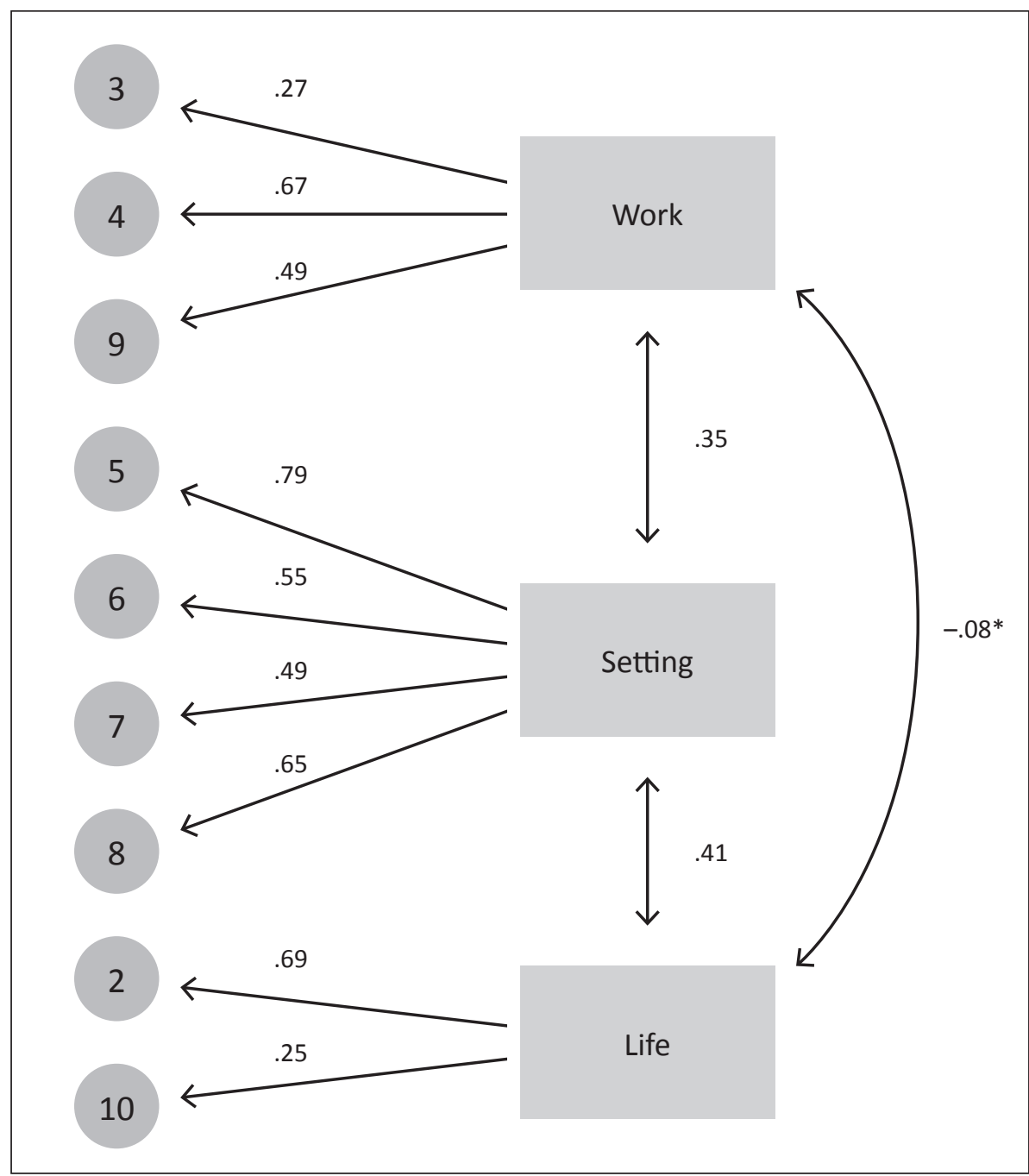

* Non-significant

Our results indicate that it is possible to reliably measure interests by using a 10 -item selfexplicated method, providing new opportunities for both research and practice. When applied carefully, it could advance research by enabling tests of hypothesized relationships between interests, interest dissatisfaction, power dependence as part of intra-organizational dynamics, and different forms of organizational change.

Our research shows resemblance with earlier work with respect to physician' values (Dawis, 1991; Hartung et al., 2005). However, by defining and measuring interests in the context 
of dependencies experienced in the hospital or clinic rather than values, we were able to develop a framework from an intra-organizational perspective rather than from a more isolated viewpoint of the individual physician.

Managers in hospitals may use the instrument to assess areas of importance for physicians, allowing the managers to identify areas of organizational decision-making in which close cooperation with physicians may or may not be necessary. In addition, they may take advantage of differences in the value attached to interests between different specialty groups or types of hospital.

Our development of an instrument measuring physicians' interests has some limitations. First, the finding of an overriding primary interest in all groups raises the question whether the responses are socially correct and inevitably a basic characteristic of physicians' value sets.

The use of personalized invitations by e-mail increased the response rate, but it simultaneously may have led to some bias when dealing with sensitive issues like the relative importance of 'a good income' versus 'helping patients as well as possible' (Heerwegh, Vanhove et al. 2005). The different findings of rankings scores on this particular interests however indicate that this has to be maintained in our model.

Second, personality traits may be an implicit selection criterion for students leaving medical school and applying for a specialty (Vaidya et al., 2004). As personality type may influence interests, this may introduce a bias when researching interests among specialties.

Although the Dutch health-care system is comparable to many Western systems, it has a social insurance based payment structure in which elements of managed competition were introduced only recently. This may have had an impact on the interest scores in areas that are strongly influenced by the introduction of managed competition such as salaries and autonomy. So a second caveat is the generalizability of findings among different health-care systems.

Further research could focus on the influence of interests held by physicians on the performance of both specialty groups and hospitals. Although we expect a positive relationship between patient satisfaction and the value attached to the primary interest of helping patients, this has to our knowledge not been operationalized or tested. Finally, the relationship could be investigated between the interest in working autonomously and the rise of specialty clinics started by individual physicians. 
Finally, as interests held by individuals are influenced by local cultures (Hofstede, 2001) our research could be replicated in other countries to assess its value across cultures.

\section{Conclusion}

Our study contributes to current understanding of the nature and structure of physicians' interests. In this study, we identified, measured, and modeled the interests of physicians in the Netherlands. We found evidence for the existence of both a single primary interest ('helping patients as well as possible') and nine secondary interests. These secondary interests are grouped in work-related, setting-related and life-related interests. Although we found no significant relationship between specialty group or hospital type and settingrelated interests, we did find significant relationships with specialty and hospital type for work-related and life-related interests. Here, the influence of hospital type outweighs the influence of specialty group. 


\section{References}

Asparouhov, T., \& Muthen, B. (2009). Exploratory Structural Equation Modeling. Structural Equation Modeling-a Multidisciplinary Journal, 16, 397-438.

Berkowitz, L., Fraser, C., Treasure, F.P., \& Cochran, S. (1987). Pay, equity, job gratification, and comparisons in pay satisfaction. Journal of Applied Psychology, 72, 544-551.

Bidwell, M.J. (2012). Politics and Firm Boundaries: How Organizational Structure, Group Interests, and Resources Affect Outsourcing. Organization Science, 23, 1622-1642.

Brennan, T.A., Rothman, D.J., Blank, L., Blumenthal, D., Chimonas, S.C., Cohen, J.J., et al. (2006). Health industry practices that create conflicts of interest - A policy proposal for academic medical centers. Jama-Journal of the American Medical Association, 295, 429-433.

Browne, M.W., \& Cudeck, R. (1992). Alternative Ways of Assessing Model Fit. Sociological Methods \& Research, 21, 230-258.

Byrne, B.M. (2012). Structural equation modeling with Mplus : basic concepts, applications, and programming. New York: Routledge Academic.

Catell, R.B. (1966). The scree test for the number of factors. Multivariate Behavioral Research, I, 245-276.

Chen, K., Ali, M., \& Veeman, M. (2002). Relative importance rankings for pork attributes by Asian-Origin Consumers in California: applying an ordered probit model to a choice-based sample. Journal of Agricultural and Applied Economics, 34, 67-79.

Covaleski, M.A., \& Dirsmith, M.W. (1988). An institutional perspective on the rise, social transformation, and fall of a university budget category. Administrative Science Quarterly, 33, 562-587.

Dawis, R. V. (1991). Vocational interests, values, and preferences. In M. D. D. L. M. Hough (Ed.), Handbook of industrial and organizational psychology, Vol. 2 (2nd ed.) (pp. 833-871). Palo Alto, CA, US: Consulting Psychologists Press.

DiStefano, C., Zhu, M., \& Mindrila, D. (2009). Understanding and Using Factor Scores: Considerations for the Applied Researcher. Practical Assessment, Research \& Evaluation, 14.

Donabedian, A. (1988). The quality of care. How can it be assessed? JAMA, 260, 1743-1748.

Field, A.P. (2009). Discovering statistics using SPSS : (and sex, drugs and rock ' $n$ ' roll). Los Angeles: SAGE Publications.

Greenwood, R., \& Hinings, C.R. (1996). Understanding radical organizational change: bringing together the old and the new institutionalism. The Academy of Management review, 1022-1054.

Hair, J.F. (2010). Multivariate data analysis. Upper Saddle River, NJ: Prentice Hall.

Hall, M.A., Dugan, E., Zheng, B.Y., \& Mishra, A.K. (2001). Trust in physicians and medical institutions: What is it, can it be measured, and does it matter? Milbank Quarterly, 79, 613-639.

Hartung, P. J., Taber, B. J., \& Richard, G. V. (2005). The physician values in practice scale: Construction and initial validation. Journal of Vocational Behavior, 67(2), 309-320.

Heerwegh, D., T. Vanhove, et al. (2005). "The effect of personalization on response rates and data quality in web surveys." International Journal of Social Research Methodology, 8 (2): 85-99.

Hofstede, G.H. (2001). Culture's consequences: comparing values, behaviors, institutions, and organizations across nations. Thousand Oaks, California: Sage Publications.

Jarzabkowski, P., Matthiesen, J., \& Van De Ven, A.H. (2009). Doing which work? A practice approach to institutional pluralism. In T.B. Lawrence, R. Suddaby, \& B. Leca (Eds.), Institutional work pp. 284-316). Cambridge: Cambridge University Press.

Kikulis, L.M., Slack, T., \& Hinings, C.R. (1995). Sector-specific patterns of organizational design change. Journal of Management Studies, 32, 67-100. 
Kim, T.Y., Shin, D., Oh, H., \& Jeong, Y.C. (2007). Inside the iron cage: Organizational political dynamics and institutional changes in presidential selection systems in Korean universities, 1985-2002. Administrative Science Quarterly, 52, 286-323.

Kline, R.B. (2011). Principles and practice of structural equation modeling. New York: Guilford Press. Klopper-kes, A.H.J., Meerdink, N., Wilderom, C.P.M., \& Van Harten, W.H. (2011). Effective cooperation influencing performance: a study in Dutch hospitals. International Journal for Quality in Health Care, 23, 94-99.

Koelewijn, W.T., Ehrenhard, M.L., Groen, A.J., \& van Harten, W.H. (2012). Intra-organizational dynamics as drivers of entrepreneurship among physicians and managers in hospitals of western countries. Social Science \& Medicine, 75, 795-800.

Kraatz, M.S., \& Block, E.S. (2008). Organizational Implications of Institutional Pluralism. In R. Greenwood, C. Oliver, R. Suddaby, \& K. Sahlin (Eds.), The Sage Handbook of Organizational Institutionalism (p. 840). London: Sage.

Kraatz, M.S., \& Moore, J.H. (2002). Executive migration and institutional change. Academy of Management Journal, 45, 120-143.

Kruijthof, K. (2005). Doctors' Orders. Specialists' day to day work and their jurisdicational claims in Dutch hospitals. iBMG. Alkmaar: Erasmus Universiteit Rotterdam.

Marsh, H.W., Muthen, B., Asparouhov, T., Ludtke, O., Robitzsch, A., Morin, A.J.S., et al. (2009). Exploratory Structural Equation Modeling, Integrating CFA and EFA: Application to Students' Evaluations of University Teaching. Structural Equation Modeling-a Multidisciplinary Journal, 16, 439-476.

McMurray, J.E., Kirk van, J., \& Linzer, M. (1997). Physician Job Satisfaction, Developing a Model Using Qualitative Data. Journal of General Internal Medicine, 12, 711-714.

Powell, W., \& DiMaggio, P. (1991). The new institutionalism in organizational analysis: Chicago: University of Chicago Press.

Rodwin, M.A. (1993). Medicine, Money, and Morals: Physicians' Conflicts of Interest. New York: Oxford University Press.

Sartori, G. (1970). Concept Misformation in Comparative Politics. American Political Science Review, 64, 1033-1053.

Thompson, D.F. (1993). Understanding Financial Conflicts-of-Interest. New England Journal of Medicine, 329, 573-576.

Vaidya, N.A., Sierles, F.S., Raida, M.D., Fakhoury, F.J., Przybeck, T.R., \& Cloninger, C.R. (2004). Relationship between Specialty choice and medical student temperament and character assessed with Cloninger inventory. Teaching and Learning in Medicine, 16, 150-156.

Williams, E.S., Konrad, T.R., Linzer, M., McMurray, J., Pathman, D.E., Gerrity, M., et al. (1999). Refining the Measurement of Physician Job Satisfaction: Results From the Physician Worklife Survey. Medical Care, 37, 1140-1154.

Zazzali, J.L., Alexander, J.A., Shortell, S.M., \& Burns, L.R. (2007). Organizational culture and physician satisfaction with dimensions of group practice. Health Services Research, 42, 1150-1176.

\section{Web reference}

https://www.bigregister.nl/en/ Last accessed: september 27, 2013. 


\section{Appendix A}

\section{Preliminary analysis}

As our measurement instrument will produce some cross-loadings between different interests and possibly between clusters of interests, we tested for multicollinearity and univariate normality as a minimum. Then, we applied exploratory and confirmatory techniques as part of structural equation modeling (SEM) "in tandem" (Asparouhov \& Muthen, 2009; Donabedian, 1988).

Following Asparouhov \& Muthen (2009), we first checked for multicollinearity as a minimum requirement for the exploratory factor analysis (EFA) and confirmatory factor analysis (CFA) by analyzing squared multiple correlations between each interest and all the other interests. The average squared multiple correlation found between each interest and all the others was $\mathrm{R} 2 \mathrm{smc}=.22$ with a minimum of $\mathrm{R} 2 \mathrm{smc}=.075$ for interest $\# 1$ and a maximum of R2smc $=.467$ for interest $\# 5$. These scores are well below the maximum permitted multicollinearity of $\mathrm{R} 2 \mathrm{smc}=.90$, for the application of EFA and CFA (Kline, 2011).

Secondly, we tested the assumption of univariate normality as proposed by Kline (2011). We took \pm 2.0 as the "early departure point of non-normality" (Byrne, 2012). In our study, the kurtosis value for interest \#1 was 5.45 while the average for the other interests with positive kurtosis values, \#5 and \#9 was .58. For the remaining interests with negative kurtosis values, the average was - $.61(S D=0.114)$. As the kurtosis value for interest \#1 well exceeds the stated departure point, we were not able to apply estimation methods that assume a normal distribution (Hu et al., 1992). Instead, we applied the robust maximum likelihood estimator (MLM) that incorporates the Satorra-Benter X2 test, taking into account the model, estimation method, and kurtosis values (Curran et al., 1996).

\section{Exploratory factor analysis (EFA)}

To establish latent constructs of interests, we use an exploratory factor analysis, using $50 \%$ of the respondents to determine the optimum number of factors that describe the interests (Byrne, 2012).

Using the scree plot, in which the eigenvalues are plotted from the largest to the smallest, we selected the factor after which the plotted curve 'levels out' (Catell, 1966). Based on the plot, we concluded this was after the fourth factor. 
Figure 1: Scree plot

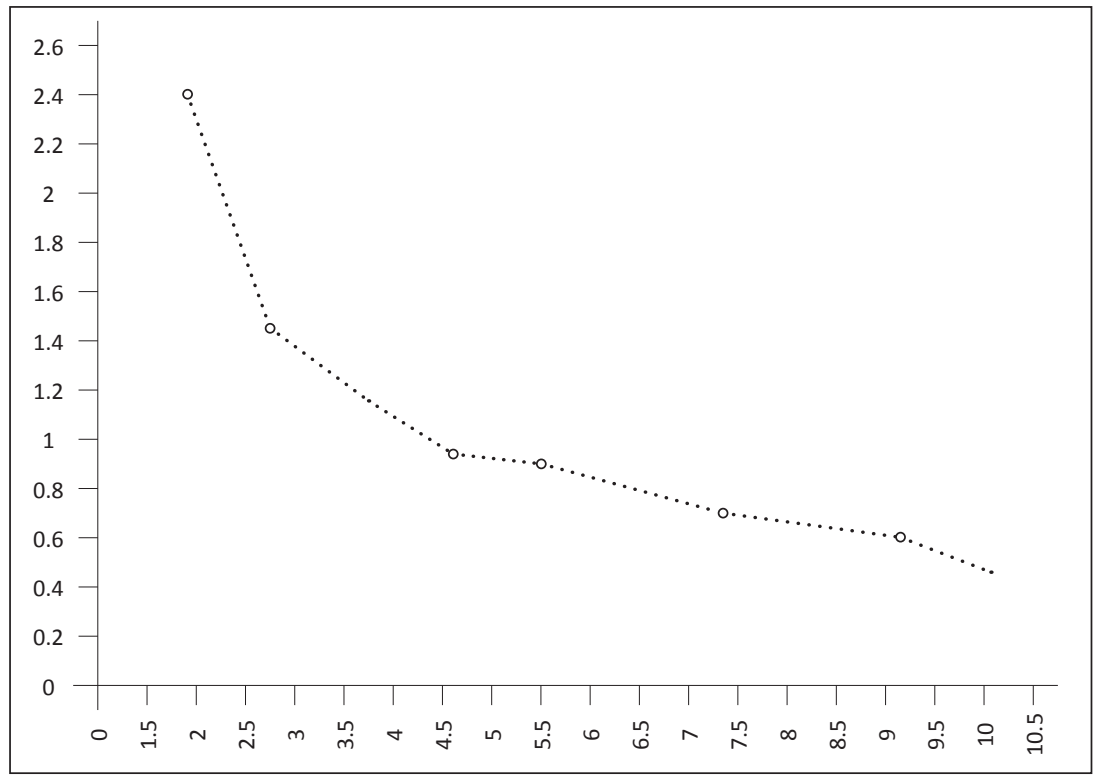

In addition to the scree plot in Figure 1, we looked at the RMSEA to compare models with different factor numbers. We selected the smallest number of factors for which the probability that the RMSEA <= .05 is 1 (Browne \& Cudeck, 1992), which leads to the selection of the four-factor model. Factor loadings for the 10 interests on each of the four factors are provided in Table 3. 
Table 3: Eigenvalues for interests in the four-factor model

\begin{tabular}{|c|l|c|c|c|c|}
\hline & & \multicolumn{4}{|c|}{ Factor } \\
\hline & Interest & 1 & 2 & 3 & 4 \\
\hline 1 & Helping patients & 0.693 & -0.024 & -0.005 & 0.024 \\
\hline 2 & A good salary & 0.012 & 0.013 & 0.115 & 0.524 \\
\hline 3 & Varied work & 0.105 & 0.238 & 0.035 & 0.027 \\
\hline 4 & Specialization & -0.028 & 0.756 & -0.023 & 0.036 \\
\hline 5 & Determining which employees to work with & -0.052 & 0.058 & 0.772 & 0.009 \\
\hline 6 & Working with the best facilities & 0.190 & 0.141 & 0.500 & -0.055 \\
\hline 7 & Autonomy & -0.044 & -0.101 & 0.495 & 0.137 \\
\hline 8 & Influence in hospital policies & 0.053 & -0.058 & 0.661 & 0.025 \\
\hline 9 & Conducting research & 0.013 & 0.404 & 0.086 & -0.215 \\
\hline 10 & A good work-life balance & 0.134 & 0.036 & -0.013 & 0.281 \\
\hline
\end{tabular}

Based on the robust maximum likelihood estimator (MLM), this model provides a good fit: $\chi 2$ (df) $=19.623(11), p=.0508$, RMSEA $=.021, \mathrm{CFI}=.996, \mathrm{TLI}=.983$. Based on this model, we identified 'helping patients' as an independent construct, along with three other latent constructs consisting of multiple items, as depicted in Table 4.

Table 4: Grouping of interests based on EFA

\begin{tabular}{|l|l|l|l|}
\hline Mission & Work & Setting & Life \\
\hline 1. Helping patients & 3. Varied work & $\begin{array}{l}\text { 5. Determining which } \\
\text { employees to work } \\
\text { with }\end{array}$ & 2. A good salary \\
\hline & 4. Specialization & $\begin{array}{l}\text { 6. Working with the } \\
\text { best facilities }\end{array}$ & $\begin{array}{l}\text { 10. A good work-life } \\
\text { balance }\end{array}$ \\
\hline & 9. Conducting research & 7. Autonomy & $\begin{array}{l}\text { 8. Influence in hospital } \\
\text { policies }\end{array}$ \\
\hline & &
\end{tabular}

Following Thompson (1993), we distinguished between primary and secondary interests. As a result, we considered 'helping' patients as a primary interest, while the other interests were considered as secondary interests. We applied this distinction in our confirmatory factor analysis. 



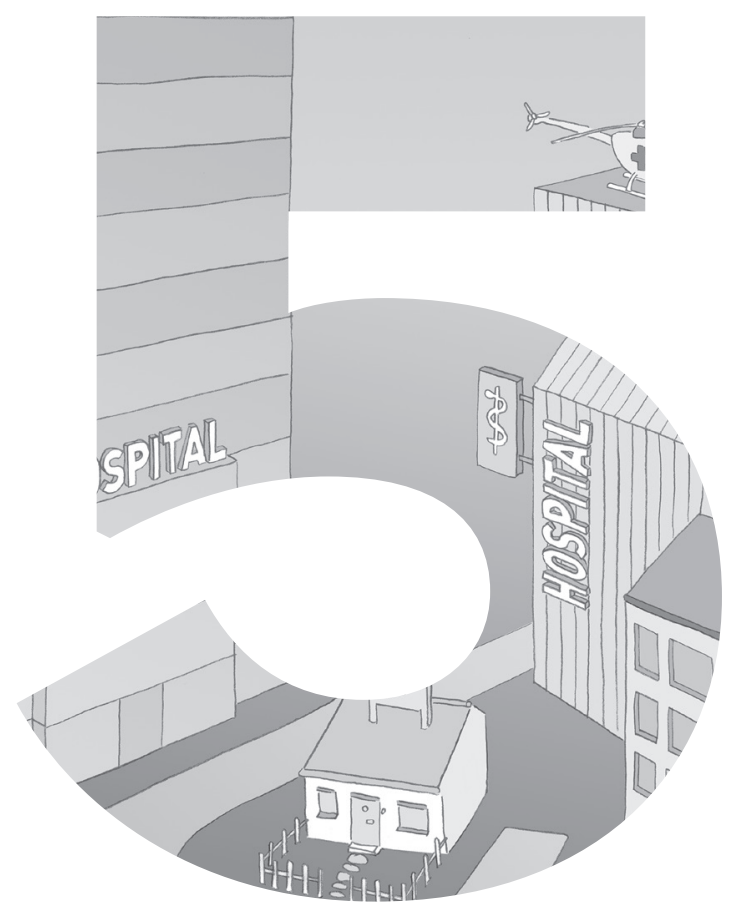

BRIDGING NEO-INSTITUTIONAL THEORY AND ENTREPRENEURSHIP THEORY: VALIDATION IN A HOSPITAL SETTING

Wout T. Koelewijn

Michel L. Ehrenhard

Aard J. Groen

Wim H. van Harten 


\begin{abstract}
The combination of institutional theory and entrepreneurship theory has been identified as having significant potential to add to current explanations of differences in nascent entrepreneurship. However, relatively little of this potential has been realized. This research seeks to materialize some of this potential. For our study of nascent entrepreneurship among physicians in a hospital setting, we related the neo-institutional model of radical change proposed by Greenwood and Hinings (1996) to entrepreneurship and operationalized and tested it. Using data from a large-scale survey among hospital-based physicians in the Netherlands, we found support for our hypothesis linking intra-organizational dynamics -including power dependence, interest dissatisfaction and logics- to entrepreneurial intent. Furthermore, self-efficacy was found to positively influence entrepreneurial intent among individual physicians while organizational efficacy had a negative effect. In addition, evidence was found for the inter-relatedness of market and institutional turbulence, with both having an influence on the perceived power dependence of physicians on hospital management, but opposite effect on the perceived organizational entrepreneurial efficacy. Finally, we contribute to theory by providing and testing a refined model of radical change most likely also applicable in other corporate settings.
\end{abstract}

\title{
Introduction
}

Over the past decades, both institutional theory and entrepreneurship theory have grown into well-established research domains. Although the two theories were developed to answer different questions, there is a link: Where institutional theory answers questions on many types of action and change in social-organizational settings by looking at specific institutional factors, entrepreneurship theory answers question on entrepreneurial action and change mechanisms using multiple elements from economics, psychology, and organizational theory. The combination of the two areas has been identified as having significant potential, but so far little progress has been made in realizing that potential (Phillips \& Tracey, 2007). Furthermore, efforts to combine the two strands have often failed to adopt an institutional perspective in explaining nascent entrepreneurship at the individual level (Bruton, Ahlstrom, \& Li, 2010; Greenwood, Raynard, Kodeih, Micelotta, \& Lounsbury, 2011; Smets, Morris, \& Greenwood, 2012). Here, we will contribute to the literature by doing exactly these two things, combining institutional and entrepreneurship theory to explain patterns of nascent entrepreneurship of individual actors. Hereby, our fieldwork focuses on entrepreneurship among physicians in hospital settings, but the findings may have meaning for the broader context of corporate entrepreneurship. 
In general, we assume our approach is relevant in situations where institutional influences are clearly important and where entrepreneurial activity is present. Corporate entrepreneurship is such a phenomenon; many larger firms stimulate corporate entrepreneurship as an answer to the problem of how to become an ambidextrous organization (Birkinshaw \& Gibson, 2004; Duncan, 1976; Tushman \& O'Reilly III, 1996). Two forms can be distinguished: centralized corporate venture centers and dispersed corporate entrepreneurship (Belousova \& Gailly, 2012; Burgelman, 1983a; Guth \& Ginsberg, 1990). As an outcome of such processes, we see structural corporate entrepreneurship leading to new units performing tasks not fitting in the mother organization and contextual corporate entrepreneurship, which leads to new business having a better fit with the existing business (Birkinshaw \& Gibson, 2004). In both cases, a more or less radical change of logic occurs (Greenwood \& Hinings, 1996), meaning that existing patterns of values, norms, and practices are changing in the context of the entrepreneurial process.

In the medical sector as well, we see increasing attention being paid to corporate entrepreneurship, with physicians starting up new units within hospitals or their own private hospitals or specialty clinics. This is a phenomenon which has been seen for some time in the US and is growing fast in some countries in Europe (Cutler, 2002). Institutional-related contextual factors like hospital organization, governmental rules, and medical professional standards are likely to influence this process. Still, we lack empirical research explaining differences in entrepreneurial behavior in such institutional settings.

Our research examines how institutional concepts relate to contextual and structural intraorganizational dynamics influencing the birth of entrepreneurship. The research question of interest is formulated as "How do contextual factors influence intra-organizational dynamics and how do these dynamics contribute to the entrepreneurship of physicians?"

We chose to perform our research in the Dutch hospital setting. Hospitals can be characterized as organizations built on fault lines of separate societal groups holding different logics (Kraatz, 2009). With physicians generally embedded in the traditional logic of medical professionalism and hospital management embedded in the logic of businesslike healthcare, intra-organizational dynamics are expected to be highly interesting from a neoinstitutional perspective. Secondly, the shift in the relative ascendancy of the two logics brought about by widespread deregulation of the healthcare system in Western countries (Saltman \& Figueras, 1997) has resulted in growing tensions between the two groups (Reay \& Hinings, 2009). Values that are part of the traditional medical logic, such as strict isolation from commercial interests and aiming for maximum quality in medical procedures, are no longer prevalent over businesslike values such as efficiency and cost containment. This potentially gives rise to radical change among physicians who are no longer willing to 
work in a hospital setting under an alien but dominant logic (Koelewijn, Ehrenhard, Groen, \& van Harten, 2012). Of course, account needs to be taken of the differences in internal organization between countries, often resulting from national funding choices. However, the chosen approach is based on relative general theoretical mechanisms of which we expect that the working will be on an abstract level similar in multiple countries. As the Netherlands has a rather strict distinction between physicians working in hospitals and physicians with a private practice, decisions by physicians to start their own business or leave the hospital setting for a specialty clinic can be more emphatically characterized as radical change in Greenwood and Hinings' terms.

Our study contributes to theory in four ways. First, we will build on the bridge between two influential strands of literature by merging the domain of institutionalism with the domain of entrepreneurship to explain physicians' entrepreneurship in a hospital setting. As a result, we will be able to capitalize on both strands. Second, in our development of both strands of literature, we created a refined model based on the theoretical model on radical change of Greenwood and Hinings'(1996). In refining this model, we replaced the construct of capacity for action with the concept of efficacy (Bandura, 2002) and use construct of entrepreneurial intent (Thompson, 2009) as a proxy for entrepreneurship. Subsequently, we operationalized and tested this model, thereby providing a new model for future comparative research. Third, we help to "reconnect institutional research with processes that occur inside the organization" (Suddaby, Elsbach, Greenwood, Meyer, \& Zilber, 2010). Finally, our study contributes to the literature on corporate entrepreneurship specifically by shedding more light on the institutional antecedents of entrepreneurship.

To achieve these objectives, we first formalize hypotheses based on the refined model. Next, we operationalize the constructs by both applying existing measures and developing new measures. In our result section, we provide a measurement model by analyzing the data using both exploratory and confirmatory factor analyses. In addition, we use regression analysis to derive a path model. Finally, we discuss our conclusions regarding the results, implications, and limitations.

\section{Theory}

\section{Entrepreneurship and Institutional Theory Defined}

Theories of entrepreneurship can be summarized as theories of action in social systems (Groen, 2005; McMullen \& Shepherd, 2006). Whether it concerns the act of creating new products or processes (Schumpeter, 1934), entering new markets or starting new ventures (Gartner, 1985; Lumpkin \& Dess, 1996), entrepreneurship relates personal action to 
contextual or system outcomes. (Shane \& Venkataraman, 2000). In these theories, economic factors are assumed to be of critical importance. Increasingly however, other factors such as culture, the regulatory environment, and traditions in an industry are recognized to be of influence in shaping entrepreneurship (Baumol, Litan, \& Schramm, 2007). Institutional theories provide concepts that help analyze these factors.

Institutional theory can be summarized as the set of theories of contextual power and influence explaining either the absence or presence of variation and action (Powell \& DiMaggio, 1991). For a long time, institutionalists applied these concepts in explaining isomorphic stability rather than variation and change (Buchko, 1994). With the recognition of Dougherty (1994) that these concepts could explain the presence of variation and change as well as their absence, the focus gradually shifted to explaining dynamics at the field, organizational, and group levels (Greenwood \& Hinings, 1996; Lounsbury \& Glynn, 2001; Pache \& Santos, 2010). The level of the individual actor however, remains rather unexplored (Bruton et al., 2010; Wicks, 2001). On that level entrepreneurship theory is strong, but there institutional factors are underdeveloped, so in the combination we could gain from the understanding provided by institutionalism about the contextual influence and intra-organizational dynamics giving rise to entrepreneurship (Pache \& Santos, 2010; Phillips \& Tracey, 2007).

Traditionally, institutionalism and entrepreneurship are combined by means of the theory of "institutional entrepreneurship". Institutional entrepreneurship has focused on explaining how actors can shape the institutions they operate in while being constrained by them (Holm 1995; Seo and Creed 2001). As a result, "institutional entrepreneurship" refers to individuals or organizations that act in discordance with the established institutional arrangements, and may eventually change them (e.g. DiMaggio 1988; Lawrence 1999; Zilber 2002). Despite the presence of similarities between institutional and conventional entrepreneurs, such as opportunity recognition and the presence of entrepreneurial capabilities (Phillips \& Tracey, 2007), this element of changing institutional arrangements is specific to institutional entrepreneurs. Entrepreneurship scholars however, are not concerned with how current institutions may be changed, but rather with exploiting opportunities by establishing new ventures. As a result, we define entrepreneurship as "new entries of actors who discover, evaluate, and exploit opportunities to create future products or services by bearing the risk of profit and loss" (Burgelman, 1983b; Hisrich \& Peters, 1992; Shane \& Venkataraman, 2000).

\section{Healthcare as a case of action and radical change}

Institutional theory suggests that organizations embedded in fragmented and only moderately centralized sectors such as healthcare, are likely to face enduring conflicting demands (Pache \& Santos, 2010). In addition, Greenwood \& Hinings (1996) posit that a setting 
of two separate organizational groups holding two different, competing logics provides a recipe for the rise of "competitive value commitments", leading to the two groups fighting to gain influence over the other group's logic or template. Koelewijn (2012) distinguishes between a competitive value commitment directed to changing the group's own logic and a defensive logic directed towards the other - hostile - logic. In addition, Pache and Santos (2010) describe a number of organizational responses to conflicting institutional demands, ranging from acquiescence to defiance and manipulation. Given our research context, we consider entrepreneurship as a specific behavioral outcome resulting from a competitive value commitment or a defiant response to an increasingly dominant logic.

In analyzing intra-organizational dynamics resulting from conflicting institutional demands characterizing our research setting, it is helpful to analyze the organizational structure in which physicians, managers, and other members of the hospital organization cooperate in the Netherlands. As part of the "Integrated Medical Specialists Organization Model", physicians are given a role in the management but not in the governance structure of the hospital. Instead they are consulted by the hospital management, like any other stakeholder group within the hospital. To facilitate these consultations, physician partnerships evolved in which physicians collectively decide on issues raised. Instead of leading to an integration of physicians into the hospital organization, this resulted in them becoming a counteracting force, challenging management, which is highly dependent on physicians' cooperation for realizing its objectives (Scholten \& Grinten, 2002). As part of this setting, most physicians spend long-term careers within a single hospital and physician partnership providing little space for dispersed entrepreneurship.

Next to the fragmented structure characterizing hospitals, our research setting consists of two separate groups holding two different competing logics. In this setting, the businesslike healthcare logic held by management has gained prominence at the expense of the formerly dominant logic of medical professionalism (Reay \& Hinings, 2009). This, as a result of the growing deregulation of healthcare, for example with the introduction of DiagnosisTreatment Combinations (DTC) in 2005, the Dutch equivalent of Diagnosis-related group (DRG) as developed in the United States (Fetter, Shin, Freeman, Averill, \& Thompson, 1980), and the increasing influence of health insurers as healthcare purchasing organizations.

In explaining nascent entrepreneurship of hospital-based physicians, we will make use of the neo-institutional theory of radical change as developed by Greenwood and Hinings (1996). We will refine their model by including individual perceived efficacy at three levels: the individual self, group and organizational, and apply entrepreneurial intent as an outcome measure. The resulting research model is depicted in Figure 1. Based on this refined model, we will elaborate on organizations' context, composed of market and institutional actors. 
Then, we will analyze intra-organizational dynamics by defining power dependence, interest dissatisfaction, and logics. Finally, we will focus on the intention to create new units outside the original hospital as outcome.

\section{Context}

As institutional logics are central in the incitement of radical change, it is necessary to formalize their content at the "field" level. Given that Greenwood \& Hinings do not give a definition of "field", we adopt the definition provided by Dimaggio \& Powell (1983), who state that:

"A field is composed of those organizations that, in the aggregate, constitute a recognized area of institutional life: key suppliers, resource and product consumers, regulatory agencies and other organizations that produce similar services or products".

Although Greenwood \& Hinings do not suggest a relationship between the institutional context and market context, we follow D'Aunno, Succi and Alexander (2000), who found that heterogeneous institutional fields allow for a greater impact of markets. Stated differently, the institutional and market contexts interact. Scott argues that they are related so closely that it may be difficult to distinguish between the two (Scott, 2001). Therefore we refine the original model of Greenwood \& Hinings (1996) by adding a bi-directional hypothesis:

Hypothesis 1: There is a bi-directional or feedback relationship between institutional turbulence and market dynamics.

\section{Market turbulence}

According to Greenwood \& Hinings (1996), the market context may determine whether a physician is in an advantageous or disadvantageous position in relation to other hospitalbased groups like managers. In the hospital context for example, the preferences of referring family physicians and patients for particular physicians may change over time, strengthening or weakening their relative position in the hospital. In addition, market turbulence may fuel insecurity among physicians, leading to higher levels of interest dissatisfaction (which we will discuss separately as well).

Physicians still primarily consider it to be the responsibility of hospital management to respond to market turbulence (Klopper-Kes, Meerdink, Wilderom, \& Van Harten, 2011). Therefore, we expect physicians to feel more power dependent on hospital management as market turbulence increases. 
Hypothesis 2: Greater market turbulence will result in higher levels of interest dissatisfaction. Hypothesis 3: Greater market turbulence will result in higher levels of power dependence.

\section{Institutional turbulence}

Healthcare reforms have strengthened the position of hospital management compared with the position of physicians by providing management with addition powers (Reay \& Hinings, 2009). New rules and legislation on hospital care have continued to affirm businesslike healthcare as the dominant logic. As part of the introduction of managed competition, third parties such as insurers have been assigned tasks, like managing healthcare budgets, formerly executed by the government (Lieverdink, 2001). As a result, we expect the high pace of changes introduced by dominant institutional actors like the government and health insurers (Enthoven \& van de Ven, 2007) to lead to growing power dependence of physicians on hospital management.

Greenwood \& Hinings argue that "organizational actors are constrained in their organizing options by a logic of those within the institutional field". Based on this hypothesis, we further operationalized this premise by defining the two relevant institutional logics.

Hypothesis 4: An increasing pace of institutional change introduced by leading institutional actors is making physicians more dependent on management.

Hypothesis 5: An increasing pace of institutional change favoring a certain logic will increase the embeddedness of physicians in the logic gaining dominance.

\section{Intra-organizational dynamics}

Having defined the context, we will formalize the concepts that, taken together, comprise intra-organizational dynamics.

\section{Power dependence}

Greenwood and Hinings (1996) define power as the capacity to determine outcomes. They observe that groups use favorable power relations to promote their own interests, being supported in this by the prevailing logic that makes some groups more powerful than others. These dependencies of power act with value commitments and interest dissatisfaction to enable or impede change. As a result, Greenwood and Hinings hypothesize that radical change at the organizational level will not occur without an enabling pattern of power dependencies combined with either a reformative or competitive pattern of value commitments aiming to either change the existing logic, or replace it with another competing logic. However, as we define radical change as the entrepreneurial initiatives of individual physicians or physician groups that take place outside of hospital organizations instead of a change within the 
hospital organization itself, power dependence plays a different, though highly important, role.

In addition, as the increased power dependence of physicians on hospital management is the outcome of the growing dominance of the businesslike healthcare logic, we expect that a growing dependence on hospital management will result in a deeper embeddedness in the logic of medical professionalism. Simultaneously, a deeper embeddedness in the logic of medical professionalism is assumed to lead to more awareness on dissatisfaction caused by hospital management, causing the relation between interest dissatisfaction and logic to be bi-directional.

Finally, based on earlier research by Floyd, Kramer and Born (2005) among 1221 physicians in Connecticut, we expect that high levels of perceived power dependence on hospital management by physicians will support their development of an entrepreneurial intent.

Hypothesis 6: There is a bi-directional or feedback relationship between power dependence of physicians and their embeddedness in a logic.

Hypothesis 7: Physicians' increasing power dependence on hospital management will incite an entrepreneurial intent among physicians.

\section{Interest dissatisfaction}

Greenwood and Hinings (1996: 1035) define interest dissatisfaction as the degree of dissatisfaction of groups and individuals with the existing distribution of resources and their motivation to enhance or sustain their shares of scarce and valued resources. Groups use favorable power dependencies to promote their interests, leaving groups in unfavorable positions dependent on those in positions of power. We expect that perceived power dependence will lead to dissatisfaction among the dependent individuals or organizational groups.

Hypothesis 8: Perceived power dependence is positively associated with interest dissatisfaction.

High levels of interest dissatisfaction among physicians caused by perceived poor facilitation by management will influence their perception of the dominant logic in which management is embedded. As a result, we expect physicians experiencing high levels of interest dissatisfaction to deepen their embeddedness in the recessive logic of medical professionalism. In addition, physicians embedded in the medical logic already are expected to be more likely to experience interest dissatisfaction with the facilitation received by hospital management. 
In contrast, physicians embedded in a hybrid or businesslike healthcare logic are expected to be less sensitive to interest dissatisfaction with hospital management as their logic allows for better understanding of priorities set by management. In addition, physicians who are satisfied with facilitation received by management will perceive the businesslike healthcare logic more positively. Summarizing, we expect a bi-directional relation between interest dissatisfaction and the logic.

Hypothesis 9: There is a bi-directional or feedback relationship between interest dissatisfaction of physicians and their embeddedness in a logic.

In addition to the framework provided by Greenwood and Hinings, we propose an extra relationship between interest dissatisfaction and efficacy. We reason that dissatisfaction with the facilitation provided by management will simultaneously lower physicians' self-, group and organizational efficacy to improve a disadvantageous situation.

Hypothesis 10a: There is a negative relationship between interest dissatisfaction and self-efficacy.

Hypothesis 10b: There is a negative relationship between interest dissatisfaction and group efficacy.

Hypothesis 10c: There is a negative relationship between interest dissatisfaction and organizational efficacy.

\section{Logic}

Greenwood and Hinings (1996) apply the construct of value commitments as "a precipitator of radical organizational change". Value commitments are the commitments of groups to the core ideas and orientations embodied in a given archetype or logic. (Hinings \& Greenwood, 1988; Ranson, Hinings, \& Greenwood, 1980). Greenwood and Hinings specify four types of value commitment across groups in organizations, depending on their relative position with regard to the dominant and alternative logics. These value commitments include: a statusquo commitment in which organizational groups adhere to the status quo; an indifferent commitment in which organizational groups are indifferent about which logic is dominant; a competitive commitment in which one group challenges the dominance of the logic held by another group and a reformative commitment in which all organizational groups agree a change of logic is necessary. According to Koelewijn et al. (2012), a competitive value commitment may be either transformative or defensive oriented.

However, as both the dominant and the alternative logic are well defined in our study (businesslike healthcare and medical professionalism respectively), we focus on physicians' relative position with regard to the two logics rather than defining their position compared 
to other groups. It is expected that physicians embedded in the alternative logic of medical traditionalism will develop an entrepreneurial intent in an effort to escape a setting increasingly dominated by the logic of businesslike healthcare and maintain their desired position of autonomy and leadership (Koelewijn et al., 2012).

Hypothesis 11: Deeper embeddedness is positively associated to entrepreneurial intent.

\section{Efficacy}

Greenwood and Hinings apply the construct 'capacity for action' which they define as "the ability to manage the transition process from one logic or template to another" (1996: 1039). This requires both a deep understanding of the new logic as well as the ability to move to that logic. This concept closely resembles self-efficacy as introduced by Bandura. He defines self-efficacy as "people's judgments of their capabilities to organize and execute courses of action required to attain designated types of performance" (Bandura, 1986). Collective efficacy is usually defined as "a group shared belief in its conjoint capabilities to organize and execute the courses of action required to produce certain levels of attainments" (Bandura, 1997). Within organizations, this leads to the idea that "belief of collective efficacy affects the sense of mission and purpose of a system, and the strength of common commitment to what it seeks to achieve" (Bandura, 2002). We will jointly assess entrepreneurial efficacy at the level of the individual, physicians' group, and hospital. Hereby we expect that organizational and group efficacy given the associated common commitment to the goals of organization or group, to be negatively related to the presence of entrepreneurial intent. In contrast, self-efficacy is expected to positively related to entrepreneurial intent.

Hypotheses 12a: Self-efficacy is positively associated with entrepreneurial intent.

Hypotheses 12b: Group efficacy is negatively associated with entrepreneurial intent.

Hypotheses 12c: Organizational efficacy is negatively associated with entrepreneurial intent.

As high market and institutional turbulence will provide uncertainty for both individual organizational members such as physicians and managers (Dickson \& Weaver, 1997; Lawrence \& Phillips, 2004; Maguire, Hardy, \& Lawrence, 2004; Rao \& Sivakumar, 1999), we expect turbulence to reduce efficacy at the individual, group, and organizational levels.

Hypotheses 13a: Market turbulence leads to lower self-efficacy.

Hypotheses 13b: Market turbulence leads to lower group efficacy.

Hypotheses 13c: Market turbulence leads to lower organizational efficacy.

Hypotheses 14a: Institutional turbulence leads to lower self-efficacy.

Hypotheses 14b: Institutional turbulence leads to lower group efficacy. 
Hypotheses 14c: Institutional turbulence leads to lower organizational efficacy.

\section{Entrepreneurial intent}

Whereas in the original model, capacity for action concerns "the ability to manage the transition process from one logic or template to another" (Greenwood \& Hinings, 1996: 1039), radical change concerns the transition itself. In our research, we interpret radical change as "the transition from the hospital-based physician to physician-entrepreneur by discovering, evaluating, and exploiting opportunities for a new clinic and bearing the risk of profit and loss" (Burgelman, 1983b; Hisrich \& Peters, 1992; Shane \& Venkataraman, 2000). For physicians formerly working in hospitals, nascent entrepreneurship in essence entails endorsement (Smets et al., 2012) of the business logic. As we focus our research on physicians currently working in hospitals, we take entrepreneurial intent as outcome measure.

Figure 1: Refined neo-institutional model of entrepreneurial intent

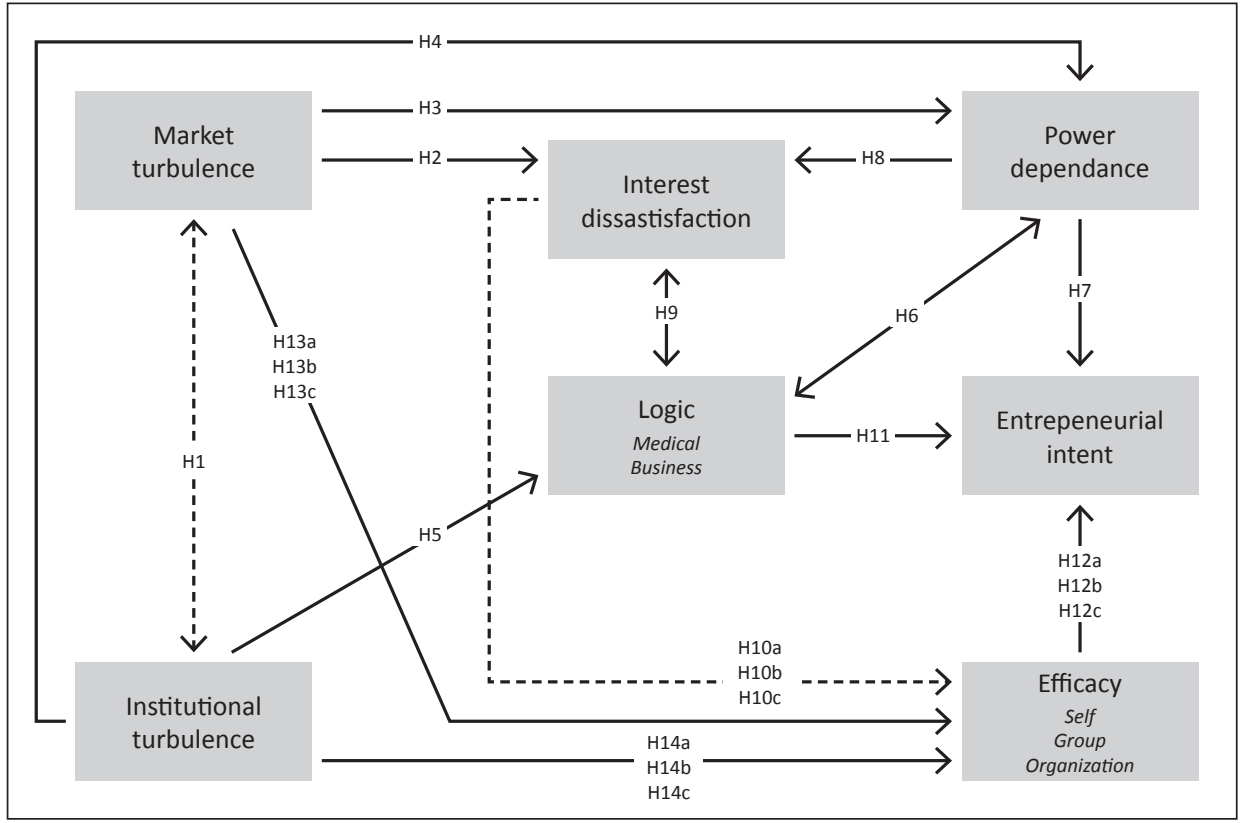

The dotted lines are an addition to the original model of Greenwood \& Hinings 


\section{Method}

\section{Sample}

To test the hypotheses on an empirical basis, we first created a questionnaire which we tested by interviewing 27 physicians, of whom 15 were working in hospitals and 12 in specialty clinics. Based on these interviews, we reformulated some questions to increase understanding. This revised questionnaire was subjected to a psychometric test among 30 physicians in a general hospital to ensure the validity of our scales.

For the survey, we sent an invitation by e-mail to a large sample of 7,913 physicians in the Netherlands, inviting them to fill out our online survey. Two reminders were sent to those who had not yet filled out the survey. For our research, we focus on 7,762 hospitalbased physicians. A total of $18.4 \%$ of these physicians filled out the questionnaire completely $(n=1,430)$, which is a somewhat higher response compared to earlier surveys on the relationship between physicians and hospital management and distributed among physicians by Kruijthof et al.(2005) and Klopper-Kes et al.(2011).

We compared our sample in terms of the number of physicians per specialty group, age, and sex as included in Table 1, with population data available from the official individual registration of healthcare professionals in The Netherlands ("BIG-register", 2013). Based on this, we concluded there were no significant differences between the population statistics for physicians in the Netherlands, and the sample statistics for our survey. 
Table 1: Respondents' characteristics

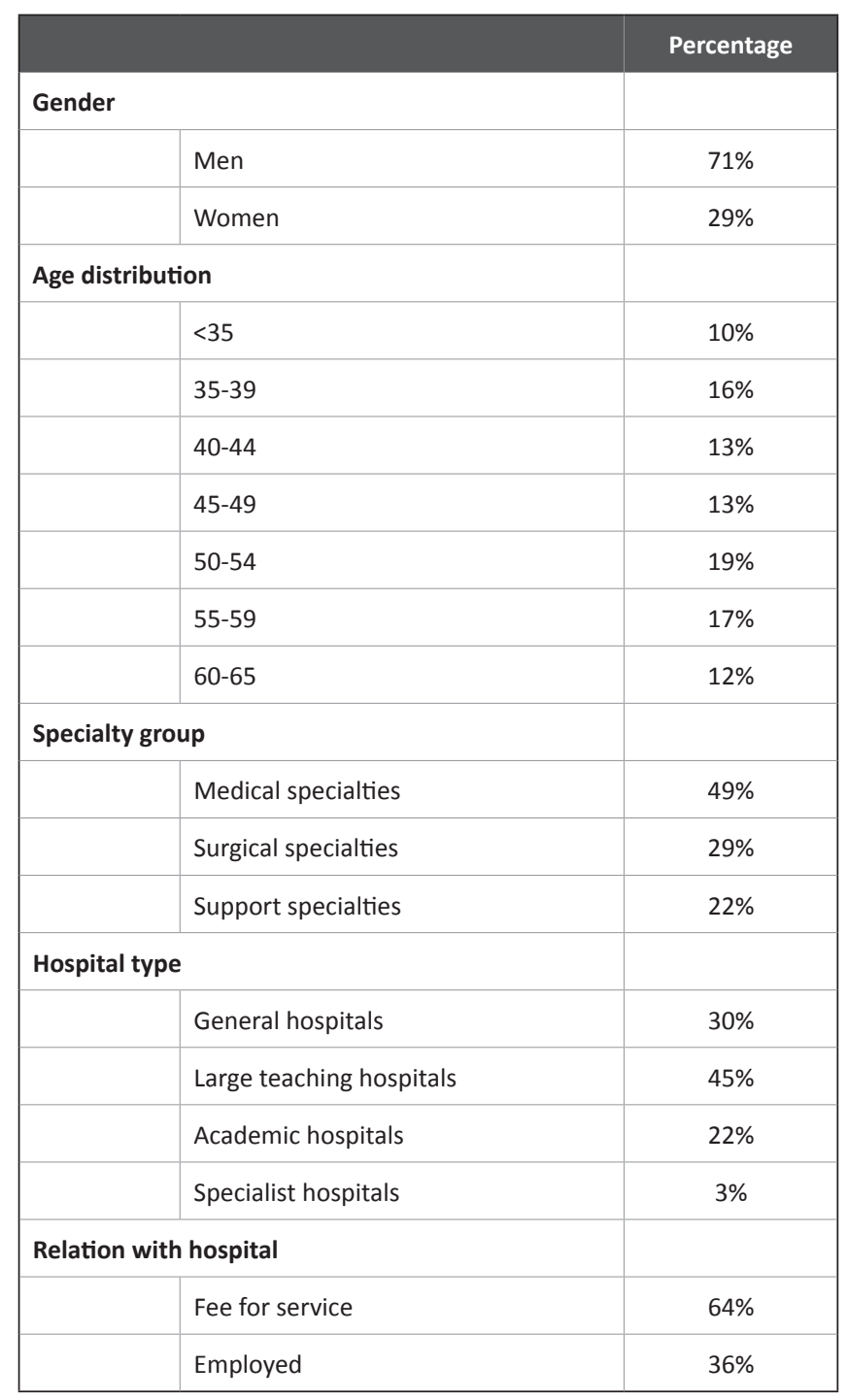

\section{Analytical Procedures}

The data were analyzed in three phases. As part of phase 1, we applied exploratory factor analysis (EFA) and confirmatory factor analysis (CFA) in tandem (Asparouhov \& Muthen, 2009; Donabedian, 1988) in order to analyze and refine our measures by controlling for multidimensionality. To do this, the EFA was first performed on a smaller subsample to assess the underlying factor structure of the scales used. Next, we analyzed the refined 
scales based on the EFA outcomes using confirmatory factor analysis on the full dataset. In addition, we analyzed areas including setting, work and life-related interests, with the highest perceived power dependence on management in order to allow for further model analysis.

In phase 2, we used the outcomes of phase 1 to examine correlations among the latent factors based on CFA analysis. Finally, in phase 3 we examined and refined the complete model by using path analysis.

We assessed the overall fit of our research model by using several fit indicators: the chi square test (denoted $\chi 2$ ), the Root Mean Square Error Of Approximation (RMSEA), the Comparative fit index (CFI; Bentler, 1990) and the Tucker-Lewis index (TLI). The chi-square test provides a measure of the model fit to the observed data. A non-significant chi square indicates a good fit. The Root Mean Square Error Of Approximation is especially useful for large sample sizes as a supplement to the chi-square test, which tends to report higher significance with higher sample sizes. As suggested by March, Hau and Wen (2004), we used the conventional cut-off criteria to assess the model fit, i.e., RMSEA $<.08$ and CFI, TLI >.90, instead of the criteria recommended by $\mathrm{Hu}$ and Bentler (1999) that include RMSEA <.06 and $\mathrm{CFI}, \mathrm{TLI}>.95$. This was done as the cut-offs suggested by $\mathrm{Hu}$ and Bentler tend to be too strict, rejecting otherwise acceptable models. For the comparison of alternative models we compared the Akaike (AIC) value. Lower values of AIC indicate a better model fit.

\section{Measures}

We used established multi-item scales to measure contextual turbulence, efficacy, logic, and entrepreneurial intent among physicians. For the remaining constructs of power dependence and interest dissatisfaction, new multi-item measures were developed by applying multistage scale development techniques. This process included 25 preliminary qualitative interviews with both physicians and hospital managers, an extensive review of academic and practitioner literature, in-person pretesting, and a pretest study. Appendix A presents the items for each construct.

Institutional and market turbulence. Our five-item scale was derived from Kumar (1998) and Laeven (2008). Institutional turbulence was measured by questioning the pace of change in laws and regulations and the preferences of health insurers. Market turbulence was measured by the speed of change in patients' preferences and patient numbers, and the preferences of health insurers and referrers.

A total of five items were used to measure contextual turbulence. Institutional turbulence was measured by a two-item scale. Market turbulence was measured by a three-item scale. 
For every measure, we checked the model fit indicators when assessing both the exploratory factor analysis (EFA) and confirmatory factor analysis (CFA). A good model fit means that the model predictions and the data set do not differ significantly (Hair, 2010). A good model fit is indicated by a low root mean square error of approximation (RMSEA < 0.08) combined with a non-significant $p$-value ( $p>0.05$ ), and by a high comparative fit index (CFI) and TuckerLewis index (TLI) both close to 1.00 (Kline, 2011).

To control for construct validity, we performed a confirmatory factor analysis for the measure of contextual turbulence. The model fit for context was good: $\chi 2(d f)=15.123(4), p=.0045$, RMSEA $=.045, \mathrm{CFI}=.990, \mathrm{TLI}=.976$.

\section{Power dependence}

Power dependence was operationalized by asking physicians about the extent of their dependence on management as experienced in pursuing ten interests. These ten interests and their categorization were established by a stepwise procedure involving both EFA and CFA techniques. The interests are:

- Helping patients as well as possible

- A good income

- Variety in my work as a physician

- Specializing further

- Deciding for myself which employees work for me

- Working with the best facilities

- Being able to do my work autonomously

- Having a say in hospital policy

- Doing research

- A good work-life balance

Based on factor analyses, we categorized these interests into a structure that comprises one primary interest (helping patients as well as possible) which we term 'Mission' and nine secondary interests. These secondary interests are grouped in three dimensions:

- Work, comprising 'variety in my work as a physician', 'specializing further' and 'doing research';

- Setting, comprising deciding for myself which employees work for me', 'working with the best facilities', 'being able to do my work autonomously' and 'having a say in hospital policy';

- Life, comprising 'a good income' and 'a good work-life balance'.

As we consider power dependence to be of prime interest in our model, we focus our analysis on the dimensions associated with the highest perceived power dependence. 
Table 2 represents both the power dependence on management for each interest in addition to the correlation between the interests.

By taking the average score for power dependence per interest we were able to identify the relative power dependence for each dimension: namely Setting (3.97), Mission (3.55), Life (3.19), and Work (2.89). As a result, we focus our analysis on Setting-related interests as this comprises an area in which physicians and managers compete directly.

By taking the model for Setting-related interests as a reference, we ran a CFA to control for construct validity. The model fit was good: $\chi 2$ (df) $=11.555(2), p=.0031$, RMSEA $=.054$, CFI $=.988, \mathrm{TLI}=.963$.

Interest dissatisfaction. Interest dissatisfaction was operationalized by asking physicians their degree of satisfaction (or dissatisfaction) with the extent to which management facilitated their pursuit of the ten interests (Koelewijn, Ehrenhard, Groen, \& van Harten, 2013). Hereby we focused on interest dissatisfaction relating to the four Setting-related interests.

Taking the model of physicians' interests as a reference, we ran a CFA. The model fit was reasonable: $\chi 2(\mathrm{df})=5.319(2), \mathrm{p}=.0700, \mathrm{RMSEA}=.032, \mathrm{CFI}=.997, \mathrm{TLI}=.99$.

\section{Logic}

Our measure for value commitment consisted of three items based on (Reay \& Hinings, 2009) and their description of the content of the two logics. In addition, we added two items that were derived from the interviews, reflecting beliefs with respect to the position of physicians in the healthcare system, the importance of autonomy versus organizational efficiencies and the preferred work relation of physicians with their hospital.

Each item consists of two extreme statements reflecting either the logic of medical traditionalism or the logic of businesslike healthcare to determine the relative position of the physician with respect to the two logics.

The model fit indicators for the CFA of the single factor model show a good model fit: $\chi 2$ (df) $=11.771(5), p=.0486$, RMSEA $=.031, \mathrm{CFI}=.991, \mathrm{TLI}=.981$.

\section{Efficacy}

As explained earlier, the concepts of capacity for action and efficacy are closely related. In assessing the level of efficacy, we will focus on entrepreneurship-related efficacy at the individual, group, and hospital levels. 
We apply the original four-item scale developed by Zhao et al. (2005), adapting it to allow efficacy at the individual, group, and organizational levels. As Zhao et al. (2005) did not check the construct validity of their measures, we performed both an exploratory factor analysis and confirmatory factor analysis in tandem (Asparouhov \& Muthen, 2009; Donabedian, 1988). The exploratory factor analysis yielded support for the single factor model as proposed by Zhao:

$\chi 2$ (df) $=49.674(2), p=.0000$, RMSEA $=.127, \mathrm{CFI}=.981, \mathrm{TLI}=.944$. This was confirmed by the confirmatory factor analysis: $\chi 2(\mathrm{df})=43.041(2), p=.0000, \mathrm{RMSEA} .118, \mathrm{CFI}=.982, \mathrm{TLI}=.946$

The indication of poor fit provided by the RMSEA may have resulted from large factor loadings (Browne, MacCallum, Kim, Andersen, \& Glaser, 2002; Miles \& Shevlin, 2007), rather than actual model misspecification.

Model fit indicators based on the CFA for group efficacy and organizational efficacy show an excellent fit: $\chi 2$ (df) = 19.301 (2), $p=.0001$, RMSEA .077, CFI = .993, TLI =.980, and $\chi 2$ (df) = $25.485(2), p=.0000$, RMSEA $.090, \mathrm{CFI}=.994, \mathrm{TLI}=.982$ respectively.

Entrepreneurial Intent. As we are interested in radical change in the form of entrepreneurship, we used the six-item scale of entrepreneurial intent as developed by Thompson (2009). To allow for better contextualization, we added a seventh question regarding physicians' current activities aimed at building a relevant network among health insurers and referrers.

However, as Thompson (2009) provided little evidence of the construct validity of his measure, we first conducted both an exploratory factor analysis and a confirmatory factor analysis, in tandem, to check its construct validity (Asparouhov \& Muthen, 2009; Donabedian, 1988). The exploratory factor analysis yielded two factors instead of the single factor proposed by Thompson.

The model fit indicators for the EFA of the single factor model include:

$\chi 2(\mathrm{df})=353.448(9), \mathrm{p}=.0000, \mathrm{RMSEA}=.163, \mathrm{CFI}=.938, \mathrm{TLI}=.896$.

The model fit indicators for the EFA of the two-factor model are:

$\chi 2(\mathrm{df})=150.348(4), \mathrm{p}=.0000, \mathrm{RMSEA}=.160, \mathrm{CFI}=.974, \mathrm{TLI}=.901$.

The two-factor model distinguishes between latent plans (items 1, 2, 4, and 5) and concrete action (items 3, 6, and the additional item 7).

A confirmatory factor analysis with the robust maximum likelihood estimator (MLM) provided evidence of a good fit of the two-factor model: $\chi 2$ (df) $=274.834(13), p=.0000$, RMSEA $=.118, \mathrm{CFI}=.958, \mathrm{TLI}=.933$. 
In our model of physicians' entrepreneurship, we will apply the measure of latent entrepreneurial intent only as health insurers' current contracting policies make it more difficult for new clinics to obtain new contracts that would enable them to generate sufficient business. This uncertainty is preventing physicians willing to start their own clinic from taking concrete action at present. The goodness of fit indicators for this four-item measure include: $\chi 2(\mathrm{df})=108.193(2), p=.0000, \mathrm{RMSEA}=.191, \mathrm{CFI}=.972, \mathrm{TLI}=.917$.

\section{Results}

A first-order CFA was performed on all scales, including both market and institutional turbulence, value commitment, capacity for action, entrepreneurship, and setting-related power dependence, and interest dissatisfaction. The model fit indicators include $\chi 2(\mathrm{df})=$ 1577.104 (491), $p=.0000$, RMSEA $=.042, \mathrm{CFI}=.928, \mathrm{TLI}=.918$. This model fits the data well, with values exceeding .9 for the TLI and the CFI, and with an RMSEA of less than .08 .

Table 3 presents the factor correlation coefficients of the first-order CFA. The latent variable scales are measured by their multiple indicators. Table 3 represents the relationships between all resulting variable scales. Preliminary results indicate strong $(\beta>.3)$ and significant $(p<.01)$ relationships between market and institutional turbulence, power dependence and interest dissatisfaction, interest dissatisfaction and organizational efficacy, self-efficacy and group efficacy, group efficacy and organizational efficacy and finally, self-efficacy and entrepreneurial intent.

Next, we applied structural equation modeling to test our hypotheses via path analysis. Using Mplus 6.2 (Muthén \& Muthén, 2010), we estimated the parameters of our research model.

Figure 2 presents our research model with the robust maximum likelihood estimators (MLM). Twelve out of twenty-one predicted links were significant.

We found a significant $(p<.001)$ correlation between institutional and market turbulence, thereby providing evidence for Hypothesis 1.Contrary to our prediction in Hypothesis 2 however, there was no evidence of a direct effect of market turbulence on interest dissatisfaction. Still, by testing Hypothesis 3, we found market turbulence to have a significant negative effect on the perceived power dependence of physicians on hospital management $(p<.05)$. However, as we predicted a positive effect, Hypothesis 3 was rejected. Hypothesis 5 was not confirmed, as a high pace of change introduced by institutional actors was not found to influence physicians' embeddedness in both the medical and business logics. However, we found evidence for Hypothesis $4(p<.001)$, which states that an 
increasing pace of institutional change would have a positive effect on power dependence experienced by physicians. This power dependence however was not found to influence physicians' embeddedness in either one of the two logics. Therefore, Hypothesis 6 was rejected. Likewise we reject Hypothesis 7, as no evidence was found for power dependence directly influencing entrepreneurial intent.

Hypothesis 8, which states that power dependency is positively related to interest dissatisfaction, was accepted $(p<.001)$. This interest dissatisfaction was found to shift physicians' embeddedness towards the recessive logic of medical professionalism, thereby providing evidence for Hypothesis $9(p<.001)$.

Evidence was found $(p<.001)$ for Hypothesis $10(a-c)$ as well, as we found interest dissatisfaction to negatively influence self-efficacy, group efficacy, and organizational efficacy. In addition, we found a significant relationship between embeddedness in the logic of medical traditionalism and entrepreneurial intent, providing evidence for Hypothesis 11 $(p<.001)$.

There was partial evidence for Hypothesis 12, stating that self-efficacy, group efficacy, and organizational efficacy would be positively associated to entrepreneurship. Self-efficacy was indeed found to have a significant $(p<.001)$ positive effect on entrepreneurship. No significant relation was found between group efficacy and entrepreneurship, while the relation between organizational efficacy and entrepreneurship was found to be significant $(p<.001)$ but negative.

Partial support was found for Hypothesis 13 as well. Self-efficacy and group efficacy are not significantly influenced by the market turbulence, but we did find a significant $(p<.05)$ negative relationship between market context and organizational efficacy. A similar pattern of evidence was found between institutional turbulence and the three levels of efficacy. Selfefficacy and group efficacy are not significantly influenced by the institutional turbulence. However, organizational efficacy was found to be significantly $(p<.05)$ and negatively related to institutional turbulence, providing partial evidence for Hypothesis 14. 


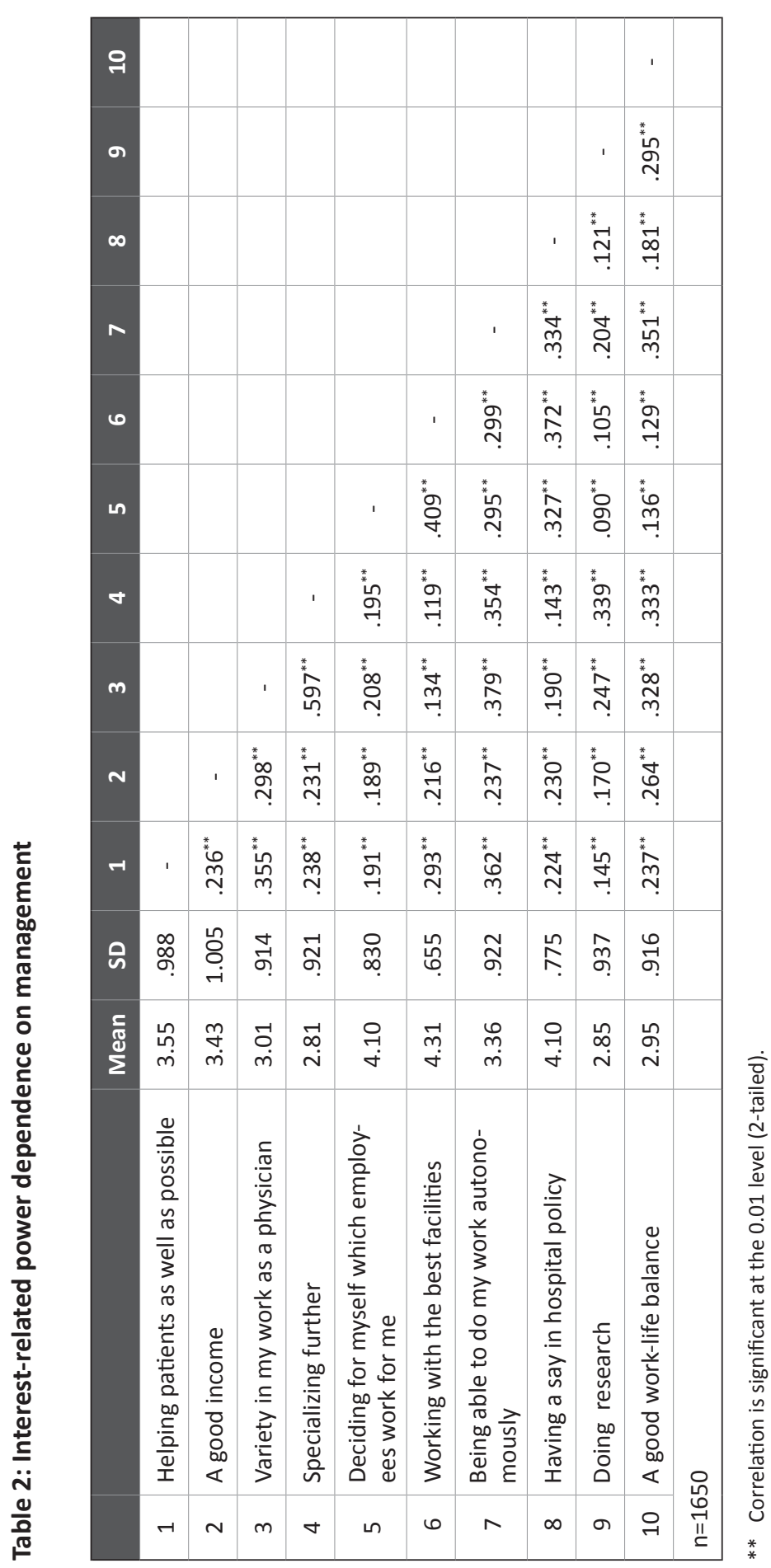




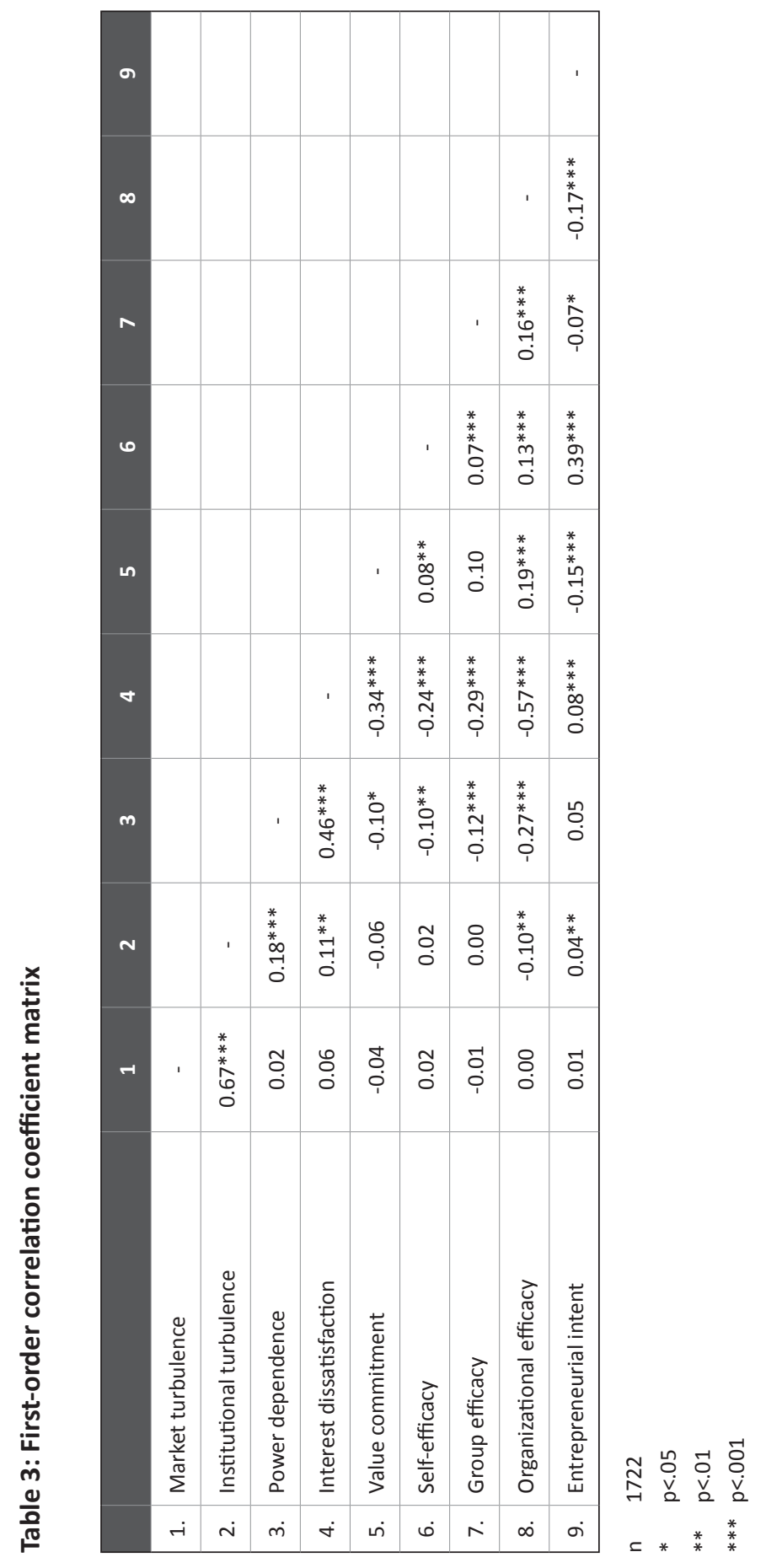




\section{Test of Substantive Relationships (Path Model)}

Figure 2 provides an illustration of the structural paths described in Hypotheses 1 to 14 and the corresponding $t$ values for the coefficients for those paths. All the factor loadings are in acceptable ranges and significant $(p<.001)$, indicating convergent validity. In addition, model fit indicators suggest the model is acceptable with $\chi 2(\mathrm{df})=1809.464$ (505), $p=$ $.0000, \mathrm{RMSEA}=.045, \mathrm{CFI}=.914, \mathrm{TLI}=.904$. However, as not all paths were significant we stepwise deleted paths, checking each time for the impact on model fit indicators (Table 3). First we dropped the path between market turbulence and interest dissatisfaction (line 1) from the model, which only marginally impacted model fit. Next we deleted the paths between institutional turbulence and logic (line 4), from power dependence to logic (line 5), between power dependence and entrepreneurial intent (line 6), between group efficacy and entrepreneurial intent (line 11b), between market turbulence and self-efficacy and group efficacy (lines 12a and 12b), and between institutional turbulence and self-efficacy and group efficacy (line 13a and 13b). Deletion of these paths only marginally impacted model fit. The result is depicted in Figure 3.

Table 4: Fit statistics for alternative models

\begin{tabular}{|c|c|c|c|c|c|c|c|}
\hline Models & $x^{2}$ & $d f$ & $\Delta \times 2$ & RMSEA & CFI & TLI & AIC \\
\hline Theoretical model (Figure 1) & 1809.464 & 505 & & 0.045 & 0.914 & 0.904 & 106965.657 \\
\hline Alternative model $1^{\mathrm{a}}$ & 1803.661 & 504 & $-5.803^{i}$ & 0.045 & 0.914 & 0.905 & 106961.833 \\
\hline Alternative model $2^{b}$ & 1804.877 & 506 & $1.216^{i}$ & 0.045 & 0.914 & 0.905 & 106958.267 \\
\hline Alternative model $3^{c}$ & 1806.84 & 508 & $1.963^{i}$ & 0.045 & 0.914 & 0.905 & 106955.926 \\
\hline Alternative model $4^{\mathrm{d}}$ & 1807.92 & 509 & $1.08^{\mathrm{i}}$ & 0.045 & 0.914 & 0.906 & 106954.641 \\
\hline Alternative model $5^{e}$ & 1809.957 & 510 & $2.037^{i}$ & 0.045 & 0.914 & 0.906 & 106954.716 \\
\hline Alternative model $6^{f}$ & 1812.426 & 510 & $2.469^{i}$ & 0.045 & 0.914 & 0.906 & 106955.579 \\
\hline Alternative model $7^{\mathrm{g}}$ & 1813.093 & 511 & $0.667^{i}$ & 0.045 & 0.914 & 0.906 & 106956.404 \\
\hline
\end{tabular}

a Deleting path from institutional turbulence to Logic

b Deleting paths from market turbulence to self-efficacy and group-efficacy (lines 12a and 12b)

c Deleting paths from institutional turbulence to self-efficacy and group-efficacy (line 13a and 13b)

d Deleting path from power dependence to entrepreneurial intent (line 6)

e Deleting the path from market turbulence to interest dissatisfaction (line 1)

$f \quad$ Deleting path from power dependence to logic (line 5)

g Deleting path from group efficacy to entrepreneurial intent (line 11b)

i Model fit compared to the previous model

Deletion of non-significant $(p>.05)$ and non-relevant $(\beta<.1)$ paths resulted in a refined model with a good model fit as $\chi 2(\mathrm{df})=1813.093(511), p=.0000, \mathrm{RMSEA}=.045, \mathrm{CFI}=.914, \mathrm{TLI}=.906$. All the factor loadings are in acceptable ranges and significant $(p<.001)$, indicating convergent validity. This refined model is depicted in figure 3 . 
Figure 2: Theoretical model, empirical relationships, and $t$ values for path coefficients

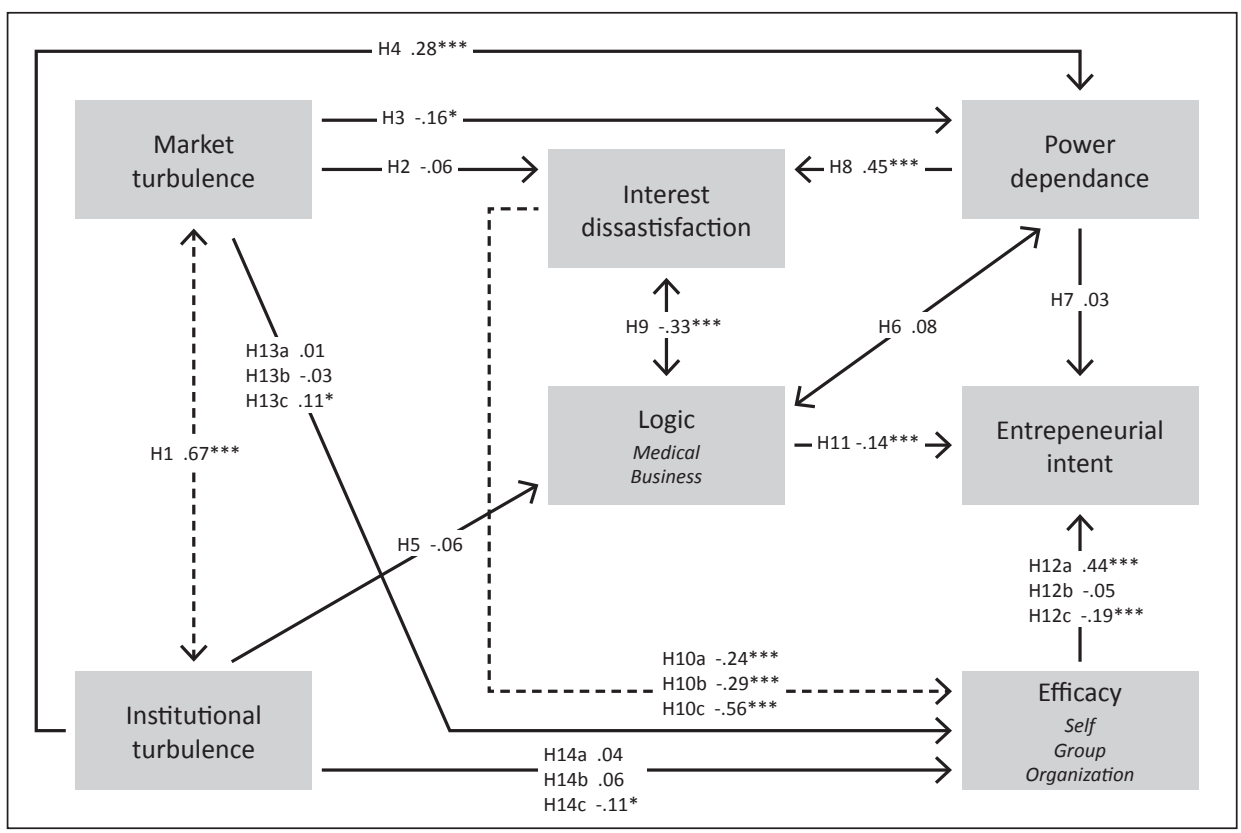

* $\quad \mathrm{p}<.05$

$* * \quad \mathrm{p}<.01$

$* * * \quad \mathrm{p}<.001$ 
Figure 3: Refined model, empirical relationships, and $t$ values for path coefficients

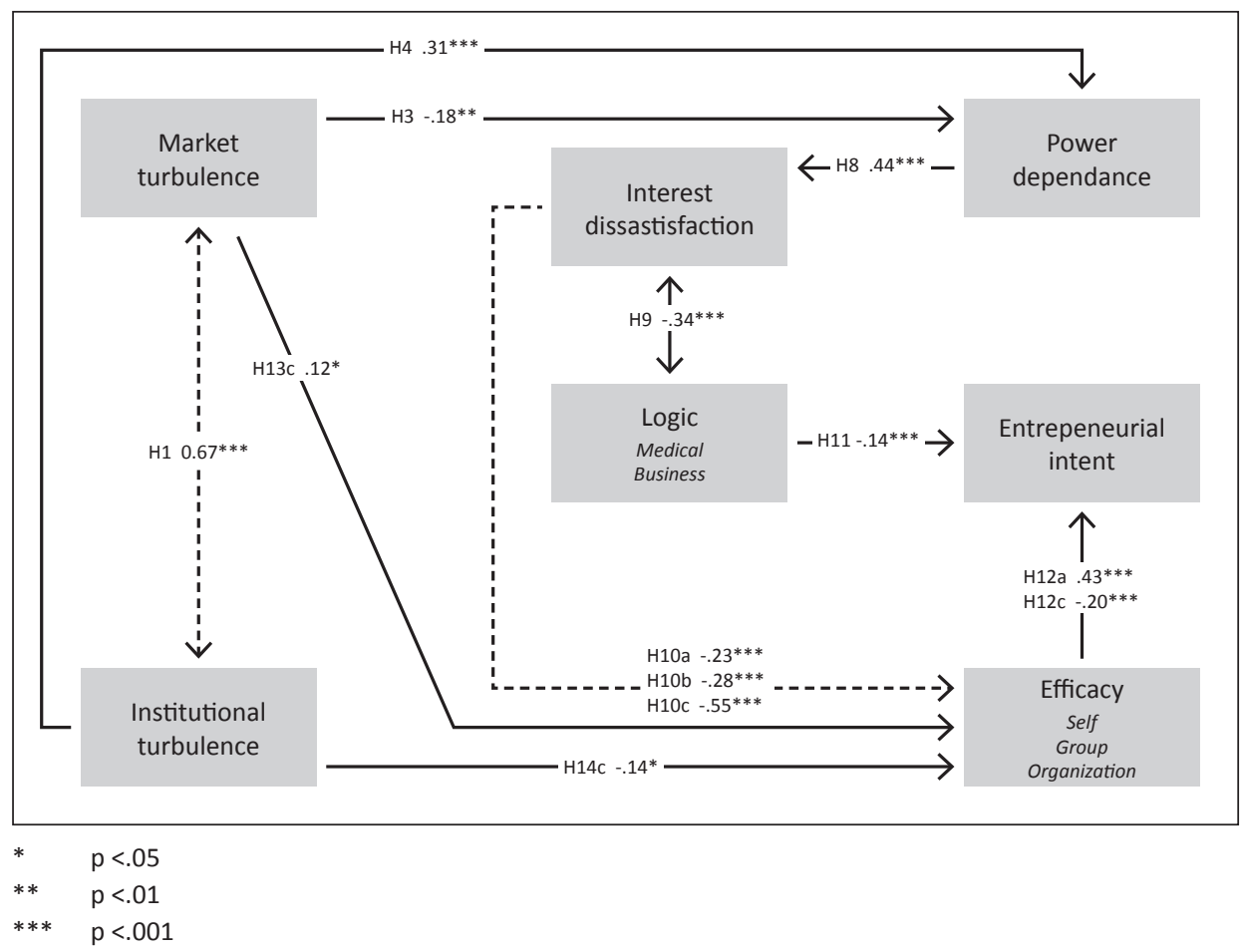

\section{Discussion}

We aimed to combine the domain of institutionalism with the domain of entrepreneurship in explaining physicians' entrepreneurship in a hospital setting. Our second objective was to operationalize and test a for this purpose refined version of Greenwood and Hinings' original theoretical model (1996). Our findings provide support for the model of Greenwood \& Hinings on radical change while in addition we were able to make some significant refinements. Finally we were able to provide evidence for the influence of contextual and intra-organizational dynamics on the development of nascent entrepreneurship, thereby underpinning the value of drawing from both strands of institutional and entrepreneurial theory. We discuss the research and practical implications of our findings below.

\section{Research Implications}

Our research offers a number of important theoretical contributions. First, we were able to operationalize and test the refined neo-institutional model of Greenwood \& Hinings on radical change (1996). In presenting this operationalization, we provide others with the 
opportunity to test this influential model as well, thereby building on its empirical validation across different settings.

With respect to context, we did find evidence of a high correlation between market- and institutional turbulence (Hypothesis 1). Still, we found a striking difference between the influence of institutional and market turbulence on power dependence. Whereas turbulence in the institutional context is associated with higher levels of perceived power dependence on management by physicians (Hypothesis 4), turbulence in the market context shows a reverse relationship (Hypothesis 3). Hereby market turbulence actually lowers perceived power dependence on management by physicians, which runs contrary to our hypothesis. We reason that physicians perceive political instruments are required to respond to institutional turbulence making them dependent on management, while an entrepreneurial response both by management or physicians may well fit market dynamics.

Although in institutional theory, the institutional context is considered of defining importance in shaping the logics of its field members, with institutional change pushing them towards the dominant logic, we did not find such a relationship (Hypothesis 5). Likewise, Greenwood \& Hinings hypothesize a relationship between interest dissatisfaction and market turbulence (Hypothesis 2), but we found no evidence for this relationship either. Nor was the hypothesized relationship between power dependence and logic supported by our study (Hypothesis 6). Still, there appears to be an indirect relationship between the two constructs as power dependence was found to significantly influence interest dissatisfaction (Hypothesis 8), which in turn has a significant relationship with the logic held by physicians. In fact, interest dissatisfaction with the facilitation provided by hospital management was found to strengthen physicians in their traditional logic of medical professionalism (Hypothesis 9), thereby deepening the gap with the increasingly dominant logic of businesslike healthcare.

In addition to the original model of Greenwood \& Hinings, we proposed a relationship between interest dissatisfaction and efficacy at the individual, group and organizational levels (Hypothesis 10). All three relationships were found to be both significant and negative. The strongest relationship was found between interest dissatisfaction and organizational efficacy ( $\beta$ -.56). However, we found a similar though weaker relationship between interest dissatisfaction and self-efficacy ( $\beta$-.24). Apparently, dissatisfaction with facilitation by management negatively influences the perceived entrepreneurial capabilities of the individual as well.

Although we were interested in nascent entrepreneurship by individual physicians, rather than radical change in the sense of an entire organization moving towards a new or different logic, we expected power dependence to negatively influence entrepreneurial intent (Hypothesis 7). We did not find support for this relationship. More importantly, we found only 
a weak relationship ( $\beta$-.14) between embeddedness in the logic of medical traditionalism and entrepreneurial intent (Hypothesis 11). On the one hand, this could point to a weakness in the model. However, it may also provide evidence for a different phenomenon: Thinking in entrepreneurial terms in essence requires adopting elements of the logic of businesslike healthcare. In fact, a new hybrid logic may be the result, as suggested by Tracey, Philips and Jarvis (2011). In addition, we did find a positive relationship between entrepreneurial intent and self-efficacy (Hypotheses 12a) and a negative relationship between entrepreneurial intent and organizational efficacy (Hypotheses 12c). The positive contribution of self-efficacy adds to the body of evidence already present on this relationship (Bandura, 1986; Zhao et al., 2005). There is a clear explanation for the inverse relationship between organizational efficacy and entrepreneurial intent by individual physicians: our research clearly indicates that a lack of belief in the entrepreneurial capabilities of hospital management may actually provide an incentive for physicians to become entrepreneurs, while a strong belief in managements' entrepreneurial capabilities will induce physicians to strive for shared entrepreneurship. In contrast to self-efficacy and organizational efficacy, we found no relation between group efficacy and entrepreneurial intent (Hypothesis 12b). Apparently, other factors influence the relation between perceived efficacy of the group and individual entrepreneurial intent, for example the relative locked-in position of physicians working in hospital partnerships.

An interesting conclusion can be drawn from Hypothesis 13, where we find some evidence that turbulence in the market context is positively related to organizational efficacy. This seems to contradict our finding with respect to Hypothesis 2 where we concluded that market turbulence is negatively related to power dependence. Apparently, physicians perceive themselves as better positioned than hospital management to respond to market turbulence, making them less dependent on hospital management. At the same time, hospital management is regarded as being responsible for mitigating the organizational effects of market turbulence (Klopper-Kes et al., 2011) e.g. by developing entrepreneurial initiatives. However, lowering physicians' perceived power dependence appears to the best way of increasing their opinion on organizational efficacy, as indicated by Table 3.

There is an interesting additional finding for Hypothesis 14. Institutional turbulence was found to negatively influence organizational efficacy. Yet the results for Hypothesis 4 led us to conclude that institutional turbulence had a positive influence on power dependence. Apparently, physicians feel more dependent on hospital management in responding to institutional pressures, while at the same time physicians' belief in the entrepreneurial capabilities of management to respond to these pressures is low. Overall, results indicate that perceive institutional pressures appear to widen the gap between physicians and hospital management, with increased perceived power dependence of physicians on management but reduced confidence among physicians in the abilities of management. 
From a broader perspective of corporate entrepreneurship this works shows some interesting research avenues for settings with different, competing logics, for example, the energy industry or public transport bodies that change from public-sector organizations to market enterprises. Certainly this could be an interesting approach when new technologies also open up possibilities for developing new types of business (in energy, e.g. green energy technologies). More generally, a shift of logic needs to take place in situations where Schumpeterian radical or disruptive innovation is possible in the context of large firms and this may also be a situation where the same dynamics may occur.

\section{Practical Implications}

In addition to research implications, our study also offers implications for both physicians and hospital management. Our model offers some suggestions for attaining the objective of greater cooperation. First and foremost, perceived power dependence among physicians is crucial in managing interest dissatisfaction, and reducing such dependence may help physicians accept the logic of businesslike healthcare. Although this logic is focused on efficiency and process rationalization (Reay \& Hinings, 2009), its acceptance and effectiveness among physicians may depend on the extent to which management is willing to share power.

Lower levels of interest dissatisfaction may also increase physicians' belief in the entrepreneurial capabilities of hospital management, thereby reducing the likelihood of the physicians engaging in nascent entrepreneurship themselves. Another way of achieving this is if hospital management explicitly expresses its interest in engaging in entrepreneurial initiatives in which more autonomy is granted to physicians. Increasing hospital efficacy and lowering power dependence may enable nascent entrepreneurial initiatives to be channeled into hospital-based ventures.

Finally, interest dissatisfaction with perceived facilitation of hospital management was found to be related to physcians' embeddedness in a certain logic. This embeddedness however, the result of medical training and later socialization in the medical profession. Recent research on the transition from specialty training to hospital-based physicians indicates that new physicians perceive themselves to be better prepared for medical competencies compared to more generic competencies necessary to work in a multidisciplinary hopital setting (Westerman et al., 2013). Therefore, offering training and socialization programs by hospitals and specialty clinics that included elements like leadership, collaboration with management, lean management, and finance, could help new physicians to develop a more hybrid logic thereby improve understanding between physicians and hospital managers 


\section{Limitations and Future Research}

Several limitations should be noted regarding our study. First, the healthcare sector offers a highly interesting research domain due to the presence of different competing logics. Although the development of an entrepreneurial intent among physicians can be considered as exceptional given their position of relative dependence and long term work-relations with both a hospital and a physician partnership, this position itself is in fact highly similar with other healthcare professionals.

Second, our study had a cross-sectional design implying a measurement of a single point in time, which may limit conclusions regarding the direction of mechanisms. The results from the current investigation should be interpreted with this limitation in mind. In essence, the model of Greenwood \& Hinings concerns processes, which we tried to encapsulate by testing our instrument in practice through interviews. Still, longitudinal research is preferable and we encourage other researchers to apply our operationalization using longitudinal designs.

Third, we measure radical change by using a scale for entrepreneurial intent as a proxy for entrepreneurship. Additional research could use the actual initiatives of physicians as the dependent variable instead of a proxy.

Fourth, given our specific research setting in which physicians' entrepreneurship has long been regarded as alien to the profession, we regarded physicians' entrepreneurship in the Dutch context to be an example of radical change. Future research could elaborate on the issue whether this change is in fact transformational entailing the creation of an entirely new logic or sedimented, suggesting that elements from another sometimes conflicting logic may be added to the present logic (Cooper, Hinings, Greenwood, \& Brown, 1996).

Fifth, we apply self-reported measures. In the case of power dependence and interest dissatisfaction, for example, this may result in a bias between perceived power dependence and actual power dependence. However, since we belief only perceived power dependence matters, we made no effort to control for this bias. Still, further research could include more objective ratings of the dependence of physicians on hospital management.

Finally, cultural differences may interfere with our neo-institutional model for example with respect to interests like autonomy and power (Hofstede, 2001) and research in more collectivistic cultures may render both different intra-organizational dynamics as well as outcomes. An international research design may provide additional insights on this matter. 


\section{Conclusion}

For our research, we first to bridged neo-institutional theory and entrepreneurship theory, by including entrepreneurial intent derived from entrepreneurship theory, into the neoinstitutional model of Greenwood and Hinings (1996). Our operationization and test of this model in a hospital context rendered both partial support and additional refinements, which allow for further testing in new and different settings. We argued that our refined model bridges the gap between institutional theory and entrepreneurship and the results of our study supported this idea. Finally, we conclude that institutional theory brings new concepts to the field of entrepreneurship, enriching our understanding of the creation of new entities by individual organizational members. 


\section{5 - Bridging neo-institutional theory and entrepreneurship theory: validation in a hospital setting}

\section{References}

Asparouhov, T., \& Muthen, B. 2009. Exploratory Structural Equation Modeling. Structural Equation Modeling-a Multidisciplinary Journal, 16(3): 397-438.

Bandura, A. 1986. The Explanatory and Predictive Scope of Self-Efficacy Theory. Journal of Social and Clinical Psychology, 4(3): 359-373.

Bandura, A. 1997. The anatomy of stages of change. American Journal of Health Promotion, 12(1): 8-10.

Bandura, A. 2002. Self-efficacy, The exercise of control. New York: Freeman and Company.

Baumol, W. J., Litan, R. E., \& Schramm, C. J. 2007. Good capitalism, bad capitalism, and the economics of growth and prosperity. New Haven: Yale University Press.

Belousova, O., \& Gailly, B. 2012. Promoting corporate entrepreneurship within a large company: an in-depth case study. In F. Welter, D. Smallbone, \& A. Van Gils (Eds.), Entrepreneurial Processes in a Changing Economy: Frontiers in European Entrepreneurship Research: 159-176. Nothhampton: Edward Elgar Publishing, Incl.

Birkinshaw, J., \& Gibson, C. 2004. Building ambidexterity into an organization. MIT Sloan Management Review, 45: 47-55.

Browne, M. W., MacCallum, R. C., Kim, C. T., Andersen, B. L., \& Glaser, R. 2002. When fit indices and residuals are incompatible. Psychological Methods, 7(4): 403-421.

Bruton, G. D., Ahlstrom, D., \& Li, H. L. 2010. Institutional Theory and Entrepreneurship: Where Are We Now and Where Do We Need to Move in the Future? Entrepreneurship Theory and Practice, 34(3): 421-440.

Buchko, A. A. 1994. Barriers to strategic transformation. In P. Shrivastava, A. Huff, \& J. Dutton (Eds.), Advances in strategic management, Vol. 10: 81-106. Greenwhich: JAI Press.

Burgelman, R. A. 1983a. Corporate entrepreneurship and strategic management: Insights from a process study. Management Science, 29(12): 1349-1364.

Burgelman, R. A. 1983b. Corporate entrepreneurship and strategic management: Insights from a process study. Management Science: 1349-1364.

Cooper, D. J., Hinings, B., Greenwood, R., \& Brown, J. L. 1996. Sedimentation and transformation in organizational change: The case of Canadian law firms. Organization Studies, 17(4): 623-647.

Cutler, D. M. 2002. Equality, efficiency, and market fundamentals: The dynamics of international medicalcare reform. Journal of Economic Literature, 40(3): 881-906.

D’Aunno, T., Succi, M., \& Alexander, J. 2000. The role of institutional and market forces in divergent organizational change. Administrative Science Quarterly: 679-703.

Dickson, P. H., \& Weaver, K. M. 1997. Environmental Determinants and Individual-Level Moderators of Alliance Use. Academy of Management Journal, 40(2): 404-425.

DiMaggio, P., \& Powell, W. 1983. The iron cage revisited: Institutional isomorphism and collective rationality in organizational fields. American Sociological Review: 147-160.

Donabedian, A. 1988. The quality of care. How can it be assessed? JAMA, 260(12): 1743-1748.

Dougherty, D. 1994. Commentary. In P. Shrivastava, A. Huff, \& J. Dutton (Eds.), Advances in strategic management, Vol. 10. Greenwich,: CT: JAI Press.

Duncan, R. B. 1976. The ambidextrous organization: designing dual structures for innovation. In R. H. Kilmann, L. R. Pondy, \& D. P. Slevin (Eds.), The Management of Organizational Design: Strategy Implementation, Vol. 1: 167-188. New York: North-Holland.

Enthoven, A. C., \& van de Ven, W. P. M. M. 2007. Going dutch - Managed-competition health insurance in the Netherlands. New England Journal of Medicine, 357(24): 2421-2423. 
Fetter, R. B., Shin, Y., Freeman, J. L., Averill, R. F., \& Thompson, J. D. 1980. Case mix definition by diagnosisrelated groups. Medical Care, 18(2): i-53.

Floyd, S. W., Kramer, J. A., \& Born, P. H. 2005. Institutional forces in the acceptance of managed care practices by physicians. Health Care Management Review, 30(3): 237-250.

Gartner, W. B. 1985. A conceptual framework for describing the phenomenon of new venture creation. The Academy of Management Review: 696-706.

Greenwood, R., \& Hinings, C. R. 1996. Understanding radical organizational change: Bringing together the old and the new institutionalism. Academy of Management Review, 21(4): 1022-1054.

Greenwood, R., Raynard, M., Kodeih, F., Micelotta, E. R., \& Lounsbury, M. 2011. Institutional Complexity and Organizational Responses. Academy of Management Annals, 5: 317-371.

Groen, A. J. 2005. Knowledge intensive entrepreneurship in networks: towards a multi-level/multi dimensional approach. Journal of Enterprising Culture, 13(1): 69-88.

Guth, W. D., \& Ginsberg, A. 1990. Guest editors' introduction Corporate entrepreneurship. Strategic Management Journal, 11(Summer): 5-15.

Hair, J. F. 2010. Multivariate data analysis (7th ed.). Upper Saddle River, NJ: Prentice Hall.

Hinings, C. R., \& Greenwood, R. 1988. The dynamics of strategic change. Oxford, UK ; New York, NY, USA: B. Blackwell.

Hisrich, R. D., \& Peters, M. P. 1992. Entrepreneurship: Starting, developing, and managing a new enterprise.: McGraw-Hill/Irwin.

Hofstede, G. H. 2001. Culture's consequences: comparing values, behaviors, institutions, and organizations across nations ( 2 nd ed.). Thousand Oaks, California: Sage Publications.

Hu, L. T., \& Bentler, P. M. 1999. Cutoff Criteria for Fit Indexes in Covariance Structure Analysis: Conventional Criteria Versus New Alternatives. Structural Equation Modeling-a Multidisciplinary Journal, 6(1): 1-55.

Kline, R. B. 2011. Principles and practice of structural equation modeling (3rd ed.). New York: Guilford Press. Klopper-Kes, A. H. J., Meerdink, N., Wilderom, C. P. M., \& Van Harten, W. H. 2011. Effective cooperation influencing performance: a study in Dutch hospitals. International Journal for Quality in Health Care, 23(1): 94-99.

Koelewijn, W. T., Ehrenhard, M. L., Groen, A. J., \& van Harten, W. H. 2012. Intra-organizational dynamics as drivers of entrepreneurship among physicians and managers in hospitals of western countries. Social Science \& Medicine, 75(5): 795-800.

Koelewijn, W. T., Ehrenhard, M. L., Groen, A. J., \& van Harten, W. H. 2013. Exploring personal interests of physicians in hospitals and specialty clinics. Social Science \& Medicine.

Kraatz, M. S. 2009. Leadership as institutional work: A bridge to the other side. In T. B. Lawrence, R. Suddaby, \& B. Leca (Eds.), Institutional work: Actors and agency in institutional studies of organization. Cambridge: Cambridge University Press.

Kruijthof, K. 2005. Doctors' Orders. Specialists' day to day work and their jurisdicational claims in Dutch hospitals., Erasmus Universiteit Rotterdam, Alkmaar.

Kumar, K., Subramanian, R., \& Yauger, C. 1998. Examining the Market Orientation-Performance Relationship: A Context-Specific Study. Journal of Management, 24(2): 201.

Laeven, A. M. W. 2008. Een gezonde blik naar buiten: een onderzoek naar oorzaken en gevolgen van marktoriëntatie bij algemene ziekenhuizen. Universiteit van Tilburg, Tilburg.

Lawrence, T. B., \& Phillips, N. 2004. From Moby Dick to Free Willy: Macro-cultural discourse and institutional entrepreneurship in emerging institutional fields. Organization, 11(5): 689-711.

Lieverdink, H. 2001. The marginal success of regulated competition policy in the Netherlands. Social Science \& Medicine, 52(8): 1183-1194. 
Lounsbury, M., \& Glynn, M. A. 2001. Cultural entrepreneurship: Stories, legitimacy, and the acquisition of resources. Strategic Management Journal, 22(6-7): 545-564.

Lumpkin, G. T., \& Dess, G. G. 1996. Clarifying the Entrepreneurial Orientation Construct and Linking it to Performance. Academy of Management Review, 21: 135-172.

Maguire, S., Hardy, C., \& Lawrence, T. B. 2004. Institutional entrepreneurship in emerging fields: HIV/AIDA treatment advocacy in Canada. Academy of Management Journal, 47(5): 657-679.

Marsh, H. W. 2004. In search of golden rules: Comment on hypothesis-testing approaches to setting cutoff values for fit indexes and dangers in overgeneralizing Hu and Bentler's (1999) findings. Structural Equation Modeling-a Multidisciplinary Journal, 11(3): 320-341.

McMullen, J. S., \& Shepherd, D. A. 2006. Entrepreneurial action and the role of uncertainty in the theory of the entrepreneur. Academy of Management Review, 31(1): 132-152.

Miles, J., \& Shevlin, M. 2007. A time and a place for incremental fit indices. Personality and Individual Differences, 42(5): 869-874.

Muthén, L. K., \& Muthén, B. O. 2010. Mplus user's guide (6 ed.). Los Angeles.

Pache, A. C., \& Santos, F. 2010. When Worlds Collide: The Internal Dynamics of Organizational Responses to Conflicting Institutional Demands. Academy of Management Review, 35(3): 455-476.

Phillips, N., \& Tracey, P. 2007. Opportunity recognition, entrepreneurial capabilities and bricolage: connecting institutional theory and entrepreneurship in strategic organization. Strategic Organization, 5(3): 313.

Powell, W., \& DiMaggio, P. 1991. The new institutionalism in organizational analysis: Chicago: University of Chicago Press.

Ranson, S., Hinings, B., \& Greenwood, R. 1980. The Structuring of Organizational Structures. Administrative Science Quarterly, 25(1): 1-17.

Rao, H., \& Sivakumar, K. 1999. Institutional sources of boundary-spanning structures: The establishment of investor relations departments in the Fortune 500 industrials. Organization Science, 10(1): 27-43.

Reay, T., \& Hinings, C. R. 2009. Managing the Rivalry of Competing Institutional Logics. Organization Studies, 30(6): 629-652.

Saltman, R. B., \& Figueras, J. 1997. European healthcare reform: Analysis of current strategies, WHO Regional Publications, Vol. European Series No. 72. Copenhagen: WHO Regional Office for Europe.

Scholten, G. R. M., \& Grinten, T. E. D. 2002. Integrating medical specialists and hospitals. The growing relevance of collective organisation of medical specialists for Dutch hospital governance. Health policy, 62(2): 131-139.

Schumpeter, J. A. 1934. The theory of economic development. Cambridge Mass.: Springer.

Scott, W. R. 2001. Institutions and Organizations (2nd edition ed.). Thousand Oaks: Sage Publications.

Shane, S., \& Venkataraman, S. 2000. The Promise of Entrepreneurship As a Field of Research. The Academy of Management Review, 25(1): 217-226.

Smets, M., Morris, T., \& Greenwood, R. 2012. From practice to field: A multilevel model of practice-driven institutional change. Academy of Management Journal, 55(4): 877-904.

Suddaby, R., Elsbach, K. D., Greenwood, R., Meyer, J. W., \& Zilber, T. B. 2010. Organizations and Their Institutional Environments-Bringing Meaning, Values, and Culture Back In: Introduction to the Special Research Forum. Academy of Management Journal, 53(6): 1234-1240.

Thompson, E. R. 2009. Individual Entrepreneurial Intent: Construct Clarification and Development of an Internationally Reliable Metric. Entrepreneurship Theory and Practice, 33(3): 669-694.

Tracey, P., Phillips, N., \& Jarvis, O. 2011. Bridging Institutional Entrepreneurship and the Creation of New Organizational Forms: A Multilevel Model. Organization Science, 22(1): 60-80. 


\section{Doctors in Business}

Tushman, M. L., \& O’Reilly III, A. 1996. Ambidextrous Organizations: Managing Evolutionary and Revolutionary Change. California Management Review, 38(4): 8-30.

Westerman, M., Teunissen, P. W., Fokkema, J. P. I., Van der Vleuten, C. P. M., Scherpbier, A. J. J. A., Siegert, C. E. H., \& Scheele, F. 2013. The transition to hospital consultant and the influence of preparedness, social support, and perception: A structural equation modelling approach. Medical Teacher, 35(4): 320-327.

Wicks, D. 2001. Institutionalized mindsets of invulnerability: Differentiated institutional fields and the antecedents of organizational crisis. Organization Studies, 22(4): 659-692.

Zhao, H., Seibert, S. E., \& Hills, G. E. 2005. The mediating role of self-efficacy in the development of entrepreneurial intentions. Journal of Applied Psychology, 90(6): 1265-1272. 


\section{Appendix A - measures}

\section{Contextual turbulence}

Our hospital's environment can be characterized as an environment in which:

(1 fully disagree - 5 fully agree)

- Patients' preferences change rapidly.

- Health insurers' preferences change rapidly.

- Referrers' preferences change rapidly.

- The number of customers (patients) changes rapidly.

- Legislation and regulations change rapidly.

\section{Power dependence}

To what extent do you experience dependence on management in striving to achieve the following interests?

(1 very independent to 5 very dependent)

- Helping patients as well as possible

- A good income

- Variety in my work as a physician

- Specializing further

- Deciding for myself which employees work for me

- Working with the best facilities

- Being able to do my work autonomously

- Having a say in hospital policy

- Doing research

- A good work-life balance

\section{Interest dissatisfaction}

To what extent do you experience dissatisfaction or satisfaction with the facilitation provided by management to help you achieve the following objectives?

(1 Very dissatisfied to 5 very satisfied)

- Helping patients as well as possible

- A good income

- Variety in my work as a physician

- Specializing further

- Deciding for myself which employees work for me

- Working with the best facilities 
- Being able to do my work autonomously

- Having a say in hospital policy

- Doing research

- A good work-life balance

\section{Logic}

Please indicate your relative position with respect to the following items

\section{(1 fully agree with item 1 to 5 fully agree with item 2)}

Physicians should be the leaders of the healthcare system

vs.

Physicians should carry out their practice in accordance with resource management guidelines from government.

Patients rely solely on physicians to provide appropriate care.

vs.

Some services currently provided by physicians can be provided by other healthcare workers.

The physician-patient relationship should guide decisions about how health services are delivered.

vs.

The health system should be organized based on facts, quality indicators and input from citizens and government.

Working as an employee severely hampers physicians' autonomy.

vs.

Working as an employee provides sufficient space for physicians' autonomy.

Discussing physicians' failures in public undermines trust in medical care.

vs.

Discussing physicians' failures in public is necessary to improve the quality of medical care.

* Items derived from Reay and Hinings (2009).

* Items derived from interviews

\section{Self-Efficacy}

How confident are you in your present readiness for successfully managing or doing the following? 
(1 no confidence - 5 complete confidence)

- Identifying new business opportunities

- Creating new products

- Thinking creatively

- Commercializing an idea or development

\section{Group-Efficacy}

How confident are you the present readiness of your physician' group or partnership for successfully managing or doing the following?

(1 no confidence - 5 complete confidence)

- Identifying new business opportunities

- Creating new products

- Thinking creatively

- Commercializing an idea or development

\section{Organizational-Efficacy}

How confident are you the present readiness of the hospital organization for successfully managing or doing the following?

(1 no confidence - 5 complete confidence)

- Identifying new business opportunities

- Creating new products

- Thinking creatively

- Commercializing an idea or development

\section{Entrepreneurial intent}

Thinking of yourself, how true or untrue is it that you:

(1 very untrue -6 very true)

- Intend to set up a company in the future

- Never search for business start-up opportunities (R)

- Are saving money to start a business

- Do not read books on how to set up a firm (R)

- Have no plans to launch your own business (R)

- Spend time learning about starting a firm

- Items marked (R) are reverse coded in scale analyses. 



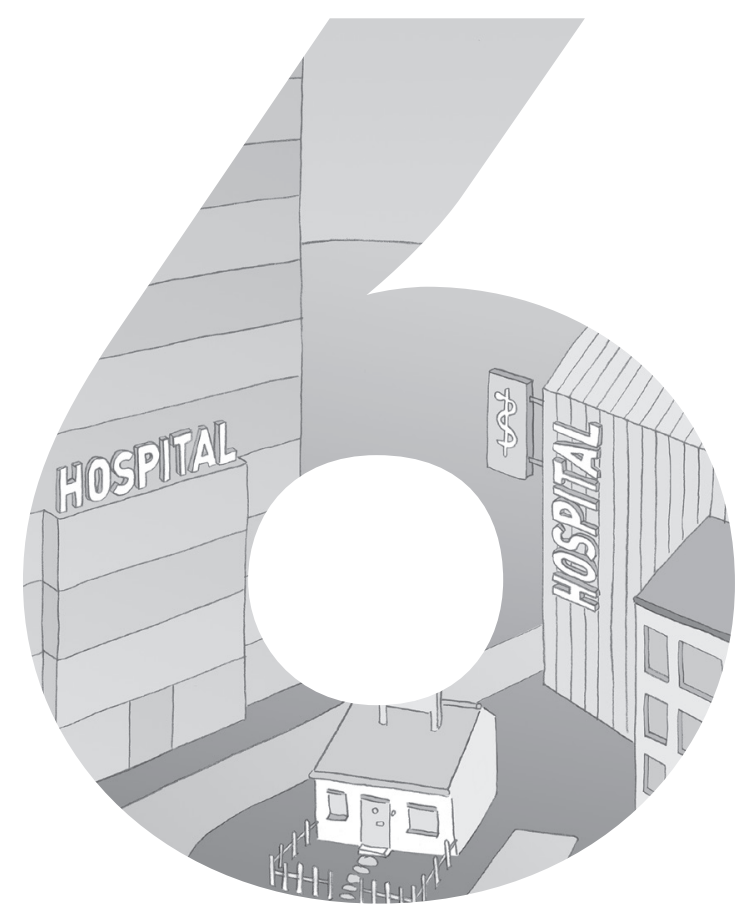

MOTIVATIONAL NEEDS AND SELF-

EFFICACY AS PREDICTORS OF ENTREPRENEURIAL INTENT OF HOSPITAL-BASED PHYSICIANS

Wout T. Koelewijn

Michel L. Ehrenhard

Aard J. Groen

Wim H. van Harten 


\begin{abstract}
Although physician' entrepreneurship is becoming increasingly powerful in shaping healthcare, it is still unclear what motivates physicians to become entrepreneurs. Therefore, we investigate the influence of motivational needs and self-efficacy on the development of physicians' intentions to become entrepreneurs. Starting from the traditional, unmediated model of motivational needs and self-efficacy, and their influence on entrepreneurial intent, a new model was built. This new model includes mediating effects by using structuring equation modeling based on data derived from the responses of a representative sample of 1475 physicians in both hospitals and specialty clinics. Findings indicate that a partial mediation model in which need for achievement and need for dominance are mediated through need for autonomy, need for affiliation and self-efficacy, achieves a better overall fit than two alternative models. In addition, we found that motivational needs, entrepreneurial self-efficacy and entrepreneurial intent are not homogeneous across hospitals and specialty clinics. Based on these findings, we conclude that for physicians, after having completed their specialty training, it is important to choose a setting that best fits their motivational needs, allowing them to be more effective. For hospital managers, developing entrepreneurial strategies should match the motivational needs of the physicians involved.
\end{abstract}

\title{
Introduction
}

Physicians' entrepreneurship has grown into a powerful force shaping healthcare (Saltman et al., 2002). After two waves of healthcare reforms in Western countries, first to ensure access to medical care and second to contain costs, the third wave introduced incentives and competition among healthcare providers to tackle the problem of rising costs and growing inefficiencies (Cutler, 2002). As a result of the third-wave reforms in the Netherlands, the number of specialty clinics, mostly founded by physician-entrepreneurs, has risen by $62 \%$ from 149 in 2007 to 241 in 2010 (NZA, 2012). Still, much is unknown about what drives physicians to turn into entrepreneurs and more specifically, to develop an entrepreneurial intent in the first place.

Based on earlier research, we assume that contextual factors together with personality type influence entrepreneurial intent resulting entrepreneurship (Carsrud et al., 1987). Hereby we define physician' entrepreneurship as 'a new entry by one or more physicians who discover, evaluate and exploit opportunities to create future health services by bearing the risk of profit and loss' (Burgelman, 1983; Hisrich \& Peters, 1992; Shane \& Venkataraman, 2000). In the Netherlands, only a relatively small number of physicians turn into entrepreneurs. As explained in Box 1, the vast majority of physicians have a long-term and exclusive 
relationship with a single hospital. As the contextual factors alone seem unable to provide the ultimate answer on why just a minority of physicians turn into entrepreneurs, we will consider physicians' traits to understand this (Kets de Vries, 1977; McClelland, 1961). To shed more light on the question of what personality-related traits cause physicians to develop an entrepreneurial intent, two influential personality-related theories are particularly important: motivational needs theory and self-efficacy theory.

Motivational needs theory as developed by McCelland (1953), states that motivated behavior is a composite measure of the strength of various needs: the need for autonomy, the need for achievement, the need for affiliation, and the need for dominance. The need for autonomy describes the desire for self-direction, rather than direction from others (Heckert et al., 2000). It refers to the independent action of an individual or a team in bringing forth an ideal or a vision and carrying it through to completion (Lumpkin \& Dess, 1996).

The need for achievement, originally developed by McClelland and his colleagues (1953). It is defined as the desire to excel in tasks that involve both skill and effort and involves attempting to improve on past performance (Heckert et al., 2000).

The need for affiliation is defined as "the need to be with people and expressed concern for establishing, maintaining, and restoring positive relationships with others" (Brody \& Ehrlichman, 1998). Physicians with a high need for affiliation try to refrain from interpersonal conflicts, which may lead them to alter behavior for the sake of the relationship. Finally, the need for dominance, sometimes called the need for power, is the desire to influence and direct others, for example, controlling them, impressing them or otherwise influencing them (Brody \& Ehrlichman, 1998). In addition, power-oriented individuals are generally also prestige or status oriented (McClelland, 1975; Winter, 1973).

Motivational needs theory has been highly influential in explaining various types of choices and behavior. For example, it suggests that students' motivation to exert effort in the quest to attain academic success is driven by their relative need levels particularly their need to achieve (Atkinson, 1958; Steers \& Braunstein, 1976). Prior studies reviewed as part of a meta-analysis by Rauch and Frese (2007) on the influence of traits on entrepreneurship included 62 studies dealing with new entry. Based on 29 studies, the authors concluded there was an average influence of the need for achievement of $r=.22,11$ studies on the need for autonomy led to $r=.31$ and an influence of (generalized) self-efficacy of .38 was found based on 8 studies. No relationship with new entry was found for the need for dominance or the need for affiliation. 


\section{BOX 1: Description of physicians' position in Dutch hospitals}

In the Netherlands, physicians working in academic and specialty hospitals have an employment relationship with their hospital. Physicians working in general and large teaching hospitals, comprising a majority of all physicians in the Netherlands, are generally not employed by a hospital but associated with it through a partnership with other physicians practicing a similar specialty. These partnerships constitute within-hospital firms in which accumulated fees are divided among the partners. The relationship between an individual physician and a hospital is exclusive and based on an admission agreement. Physicians charge their fees to the health insurers through the hospital and depend on hospital management for the allocation of both staff (e.g. nurses and secretaries) and facilities (e.g. operating rooms, diagnostic equipment, and medical devices). Most physicians acquire a position in a hospital by buying shares in a partnership after finishing their specialization in their mid twenties to early thirties and stay until retirement.

In addition to motivational needs, self-efficacy too has been found to be a distinct characteristic of the entrepreneur (Chen et al., 1998; Zhao et al., 2005). Bandura defines self-efficacy as "people's judgments of their capabilities to organize and execute courses of action required to attain designated types of performance" (Bandura, 1986). Choices, ambitions, actions, and perseverance are all influenced by the self-perception of one's owns capabilities (Bandura, 1991).

Self-efficacy is found to be positively related to entrepreneurial intent (Zhao et al., 2005). Based on a sample of 107 MBA students, Chen et al. (1998) found a positive relationship between entrepreneurial self-efficacy and entrepreneurial intent $(r=.44)$. In their second study covering 175 entrepreneurs and managers, a correlation of $r=.15$ was found between entrepreneurial self-efficacy and entrepreneurial intent. Zhao et al. (2005) also found a positive relationship between entrepreneurial self-efficacy and entrepreneurial intent in their study among $265 \mathrm{MBA}$-students. This relationship ranged between $r=.25$ for the first measurement and $r=.31$ for the second measurement.

In this study, we are interested in how motivational needs and self-efficacy relate to entrepreneurial intent among physicians and how these differ across hospitals and specialties. Hereby entrepreneurial intent is defined as "defined as a self-acknowledged conviction by a person that they intend to set up a new business venture and consciously plan to do so at some point in the future." (Thompson, 2009). 
Researching the influence of personality is not uncontentious. Two decades ago, this type of research was claimed to be an empirical dead end that should therefore be abandoned (Aldrich, 1999; Chell, 1985; Gartner, 1989). However, the problem identified with this type of research was not the absence of psychological characteristics distinguishing entrepreneurs from other individuals, but rather the theories and methods applied in identifying these characteristics (Robinson et al., 1991). Specific issues include e.g. non-comparable samples, a bias favoring successful entrepreneurs, and the possibility that observed traits are a result, rather than a cause, of entrepreneurial experience (Brandstatter, 1997). Recent meta-analysis however, has provided new evidence for the predictive validity of personality traits in entrepreneurship research (Brandstatter, 2011; Collins et al., 2004; Rauch \& Frese, 2007; Zhao \& Seibert, 2006; Zhao et al., 2010). This has thereby reinvigorated interest in this relationship, based on the premise that theories of entrepreneurial motivations are still relevant and important when studying entrepreneurial behavior (Carsrud \& Brannback, 2011; Shane et al., 2003).

To effectively deal with issues identified, we decided to take entrepreneurial intent, rather than entrepreneurial behavior as the dependent variable as this enables us to focus on traits that are a cause rather than an outcome of entrepreneurial behavior. In addition, by including physicians from different types of hospitals sharing a similar institutional and market context, we control for structural factors, thus allowing us to focus on the role of personality in developing an entrepreneurial intent.

\section{New Contribution}

Our aim is to contribute to entrepreneurship research in the hospital setting. First, although a considerable number of studies have been found on the influence of self-efficacy on entrepreneurial intent, there has been no such interest in the influence of motivational needs. As a result, we extend the theory of motivational needs by relating it to entrepreneurial intent. In addition, we contribute to the understanding of physicians' motivational needs, entrepreneurial self-efficacy, and entrepreneurial intent by measuring these variables across hospital types and specialty groups, thereby identifying differences and similarities.

Finally, our study reveals a mediating model of motivational needs: the need for achievement and need for dominance provide the impetus, whereas the need for autonomy and need for affiliation provide the direction.

\section{Conceptual Model}

In relating motivational needs theory and self-efficacy theory to entrepreneurial intent, we will first provide a theoretical model in which the two theories are explained and linked. Hereby, we will define each construct and formulate hypotheses enabling us to derive a model. 


\section{Need for Autonomy - Entrepreneurial Intent}

Need for autonomy is of special importance to physicians, directly related to their professional identity (Rivers \& Woodard, 1997). Their autonomy is deeply rooted in the traditional logic of medical professionalism (Reay \& Hinings, 2009), and it has been proposed that perceived inroads made by hospital management contribute to physicians' entrepreneurship (Koelewijn et al., 2012). As a result, we expect a positive relation between the need for autonomy and entrepreneurial intent.

Hypothesis 1: Physicians' need for autonomy is positively linked with entrepreneurial intent.

\section{Need for Achievement - Entrepreneurial Intent}

The need for achievement, is one of the most researched traits in relation to entrepreneurship (Rauch \& Frese, 2007). McClelland argued that as entrepreneurial positions have a greater degree of task attributes compared to other jobs, persons with a high need for achievement will be more likely to pursue entrepreneurial roles.

Current studies continue to support the validity and applicability of this motivational need in explaining behavior (Carsrud \& Brannback, 2011). More specifically, Collins et al. (2004) concluded, based on a meta-analysis of 47 studies, that achievement motivation is significantly correlated with both the choice for entrepreneurial positions and performance. Summarizing, we expect a positive relationship between the need for achievement and the presence of an entrepreneurial intent.

Hypothesis 2: Physicians' need for achievement is positively associated with entrepreneurial intent.

\section{Need for Affiliation - Entrepreneurial Intent}

In his research, Yukl (1989) found evidence for McClelland's distinction of motivational needs as he found significant differences between managers of large organizations and entrepreneurs. Hereby, entrepreneurial managers scored significantly lower on need for affiliation. This can be explained by the fact that entrepreneurship implies the start of a new organization requiring the initiator to leave close colleagues. Given the basic need for good interpersonal relations associated with a high need for affiliation, this will negatively influence their intent of turning into an entrepreneur. We expect a similar relation for physicians resulting in the following hypothesis:

Hypothesis 3: Physicians' need for affiliation is negatively associated with entrepreneurial intent. 


\section{Need for Dominance - Entrepreneurial Intent}

The need for dominance indicates the tendency desire to influence and direct others to seek leadership opportunities. Although it would seem that large organizations like hospitals offer greater opportunities for dominance over more people and resources (Baum et al., 1993), we expect this is not the case for physicians in hospitals, as they have lost considerable power and influence to hospital management (Reay \& Hinings, 2009). Therefore, we expect that an entrepreneurship offers the opportunity to regain power over one's own work setting. This leads us to expect a positive relation between need for dominance of physicians and their entrepreneurial intent.

Hypothesis 4: Physicians' need for dominance is positively associated with entrepreneurial intent.

\section{Entrepreneurial Self-Efficacy - Entrepreneurial Intent}

These perceived capabilities associated with self-efficacy are argued to be domain specific, requiring a measure for self-efficacy that is relevant for the domain at hand (Gist, 1987). As a result, we will focus on entrepreneurial self-efficacy rather than general self-efficacy. Entrepreneurial self-efficacy is defined by Chen et al. (1998) as an individual's confidence in his or her ability to successfully perform entrepreneurial roles and tasks.

Entrepreneurial self-efficacy is considered useful in explaining the process of evaluation and decision-making related to the development of entrepreneurial intentions and the subsequent decision to engage in an entrepreneurial initiative (Boyd \& Vozikis, 1991). In our study, we will focus on this relationship among physicians. We expect physicians' entrepreneurial self-efficacy to be positively related to their perceived entrepreneurial intent.

Hypothesis 5: Physicians' entrepreneurial self-efficacy is positively associated with entrepreneurial intent.

\section{Method}

\section{Instrument Development}

For our study, we selected previously validated measures based on their reported psychometric qualities and applicability among physicians.

Need for autonomy. Our 5-item scale was derived from Heckert and Cuneio (2000). Taking the Manifest Needs Questionnaire (MNQ) developed by Steers and Braustein (1976) as 
a reference, they developed a new measure and tested it among 467 undergraduates in psychology courses. This resulted in a slightly improved Cronbach alpha of .61 versus .52 for the original scale.

Need for Achievement. To assess the need for achievement, we applied the scale developed by Eisenberger et al. (2005). They derived four items from the need for achievement subscale of Steers and Braunstein's (1976) Manifest Needs Questionnaire and added five additional items based upon the characteristics of individuals with a high need for achievement as described by McClelland $(1953,1961)$ including working to improve one's skills. The newly created measure was tested twice and resulted respectively in Cronbach alphas of 0.79 and 0.88 .

Need for Affiliation. We reviewed the two existing measures of the need for affiliation, the Manifest Needs Questionnaire (MNQ) (Steers \& Braunstein, 1976) and an adaptation of the MNQ, the Needs Assessment Questionnaire (NAQ) developed by Heckert et al. (2000), in terms of their internal consistency. As both were reported as being low, we decided to use the affiliation at work scale, developed by Shockley and Allen (2010). For their measure, they adapted some items from the MNQ and NAQ while adding new ones, thereby rooting in the original conceptualizations of Murray (1938) and McClelland's (1961). The resulting measure was reported by Shockley and Allen (2010) to have a higher internal consistency compared to the original measures ( $a=.75$ versus .72 for the NAQ and .58 for the MNQ).

Need for Dominance. Heckert et al. (2000) developed their measure as part of the Needs Assessment Questionnaire by combining new items with items from Steers and Braunstein's original Manifest Needs Questionnaire (Steers \& Braunstein, 1976). This was in response to the poor internal consistency and reliability of the original measure (Dreher \& Maidalton, 1983; Konovsky et al., 1986). In developing this new measure, Heckert et al. (2000) employed numerous procedures across multiple samples. This resulted in an improved Cronbach alpha of .74 versus .68 for the original scale. Although their confirmatory factor analysis results suggested room for improvement, there was evidence that this issue was related to a subscale not used in the present study.

Self-efficacy. In measuring entrepreneurial self-efficacy, we apply the original scale developed by Zhao et al. (2005). The items deal with the confidence of a subject in successfully identifying new business opportunities, creating new products, thinking creatively, and commercializing an idea or new development. Based on their longitudinal study on the mediating role of self-efficacy in the development of entrepreneurial intentions among MBA students, internal validity was reported to be good, with a Cronbach alpha of .78. 
Entrepreneurial intent. We apply the six substantive items part of the measure developed by Thompson (2009). Based on a preliminary construct definition, he developed a scale consisting of six substantive and four distracter items. In turn, the scale was tested across discrete populations and for one sample with different retests to determine stability, unidimensionality, internal validity, and criterion validation. The Cronbach alphas ranged from .82 to .93 .

\section{Procedure and Sample}

This research is part of a wider study designed to identify situational and personal factors inducing physicians to turn into entrepreneurs. To obtain sound measurements, we translated earlier validated measures from English into Dutch, with a back-translation as a check of the accuracy, and tested them as part of semi-structured interviews with, in total, 27 physicians. Of these physicians, 15 were working in hospitals and 12 in specialty clinics. Based on these interviews, we were able to confirm the suitability and applicability of the measures for physicians across various hospital types and specialty groups. The resulting measures were subjected to a psychometric test among 33 physicians in a general hospital to ensure the validity of our results. Cronbach alpha scores ranged from an acceptable .627 for the need for affiliation and .789 for the need for achievement to a good .808 for the need for dominance and .834 for the need for autonomy.

\section{Statistical Analysis}

In testing our hypotheses, we applied a systematic procedure in which each step built on the previous steps, using progressively more sophisticated statistical methods. This enabled us to test a structural model while assuring good validity and reliability (Asparouhov \& Muthen, 2009; Donabedian, 1988; Mars \& Lounsbury, 2009). The software programs of Mplus 6.12 and SPSS 20.0 were used for these analyses.

As our measurement instrument would produce cross-loadings between different items and latent variables, we first checked for multicollinearity as a minimum requirement for the exploratory factor analysis (EFA) and confirmatory factor analysis (CFA). To do this, we analyzed the squared multiple correlations ( $R 2 \mathrm{smc}$ ) of each item versus all other items in a given measure. The average squared multiple correlation found between each item and all the other items per scale was $\mathrm{R} 2 \mathrm{smc}=.39$, with a minimum of $\mathrm{R} 2 \mathrm{smc}=.060$ for item 9 as part of the measure for the need for achievement and a maximum of R2smc $=.671$ for item 1 as part of the measure for entrepreneurial intent. These scores are well below the maximum permitted multicollinearity of $\mathrm{R} 2 \mathrm{smc}=.90$, for the application of EFA and CFA (Kline 2011). Next, we applied exploratory and confirmatory techniques as part of structural equation modeling (SEM) "in tandem" (Asparouhov \& Muthen, 2009; Donabedian, 1988). Hereby, we conducted exploratory factor analysis on $50 \%$ of our data and confirmatory 
factor analysis on our full dataset. The results of both our EFA and CFA for each measure are discussed in Appendix A for each measure.

Next, we analyzed each construct across specialty group and hospital type by applying ANOVA and post-hoc tests. Finally, we tested the hypothesized model by applying structural equation modeling and optimized the alternatively proposed model.

\section{Results}

\section{Sample characteristics}

A large-scale survey was held with questionnaires sent by e-mail to 7,913 physicians working in hospitals and specialty clinics across the Netherlands. Two reminders were sent to those who had not yet filled out the questionnaire. In total, $18.6 \%$ of the physicians filled out the questionnaire completely $(n=1,475)$, which is somewhat higher compared to earlier surveys by Kruijthof (2005) and Klopper et al. (2011).

We compared our sample in terms of the number of physicians per specialty group, age, and sex as included in Table 1, with population data available from the official individual registration of healthcare professionals in The Netherlands (in Dutch: BIG-register). Based on these analyses, we concluded there were no significant differences between the population statistics for physicians in the Netherlands, and the sample statistics for our survey. 
Table 1: Respondents' characteristics

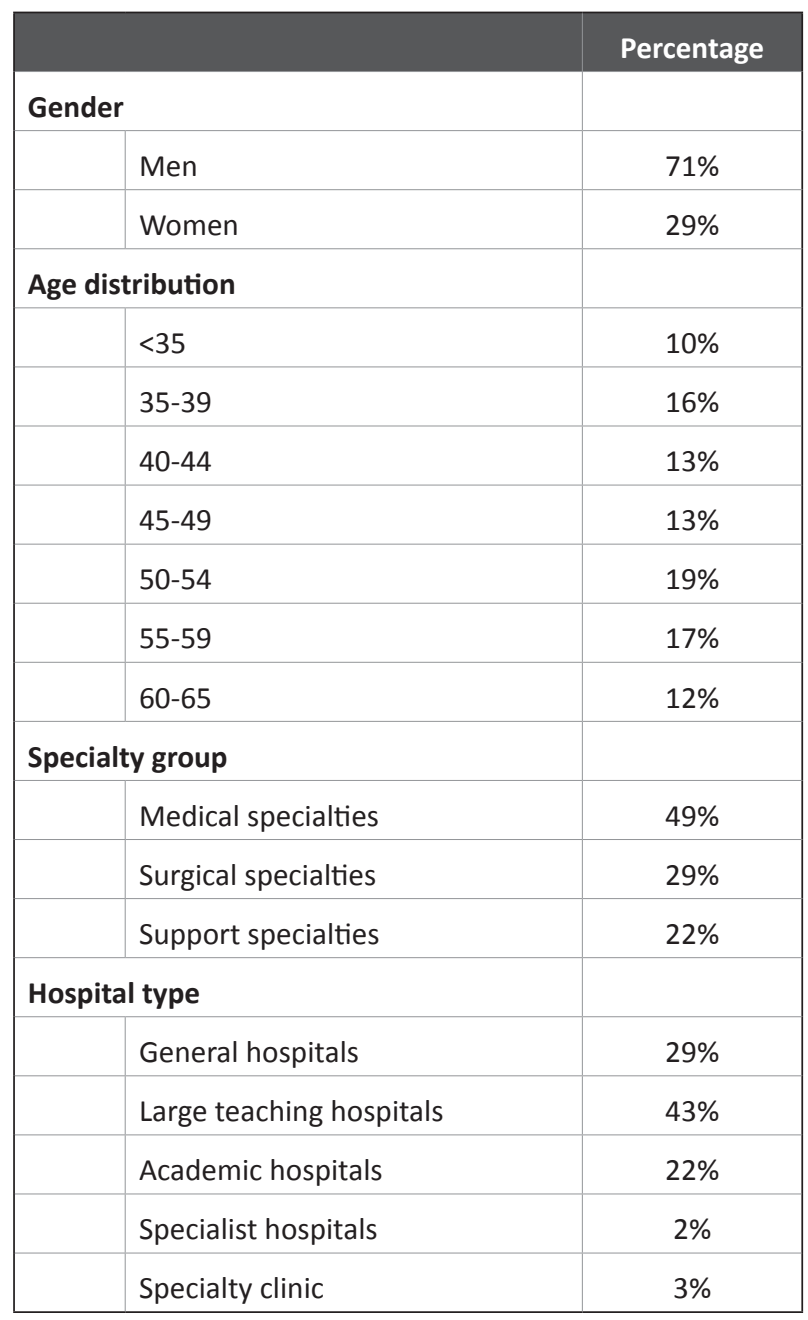

\section{Validation of measures}

We validated each measure by conducting both exploratory and confirmatory techniques (Asparouhov \& Muthen, 2009) in addition to calculating the Cronbach alpha for each refined measure.

Need for autonomy. In order to check for multidimensionality of our measure derived from Heckert and Cuneio (2000), we performed an exploratory factor analysis (EFA) of the single factor model. Model fit indicators included the chi-square test with $\chi 2$ (df) $=23.920$ (5), $p=$ .0002 , in addition to the root mean square error of approximation (RMSEA) equaling .051. 
Both the high comparative fit index (CFI) and Tucker-Lewis index (TLI) indicated good model fit with .987 and .973 respectively (Kline, 2011). This good fit was confirmed by the confirmatory factor analyses, with identical model fit indicators. The Cronbach alpha was good: 0.739.

Need for Achievement. In our survey, respondents rated their agreement with each statement using a 5-point Likert scale, ranging from 1 (strongly disagree) to 5 (strongly agree). The exploratory factor analysis revealed two dimensions present in the measure applied, as the single factor EFA resulted in a bad model fit ( $\chi 2$ (df) $=395.274(27), p=.0000$, RMSEA $=.097, \mathrm{CFI}=.890, \mathrm{TLI}=.854)$ while the two-factor model provided a good fit $(\chi 2$ $(\mathrm{df})=110.363$ (19), $\mathrm{p}=.0000$, RMSEA $=.057, \mathrm{CFI}=.973, \mathrm{TLI}=.948)$. This two-factor model distinguishes between factor 1 , which includes items $1-5$, and 7 dealing with self-steering behavior, and factor 2 , containing items 6,8 , and 9 dealing with calculative behavior related to 'fairly' difficult assignments and 'moderate' risks. Confirmatory factor analyses resulted in the following model fit indicators: $\chi 2$ (df) $=97.373$ (9), $p=.0000$, RMSEA $=.082, \mathrm{CFI}=.961$, $\mathrm{TLI}=.935$. For our model, we decided to use the six items dealing with self-steering behavior. The Cronbach alpha for this measure is good: 0.757 .

Need for Affiliation. For our research, a 5-point Likert scale was used to measure responses to each item, ranging from 1 (strongly disagree) to 5 (strongly agree). Our exploratory factor revealed two dimensions. The single factor EFA resulted in a mediocre model fit $(\chi 2(d f)=$ $257.351(14), p=.0000$, RMSEA $=.109, \mathrm{CFI}=.902, \mathrm{TLI}=.853)$, while the two-factor model provided a good fit $(\chi 2(d f)=41.203(8), p=.0000$, RMSEA $=.053, \mathrm{CFI}=.987, \mathrm{TLI}=.965)$. The two-factor model distinguishes between a first factor containing items 1-4, dealing with the attitude towards co-workers, and a second factor containing items 5-7. This factor relates to both the work setting (items 5 and 6) and acceptance or approval by co-workers (item 7). Since factor two is strongly influenced by physicians' professional methods and values, we applied the first factor only in our model. Confirmatory factor analysis reveals a good model fit: $\chi 2$ (df) $=32.806(2), p=.0000$, RMSEA $=.102, C F I=.978, T L I=.933$. The Cronbach alpha for this first factor is satisfactory, at 0.707.

Need for Dominance. In applying the measure developed by Heckert et al. (2000), we use a 5 -point Likert scale ranging from 1 (strongly disagree) to 5 (strongly agree). Model fit indicators resulting from our survey, based on the EFA, reveal no multidimensionality: $\chi 2$ $(\mathrm{df})=66.675(5), \mathrm{p}=.0000, \mathrm{RMSEA}=.092, \mathrm{CFI}=.963, \mathrm{TLI}=.926$. This is confirmed by the CFA, which renders identical fit indicators. The Cronbach alpha for this measure is good, at 0.767 .

Self-efficacy. For our research, we applied a 5-point Likert scale to measure responses to each item, ranging from 1 (strongly disagree) to 5 (strongly agree). Our exploratory factor analysis provides no indication for multidimensionality as the model-fit indicators for the 
single factor model include $\chi 2(\mathrm{df})=49.707(2), \mathrm{p}=.0000, \mathrm{RMSEA}=.125, \mathrm{CFI}=.982, \mathrm{TLI}=$ .947. This single factor model is confirmed by our CFA rendering identical fit indicators. The Cronbach alpha for this measure is good, at 0.854 .

Entrepreneurial intent. We used the six substantive items only to measure physicians' entrepreneurial intent to keep the questionnaire as short as possible. A 6-point Likert scale was used to measure responses to each item, ranging from 1 (very untrue) to 6 (very true). Our EFA and CFA provide evidence for the unidimensionality of this measure. Model-fit indicators for the single factor model include $\chi 2(\mathrm{df})=338.110(2), p=.0000$, RMSEA $=.156$, $\mathrm{CFI}=.943, \mathrm{TLI}=.905$. This unidimensionality was confirmed by our CFA providing identical model-fit indicators. The Cronbach alpha for this measure is good, at .904.

\section{Descriptive Statistics}

Based on our measurement model, we created a correlation matrix (Table 2) of the different constructs. Correlations vary from close to zero between the need for autonomy and the need for affiliation ( $r=.002$, n.s.) to a medium-sized correlation between entrepreneurial selfefficacy and entrepreneurial intent $(r=.40, p<.05)$ and between the need for achievement and the need for dominance $(r=.48, p<.01)$. A significant negative but small relationship was found between the need for affiliation and entrepreneurial intent $(r=-.08, p<.05)$. 


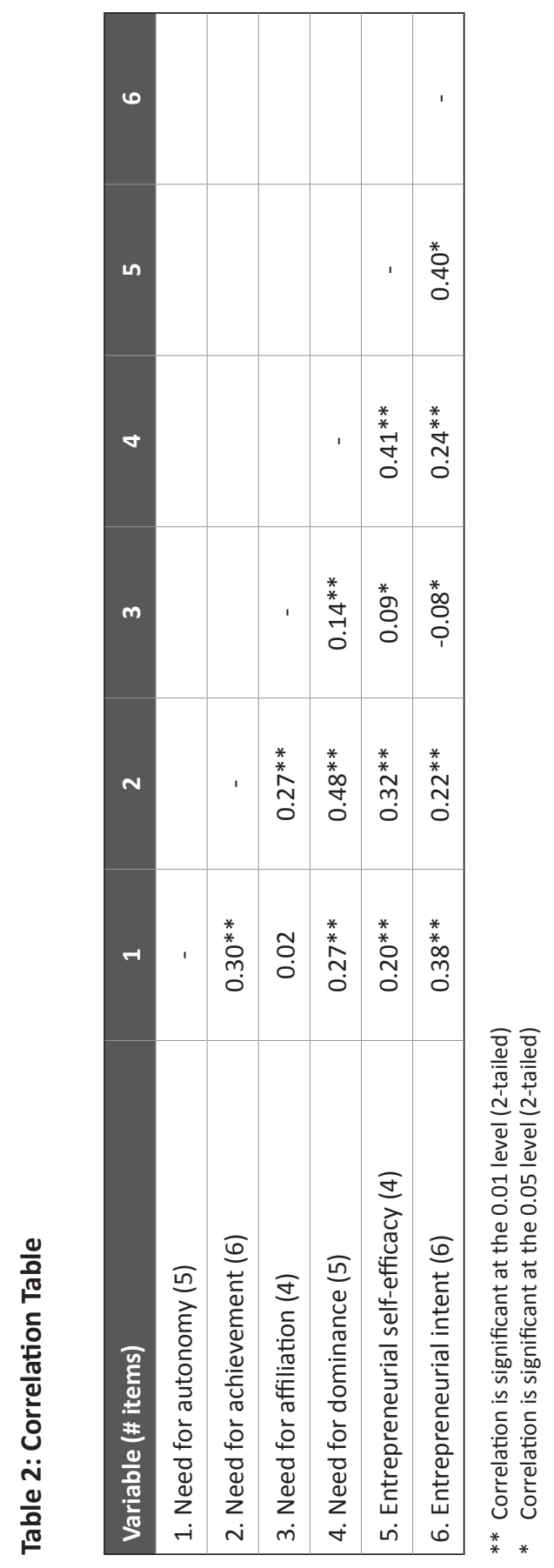




\section{Constructs across Hospital Types and Specialty Groups}

To determine differences between specialty group and type of hospital, we calculated the weighted sum scores in Mplus (DiStefano et al., 2009). Mplus uses regression analysis to determine the contribution of each factor score to factor loadings. Here, factor scores were fixed at 0 and variance was fixed at 1 to obtain a standard normal distribution, allowing the use of ANOVA and post-hoc analyses between the factor loadings of specialty groups or type of hospital in SPSS. The results are shown in Table 3. 


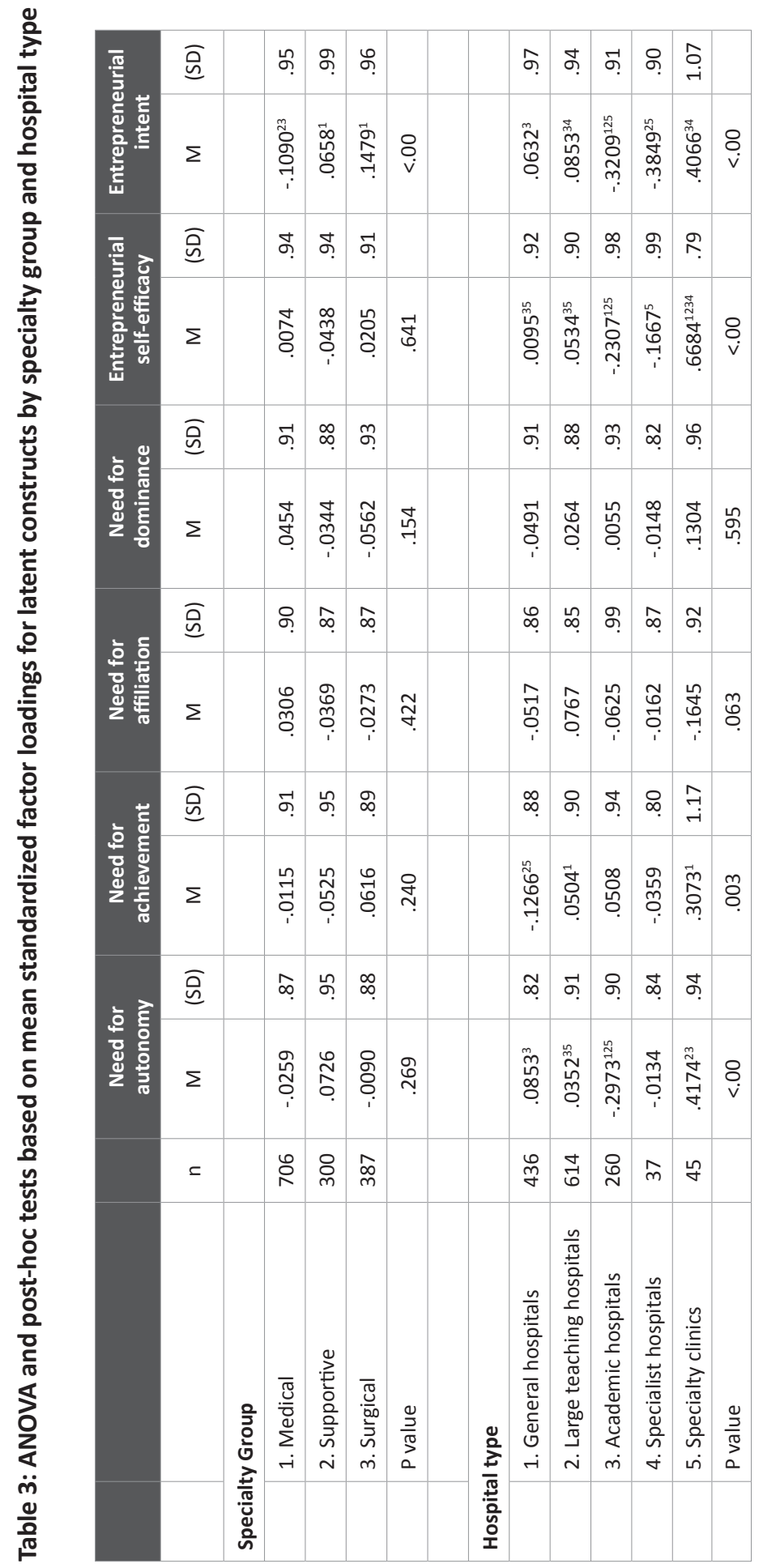


More significant differences exist between hospital types than between specialty groups. Only entrepreneurial intent is significantly different between specialties: physicians in surgical and supportive specialties have a significantly higher entrepreneurial intent than physicians in medical specialties.

In comparing hospitals, significant differences exist for the need for autonomy, the need for achievement, self-efficacy and entrepreneurial intent. Physicians working in academic hospitals have a significantly lower need for autonomy compared to general hospitals, large teaching hospitals, and specialty clinics. Physicians in specialty clinics are found to have the highest need for autonomy. In addition, the need for achievement was found to be lowest in general hospitals and significantly higher in large teaching hospitals and specialty clinics. The need for achievement was highest in specialty clinics. Entrepreneurial self-efficacy was found to be significantly higher for physicians in specialty clinics compared to every other hospital type. This type of self-efficacy was found to be lowest for physicians working in academic hospitals. Finally, entrepreneurial intent was significantly lower in specialty hospitals compared to large teaching hospitals and specialty clinics. Entrepreneurial intent was found to be highest in specialty clinics.

\section{Hypothesized Model}

To test our hypotheses, we test our hypothesized model, displayed in Figure 1 . This model has a good fit with the data, as the model fit indicators include $\chi 2$ (df) $=1807.289$ (390), $p=$ $.0000, \mathrm{RMSEA}=.051, \mathrm{CFI}=.914, \mathrm{TLI}=.904$. 


\section{Doctors in Business}

\section{Figure 1}

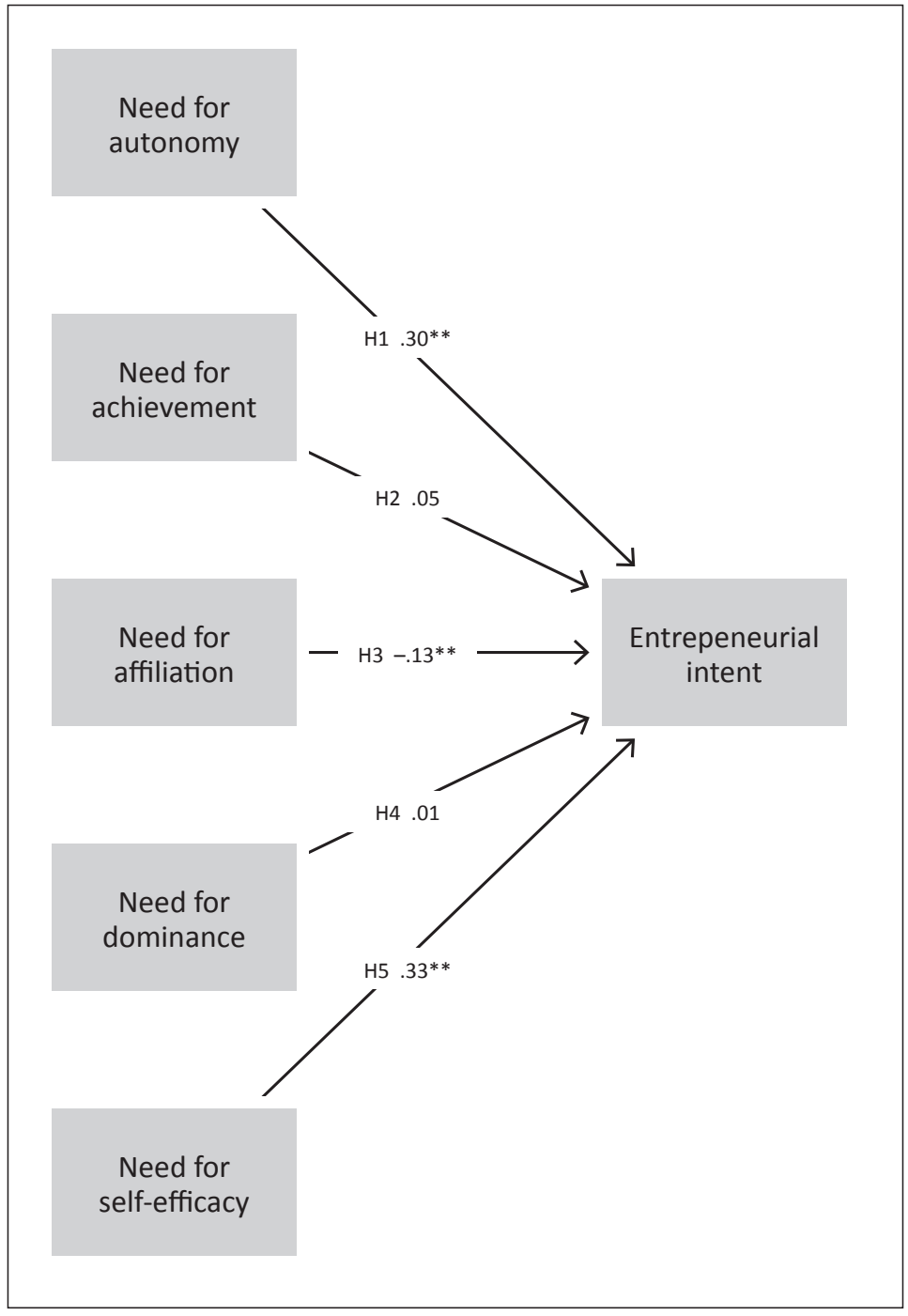

$* \mathrm{p}<.05, * * \mathrm{p}<.01, * * * \mathrm{p}<.001$ 
Hypothesis 1 predicted that the need for autonomy is positively related to entrepreneurial intent. This prediction was supported $(\beta=.30, p<.01)$. Hypothesis 2 , that the need for achievement is positively related to entrepreneurial intent, was not supported ( $\beta=.05$, n.s.). Hypothesis 3 was supported: the need for affiliation is negatively related to entrepreneurial intent $(\beta=-.13, p<.01)$. Hypothesis 4 was not supported: the need for dominance is not related to entrepreneurial intent $(\beta=.01$, n.s.). Finally, we found evidence for Hypothesis 5 : Physicians' self-efficacy is positively related to entrepreneurial intent $(\beta=.33, p<.01)$.

Given the presence of non-significant relationships between several exogenous and endogenous latent variables, our model can be further improved (Joreskog, 1993). However, the non-significant relationship between the need for achievement and need for dominance on the one hand and entrepreneurial intent on the other seems to contradict our findings summarized in the correlation table (Table 2). In addition, the need for achievement has previously been found to be positively associated with business creation across 29 studies (Rauch \& Frese, 2007). Therefore, we wanted to explore whether these two constructs may instead be indirectly related to entrepreneurial intent.

To assess this indirect effect, we applied structural equation modeling as it allows for the simultaneous testing of relations between different dependent variables. The alternative model has a slightly lower fit compared to the hypothesized model, with $\chi 2(\mathrm{df})=1819.013$ (395), $\mathrm{p}=.0000, \mathrm{RMSEA}=.051, \mathrm{CFI}=.913, \mathrm{TLI}=.904$. Given the non-significant path between the need for dominance and the need for affiliation, we improved the model by removing it. This resulted in the optimized alternative model of Figure 2. The model fit is slightly better compared to both the hypothesized model and the original alternative model (Table 4). 


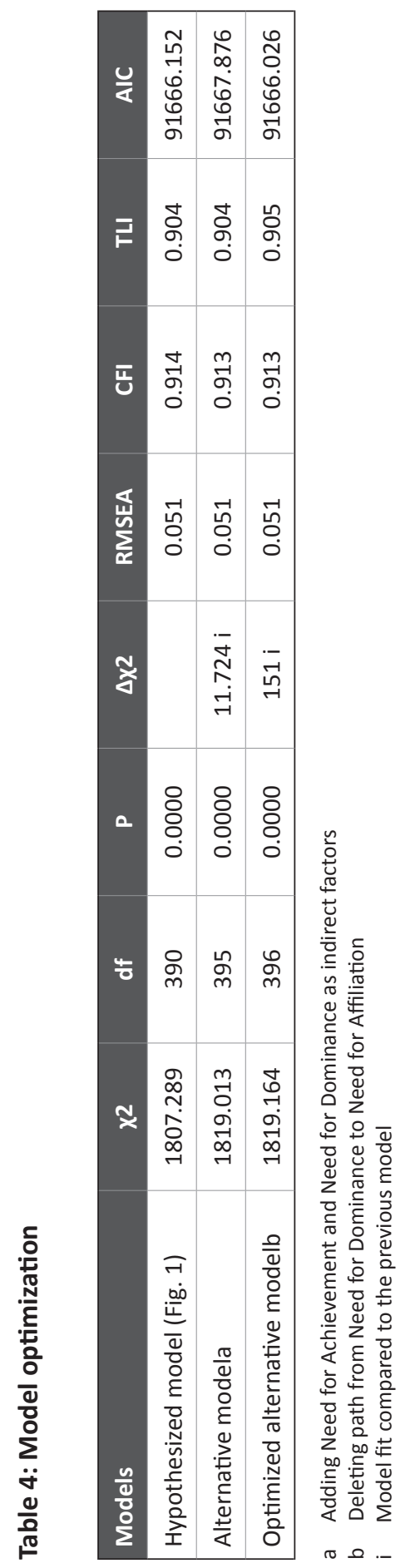




\section{Figure 2}

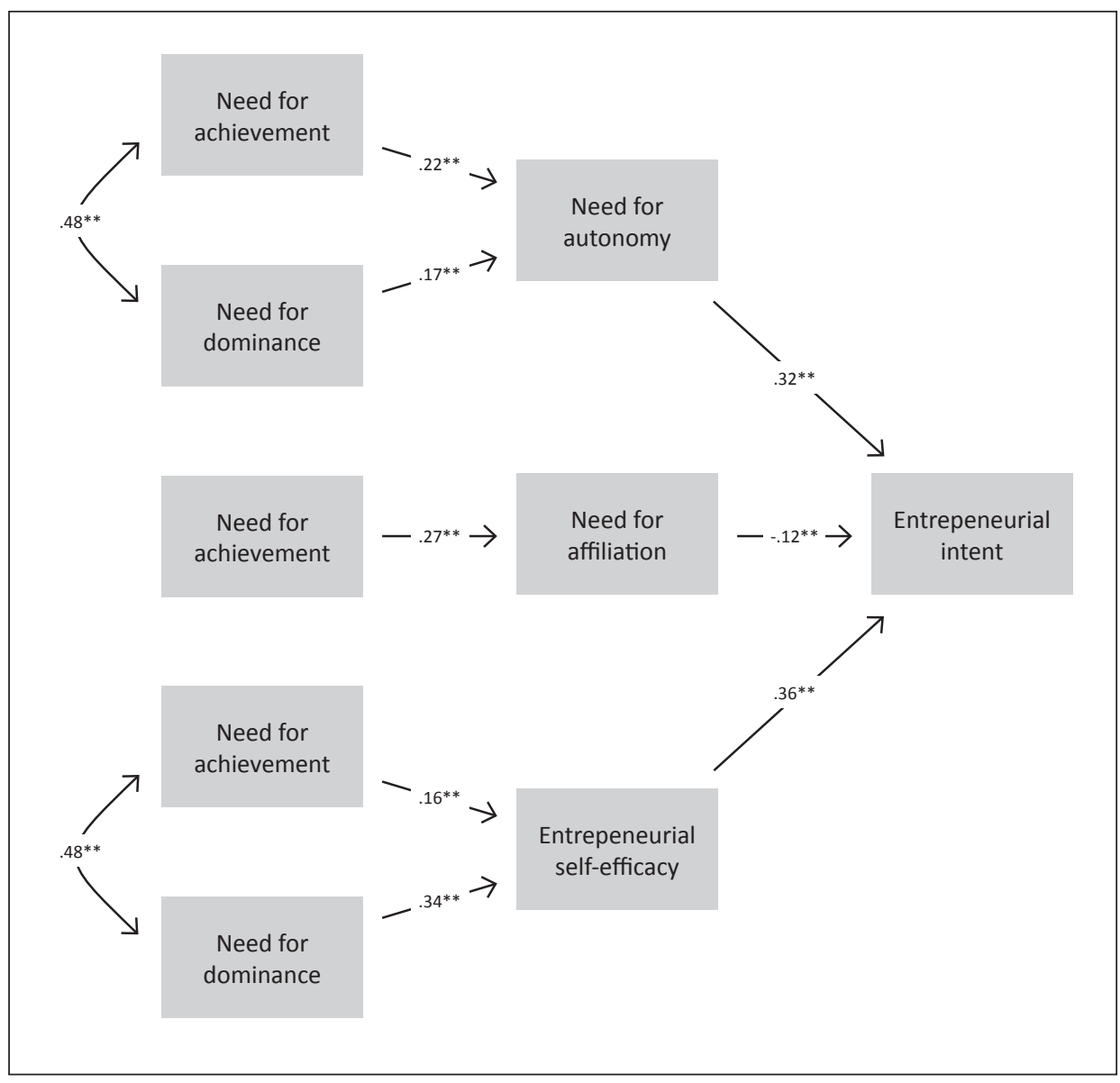

$* \mathrm{p}<.05, * * \mathrm{p}<.01, * * * \mathrm{p}<.001$

In the refined model, the total indirect effect for the need for dominance via the need for autonomy and entrepreneurial self-efficacy is significant and equals .177. The total indirect effect of the need for achievement via the need for autonomy and entrepreneurial selfefficacy excluding the need for affiliation is significant and equals .129. When we include the need for affiliation, the indirect effect of the need for achievement is significant and equals 097. 


\section{Discussion}

Given the increase in the number of physician-entrepreneurs, we researched the influence of personality in developing an entrepreneurial intent.

As hypothesized, we found the need for autonomy and entrepreneurial self-efficacy to be positively related to entrepreneurial intent and we found a significant negative relationship between the need for affiliation and entrepreneurial intent. Contrary to our hypotheses, we found no significant direct relationship between the need for achievement and entrepreneurial intent, or between the need for dominance and entrepreneurial intent. Instead, we found the need for achievement to be indirectly related to entrepreneurial intent through the need for autonomy, the need for affiliation, and entrepreneurial self-efficacy. Likewise we found an indirect relation between the need for dominance and entrepreneurial intent via the need for autonomy and entrepreneurial self-efficacy. This reveals a two-level model in which the need for achievement and the need for dominance provide the impetus whereas the need for autonomy, the need for affiliation, and entrepreneurial self-efficacy provide the direction.

In addition, we found motivational needs and entrepreneurial self-efficacy to differ across hospital type rather than specialty group. Still, specialty groups do differ in terms of entrepreneurial intent as physicians in medical groups have a significantly lower entrepreneurial intent compared to physicians in supportive or surgical specialties. The need for autonomy, the need for achievement, the need for dominance, entrepreneurial self-efficacy, and entrepreneurial intent are all highest for physicians working in specialty clinics, while their mean score on the need for affiliation is lowest compared to physicians in other hospital types. Physicians in academic hospitals and specialist hospitals score lowest on entrepreneurial intent, while physician in large teaching hospitals and general hospitals score second and third respectively, after specialty clinics.

In explaining the different levels of entrepreneurial intent across specialty groups, we point to the different degrees of multidisciplinary cooperation necessary for each specialty group. As medical groups are more multidisciplinary by definition compared to the other specialties, we postulate that their close interactions with colleagues will inhibit the development of an entrepreneurial intent. This is confirmed by their higher score for the need for affiliation, which in turn is negatively related to entrepreneurial intent. Efforts to encourage entrepreneurial intent among specialties of this type will therefore probably be most effective when targeted at a group rather than on an individual level.

We were surprised by the relatively high level of entrepreneurial intent of physicians already 
working in a specialty clinic compared to physicians working in other hospital types. We found this to be primarily the case for physicians who founded their specialty clinic, rather than physicians working on an employment basis (Table 5). Based on this, we conclude that entrepreneurs keep looking for new opportunities even when they are working in their own clinic. This difference is especially striking as a majority of physicians in the Netherlands are working in a private partnership, typical for the situation in the Netherlands. Although these partnerships are often labeled as entrepreneurial, their entrepreneurial intent is significantly lower compared to physicians working in specialty clinics.

Table 5: Entrepreneurial intent of physicians working in specialty clinics

\begin{tabular}{|l|c|c|c|}
\hline & & \multicolumn{2}{|c|}{ Entrepreneurial intent } \\
\hline & $\mathrm{n}$ & $\mathrm{M}$ & (SD) \\
\hline Entrepreneur (founder) & 21 & .9646 & .95 \\
\hline Participant (employee) & 22 & .1515 & 1.08 \\
\hline P value & & 0.013 & \\
\hline
\end{tabular}

\section{Implications for Practice}

As regards the practical implications, these are different for physicians and hospital managers. For physicians, after having completed their specialty training, it is important to choose a setting that best fits their motivational needs, allowing them to be more effective (Hinami et al., 2013; Huesch, 2011; Vandenberghe, 1999). Assessing motivational needs versus the profile of each hospital type will allow them to make a better choice.

For hospital managers, medical managers of partnership groups and policy makers, it is important to note that entrepreneurial ambitions, formulated in response to increasing competition, should match the entrepreneurial profile of the physicians involved. Especially for academic hospitals and specialty hospitals, given their relatively low scores for entrepreneurship-related motivational needs and entrepreneurial self-efficacy, it may be necessary to be more critical in the selection process of new physicians or enhance entrepreneurial capabilities by assigning these roles to (project) managers.

In addition, we found the need for autonomy to be significantly related to entrepreneurial intent. More stringent managerial policies may result in too limited a perceived space for physicians with a high need for autonomy, actually pushing them to leave the hospital organization. Strengthening the entrepreneurial capabilities of a hospital may require free space for physicians with an entrepreneurial profile that includes a high need for autonomy. 
Another way to increase the entrepreneurial capabilities of a hospital is to increase the entrepreneurial self-efficacy of its physicians. As earlier research established evidence for a positive relationship between formal education in entrepreneurship and entrepreneurial self-efficacy (Zhao et al., 2005), increasing entrepreneurial capabilities may be achieved by providing courses in entrepreneurship for physicians who already have a high need for autonomy and a relatively low score for the need for affiliation.

\section{Limitations}

Our study of the relationship between physicians' traits and entrepreneurial intent has some limitations. First, although the Dutch healthcare system is comparable to many Western systems, managed competition has been introduced only relatively recently compared to other countries. This may have had an impact on the scores for entrepreneurial intent. So a second caveat concerns the generalizability of findings to different healthcare systems.

In terms of suggestions for future research, we would like to point to the cross-sectional nature of our study. We suggest that future research should monitor the development of entrepreneurial intent in longitudinal studies as it could be valuable to assess what triggers active intent that results in new entry taking place. In addition, longitudinal research may identify the influence of contextual changes on motivational needs and entrepreneurial selfefficacy. Finally, new research may also include other medical professionals including nurses to assess their motivational needs in relation to entrepreneurial intent. 


\section{6 - Motivational needs and self-efficacy as predictors of entrepreneurial intent of hospital-based physicians}

\section{References}

Aldrich, H.E. (1999). Organizations evolving. London: Sage.

Asparouhov, T., \& Muthen, B. (2009). Exploratory Structural Equation Modeling. Structural Equation Modeling-a Multidisciplinary Journal, 16, 397-438.

Atkinson, J.W. (1958). Motives in fantasy, action, and society: a method of assessment and study. Princeton, N.J.,: Van Nostrand.

Bandura, A. (1986). The Explanatory and Predictive Scope of Self-Efficacy Theory. Journal of Social and Clinical Psychology, 4, 359-373.

Bandura, A. (1991). Social Cognitive Theory of Self-Regulation. Organizational Behavior and Human Decision Processes, 50, 248-287.

Baum, J.R., Olian, J.D., Erez, M., Schnell, E.R., Smith, K.G., Sims, H.P., et al. (1993). Nationality and work role interactions - A cultural contracts of Israeli and United-States entrepreneurs versus managers needs. Journal of Business Venturing, 8, 499-512.

Boyd, N., \& Vozikis, G.S. (1991). The Influence of Self-Efficacy on the Development of Entrepreneurial Intentions and Actions. Proceedings of the Twentieth Annual Meeting of the Western Decision Science Institute, Lihue, Kauai, Hawaii, March 19-22, 1991, 829-831.

Brandstatter, H. (1997). Becoming an entrepreneur - A question of personality structure? Journal of Economic Psychology, 18, 157-177.

Brandstatter, H. (2011). Personality aspects of entrepreneurship: A look at five meta-analyses. Personality and Individual Differences, 51, 222-230.

Brody, N., \& Ehrlichman, H. (1998). Personality Psychology: the science of individuality. Upper Saddle River, N.J.: Prentice Hall.

Burgelman, R.A. (1983). A process model of internal corporate venturing in the diversified major firm. Administrative Science Quarterly, 28, 223-244.

Carsrud, A., \& Brannback, M. (2011). Entrepreneurial Motivations: What Do We Still Need to Know? Journal of Small Business Management, 49, 9-26.

Carsrud, A., Olm, K., \& Eddy, G. (1987). Entrepreneurs-Mentors, networks, and successful new venture development: An exploratory study. American Journal of Small Business, 12, 13-18.

Chell, E. (1985). The entrepreneurial personality: A few ghosts laid to rest? International small business journal, 3, 43-54.

Chen, C.C., Greene, P.G., \& Crick, A. (1998). Does entrepreneurial self-efficacy distinguish entrepreneurs from managers? Journal of Business Venturing, 13, 295-316.

Collins, C.J., Hanges, P.J., \& Locke, E.A. (2004). The relationship of achievement motivation to entrepreneurial behavior: A meta-analysis. Human Performance, 17, 95-117.

Cutler, D.M. (2002). Equality, efficiency, and market fundamentals: The dynamics of international medicalcare reform. Journal of Economic Literature, 40, 881-906.

DiStefano, C., Zhu, M., \& Mindrila, D. (2009). Understanding and Using Factor Scores: Considerations for the Applied Researcher. Practical Assessment, Research \& Evaluation, 14

Donabedian, A. (1988). The quality of care. How can it be assessed? JAMA, 260, 1743-1748.

Dreher, G.F., \& Maidalton, R.R. (1983). A Note on the Internal Consistency of the Manifest Needs Questionnaire. Journal of Applied Psychology, 68, 194-196.

Eisenberger, R., Jones, J.R., Stinglhamber, F., Shanock, L., \& Randall, A.T. (2005). Flow experiences at work: for high need achievers alone? Journal of Organizational Behavior, 26, 755-775. 
Gartner, W.B. (1989). "Who is an entrepreneur?" Is the wrong question. Entrepreneurship Theory and Practice, 13, 47-68.

Gist, M.E. (1987). Self-Efficacy - Implications for Organizational-Behavior and Human-Resource Management. Academy of Management Review, 12, 472-485.

Heckert, T.M., Cuneio, G., Hannah, A.P., Adams, P.J., Droste, H.E., Mueller, M.A., et al. (2000). Creation of a new needs assessment questionnaire. Journal of Social Behavior and Personality, 15, 121-136.

Hinami, K., Whelan, C.T., Miller, J.A., Wolosin, R.J., \& Wetterneck, T.B. (2013). Person-job fit: An exploratory cross-sectional analysis of hospitalists. Journal of Hospital Medicine, 8, 96-101.

Hisrich, R.D., \& Peters, M.P. (1992). Entrepreneurship: Starting, developing, and managing a new enterprise.: McGraw-Hill/Irwin.

Huesch, M.D. (2011). Provider-Hospital "Fit" and Patient Outcomes: Evidence from Massachusetts Cardiac Surgeons, 2002-2004. Health Services Research, 46, 1-26.

Joreskog, K.G. (1993). Latent Variable Modeling with Ordinal Variables. Statistical Modelling and Latent Variables, 163-171.

Kets de Vries, M.F.R. (1977). The entrepreneurial personality: A person at the crossroads. Journal of Management Studies, 14, 34-58.

Kline, R.B. (2011). Principles and practice of structural equation modeling. New York: Guilford Press.

Klopper-Kes, A.H.J., Meerdink, N., Wilderom, C.P.M., \& Van Harten, W.H. (2011). Effective cooperation influencing performance: a study in Dutch hospitals. International Journal for Quality in Health Care, 23, 94-99.

Koelewijn, W.T., Ehrenhard, M.L., Groen, A.J., \& van Harten, W.H. (2012). Intra-organizational dynamics as drivers of entrepreneurship among physicians and managers in hospitals of western countries. Social Science \& Medicine, 75, 795-800.

Konovsky, M., Dalton, D.R., \& Todor, W.D. (1986). Of the Psychometric Properties of the Manifest Needs Questionnaire. Psychological Reports, 58, 309-310.

Kruijthof, K. (2005). Doctors' Orders. Specialists' day to day work and their jurisdicational claims in Dutch hospitals. iBMG. Alkmaar: Erasmus Universiteit Rotterdam.

Lumpkin, G.T., \& Dess, G.G. (1996). Clarifying the Entrepreneurial Orientation Construct and Linking it to Performance. Academy of Management Review, 21, 135-172.

Mars, M.M., \& Lounsbury, M. (2009). Raging Against or With the Private Marketplace?: Logic Hybridity and Eco-Entrepreneurship. Journal of Management Inquiry, 18, 4.

McClelland, D.C. (1953). The achievement motive. New York,: Appleton-Century-Crofts.

McClelland, D.C. (1961). The achieving society. Princeton, N.J.,: Van Nostrand.

McClelland, D.C. (1975). Power: The inner experience. New York: Irvington Publishers.

Murray, H.A. (1938). Explorations in personality; a clinical and experimental study of fifty men of college age. New York, London etc.: Oxford university press.

NZA. (2012). ZBC Monitor - Een kwalitatieve en kwantitatieve analyse. Utrecht: Dutch Healthcare Authority.

Rauch, A., \& Frese, M. (2007). Let's put the person back into entrepreneurship research: A meta-analysis on the relationship between business owners' personality traits, business creation and success. European Journal of Work and Organizational Psychology, 16, 353-385.

Reay, T., \& Hinings, C.R. (2009). Managing the Rivalry of Competing Institutional Logics. Organization Studies, 30, 629-652.

Rivers, P.A., \& Woodard, B. (1997). Organizational power and conflict regarding the hospital-physician relationship: symbolic or substantive? Health Services Management Research, 10, 91-106.

Robinson, P.B., Stimpson, D.V., Huefner, J.C., \& Hunt, H.K. (1991). An attitude approach to the prediction of entrepreneurship. Entrepreneurship Theory and Practice, 15, 13-31. 


\section{6 - Motivational needs and self-efficacy as predictors of entrepreneurial intent of hospital-based physicians}

Saltman, R.B., Busse, R., \& Mossialos, E. (2002). Regulating entrepreneurial behaviour in European health care systems. Philadelphia: Open University Press Buckingham.

Shane, S., Locke, E.A., \& Collins, C.J. (2003). Entrepreneurial motivation. Human Resource Management Review, 13, 257-279.

Shane, S., \& Venkataraman, S. (2000). The Promise of Entrepreneurship As a Field of Research. The Academy of Management review, 25, 217-226.

Shockley, K.M., \& Allen, T.D. (2010). Investigating the missing link in flexible work arrangement utilization: An individual difference perspective. Journal of Vocational Behavior, 76, 131-142.

Steers, R.M., \& Braunstein, D.N. (1976). Behaviorally-Based Measure of Manifest Needs in Work Settings. Journal of Vocational Behavior, 9, 251-266.

Thompson, E.R. (2009). Individual Entrepreneurial Intent: Construct Clarification and Development of an Internationally Reliable Metric. Entrepreneurship Theory and Practice, 33, 669-694.

Vandenberghe, C. (1999). Organizational culture, person-culture fit, and turnover: a replication in the health care industry. Journal of Organizational Behavior, 20, 175-184.

Winter, D.G. (1973). The power motive. New York: Free Press.

Yukl, G.A. (1989). Leadership in organizations. Englewood Cliffs, N.J.: Prentice Hall.

Zhao, H., \& Seibert, S.E. (2006). The Big Five Personality Dimensions and Entrepreneurial Status: A MetaAnalytical Review. Journal of Applied Psychology, 91, 259.

Zhao, H., Seibert, S.E., \& Hills, G.E. (2005). The mediating role of self-efficacy in the development of entrepreneurial intentions. Journal of Applied Psychology, 90, 1265-1272.

Zhao, H., Seibert, S.E., \& Lumpkin, G.T. (2010). The Relationship of Personality to Entrepreneurial Intentions and Performance: A Meta-Analytic Review. Journal of Management, 36, 381-404.

\section{Web reference}

https://www.bigregister.nl/en/ Last accessed: september 27, 2013. 



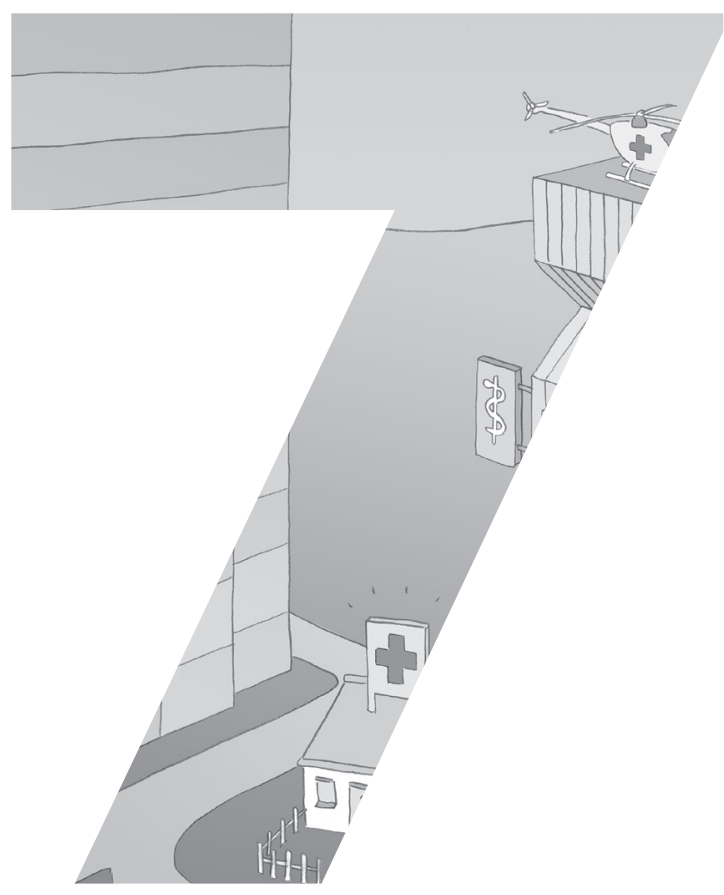

DISCUSSION 


\section{Introduction}

Both in the US and the Netherlands, entrepreneurial activities in the hospital sector increased rapidly during the 1990s as a result of the implementation of elements derived from managed competition (Enthoven, 1993), supported by a payment system based on a fee for a service.

During the course of this research however, the context faced by physician-entrepreneurs in the Netherlands changed severely as the rise in healthcare expenditure partially associated with entrepreneurial behavior of physicians, triggered a fourth wave of healthcare reforms aimed at curtailing growth of healthcare expenditures by imposing a mixture of regulations on new entrepreneurial initiatives. The impact of these regulations differ per country and will be explicated below for the US, the UK and the Netherlands.

In the US, based on the results of the earlier 18-month moratorium on new specialty clinics, Congress decided in 2010 to regulate the country's approximately 265 physician-owned specialty hospitals. These new congressional regulations prohibited new or expanded physician-owned specialty hospitals from filing Medicare claims if a financial relationship exists between the referring physician and the hospital receiving the government reimbursement, signifying an early measure to curtail physicians' entrepreneurship (Perry, 2012). Next, the Patient Protection and Affordable Care Act (better known as Obamacare) includes the prohibition of future physician investment in hospitals and a cap on existing physician investment in hospitals. It is reasoned that this will limit the commercial interests of physicians and the transfer of lucrative care from the traditional hospitals to physicianowned facilities (Perry, 2012). Next, in an effort to make healthcare plans more affordable, insurers in the US are increasingly reluctant to contract expensive hospitals which are perceived as 'best in class', including Cedars-Sinai in Los Angeles, California and Mayo Clinic in Minnesota (Kirchgaessner, 2013). As a result of these regulations, opportunities for new initiatives for physicians' entrepreneurship are now severely limited.

In the UK, policies that are the reverse of those in the US with respect to entrepreneurial activities are being implemented under the Health and Social Care Act of 2012. As part of this act, emphasis is given to privatization and competition in an effort to attract private investors and innovative entrepreneurs (Peedell, 2011). These contrasting policies can be explained first of all by the tight budgeting system of the NHS, resulting in a lower rate of growth in healthcare expenditure compared to other countries. Second, the investments in the NHS have resulted in shorter waiting lists, making it increasingly difficult for independent for-profit hospitals to compete with NHS hospitals (Jeurissen, 2010). Third, physicians in the NHS are paid salaries, in contrast to physicians in the US (and a majority of hospital- 
based physicians in the Netherlands), where a system based on a fee for a service is applied; this limits the incentives in the UK to inflate volumes. Finally, to gain access to the NHS, independent for-profit hospitals are forced to lower prices in order to be competitive. As a result, both NHS hospitals and independent for-profit hospitals operate increasingly within a single budgeting system that ensures a level playing field for price competition, thereby providing new potential for competition and entrepreneurship.

In the Netherlands, like in the US and the UK, healthcare regulations are increasingly aimed at limiting the growth in healthcare spending. Like the UK, increasing attention is being paid to setting strict national healthcare budgets. In 2012, physicians in hospitals and specialty clinics alike were placed under a single budgetary regime (beheersmodel), thereby curtailing opportunities for further growth. Similarly to the US, health insurance companies make it increasingly difficult for specialty clinics to obtain contracts by setting requirements that are particularly difficult for specialty clinics to meet, demanding excessively high discounts, minimum yearly turnovers, and unique innovative propositions (Elsen van den, 2013; Mous, 2013; Olsthoorn, 2013). Due to these developments, the Dutch Healthcare Authority (NZA, 2012) concluded that the growth of new specialty clinics is slowing down.

As the fourth wave of healthcare reforms in the US and the Netherlands includes stringent regulations aimed at curtailing entrepreneurship, new physician-entrepreneurs are facing severe challenges. However, in the UK too, competing with NHS healthcare providers, which is necessary to gain access to patients and funding, has become increasingly difficult. Despite these challenges, physicians' entrepreneurship are still emerging and resulting in new specialty clinics in the Netherlands e.g. the Alexander Monro Hospital for breast cancer in Bilthoven, and the Mohs clinic in Eindhoven, which both opened in 2013 (Abrahamian, 2013; Budding, 2013; Mundy, 2013; Plimmer, 2012; Stoffelen \& Eefting, 2013).

The central purpose of this dissertation is to examine what drives physicians' entrepreneurship. In particular, it addresses drivers related to (1) contextual factors, both in the field and at the intra-organizational level, and (2) individual factors, constituted by motivational needs and self-efficacy. In this chapter, we summarize the findings, and discuss the key benefits as well as limitations of this research. Finally, the implications for future research on physicians' entrepreneurship will be discussed. 


\section{Summary of key findings}

As set out in the introduction, five issues regarding physicians' entrepreneurship are distinguished that called for conceptual and empirical explanations. These research questions are: (1) What is known about the influence of intra-organizational dynamics among hospital managers and physicians on entrepreneurship in hospitals? (2a) How do intra-organizational dynamics between physicians and managers induce physicians to become entrepreneurs by starting a specialty clinic, and (2b) are these specialty clinics founded by physicians an example of sedimented change or transformational change? (3) What is the nature and structure of physicians' interests and how do these differ across hospitals and specialties? (4) How do contextual factors influence intra-organizational dynamics and how do these dynamics contribute to the development of entrepreneurial intent among physicians? (5) How do motivational needs and self-efficacy relate to entrepreneurial intent among physicians and how do these differ across hospitals and specialties? Each question was discussed in one of the papers included in this dissertation. The questions were addressed by applying a mixture of methods, including a review of an extensive body of literature, interviews with both physicians and managers, and finally a large-scale survey among members of the Dutch Association of Medical Specialists. The results for each research question are summarized below.

Question 1: What is known about the influence of intra-organizational dynamics among hospital managers and physicians on entrepreneurship in hospitals?

To answer this question, a literature review was conducted (see Chapter 2) by formulating three secondary research questions. Initial screening of 1,110 articles resulted in a set of 34 studies included in the review. The findings per secondary research question will be discussed below.

The first subsequent research question concerned the ways in which power interdependencies between physicians and managers lead to interest dissatisfaction in hospitals. Based on the review, it was concluded that the growing dominance of the business-like healthcare logic brought about by market reforms and deregulations has markedly altered the relationship between managers and physicians in hospitals. Power dependencies have shifted and intensified in favor of hospital managers. The diminished economic autonomy of physicians and continuous efforts to bring clinical care within a management framework are associated with interest dissatisfaction among physicians. Their level of dissatisfaction was found to be dependent on the extent of their subordination to management and the use of structural power to control their clinical practice. 
The second subsequent research question focused on the way in which power dependencies between physicians and hospital managers are related to value commitments and to an entrepreneurial orientation in hospitals.

The review results indicated that increased power dependence on hospital managers has heightened both transformative and defensive value commitments among physicians. As part of a transformatively oriented value commitment towards the traditional logic of medical professionalism, physicians may be drawn to become medical entrepreneurs and open specialty clinics by the prospect of additional income and autonomy. As part of a defensively oriented value commitment towards the logic of business-like healthcare, physicians are pushed to embrace certain elements of the business-like healthcare logic to effectively protect their professional autonomy. This last finding relates well to the notion of custodial strategy (Ackroyd et al., 1989), in which managerial practice is embraced by professional groups to maintain the status quo as defined by the professional community.

The third and final subsequent research question looked at how interest dissatisfaction, competitive value commitment (including defensive and transformative commitments), and entrepreneurial orientation interact in hospitals.

The literature review yielded insights into the relationship between interest dissatisfaction and defensive or transformative value commitments. Interest dissatisfaction can stimulate entrepreneurial activities among physicians holding a defensive or transformative value commitment. In this respect, it was reasoned that the type of value commitment determines whether entrepreneurship is need-based or opportunity-driven. This is a novel observation as need-based entrepreneurship is generally associated with low incomes and unemployment (Ritsilä \& Tervo, 2002). Finally, physicians' involvement in the entrepreneurial activities of hospitals was found to be important as research suggests that the active development by hospital management of both a hospital-wide market orientation and entrepreneurship is related to higher performance.

Question 2a \& b: How do intra-organizational dynamics between physicians and managers induce physicians to become entrepreneurs by starting a specialty clinic and are these clinics an example of sedimented change or transformational change?

The study (see Chapter 3) presented the results of interviews held with fifteen physicians and eight managers in four hospitals as well as interviews held with twelve physicians and seven managers in twelve specialty clinics. Based on these interviews it was established that, in addition to the neo-institutional focus on functionally different groups, intra-group dynamics may push physicians towards entrepreneurship as well. 
With respect to the question how intra-organizational dynamics between physicians and managers induce physicians to become entrepreneurs by starting a specialty clinic, it was found that the initial embeddedness in a certain logic influences physicians' value commitment and the related primary focus of perceived power dependence and interest dissatisfaction. Physicians embedded in the traditional logic of medical professionalism perceive high levels of bureaucracy and related power dependence on and interest dissatisfaction with hospital management, resulting in a defensively oriented competitive value commitment. The physicians embedded in the dominant logic of business-like healthcare, however, reported that interest dissatisfaction is primarily caused by the prima donna behavior of fellow physicians who are embedded in the logic of medical professionalism and unwilling to adapt to hospital policies. Thus, a transformatively oriented competitive value commitment is developed towards the traditionally dominant logic of physicians. Although intra-organizational dynamics leading to interest dissatisfaction were found to encourage entrepreneurship, personal factors, such as personality traits and coming from an entrepreneurial family, were mentioned as important drivers for the entrepreneurship of these physicians as well.

With respect to the nature of change, three indications were found for change being sedimented, implying it is temporary and reversible, rather than transformational, which is permanent. First, as part of the medical logic, physicians are supposed to be centrally positioned in the organization, allowing them to be both influential and autonomous (Reay \& Hinings, 2009). Being involved in the startup process and governance of the specialty clinic and subsequently having direct influence on clinics' policies not only diminishes the likelihood of interest dissatisfaction developing but also fits well with the medical logic in which most entrepreneurial physicians were initially embedded. In sum, physicians' satisfaction in specialty clinics is not a result of a newly created logic resulting from transformational change but rather the outcome of a good fit with the medical logic in which the physician was formerly embedded and which prevailed during the entrepreneurial process. Second, as illustrated by Mintzberg (1983) and more recently by Maquis and Lounsbur (2007), small organizations tend to turn into bureaucracies as they grow. As this growth requires more coordination, the business logic increasingly becomes dominant, so that the new organizations come to resemble the very organizations entrepreneurial physicians left in the first place. As a result, organizational members with a strong need for autonomy may leave the specialty clinic (Stuart \& Sorenson, 2003). In sum, evidence supports the conclusion that the dominance of the medical logic in specialty clinics is temporary and reversible. Finally, in specialty clinics, physicians' and managers' interests are aligned by providing incentives. Shared interests have been shown to positively affect organizational performance and collaboration (Andrews, 2010; Calciolari et al., 2011; Edwards, 2003; Klopper-Kes et al., 2010; Mache et al., 2012; Ommen et al., 2009; Purdy \& Gray, 2009). In fact, these incentives 
constitute additional cement to the sediment in which entrepreneurial values are 'glued' onto the central medical logic of physicians.

Question 3: What is the nature and structure of physicians' interests and how do these differ across hospitals and specialties?

The study presented in Chapter 4 focuses on the identification and analysis of the interests of physicians working in diverse specialties and different types of hospitals. The research question was answered by analyzing data derived from a survey among a large sample of 7,913 physicians in the Netherlands. Next, these data were analyzed by systematic exploratory and confirmatory factor analyses in addition to univariate and post-hoc analyses of the standardized factor loadings to assess differences between specialty groups and types of hospitals. The four clusters of interests that are derived from the analysis consist of one primary interest and three secondary interest dimensions, as follows:

1. Mission, a primary interest, based upon a single item 'helping patients as well as possible'

2. A work dimension: a secondary interest that is a combination of 'variety in my work as a physician', 'specializing further', and 'doing research'

3. A setting dimension: a secondary interest that covers 'deciding for myself which employees work for me', 'working with the best facilities', 'being able to do my work autonomously', and 'having a say in hospital policy'

4. A life dimension: a secondary interest consisting of 'a good income' and 'a good worklife balance'

For the work orientation, the type of hospital has a stronger effect than the specialty group. For the setting orientation, the relationship with both specialty group and hospital type is non-significant, while for the life orientation, the hospital type has a bigger effect than the specialty group. Overall, the influence of hospital type is stronger than specialty group.

Question 4: How do contextual factors influence intra-organizational dynamics and how do these dynamics contribute to the development of entrepreneurial intent among physicians?

After designing and grounding the research model and having established both the nature and structure of physicians' interests, the next issue examined is how institutional concepts relate to intra-organizational dynamics and how these dynamics contribute to physicians' entrepreneurial intent. In taking both perspectives, we actually merge two theories: institutional theory and entrepreneurship theory. The research question was answered (see Chapter 5) by analyzing data derived from the large-scale survey among 7,762 hospitalbased physicians, of whom a total of $18.4 \%$ filled out the questionnaire completely $(n=1,430)$. Structural equation modeling was used for the analyses. 
With respect to context, a high correlation was found between market turbulence and institutional turbulence. However, a striking difference was found between the influence of institutional turbulence and that of market turbulence on power dependence. Whereas turbulence in the institutional context is associated with higher levels of perceived power dependence on management by physicians, turbulence in the market context shows a reverse relationship. This means market turbulence actually reduces perceived power dependence on management by physicians, which runs contrary to the hypothesis proposed in this dissertation. It is reasoned that physicians perceive that political instruments are required to respond to institutional turbulence, making them dependent on management, while an entrepreneurial response, both by management and physicians, may well fit market dynamics.

Although in institutional theory the institutional context is considered of defining importance in shaping the logics of its field members, such a relationship was not found. Likewise, Greenwood \& Hinings hypothesize a relationship between interest dissatisfaction and market turbulence, but this research did not find any evidence for this relationship. Nor was the hypothesized relationship between power dependence and logic supported by this study. Still, there appears to be an indirect relationship between the two constructs as power dependence was found to significantly influence interest dissatisfaction, which in turn has a significant relationship with the logic held by physicians. In fact, interest dissatisfaction with the facilitation provided by hospital management strengthens physicians in their traditional logic of medical professionalism, thereby deepening the gap with the increasingly dominant logic of business-like healthcare.

In addition to the original model of Greenwood \& Hinings, a relationship between interest dissatisfaction and efficacy at the individual, group, and organizational levels was proposed. All three relationships were found to be both significant and negative. The strongest relationship was found between interest dissatisfaction and organizational efficacy ( $\beta-0.56)$. However, a similar though weaker relationship was found between interest dissatisfaction and self-efficacy $(\beta-0.24)$. Apparently, dissatisfaction with facilitation by management negatively influences the perceived entrepreneurial capabilities of the individual as well.

Power dependence was hypothesized to be negatively associated to entrepreneurial intent. However, no support for this relationship was found. More importantly, only a weak relationship ( $\beta-0.14)$ was established between embeddedness in the logic of medical traditionalism and entrepreneurial intent. On the one hand, this could point to a weakness in the model. However, it may also provide evidence for a different phenomenon: in essence, thinking in entrepreneurial terms requires the adoption of elements of the logic of businesslike healthcare. In fact, a new hybrid logic may be required, as suggested by Tracey, Philips and Jarvis (2011), though resulting in a weak relationship between logic and entrepreneurial intent. 
In addition, a positive relationship between entrepreneurial intent and self-efficacy and a negative relationship between nascent entrepreneurship and organizational efficacy were found. There is a clear explanation for the inverse relationship between organizational efficacy and entrepreneurial intent by individual physicians: this research clearly indicates that a lack of belief in the entrepreneurial capabilities of hospital management may actually provide an incentive for physicians to become entrepreneurs, while a strong belief in management's entrepreneurial capabilities will induce physicians to strive for shared entrepreneurship. In contrast to self-efficacy and organizational efficacy, no relationship was found between group efficacy and entrepreneurial intent. Apparently, other factors influence the relationship between the perceived efficacy of the group and individual entrepreneurial intent, for example the relatively locked-in position of physicians working in hospital-based partnerships.

Interestingly, there was some evidence that turbulence in the market context is positively related to organizational efficacy. This seems to contradict an earlier result where it was found that market turbulence is negatively related to power dependence. Apparently, physicians perceive themselves as better positioned than hospital management to respond to market turbulence, making them less dependent on hospital management. At the same time, hospital management is regarded as being responsible for mitigating the organizational effects of market turbulence (Klopper-Kes et al., 2011) e.g. by developing entrepreneurial initiatives. However, lowering physicians' perceived power dependence appears to be the best way of improving their opinion of organizational efficacy.

Institutional turbulence was found to negatively influence organizational efficacy. Yet the results support the conclusion that institutional turbulence has a positive influence on power dependence. Apparently, physicians feel more dependent on hospital management in responding to institutional pressures, while at the same time physicians' belief in the entrepreneurial capabilities of management to respond to these pressures is low. Overall, results indicate that perceived institutional pressures appear to widen the gap between physicians and hospital management, with increased perceived power dependence of physicians on management but reduced confidence among physicians in the abilities of management.

Question 5: How do motivational needs and self-efficacy relate to entrepreneurial intent among physicians and how do these differ across hospitals and specialties?

Although the majority of physicians share relatively similar contextual factors and intraorganizational dynamics, just a small number of them turn into entrepreneurs. Therefore it is hypothesized that personality-related factors like motivational needs and self-efficacy 
are influencing entrepreneurial intent. This research question was answered (see Chapter 6) by analyzing the data derived from the large-scale survey among 7,913 physicians in the Netherlands, including both hospital-based physicians and physicians working in specialty clinics ( $n=1,475)$.

Given the increase in the number of physician-entrepreneurs over recent years, we researched the influence of personality in the development of entrepreneurial intent.

As hypothesized, the need for autonomy and entrepreneurial self-efficacy were found to be positively related to entrepreneurial intent. A significant negative relationship between the need for affiliation and entrepreneurial intent was established. Contrary to the hypotheses, no significant direct relationship was found between the need for achievement and entrepreneurial intent, or between the need for dominance and entrepreneurial intent. Instead, the need for achievement was found to be indirectly related to entrepreneurial intent through the need for autonomy, the need for affiliation, and entrepreneurial selfefficacy. In addition, an indirect relationship was found between the need for dominance and entrepreneurial intent via the need for autonomy and entrepreneurial self-efficacy. This reveals a two-level model in which the need for achievement and the need for dominance provide the impetus whereas the need for autonomy, the need for affiliation, and entrepreneurial self-efficacy provide the direction.

In addition, motivational needs and entrepreneurial self-efficacy were found to differ across hospital type rather than specialty group. Still, specialty groups do differ in terms of entrepreneurial intent as physicians in medical groups have significantly lower entrepreneurial intent compared to physicians in supportive or surgical specialties. The need for autonomy, the need for achievement, the need for dominance, entrepreneurial self-efficacy, and entrepreneurial intent are all highest for physicians working in specialty clinics, while their mean score on the need for affiliation is lowest compared to physicians in other hospital types. Physicians in academic hospitals and specialist hospitals score lowest for entrepreneurial intent, while physicians in large teaching hospitals and general hospitals have the second and third highest scores respectively, after physicians in specialty clinics.

The different degrees of multidisciplinary cooperation necessary for each specialty group may explain the different levels of entrepreneurial intent across specialty groups. As medical groups are more multidisciplinary by definition compared to the other specialties, it is postulated that their close interactions with colleagues will inhibit the development of entrepreneurial intent. This is confirmed by their higher score for the need for affiliation, which in turn is negatively related to entrepreneurial intent. Efforts to encourage entrepreneurial intent among specialties of this type will therefore probably be most effective when targeted at a group rather than on an individual level.

Finally, a relatively high level of entrepreneurial intent was reported by physicians already working in a specialty clinic compared to physicians working in other hospital types. This 
was especially the case for physicians who founded their specialty clinic, rather than physicians working in specialty clinics as an employee. Based on this finding, it is concluded that entrepreneurs keep looking for new opportunities even when they are working in their own clinic. This difference is especially striking as most physicians in the Netherlands are working in a private partnership, which is a typical feature of the Dutch situation. Although these partnerships are often labeled as entrepreneurial, their entrepreneurial intent is significantly lower compared to physicians working in specialty clinics.

\section{Methodological considerations}

The 'mixed methodology' approach of this dissertation adds to the scientific rigor. The weakness of one method compensated the strengths of the others, thereby increasing the potential for consistent theory building. The survey for example, overcomes the limited generalizability of the interviews, while the interviews allowed for more in-depth understanding of the researched phenomena.

The literature review in the first phase of this research, resulted in a unique and integrative contribution to the current literature on entrepreneurship of physicians and hospital managers, despite rendering limited results. Based on its findings subsequent phases were designed and executed.

In the second phase of the study, in-depth interviews with physicians and managers in both hospitals and specialty clinics assisted in grounding theoretical concepts and by gaining insight on how relationships found in phase one actually happen in practice. This approach rendered a number of important implications for physicians, hospital managers and policy makers.

As part of the third phase, a large number of physicians $(n=1,475)$ participated in filling out the survey thereby constituting a representative sample of physicians working in hospitals or specialty clinics. The subsequent analysis on both the measurement model and the structural models proved to be an appealing methodology for building models on physicians' interests, their motivational needs and finally on the intra-organizational dynamics driving their entrepreneurial intent.

Despite the methodological strengths of this research, for the correct interpretation of the results it is still important to be aware of any limitations in the methodology. The following limitations will be discussed:

- The use of self-report measures

- The cross-sectional design

- The single occupational and national context 


\section{The use of self-report measures}

The studies reported on in Chapters 3, 4, and 5 used self-report measures to capture physicians' perceptions. This method may lead to measurement errors due to distortions caused by social desirability, acquiescence etc., in addition to the usual method bias, which may adversely affect the validity of the results. Also, in the case of interests and entrepreneurial intent, we used shortened scales from which we deleted the distracter items to avoid survey fatigue. Using short scales has also been mentioned as a source of common method bias (Podsakoff et al., 2003). Further research could include more objective ratings of the dependence of physicians on hospital management.

The issue of distortions caused by social desirability may be enhanced by the use of personalized invitations by e-mail. Although this increased the response rate, at the same time it may have led to some bias when dealing with sensitive issues like the relative importance of 'a good income' versus 'helping patients as well as possible' because they are more likely to give a socially desirable answer? (Heerwegh, 2005). However, this is not a reason to remove these particular interests from the model as systematic differences are seen in the relative scores of these interests between different groups of physicians (as defined by specialty and hospital type).

\section{The cross-sectional design}

Furthermore, the study had a cross-sectional design, meaning it took the form of a measurement at a single point in time, which may limit conclusions regarding the direction of mechanisms. The results from the current investigation should be interpreted with this limitation in mind. In essence, the model of Greenwood \& Hinings concerns processes; we sought to encapsulate this by testing an instrument through a series of interviews. Still, longitudinal research is preferable and is therefore to be encouraged in future research.

To capture entrepreneurial behavior, we used entrepreneurial intent as the intention to make a change. Although this method has certain advantages as it enables a focus on intraorganizational dynamics and motivational needs that are a cause rather than an outcome of entrepreneurial behavior, it brings disadvantages as well as it is uncertain to what extent intent will turn into action. Additional research could use the actual initiatives of physicians as the dependent variable, instead of the proxy of entrepreneurial intent.

\section{The single occupational and national context}

Moving on from method-related issues, the sample of physicians was limited to members of the Dutch Association of Medical Specialists. Although this offered the advantage of obtaining a larger sample, it may also have caused a bias towards non-entrepreneurial physicians as the fact that recent governmental policies were designed in conjunction with the association. 
As this research is executed in a single occupational setting a homogeneous sample of physicians working in hospitals and specialty clinics this may limit generalizability to other occupations and organizations beyond healthcare, since organizations may be quite unique in terms of culture and hierarchal structures (Bryant et al., 1985). It is therefore important to replicate the studies of relationships presented in Chapters 5 and 6 in other occupational settings.

Although the Dutch healthcare system is comparable to many Western systems, it has a social insurance based payment structure in which elements of managed competition were introduced only recently. This may have had an impact on the interest scores in areas that are strongly influenced by the introduction of managed competition, such as salaries, autonomy and entrepreneurial intent. In addition, cross-cultural differences may interfere with the neo-institutional model, for example with respect to interests like autonomy and power (Hofstede, 2001), and research in more collectivist cultures may reveal both different intraorganizational dynamics and different outcomes. A research design comparing different countries may provide additional insights on these matters.

\section{Implications for future research}

The findings and methodological considerations have implications for further research and hospital practice. The recommendations for further research focus on actions needed to improve the cooperation between physicians and managers as well as to improve the entrepreneurial capabilities of specialty groups and hospitals.

\section{Extend the temporal research scope}

It is suggested that future research should monitor the development of entrepreneurial intent using longitudinal studies as it could be valuable to assess what triggers the active intent that results in new entry taking place. In addition, longitudinal research may help reveal the influence of contextual changes on motivational needs and entrepreneurial selfefficacy. Finally, new research could also include other medical professionals, such as nurses, to assess their motivational needs in relation to entrepreneurial intent.

Next, future research could elaborate on the issue of whether this change is in fact transformational, entailing the creation of an entirely new logic, or sedimented, suggesting that elements from another logic, which can be conflicting, are perhaps being added to the present logic (Cooper et al., 1996). A follow-up longitudinal study could focus on this process of transformation and sedimentation and shed more light on the mechanisms involved. 


\section{Focus the research scope by adopting a process perspective}

Although this research provides in-depth knowledge of the factors driving physicians to become entrepreneurs, it still tells us little about the exact sequence of activities in the process resulting in physicians' entrepreneurship. This includes interactions, decision-making processes, and triggers driving physicians and managers to implement entrepreneurial initiatives. Further qualitative research addressing these questions would provide important additional insights into the question as to how and when entrepreneurial behavior takes place in a hospital setting.

\section{Extend the research scope towards other professions and settings}

This research set out to operationalize and test a refined version of the neo-institutional model of Greenwood \& Hinings (1996). The results revealed that the model applies to physicians in hospitals. To establish its wider applicability, further research should be executed among other professions and settings.

From a broader perspective of corporate entrepreneurship, this dissertation shows some interesting research avenues for settings with different, competing logics for example, the energy industry or public transport bodies that have changed from public-sector organizations to market enterprises. Certainly this could be an interesting approach for sectors where new technologies also open up opportunities for developing new types of business (in energy, e.g. green energy technologies). More generally, a shift of logic has to take place in situations where Schumpeterian radical or disruptive innovation is possible in large firms and this may also be a situation where the same dynamics occur.

\section{Extend the research scope to include intrapreneurship as well as extrapreneurship}

The focus in the current study was on extrapreneurship rather than intrapreneurship, as the definition used of entrepreneurship implied the start of a new entry. Future research could determine whether the contextual and intra-organizational dynamics plus personalityrelated factors apply to intrapreneurial activities as well. In doing this, it would advance the state of knowledge considerably on current issues identified in the field of institutional entrepreneurship (Battilana et al., 2009).

\section{Implications for practice}

The implications for hospital management, physicians and policy-makers elaborate on the lessons derived from this dissertation. 


\section{Implications for hospital management}

Interest dissatisfaction among physicians may be reduced by sharing power ...

Based on the literature review, first it was found that the level of physicians' dissatisfaction is dependent on the extent of their subordination to management and the use of structural power to control the clinical practice. Physicians' increased power dependence on hospital managers has heightened both transformative and defensive value commitments among physicians. Reducing perceived power dependence by physicians may help them accept the logic of business-like healthcare. Although this logic is focused on efficiency and process rationalization (Reay \& Hinings, 2009), its acceptance and effectiveness among physicians may depend on the extent to which management is willing to share power.

... or by expressing an interest in the entrepreneurial initiatives of physicians.

Another way of reducing interest dissatisfaction, derived from the literature review, is by explicitly expressing an interest in having physicians engage in entrepreneurial initiatives, thereby granting more autonomy to physicians. Increasing hospital efficacy as perceived by physicians and lowering power dependence may enable nascent entrepreneurial initiatives to be channeled into hospital-based ventures. In fact, management's attitudes to entrepreneurial initiatives by physicians influence how they will be implemented. If a hospital's management explicitly discourages entrepreneurial initiatives, physicians may have no alternative but to execute their entrepreneurial initiative outside the hospital (extrapreneurship), while if management is more facilitating, physicians will prefer to collaborate with the hospital organization (intrapreneurship).

Build confidence by communicating an interest in entrepreneurial initiatives by the hospital ...

Next, based on the large-scale survey, a strong, negative relationship was found between interest dissatisfaction and organizational efficacy, while low levels of organizational efficacy are associated with entrepreneurial intent. In short, a dissatisfied physician with little confidence in the capabilities of hospital management is more likely to leave the hospital organization. Given this relationship, it is important to be aware of the interests of entrepreneurial physicians, and to share and facilitate entrepreneurial opportunities at an individual level, in order to prevent them from leaving the hospital organization. For hospital managers aiming to retain entrepreneurial talent among physicians, it may be helpful to explicitly communicate their own interest in entrepreneurial activities in order to increase their entrepreneurial capabilities as perceived by physicians. This may be especially relevant 
for physicians in general hospitals, large teaching hospitals, and specialty clinics as they exhibit the highest degree of entrepreneurial intent for entrepreneurship outside of the hospital.

... or by sharing information on initiatives aimed at influencing the institutional context.

The large-scale survey results have a number of implications for hospital management with respect to intra-organizational dynamics. First, it was found that institutional turbulence caused by regulatory authorities is associated with higher levels of power dependence, whereas market turbulence shows an inverse relationship. Apparently, physicians feel political instruments are required to respond to institutional turbulence, making them dependent on management. This may well provide hospital management with the opportunity to gain the confidence of physicians by sharing information on initiatives aimed at influencing the institutional context.

In the portfolio planning of specialties, take notice of levels of self-efficacy and motivational needs across specialties...

With respect to self-efficacy and motivational needs, self-efficacy was found to be related to entrepreneurial intent. Management can take advantage of this finding by being aware of the levels of entrepreneurial self-efficacy of the hospital's physicians across the hospital when planning future entrepreneurial initiatives. For intrapreneurial activities as well, it is reasoned that a basic level of self-efficacy is required to develop an intent to participate in these initiatives (Zhao et al., 2005). As entrepreneurial self-efficacy was found to be lowest for physicians working in supportive specialties and for physicians working in academic hospitals or specialist hospitals, offering classes and workshops on entrepreneurship to these groups may enhance their self-efficacy (Chen et al., 1998).

In addition, motivational needs differ across specialty groups; the need for affiliation, for example, was found to be highest for physicians working in medical specialties. Furthermore, the need for autonomy was found to be lowest for physicians working in medical specialties and for physicians working in academic hospitals. As a result, entrepreneurial initiatives developed by hospital management could focus on entire groups rather than on individual physicians.

... and understand the relevance and content of physicians' interests.

As interests are considered extremely powerful in shaping intra-organizational dynamics (Bidwell, 2012; Greenwood \& Hinings, 1996; Kim et al., 2007; Koelewijn et al., 2012), it is important for hospital managers to understand both the nature and structure of physicians' 
interests as well as the value attached to them. In hospital managers' relationship with the medical staff, this understanding may help avoid directing managerial effort at satisfying interests that are not considered a priority by the physicians themselves. Based on the analysis of data derived from our large-scale survey, it was found that work orientation and setting-related interests are most important to physicians working in support specialties and to physicians working in academic hospitals, specialist hospitals, and specialty clinics. For these physicians, having opportunities for varied work, specialization, and research is highly valued. In addition, life-related interests are valued most by surgeons and physicians practicing supportive specialties, and by physicians working in general hospitals and large teaching hospitals. For them, it is important to have the opportunity to earn a good income combined with a good work-life balance. Setting-related interests are valued most by physicians working in supportive specialties and by physicians working in general hospitals, large teaching hospitals, and specialty clinics. These physicians consider having influence on which employees they work with as well as good facilities, autonomy, and a say in hospital policy to be very important.

Diminish potential for interest dissatisfaction among physicians by providing shared incentives...

Based on the interviews with both physicians and managers in hospitals, it was deduced that the need for autonomy as part of the logic of medical professionalism is related to interest dissatisfaction with the perceived facilitation provided by hospital management in striving to satisfy personal interests. Next however, based on the studies conducted in specialty clinics, it was concluded that in these clinics, this interest dissatisfaction is reduced by providing shared incentives. Shared incentives have been shown to positively affect organizational performance and collaboration (Andrews, 2010; Calciolari et al., 2011; Edwards, 2003; Klopper-Kes et al., 2010; Mache et al., 2012; Ommen et al., 2009; Purdy \& Gray, 2009). In our study, these shared incentives were found to constitute cement through which entrepreneurial values are 'glued' onto the logic of medical professionalism. For hospital management as well, providing shared incentives may help to improve collaborative relations.

... and align these incentives based on the individual interest structure.

Given the results of both the interviews and the large-scale survey, it is reasoned that these shared incentives could be aligned with the personal interest structure of physicians. For example, for physicians attaching most value to work-related interests, incentives could involve elements related to work variety, specialization or research, whereas for physicians valuing the setting, it could be effective to offer investments in facilities or a position in the 
governance system in return for meeting certain goals and objectives. Likewise, physicians valuing life-related interests could be rewarded by financial benefits or a working schedule allowing for a better work-life balance.

Improve the mutual understanding between physicians and hospital managers by implementing a process of socialization/sedimentation for (new) physicians and managers.

It was also established that involvement in the startup phase and governance of a specialty clinic consists of a sedimentation process, allowing physicians traditionally embedded in the logic of medical professionalism to adopt elements of the business-like healthcare logic, thereby developing a hybrid logic shared with management. Based on this finding, it is reasoned that for physicians working in hospitals, a similar process of sedimentation may help them become more effective in working in a hospital organization.

In contrast to the traineeships offered by private companies to allow for the fast socialization of new employees, similar programs for new physicians entering a hospital are lacking. Still, given the presence of different and sometimes conflicting logics among functionally differentiated groups in hospitals, the need for such a program in this context is reasoned to be much greater compared to the simpler institutional structure of companies. Recent research on the transition from specialty training to hospital-based physicians indicates that new physicians perceive themselves to be better prepared for medical competencies compared with more generic competencies (Westerman et al., 2013). Therefore, if hospitals and specialty clinics offered a socialization program that included elements like leadership, collaboration with management, lean management, and basic finance, this could improve dialogue and collaboration between the two professional groups (physicians and hospital managers).

Also managers may improve their collaboration with physicians in hospitals by adopting elements of the medical logic for example by paying explicit attention to the leading position of physicians in providing care. In doing this, they too may develop a more hybrid logic.

Allow for continuous involvement of physician-entrepreneurs in strategic planning process.

Finally, it is noteworthy for managers of specialty clinics that this research revealed high levels of entrepreneurial intent among physicians already working in specialty clinics. Apparently, these physicians keep trying to identify new opportunities. Sharing strategic planning activities may help these physicians to stay committed to that clinic's success. 


\section{Implications for physicians}

Improve awareness of the presence of, and embeddedness in, institutional logics.

Based on the interviews, we found that physicians who are embedded in the medical logic and perceive high levels of power dependence and bureaucracy may develop a defensively oriented competitive value commitment towards management. However, physicians embedded in the business logic or hybrid logic report their interest dissatisfaction to be primarily caused by the prima donna behavior of fellow physicians who are unwilling to adapt to hospital policies. Being aware of the logic in which the individual physician is embedded next to his/her fellow physicians may help to increase mutual understanding. In addition, physicians embedded in a hybrid logic may well be able to liaise between groups of physicians as well as between physicians and management. The instrument used in this research may prove to be valuable in assessing the embeddedness of physicians.

For those physicians embedded in a hybrid or businesslike logic, be aware of your potential as a change agent.

For those physicians who are able to span the borders between the logic of medical professionalism and businesslike healthcare, the potential may reach beyond this acceptance of the status quo. In fact, physicians with an embeddedness in a hybrid of business-like logic may serve as change leaders both within and outside their hospital. Examples include Gary Kaplan, CEO of Virginia Mason Medical Center and Loek Winter, founder and CEO of DC Klinieken.

In choosing a hospital to work in as a medical specialist, awareness of the general interest structure and overall motivational needs across hospitals may help identify a good fit.

With respect to physicians' work and life orientations, the type of hospital was found to have a stronger effect than the specialty group. For physicians who have completed their specialty training and are searching for a position in a hospital, awareness of their interest structure as well as of the interest structure held by physicians across different types of hospitals may help them to choose a hospital type with an optimal fit. Likewise, it is important to choose a setting that best fits their motivational needs, allowing them to be more effective (Hinami et al., 2013; Huesch, 2011; Vandenberghe, 1999).

Discuss drivers of entrepreneurial intent with hospital management.

Evidence was found that the hospital management's response to the entrepreneurial 
ambitions of physicians altered during the course of this research (Koelewijn \& Van Harten, 2012). Whereas initially these ambitions were perceived by management as dangerous for the position of the hospital, nowadays they are more willing to discuss the drivers of entrepreneurial intent and the possibilities for meeting this need within the hospital organization itself. Discussing the drivers of entrepreneurial intent may shed new light on entrepreneurial possibilities within the current hospital organization.

Include logics, interests and motivational needs as design criteria for the future position of hospital-based physicians

As part of the current discussion concerning the position of physicians from 2015 onward, many point at the advantages associated to an obligatory employment relationship for healthcare costs and the governance of hospitals (NRC, 2013; Dijl, 2013). Currently however, $80 \%$ of the physicians included in this research (Orde van Medisch Specialisten, 2012), who work in partnerships indicate not to prefer this type of work relation with the hospital. Based on the other findings, it is suggested that logics, interests and motivational needs are taken into regard when designing the future position of hospital-based physicians. This may help preventing friction and a potential loss of experienced and entrepreneurial physicians for hospitals. Redesign and implementation of new governance models for hospitals however, will require active participation and new management-related competencies of physicians.

In turning into an entrepreneur, dependencies alter and this may require additional competencies or support.

As this research indicates, the factors driving physicians to engage in entrepreneurial activities are complex and intertwined. For physicians embedded in the traditional logic of medical professionalism, whose entrepreneurial intent is triggered by high levels of interest dissatisfaction and need for autonomy, it is important to be aware that turning into an entrepreneur may imply new, though different, types of dependence. An entrepreneur may experience dependence on other powerful actors outside of the specialty clinic, such as health insurers and banks that are, like hospital management, embedded in the logic of businesslike healthcare. To be successful as an entrepreneur, it may be worth finding support or invest in competencies to improve skills like business planning, finance, and negotiations, in order to deal effectively with these actors. This may also be the case for physicians embedded in the logic of business-like healthcare or a hybrid logic as medical schools have been found to prepare physicians poorly for these activities (Westerman et al., 2013). 


\section{Implications for policy-makers}

Involve physicians and representatives of the medical logic in policy-making.

At the national level, budget constraints resulting from the enduring economic downturn in Western countries have provided an impetus for new and additional healthcare reforms relying heavily on the logic of business-like healthcare. However, the involvement of physicians, decentralized decision-making, and common ground with stakeholders embedded in - or representatives of the medical logic are needed for the reforms to be effective, simultaneously allowing for a hybrid logic to develop containing elements of both the medical logic and the business-like logic.

In formulating policies on entrepreneurship, be aware that financial rewards may not be the only driver for physicians' entrepreneurship.

The neo-institutional model, as well as the motivational needs and interests applied in this research, are applicable across countries and healthcare systems. For the US, the UK, and the Netherlands, there is an increasing demand for healthcare to be 'doing more with less'. Enabling healthcare entrepreneurship based on efficient, low-cost, high-quality care governed by a national health budget may attract physician-entrepreneurs who are motivated by non-financial interests but still want to improve the healthcare system. This research provides evidence that interests such as the desire to help patients, do varied work, work with the best facilities, and have autonomy are valued more by physicians on average than earning a good salary. Alongside intra-organizational dynamics and motivational needs, this finding indicates that financial rewards may not be the only driver for physicians' entrepreneurship.

Constraints on physicians' entrepreneurship in the Dutch healthcare system are not in the public interest and will backfire. Instead, a budget for innovative entrepreneurial initiatives is advocated.

As described in the introduction of this dissertation, physicians' entrepreneurship was regarded during the 1990s as a logical and integral part of managed competition but in retrospect it can be concluded that there was too big an incentive to increase volumes. As a result, focus has shifted to the strict curtailment of budgets. In doing this, new entrepreneurial initiatives are being given little to no space for growth by most insurers (NZA, 2014), so that they are smothered and potentially failing to survive. 
Providing space for those entrepreneurs offering the best value for money may help to further improve the healthcare system.

The current system of financing hospitals and specialty clinics in the Netherlands is geared to preventing budget overruns, thereby signaling discouragement to potential new entrants. However, in order to enhance value-based healthcare, new innovative entrants providing good care at relatively low costs should be encouraged instead of discouraged. Therefore it is proposed that a certain percentage of the budgetary framework should be earmarked for new and innovative entrants and low-cost/high-quality providers experiencing rapid growth, providing them with the opportunity to establish further evidence of both their medical effectiveness and their cost effectiveness. Providing space for those entrepreneurs offering the best value for money may help to further improve the healthcare system in the Netherlands and other Western countries.

Adaptations in the curriculum for medical specialists are necessary to resolve tensions with hospital management.

Furthermore, the current educational system for medical specialists is highly regulated. Earlier research indicates that as this curriculum is technically oriented, it does not prepare physicians for more generic and organizational tasks (Westerman et al., 2013). Increasingly however, these activities are undertaken as part of a team and organization, demanding the skills and understanding to deal with organizational members embedded in what can be a different and conflicting logic. Stated differently: an embeddedness in a more hybrid logic is required. The necessary socialization or sedimentation process could be achieved by project-based training courses, including in-depth experience in working on managerial issues alongside hospital managers. If training courses like these are accredited, they may gain legitimacy among physicians.

Logics and intra-organizational dynamics should be taken into consideration when developing new forms of cooperation between physicians and hospitals.

Currently, the relationship between physicians and hospitals is being redefined through the implementation of integral tariffs for hospitals to replace the current system of tariffs per treatment, consisting of a costs component and fee component. In addition, the fiscal ruling with regard to the entrepreneurial status of physicians will end by the end of 2014 . As a result, hospitals and their medical staff are considering new forms of cooperation. One option that is frequently mentioned in this respect concerns the abolition of the right to freedom of establishment (vrije vestiging) of physicians in hospitals and the associated payment based on a fee-for-a-service (Dijl van et al., 2013). This abolition, however, will 
not resolve the problems in the complex relationship between physicians and hospital management as both groups remain embedded in their own, sometimes conflicting, logics. As the abolition will have the biggest impact on physicians working in general hospitals and large teaching hospitals, it is important to note that physicians in these hospitals are found to have a significantly higher need for autonomy than their counterparts in university hospitals and specialist hospitals where physicians have an employment contract with the hospital. This research indicates that $80 \%$ of the physicians currently working on a fee-fora-service basis reject the idea of an employment relationship with the hospital (Orde van Medisch Specialisten, 2012). Instead of providing a solution to the current complexity, this research gives evidence that abolition of the right to freedom of establishment will instead cause physicians to "flee" the hospital and render their services from independent entities. Rather than reducing complexity, this will lead to the exact opposite. Whatever model is chosen, intra-organizational dynamics and their underlying logics will have to be taken into consideration to provide for the best model for every individual hospital.

\section{Final remark}

It is safe to conclude that the concept of entrepreneurship is troublesome for policy-makers aiming to curtail the increase in healthcare expenditure. However, as part of managed competition it is important to leave space for entrepreneurial physicians aiming to change healthcare by providing innovative concepts and treatments. As the market regulator, the Dutch Healthcare Authority (NZA) is responsible for safeguarding access and competition. It could provide suggestions with respect to the purchasing policies applied by health insurance companies, thereby stimulating the adoption of an entrepreneurship-and-innovation margin. Even without the intervention of the NZA, health insurers could implement the earmarking of a certain percentage of the overall budget for innovative and fast-growing entrepreneurial initiatives. These initiatives could be selected based on transparent and objective criteria such as the degree of innovativeness, projected cost effectiveness and contribution to patients' wellbeing, and applied in a non-discriminatory manner. Transparent communication about these criteria may help steer physicians' entrepreneurial intent towards areas of importance, thereby providing the space for innovative entrepreneurial initiatives that is necessary to make sustainable improvements to both the healthcare sector and the quality of patient care. 


\section{References}

Ackroyd, S., Hughes, J.A., \& Soothill, K. (1989). Public-Sector Services and Their Management. Journal of Management Studies, 26, 603-619.

Andrews, R. (2010). Organizational social capital, structure and performance. Human Relations, 63, 583-608.

Bidwell, M.J. (2012). Politics and Firm Boundaries: How Organizational Structure, Group Interests, and Resources Affect Outsourcing. Organization Science, 23, 1622-1642.

Bryant, I., Dunkerley, D., \& Kelland, G. (1985). One of the boys? Policing, 1, 236-244.

Calciolari, S., Cantu, E., \& Fattore, G. (2011). Performance management and goal ambiguity: Managerial implications in a single payer system. Health Care Management Review, 36, 164-174.

Chen, C.C., Greene, P.G., \& Crick, A. (1998). Does entrepreneurial self-efficacy distinguish entrepreneurs from managers? Journal of Business Venturing, 13, 295-316.

Cooper, D.J., Hinings, B., Greenwood, R., \& Brown, J.L. (1996). Sedimentation and transformation in organizational change: The case of Canadian law firms. Organization Studies, 17, 623-647.

Edwards, N. (2003). Doctors and managers: poor relationships may be damaging patients - what can be done? Quality and Safety in Health Care, 12, i21-i24.

Elsen van den, W. (2013). Zelfstandige Klinieken luiden Noodklok. Zorgvisie.

Enthoven, A.C. (1993). The History and Principles of Managed Competition. Health Affairs, 12, 24-48.

Greenwood, R., \& Hinings, C.R. (1996). Understanding radical organizational change: Bringing together the old and the new institutionalism. Academy of Management Review, 21, 1022-1054.

Heerwegh, D. (2005). Effects of personal salutations in e-mail invitations to participate in a web survey. Public Opinion Quarterly, 69, 588-598.

Hinami, K., Whelan, C.T., Miller, J.A., Wolosin, R.J., \& Wetterneck, T.B. (2013). Person-job fit: An exploratory cross-sectional analysis of hospitalists. Journal of Hospital Medicine, 8, 96-101.

Hofstede, G.H. (2001). Culture's consequences: comparing values, behaviors, institutions, and organizations across nations. Thousand Oaks, California: Sage Publications.

Huesch, M.D. (2011). Provider-Hospital "Fit" and Patient Outcomes: Evidence from Massachusetts Cardiac Surgeons, 2002-2004. Health Services Research, 46, 1-26.

Kim, T.Y., Shin, D., Oh, H., \& Jeong, Y.C. (2007). Inside the iron cage: Organizational political dynamics and institutional changes in presidential selection systems in Korean universities, 1985-2002. Administrative Science Quarterly, 52, 286-323.

Klopper-Kes, A.H.J., Meerdink, N., Wilderom, C.P.M., \& Van Harten, W.H. (2010). Effective cooperation influencing performance: a study in Dutch hospitals. International Journal for Quality in Health Care, 23, 94-99.

Klopper-Kes, A.H.J., Meerdink, N., Wilderom, C.P.M., \& Van Harten, W.H. (2011). Effective cooperation influencing performance: a study in Dutch hospitals. International Journal for Quality in Health Care, 23, 94-99.

Koelewijn, W.T., Ehrenhard, M.L., Groen, A.J., \& van Harten, W.H. (2012). Intra-organizational dynamics as drivers of entrepreneurship among physicians and managers in hospitals of western countries. Social Science \& Medicine, 75, 795-800.

Mache, S., Vitzthum, K., Klapp, B.F., \& Groneberg, D.A. (2012). Improving quality of medical treatment and care: are surgeons' working conditions and job satisfaction associated to patient satisfaction? Langenbecks Archives of Surgery, 397, 973-982.

Marquis, C., \& Lounsbury, M. (2007). Vive la résistance: competing logics and the consolidation of US community banking. Academy of Management Journal, 50, 799-820. 
Mintzberg, H. (1983). Structure in fives: Prentice-Hall.

Mous, K. (2013). Beleid CZ in strijd met Zorgverzekeringswet. Het Financieele Dagblad Amsterdam.

Olsthoorn, S. (2013). Klein en niet vernieuwend? Dan geen contract meer met Achmea. Het Financieele Dagblad. Amsterdam.

Ommen, O., Driller, E., Koehler, T., Kowalski, C., Ernstmann, N., Neumann, M., et al. (2009). The Relationship between Social Capital in Hospitals and Physician Job Satisfaction. BMC Health Services Research, 9.

Podsakoff, P.M., MacKenzie, S.B., Lee, J.Y., \& Podsakoff, N.P. (2003). Common method biases in behavioral research: A critical review of the literature and recommended remedies. Journal of Applied Psychology, 88, 879-903.

Purdy, J.M., \& Gray, B. (2009). Conflicting logics, mechanisms of diffusion, and multilevel dynamics in emerging institutional fields. Academy of Management Journal, 52, 355-380.

Reay, T., \& Hinings, C.R. (2009). Managing the Rivalry of Competing Institutional Logics. Organization Studies, 30, 629-652.

Ritsilä, J., \& Tervo, H. (2002). Effects of unemployment on new firm formation: micro-level panel data evidence from Finland. Small Business Economics, 19, 31-40.

Stuart, T.E., \& Sorenson, O. (2003). Liquidity events and the geographic distribution of entrepreneurial activity. Administrative Science Quarterly, 175-201.

Tracey, P., Phillips, N., \& Jarvis, O. (2011). Bridging Institutional Entrepreneurship and the Creation of New Organizational Forms: A Multilevel Model. Organization Science, 22, 60-80.

Vandenberghe, C. (1999). Organizational culture, person-culture fit, and turnover: a replication in the health care industry. Journal of Organizational Behavior, 20, 175-184.

Zhao, H., Seibert, S.E., \& Hills, G.E. (2005). The mediating role of self-efficacy in the development of entrepreneurial intentions. Journal of Applied Psychology, 90, 1265-1272. 



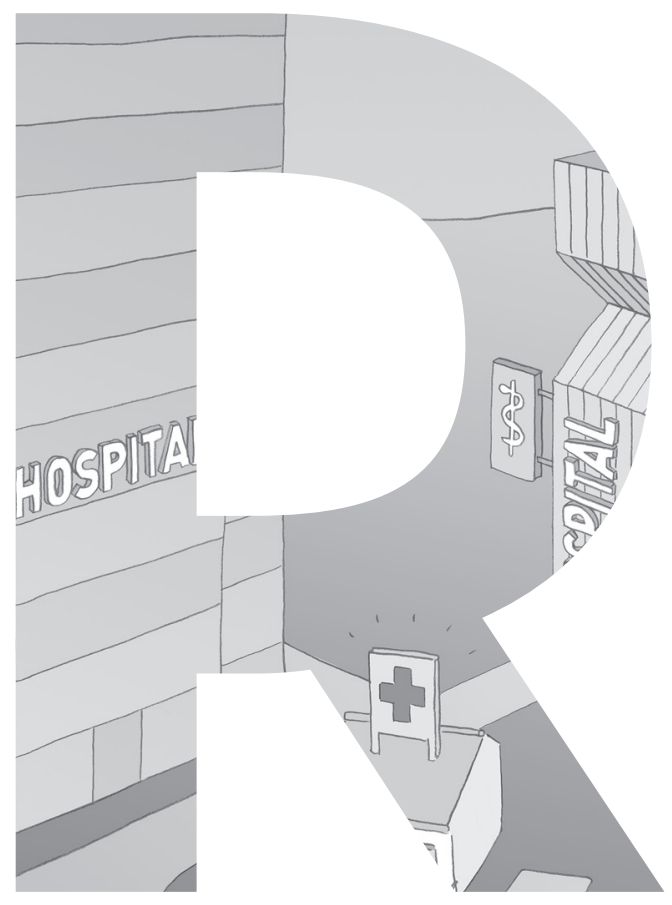

\section{LIST OF RESPONDENTS}




\section{List of respondents}

This list contains the names and positions of the respondents who were interviewed as part of this research. In the case of some of the respondents, multiple interviews were conducted over time. In addition, a few respondents are not included as they indicated the desire to remain anonymous. The list shows the positions of the respondents at the time of the interviews.

\section{Respondents in hospitals}

Dhr. drs. J.G.M Hendriks, Bestuurder, Stichting Bronovo-Nebo

Mevr. drs. C.J.W. Hirschler-Schulte, Voorzitter RvB, Deventer Ziekenhuis

Dhr. W. Hondeveld, Zorgmanager, Deventer Ziekenhuis

Dhr. dr. R.H. Houwing, Dermatoloog, Deventer Ziekenhuis

Dhr. drs. D.R. Siewertsz van Reesema, Reumatoloog, Deventer Ziekenhuis

Dhr. dr. Y.S. Tuininga, Cardioloog, Deventer Ziekenhuis

Dhr. dr. G.J. Clevers, Chirurg, Diakonessenhuis

Dhr. dr. R.A. Faaij, Geriater, Diakonessenhuis

Dhr. drs. R. Florijn, Bestuurder, Diakonessenhuis

Dhr. drs. L. Van Bogerijen, Cardioloog, Diakonessenhuis

Mevr. R. van der Heeft, Zorgmanager, Diakonessenhuis

Dhr. Dhr. W.J.G. Blaauw, Bestuurder, Medisch Centrum Leeuwarden

Mevr. drs. D.M.M. Edens, Oogarts, Medisch Centrum Leeuwarden

Dhr. drs. M. Schram, Manager, Medisch Centrum Leeuwarden

Dhr. drs. J. Uitentuis, Kinderarts, Medisch Centrum Leeuwarden

Dhr. drs. D. Wilbers, Gynaecoloog, Medisch Centrum Leeuwarden

Dhr. drs. E.E. Blauwwiekel, Internist, Nij Smellinghe

Dhr. F.P. Brouwers MBA, Facilitair Manager, Nij Smellinghe

Dhr. dr. R.J. Damstra, Dermatoloog, Nij Smellinghe

Dhr. C. Meijer, Bestuurder, Nij Smellinghe

Dhr. drs. E.A. Timmerman, Oogarts, Nij Smellinghe

Dhr. drs. J. van Arnhem, Manager, Nij Smellinghe

Dhr. drs. A.J. Verhoeff, Chirurg, Nij Smellinghe

Dhr. drs. F.D. Eefting, Cardioloog, Sint Antonius Ziekenhuis

Dhr. drs. H. de Jong, Bestuurder, Sint Jans Gasthuis

Dhr. drs. G.P.J. Kamps, KNO, Sint Jans Gasthuis

Dhr. G. Philipsen MHA, Manager, Sint Jans Gasthuis

Dhr. dr. R. Braakman, Oogarts, Spaarne Ziekenhuis

Dhr. drs. D. Jairath, Plastisch Chirurg, Spaarne Ziekenhuis

Dhr. dr. H.C. Knipscheer, Gynaecoloog, Spaarne Ziekenhuis

Dhr. dr. W.H. van Houtum, Internist, Spaarne Ziekenhuis

Mevr. drs. Y. Wilders, Bestuurder, Spaarne Ziekenhuis

Mevr. drs. L. Van Reeuwijk, Secretaris RvB, St. Antonius Ziekenhuis

Dhr. drs. J. Dekker, Manager, St. Antonius Ziekenhuis - Cardicare

Dhr. F. Ruigrok, Manager, Transpaarne

Mevr. dr. A.H.J. Klopper-Kes, Directeur, Zorggroep Twente 


\section{Respondents in specialty clinics (ZBC's)}

Dhr. W. Malenstein, Directievoorzitter, Bergman Clinics

Mevr. drs. A. Posthouwer, Manager, Bergman Clinics

Dhr. drs. M.J.P. van der List, Orthopeed, Bergman Clinics

Dhr. dr. R.H.G.P. van Erve, Orthopeed, Beter Lopen

Dhr. prof. dr. drs. L.H.L. Winter, Ondernemer, DC Groep

Dhr. dr. W.B. Vreede, Kinderarts, De Kinderkliniek

Dhr. dr. D.J. der Kinderen, Dermatoloog, Dermalink

Dhr. drs. M. Hoedt, vaatchirurg/ Oprichter, Mauritsklinieken

Dhr. Dhr. R. Rempe, Algemeen directeur, Mauritsklinieken

Dhr. drs. H. Niendieker, Directeur/ Oprichter, Mohs Klinieken

Mevr. dr. A. van Rengen, Dermatoloog/ Oprichter, Mohs Klinieken

Dhr. ir. J. Oudenhoven, Algemeen directeur/ Oprichter, Nedspine

Dhr. drs. H. van de Weijer, Orthopeed/ Oprichter, Nedspine

Mevr. A. de Bruijn, Manager, Oogziekenhuis Zonnestraal

Dhr. P. de Koning, Algemeen directeur/ Oprichter, Oogziekenhuis Zonnestraal

Dhr. dr. A.H.F. Rulo, Oogarts, Oogziekenhuis Zonnestraal

Dhr. dr. P.G. Verduijn, KNO, Reinaert Kliniek

Dhr. drs. M. Schepers, Orthomanueel geneeskundige/ Oprichter, Rugpoli

Mevr. I. Wiegerink, Manager, Rugpoli

Dhr. J. de Bruin , Algemeen directeur, Viasana

Dhr. dr. T. Moojen, Medisch Directeur en handchirurg, Xpert Clinic

\section{Respondents in a solo practice}

Mevr. F.M.H. Scheps-Pasman, Oogarts/ Oprichter, Oogartsenpraktijk Scheps-Pasman

\section{Respondents in miscellaneous organizations}

Mevr. M. Baatz, Zorginkoper, Achmea Zorg

Dhr. G. Jager, Adviseur, Aduard

Dhr. J. Dijkers, Manager, Agis Participaties \& Deelnemingen

Dhr. M.A. Imkamp, Adviseur, Imkamp M+A

Mevr. drs. M. Oplaat, Interim manager

Dhr. G. Rietveld, Adviseur Zorg, Menzis

Dhr. dr. R. Baumgarten, Bestuurder, Orde van medisch specialisten

Dhr. drs. J. de Jonge, Voorzitter kamer vrij beroep, Orde van medisch specialisten

Dhr. drs. E.T. Ziere, Secretaris kamer vrij beroep, Orde van medisch specialisten

Dhr. drs. J. Vos Van Marken, directeur Unovate, UMC Utrecht

Dhr. dr. Dhr. W.I. Koelewijn, Van der Feltz advocaten

Dhr. drs. J.H.A. Hemmer, Adviseur, VVAA Business Care 



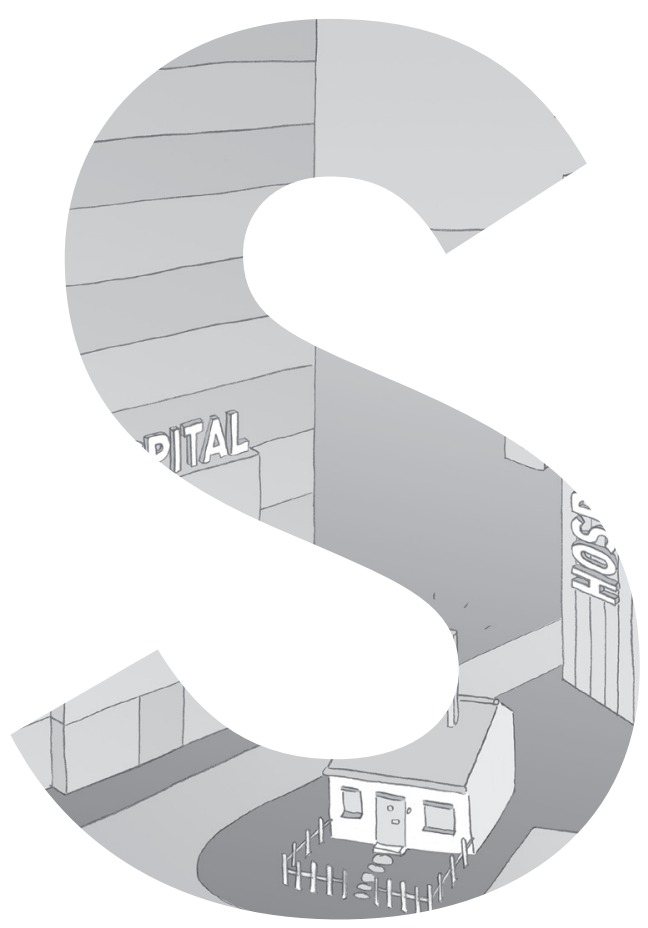

SUMMARY 


\section{Introduction}

During the 1990s, physicians' entrepreneurship grew into a powerful force shaping healthcare in many Western countries (Saltman et al., 2002). Deregulations implemented during this period were part of a third consecutive wave of healthcare reforms starting after the Second World War (Cutler, 2002). The first wave started after 1945 and continued until the 1980s; its aim was to ensure access to medical care. Wide accessibility and scientific and technological developments led to rising costs and to limit these costs, the second wave (from the 1980s until the early 1990s) introduced widespread budget and control systems across different nations. To tackle the problem of growing inefficiencies resulting from these budget systems, the third wave introduced incentives and competition among healthcare providers from the early 1990s onward. This resulted in a surge of medical entrepreneurial activities (Cutler, 2002; Ikkersheim \& Koolman, 2013; Saltman \& Figueras, 1997).

Despite the positive perception of physicians' entrepreneurship as a part of managed competition, it still remained a relatively rare phenomenon as the vast majority of physicians continued to work in hospitals, leaving the start of specialty clinics to the 'entrepreneurial few'. At times, the entrepreneurial ambitions of these physicians resulted in fierce conflicts with hospital management who felt surprised by their aspirations (Hopstaken, 2008; Kiers, 2008). This triggered the questions answered in this dissertation: What drives physicians' entrepreneurship and how can latent entrepreneurship in hospitals be identified and developed?

In explaining the causes for developing entrepreneurial intent, this study focusses on two perspectives influencing a physician's decision to become an entrepreneur, namely (1) contextual factors, both in the field and at the intra-organizational level, and (2) individual factors, constituted by motivational needs and self-efficacy. The most important findings per chapter are summarized below.

\section{Intra-organizational dynamics as drivers of entrepreneurship among physicians and managers in hospitals of western countries}

The literature review described in this chapter was designed using the neo-institutional framework of Greenwood and Hinings (1996). The analysis focuses on dynamics in terms of power dependencies, interest dissatisfaction, and value commitments. The results revealed that physicians' dependence on hospital management has increased along with healthcare reforms and the resulting emphasis on business logics. This has prompted two types of responses by physicians. First, physicians can be pushed to adopt an entrepreneurial attitude as part of a defensive value commitment toward the business-like healthcare logic, to defend 
their traditionally dominant position and professional autonomy. In contrast, physicians holding a transformative attitude toward traditional medical professionalism seem more prone to adopt the entrepreneurial elements of business-like healthcare, encouraged by the prospect of increased autonomy and income. The focus on the competitive stance towards either logic determines whether entrepreneurship is necessity-based or opportunity-driven.

\section{$3 \quad$ Physicians' entrepreneurship explained: intra-organizational dynamics in Dutch hospitals and specialty clinics}

The qualitative study described in this paper has a two-step design. First, fifteen physicians and eight managers in four hospitals were interviewed to ground the research model on the influence of intra-organizational dynamics on physicians' entrepreneurship. In the second step, twelve physicians and seven managers in twelve specialty clinics were interviewed to establish the nature of the change brought about by starting a specialty clinic.

Based on the results of step 1, physicians were found to be influenced by intra-organizational dynamics, including power dependence, interest dissatisfaction, and value commitments, between physicians and managers as well as among physicians' groups. The precise motivation for starting a new clinic can vary depending on the medical or business logic in which the entrepreneurs are embedded. Based on the results of step 2, the entrepreneurial process of starting a specialty clinic can be described as a process of sedimented change in which elements of the business logic are added to the existing logic of medical professionalism.

These findings have implications for policy at both the national level and the hospital level, as shared ownership and aligned incentives may provide the additional cement in which the developing entrepreneurial values are 'glued' to the central medical logic.

\section{$4 \quad$ Exploring the personal interests of physicians in hospitals and specialty clinics}

Physicians' interests strongly influence intra-organizational dynamics in hospitals (Greenwood \& Hinings, 1996; Kim et al., 2007). However, little is known about the actual content and structure of these interests of hospital-based physicians. The objective of this study was to both identify and build a structured model of physicians' interests. A questionnaire containing ten interests was developed based on the literature and 27 semistructured interviews with physicians. Next, 1,475 physicians in the Netherlands filled out this questionnaire in an online survey. 
Analyses of the data revealed a distinction between the primary interest of 'helping patients as well as possible' and nine secondary interests. Factor analysis identified the main secondary interest dimensions as work-related, setting-related, and life-related.

The value attached to the various interests differs between specialties and types of hospitals. The influence of hospital type on the value attached to interests is stronger than the influence of specialty group on the value attached to interests. Insight into the relative importance of different interests may help policy-makers make decisions that foster shared interests.

\section{$5 \quad$ Bridging and testing neo-institutional theory and entrepreneurship theory in a hospital setting}

Combining institutional theory and entrepreneurship theory has long been identified as having significant though still unrealized potential in explaining differences in nascent entrepreneurship (Phillips \& Tracey, 2007). This research seeks to realize this potential.

For our study of nascent entrepreneurship among physicians in a hospital setting, we refined the neo-institutional model proposed by Greenwood and Hinings (1996) and included entrepreneurial intent as an outcome measure. The resulting model was operationalized and tested. Using data from a large-scale survey among hospital-based physicians in the Netherlands $(n=1,430)$, we found support for our hypothesis linking intra-organizational dynamics - including power dependence, interest dissatisfaction, and embeddedness in the logic of medical professionalism - to entrepreneurial intent among physicians.

Furthermore, self-efficacy was found to positively influence nascent entrepreneurship among individual physicians while organizational efficacy had a negative effect. In addition, evidence was found for the inter-relatedness of market turbulence and institutional turbulence, which had a negative and a positive influence respectively on the perceived power dependence of physicians on hospital management. Finally, we contribute to theory by providing a forward-looking institutional model of entrepreneurial intent, validated in a healthcare setting.

\section{$6 \quad$ Motivational needs and self-efficacy as predictors of the entrepreneurial intent of hospital-based physicians}

In this chapter, the influence of physicians' motivational needs and entrepreneurial selfefficacy on their intention to start a specialty clinic is examined. 
Using data from a large-scale survey among hospital-based physicians in the Netherlands $(n=1,430)$, descriptive statistics and factor analysis were performed to examine physicians' motivational needs, entrepreneurial self-efficacy, and entrepreneurial intent across hospital types and specialty groups. In addition, structural equation modeling was used to analyze the relationship between these constructs.

The need for autonomy and entrepreneurial self-efficacy positively influence entrepreneurial intent, while the need for affiliation negatively influences entrepreneurial intent. The influence of the need for achievement and need for dominance on entrepreneurial intent is positive though indirect. In addition, the need for autonomy and entrepreneurial selfefficacy were found to be significantly higher in specialty clinics compared to large teaching hospitals and academic hospitals $(p<0.01)$. Entrepreneurial intent was found to be higher for physicians in surgical specialties compared to physicians in medical specialties $(p<0.01)$. Based on this, it was concluded that motivational needs, entrepreneurial self-efficacy, and entrepreneurial intent are not homogenous across hospital types and specialty groups.

\section{$7 \quad$ Overall conclusion and implications}

This dissertation examined the factors driving physicians' entrepreneurship. In particular, it addressed drivers related to:

- Contextual factors, both at the field level and the intra-organizational level

- Individual factors, constituted by motivational needs and self-efficacy

The presence of the business-like healthcare logic and the logic of medical professionalism across professionally differentiated groups gives rise to unique intra-organizational dynamics. These dynamics are also based on personal primary and secondary interests as these interests shape perceived power dependence on hospital management as well as the resulting interest satisfaction or dissatisfaction. High levels of interest dissatisfaction may deepen the embeddedness of physicians in the logic of medical professionalism. If this embeddedness coincides with a high level of entrepreneurial self-efficacy, this may lead to physicians' entrepreneurship.

In addition, individual factors were also found to influence physicians' entrepreneurship, as the need for autonomy and self-efficacy were positively related to entrepreneurial intent, in contrast to the need for affiliation, which was negatively related to entrepreneurial intent. 


\section{Implications for practice}

\section{For management}

Diminish potential for interest dissatisfaction among physicians by providing shared incentives...

Based on the studies conducted in specialty clinics, it was concluded that in these clinics, this interest dissatisfaction is reduced by providing shared incentives. Shared incentives have been shown to positively affect organizational performance and collaboration (Andrews, 2010; Calciolari et al., 2011; Edwards, 2003; Klopper-Kes et al., 2010; Mache et al., 2012; Ommen et al., 2009; Purdy \& Gray, 2009). In our study, these shared incentives were found to constitute cement through which entrepreneurial values are 'glued' onto the logic of medical professionalism. For hospital management as well, providing shared incentives may help to improve collaborative relations.

... and align these incentives based on the individual interest structure.

Given the results of both the interviews and the large-scale survey, it is reasoned that these shared incentives could be aligned with the personal interest structure of physicians. For example, for physicians attaching most value to work-related interests, incentives could involve elements related to work variety, specialization or research, whereas for physicians valuing the setting, it could be effective to offer investments in facilities or a position in the governance system in return for meeting certain goals and objectives.

Improve the mutual understanding between physicians and hospital managers by implementing a process of socialization/sedimentation for (new) physicians and managers.

It was also established that involvement in the startup phase and governance of a specialty clinic consists of a sedimentation process, allowing physicians traditionally embedded in the logic of medical professionalism to adopt elements of the business-like healthcare logic, thereby developing a hybrid logic shared with management. Based on this finding, it is reasoned that for physicians working in hospitals, a similar process of sedimentation may help them become more effective in working in a hospital organization.

Recent research on the transition from specialty training to hospital-based physicians indicates that new physicians perceive themselves to be better prepared for medical competencies compared with more generic competencies (Westerman et al., 2013). Therefore, if hospitals and specialty clinics offered a socialization program that included elements like leadership, collaboration with management, lean management, and basic finance, this could improve dialogue and collaboration between the two professional groups 
(physicians and hospital managers).

Also managers may improve their collaboration with physicians in hospitals by adopting elements of the medical logic for example by paying explicit attention to the leading position of physicians in providing care. In doing this, they too may develop a more hybrid logic.

\section{Implications for physicians}

Improve awareness of the presence of, and embeddedness in, institutional logics.

Being aware of the logic in which the individual physician is embedded next to his/her fellow physicians may help to increase mutual understanding. In addition, physicians embedded in a hybrid logic may well be able to liaise between groups of physicians as well as between physicians and management. The instrument used in this research may prove to be valuable in assessing the embeddedness of physicians.

For those physicians embedded in a hybrid or businesslike logic, be aware of your potential as a change agent.

For those physicians who are able to span the borders between the logic of medical professionalism and businesslike healthcare, the potential may reach beyond this acceptance of the status quo. In fact, physicians with an embeddedness in a hybrid of business-like logic may serve as change leaders both within and outside their hospital. Examples include Gary Kaplan, CEO of Virginia Mason Medical Center and Loek Winter, founder and CEO of DC Klinieken.

Include logics, interests and motivational needs as design criteria for the future position of hospital-based physicians

As part of the current discussion concerning the position of physicians from 2015 onward, many point at the advantages associated to an obligatory employment relationship for healthcare costs and the governance of hospitals (Dijl van et al., 2013; NRC, 2013). Currently however, $80 \%$ of the physicians included in this research (Orde van Medisch Specialisten, 2012), who work in partnerships indicate not to prefer this type of work relation with the hospital. Based on the other findings, it is suggested that logics, interests and motivational needs are taken into regard when designing the future position of hospital-based physicians. This may help preventing friction and a potential loss of experienced and entrepreneurial physicians for hospitals. 
In turning into an entrepreneur, dependencies alter and this may require additional competencies or support.

As this research indicates, the factors driving physicians to engage in entrepreneurial activities are complex and intertwined. For physicians embedded in the traditional logic of medical professionalism, whose entrepreneurial intent is triggered by high levels of interest dissatisfaction and need for autonomy, it is important to be aware that turning into an entrepreneur may imply new, though different, types of dependence. An entrepreneur may experience dependence on other powerful actors outside of the specialty clinic, such as health insurers and banks that are, like hospital management, embedded in the logic of businesslike healthcare. To be successful as an entrepreneur, it may be worth finding support or invest in competencies to improve skills like business planning, finance, and negotiations, in order to deal effectively with these actors. This may also be the case for physicians embedded in the logic of business-like healthcare or a hybrid logic as medical schools have been found to prepare physicians poorly for these activities (Westerman et al., 2013).

\section{Implication for policymakers and health insurers}

Providing space for those entrepreneurs offering the best value for money may help to further improve the healthcare system.

It is safe to conclude that the concept of entrepreneurship is troublesome for policy-makers aiming to curtail the increase in healthcare expenditure. However, as part of managed competition it is important to leave space for entrepreneurial physicians aiming to change healthcare by providing innovative concepts and treatments. As the market regulator, the Dutch Healthcare Authority (NZA) is responsible for safeguarding access and competition. It could provide suggestions with respect to the purchasing policies applied by health insurance companies, thereby stimulating the adoption of an entrepreneurship-and-innovation margin. Even without the intervention of the NZA, health insurers could implement the earmarking of a certain percentage of the overall budget for innovative and fast-growing entrepreneurial initiatives. These initiatives could be selected based on transparent and objective criteria such as the degree of innovativeness, projected cost effectiveness and contribution to patients' wellbeing, and applied in a non-discriminatory manner. Transparent communication about these criteria may help steer physicians' entrepreneurial intent towards areas of importance, thereby providing the space for innovative entrepreneurial initiatives that is necessary to make sustainable improvements to both the healthcare sector and the quality of patient care. 


\section{References}

Andrews, R. (2010). Organizational social capital, structure and performance. Human Relations, 63, 583-608.

Calciolari, S., Cantu, E., \& Fattore, G. (2011). Performance management and goal ambiguity: Managerial implications in a single payer system. Health Care Management Review, 36, 164-174.

Chen, C.C., Greene, P.G., \& Crick, A. (1998). Does entrepreneurial self-efficacy distinguish entrepreneurs from managers? Journal of Business Venturing, 13, 295-316.

Dijl van, M., Schraverus, J., Linders, H., Bochove, K., Moors, M., \& Crijns, R. (2013). Onderzoek naar besturingsmodellen voor een duurzame relatie tussen ziekenhuis en specialist. Utrecht: PwC in opdracht van de NVZ.

Edwards, N. (2003). Doctors and managers: poor relationships may be damaging patients-what can be done? Quality and Safety in Health Care, 12, i21-i24.

Greenwood, R., \& Hinings, C.R. (1996). Understanding radical organizational change: Bringing together the old and the new institutionalism. Academy of Mangement Review, 21, 1022-1054.

Kim, T.Y., Shin, D., Oh, H., \& Jeong, Y.C. (2007). Inside the iron cage: Organizational political dynamics and institutional changes in presidential selection systems in Korean universities, 1985-2002. Administrative Science Quarterly, 52, 286-323.

Klopper-Kes, A.H.J., Meerdink, N., Wilderom, C.P.M., \& Van Harten, W.H. (2010). Effective cooperation influencing performance: a study in Dutch hospitals. International Journal for Quality in Health Care, 23, 94-99.

Mache, S., Vitzthum, K., Klapp, B.F., \& Groneberg, D.A. (2012). Improving quality of medical treatment and care: are surgeons' working conditions and job satisfaction associated to patient satisfaction? Langenbecks Archives of Surgery, 397, 973-982.

NRC. (2013). Goedkopere zorg hoeft niet ingewikkeld te zijn.

Ommen, O., Driller, E., Koehler, T., Kowalski, C., Ernstmann, N., Neumann, M., et al. (2009). The Relationship between Social Capital in Hospitals and Physician Job Satisfaction. BMC Health Services Research, 9.

Orde van Medisch Specialisten. (2012). Discussienota Positionering 2015.

Phillips, N., \& Tracey, P. (2007). Opportunity recognition, entrepreneurial capabilities and bricolage: connecting institutional theory and entrepreneurship in strategic organization. Strategic Organization, 5, 313.

Purdy, J.M., \& Gray, B. (2009). Conflicting logics, mechanisms of diffusion, and multilevel dynamics in emerging institutional fields. Academy of Management Journal, 52, 355-380.

Westerman, M., Teunissen, P.W., Fokkema, J.P.I., Van der Vleuten, C.P.M., Scherpbier, A.J.J.A., Siegert, C.E.H., et al. (2013). The transition to hospital consultant and the influence of preparedness, social support, and perception: A structural equation modelling approach. Medical Teacher, 35, 320-327.

Zhao, H., Seibert, S.E., \& Hills, G.E. (2005). The mediating role of self-efficacy in the development of entrepreneurial intentions. Journal of Applied Psychology, 90, 1265-1272. 



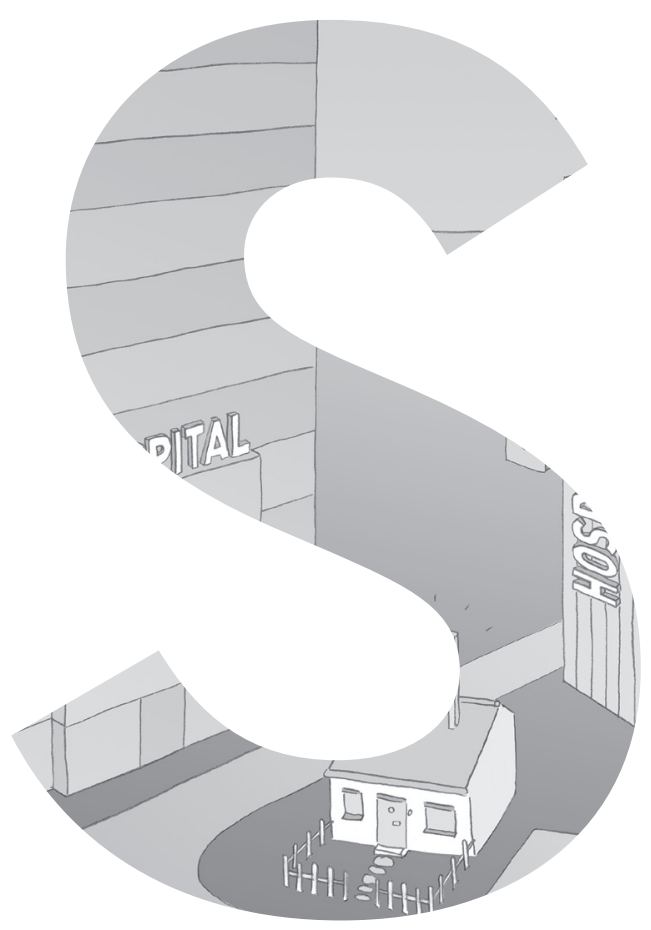

SAMENVATTING 


\section{$1 \quad$ Introductie}

Gedurende de jaren '90 is ondernemerschap door medisch specialisten uitgegroeid tot een invloedrijk fenomeen binnen het zorglandschap van veel Westerse landen (Saltman et al. 2002). Sinds de tweede wereldoorlog hebben drie opeenvolgende golven van hervormingen van de gezondheidszorg hun stempel op het zorgstelsel gedrukt (Cutler, 2002). De eerste golf begon na de tweede wereldoorlog en duurde tot de jaren ' 80 . Het voornaamste doel was het garanderen van toegang tot medische zorg. Brede toegankelijkheid naast wetenschappelijke en technologische ontwikkelingen resulteerden in stijgende kosten die moesten worden beperkt. Met dat doel ontstond een tweede golf hervormingen die startte in de jaren ' 80 en duurde tot de vroege jaren '90 en leidde tot de introductie van wijdverspreide budgeten controlesystemen binnen diverse landen. Om vervolgens het probleem op te lossen van groeiende inefficiënties die het gevolg waren van de budgetteersystematiek, werd een derde golf aan hervormingen ingezet. Als onderdeel van deze golf werden vanaf het begin van de jaren '90 marktprikkels en concurrentie tussen zorgaanbieders geïntroduceerd. Dit resulteerde in een groei van ondernemerschap in diverse landen (Cutler, 2002; Ikkersheim \& Koolman, 2013; Saltman \& Figueras, 1997).

Ondanks de positieve perceptie en het gunstige klimaat ten aanzien van ondernemerschap door medisch specialisten gedurende deze periode, bleef het in Nederland een relatief zeldzaam fenomeen. De grote meerderheid van medisch specialisten werkzaam binnen ziekenhuizen, liet het starten van ZBC's over aan enkele ondernemers. Daarnaast resulteerden de ondernemende ambities van medisch specialisten soms in conflicten met ziekenhuismanagement die zich overvallen voelde door deze aspiraties (Hopstaken, 2008; Kiers, 2008). Deze observaties vormde de basis voor de vragen die wordt beantwoord in dit proefschrift: Wat drijft ondernemerschap door medisch specialisten en hoe kan latent ondernemerschap worden opgespoord en ontwikkeld?

Deze vraag wordt beantwoord door te focussen op factoren die gerelateerd zijn aan (1) de dynamiek op sector- en organisatieniveau en (2) individuele eigenschappen bestaande uit motivationele behoeften en de inschatting van het eigen ondernemend vermogen. Onderstaand worden de belangrijkste bevindingen per hoofdstuk samengevat.

\section{Interne organisatiedynamiek als aandrijver van ondernemerschap onder artsen en managers in ziekenhuizen in westerse landen}

Het literatuuronderzoek beschreven in dit hoofdstuk, is ontworpen op basis van het neo-institutionele model van Greenwood and Hinings (1996). Dit model definieert de 
dynamiek binnen organisaties in termen van gepercipieerde afhankelijkheid, mate van ontevredenheid met de facilitering bij het nastreven van belangen en de ervaren discrepantie ten aanzien van een andere dominante logica binnen de organisatie. Met logica's worden organisatieprincipes bedoeld binnen een sector (Friedland \& Alford, 1991). Aangezien ze bestaan uit diepgewortelde overtuigingen en praktijken (Scott, Ruef, Mendel, \& Caronna, 2001), zijn ze richtinggevend voor de actoren die binnen een sector actief zijn. De introductie van een nieuwe logica of een wijziging van de onderlinge verhouding tussen logica's binnen een sector, heeft daarmee een sterke invloed op alle betrokken actoren.

Uit resultaten blijkt dat de door medisch specialisten ervaren afhankelijkheid van ziekenhuismanagement is toegenomen als gevolg van hervormingen van de gezondheidszorg die hebben geleid tot een sterkere nadruk op de bedrijfsmatige logica die de nadruk legt op waardecreatie, kostenbeheersing en efficiency. De groeiende invloed van de bedrijfsmatige logica ging ten koste van de logica van het medisch professionalisme waarin medisch specialisten van oudsher zijn verankerd. Deze professionele logica beschouwt de artspatiënt relatie als centrale spil in het zorgproces en hecht veel waarde aan maximalisatie van de zorgkwaliteit.

Medisch specialisten hebben verschillende competitieve houdingen ontwikkeld als gevolg van de toegenomen invloed van de bedrijfsmatige logica. Hierbij kan onderscheid worden gemaakt tussen een defensieve- en transformatieve houding. Als onderdeel van een defensieve houding ten aanzien van de bedrijfsmatige logica hebben sommige artsen hun toevlucht gezocht in ondernemend gedrag om daarmee hun traditionele dominante positie en professionele autonomie te beschermen binnen nieuwe organisatorische entiteiten zoals een ZBC's.

Aan de andere kant zijn artsen met een transformatieve houding ten aanzien van de professioneel medische logica meer geneigd om ondernemende elementen uit de bedrijfsmatige logica van het management te adopteren, daarbij aangemoedigd door het vooruitzicht van meer autonomie en inkomen.

Samenvattend is de focus van de competitieve houding ten aanzien van één van de twee logica's bepalend of het ondernemerschap is gedreven uit noodzaak of door een kans. 


\section{Ondernemerschap door artsen verklaard: Interne organisatie dynamiek in Nederlandse ziekenhuizen en ZBC's}

Het kwalitatieve onderzoek beschreven in dit hoofdstuk bestaat uit twee stappen. Als onderdeel van stap één zijn vijftien medisch specialisten en acht managers in vier ziekenhuizen geïnterviewd om de theorie te funderen met betrekking tot de invloed van de interne organisatie dynamiek op ondernemerschap door medisch specialisten. Vervolgens zijn als onderdeel van stap twee, twaalf medisch specialisten en zeven managers in twaalf ZBC's geïnterviewd om daarmee het type verandering vast te stellen dat samenhangt met de oprichting van een ZBC.

De resultaten uit stap één tonen aan dat medisch specialisten worden beïnvloed door interne organisatiedynamiek veroorzaakt door ervaren afhankelijkheid en ontevredenheid ten aanzien van het management en de relatieve verankering in één van de twee soms conflicterende logica's. Deze dynamiek doet zich voor op het niveau van het ziekenhuis en dat van de maatschap of vakgroep. De motivatie om een nieuwe ZBC te starten varieert afhankelijk van de logica waarin de artsen zijn verankerd.

Uit de resultaten van stap twee blijkt dat het oprichtingsproces van een ZBC kan worden beschouwd als een proces van sedimentatie. Hierbij worden elementen uit de bedrijfsmatige logica als het ware 'gelijmd' op de reeds aanwezige medisch professionele logica van medisch specialisten.

Deze uitkomst heeft implicaties voor beleid zowel op landelijk- als ziekenhuisniveau. Gedeeld eigenaarschap en gelijkgeschakelde belangen met bijbehorende incentives of prikkels kunnen dienen als cement waarmee elementen uit de bedrijfsmatige logica 'gelijmd' worden aan de medisch professionele logica van medisch specialisten.

\section{$4 \quad$ Verkenning van persoonlijke belangen van medisch specialisten in ziekenhuizen en ZBC'S}

Belangen van medisch specialisten zijn sterk van invloed op de interne organisatiedynamiek in ziekenhuizen (Greenwood \& Hinings, 1996; Kim et al., 2007). Desondanks is relatief weinig bekend over de inhoud en structuur van de belangen van medisch specialisten. Doel van dit onderzoek is dan ook een structureel model van belangen van medisch specialisten te ontwikkelen en te schatten. 
Op basis van literatuur en 27 semigestructureerde interviews met medisch specialisten is een vragenlijst ontwikkeld bestaande uit tien belangen. Vervolgens hebben 1.475 medisch specialisten in Nederland deze vragenlijst online ingevuld.

Uit de resultaten blijkt een onderscheid tussen één primair belang namelijk 'patiënten zo goed mogelijk helpen' en negen secundaire belangen. Op basis van verdere factor analyse werden binnen de secundaire belangen drie oriëntaties onderscheiden te weten: Werk, setting en leven.

De waarde die aan de verschillende belangen wordt gehecht verschilt tussen specialismen en type ziekenhuizen. Hierbij is de invloed van het type ziekenhuis op de waarde die aan belangen wordt gehecht sterker dan het type specialisme. Inzicht in het relatieve belang dat aan verschillende belangen wordt gehecht kan managers en beleidsmakers helpen beleid te formuleren dat de ontwikkeling van gedeelde belangen ondersteunt.

\section{$5 \quad$ Overbruggen en testen van neo-institutionele theorie en ondernemerschaps-theorie in een ziekenhuis context}

Reeds lang wordt de combinatie van institutionele- en ondernemerschaptheorie gezien als potentieel waardevol om verschillen in het ontstaan van ondernemerschap te verklaren (Phillips \& Tracey, 2007). Dit onderzoek had als doel dit potentieel te ontginnen.

Voor dit onderzoek naar het ontstaan van ondernemerschap onder medisch specialisten binnen ziekenhuizen, is het neo-institutionele model zoals ontwikkeld door Greenwood and Hinings (1996) gebruikt. Op basis van dit model wordt de interne dynamiek binnen ziekenhuizen gedefinieerd als een samenspel van de door medisch specialisten gepercipieerde afhankelijkheid van het management, (on)tevredenheid met de mate van facilitering door het management bij het nastreven van de persoonlijke belangen en de relatieve verankering in bepaalde logica's. Vervolgens is het model onder andere aangepast door de intentie om te gaan ondernemen op te nemen als een uitkomstvariabele. Het nieuwe model is vervolgens geoperationaliseerd en getest.

Op basis van een grootschalig onderzoek onder medisch specialisten in Nederlandse ziekenhuizen ( $n=1.430)$, werd ondersteuning gevonden voor de vooraf geformuleerde hypothesen die intra-organisatiedynamiek relateren aan de intentie van medisch specialisten om te gaan ondernemen. 
Verder bleek de inschatting van het eigen ondernemend vermogen positief gerelateerd aan latent ondernemerschap van individuele medisch specialisten, terwijl de inschatting van de capaciteiten van de organisatie hier negatief aan gerelateerd bleek. Ook werd bewijs gevonden voor de verbondenheid tussen markt- en institutionele turbulentie. Daar waar turbulentie in de markt een negatieve invloed heeft op de door medisch specialisten gepercipieerde afhankelijkheid ten opzichte van het management, blijkt de institutionele turbulentie juist een positieve invloed op deze gepercipieerde afhankelijkheid te hebben.

Samenvattend heeft dit onderzoek bijgedragen aan de theorie door een toekomstgericht institutioneel model van latent ondernemerschap te valideren binnen de gezondheidszorg.

\section{Motivationele behoeften en de inschatting van het eigen kunnen als voorspellers van latent ondernemerschap onder medisch specialisten in ziekenhuizen}

In dit hoofdstuk wordt de invloed onderzocht van motivationele behoeften en de inschatting van het eigen kunnen van medisch specialisten op hun intentie om een ZBC op te richten.

Op basis van data verkregen uit een grootschalige meting onder medisch specialisten werkzaam binnen ziekenhuizen in Nederland ( $n=1.430)$, werden beschrijvende statistieken en factoranalyses uitgevoerd in relatie tot motivationele behoeften, inschatting van het eigen ondernemend vermogen en de intentie om te ondernemen binnen verschillende soorten ziekenhuizen en typen specialisten. Daarnaast werden met behulp van 'structural equation modelling' technieken de relaties tussen deze constructen onderzocht.

De behoefte aan autonomie en de inschatting van het eigen ondernemend vermogen bleken positief samen te hangen met de intentie om te gaan ondernemen, terwijl de behoefte om ergens bij te horen hier een negatieve invloed op heeft. De behoefte om iets te bereiken en de behoefte invloed uit te oefenen bleken positief maar indirect van invloed op de intentie om te gaan ondernemen. Daarnaast bleken de behoefte aan autonomie en de inschatting van het eigen ondernemend vermogen significant hoger binnen ZBC's vergelijken met STZ-ziekenhuizen en UMC's ( $p<0.01$ ). De intentie om te gaan ondernemen bleek hoger bij medisch specialisten in snijdende specialismen dan in beschouwende specialismen $(p<0.01)$. Op basis hiervan kan worden geconcludeerd dat motivationele behoeften, de inschatting van het eigen ondernemend vermogen en de intentie om te gaan ondernemen niet homogeen verdeeld zijn over typen ziekenhuizen en specialismen. 


\section{$7 \quad$ Conclusies op hoofdlijnen en belangrijkste implicaties}

Dit proefschrift beschrijft het onderzoek naar de factoren die van invloed zijn op het ontstaan van ondernemerschap door medisch specialisten. Hierbij wordt onderscheid gemaakt tussen:

- Dynamiek op sector- en organisatieniveau

- Individuele eigenschappen bestaande uit motivationele behoeften en de inschatting van het eigen ondernemend vermogen

De aanwezigheid van de bedrijfsmatige logica naast de logica van het medisch professionalisme waarin professioneel gedifferentieerde groepen zijn verankerd, vormt de basis voor unieke intra-organisatie dynamieken binnen ziekenhuizen. Deze dynamieken worden verder beïnvloed door persoonlijke primaire en secundaire belangen van medisch specialisten die aan de basis staan van gepercipieerde afhankelijkheid van ziekenhuismanagement en mogelijke (on-)tevredenheid over de wijze waarop deze belangen worden gefaciliteerd. Sterke ontevredenheid over de facilitering door het management wordt versterkt door de verankering van artsen in de logica van het medisch professionalisme en kan vervolgens deze verankering verder versterken. Als deze verankering vergezeld gaat van een positieve inschatting van het eigen ondernemend vermogen dan heeft dit een positieve invloed op de intentie om te gaan ondernemen.

Daarnaast werden individuele factoren gevonden die ondernemerschap door medisch specialisten beïnvloeden. Zo bleken de behoefte aan autonomie en een positieve inschatting van het eigen ondernemend vermogen positief samen te hangen met de intentie om te gaan ondernemen. De behoefte om ergens bij te horen bleek die intentie negatief te beïnvloeden.

\section{Belangrijkste implicaties voor de praktijk Implicaties voor het management}

Verklein potentiële ontevredenheid onder medisch specialisten door het introduceren van gedeelde incentives...

Op basis van het onderzoek binnen ZBC's werd geconcludeerd dat ontevredenheid onder medisch specialisten kan worden gereduceerd door het bieden van gedeelde incentives. Deze incentives bleken al eerder een positief effect te hebben op het functioneren van de organisatie en op onderlinge samenwerking (Andrews, 2010; Calciolari et al., 2011; Edwards, 2003; Klopper-Kes et al., 2010; Mache et al., 2012; Ommen et al., 2009; Purdy \& Gray, 2009). In dit onderzoek bleken gelijkgeschakelde belangen door gedeelde incentives binnen ZBC's het cement waarmee ondernemende waarden werden 'gelijmd' op de logica van het 
medisch professionalisme. Er wordt verondersteld dat managers van ziekenhuizen kunnen bijdragen aan de onderlinge samenwerking door vergelijkbare incentives te introduceren.

... en ontwerp die incentives op basis van de individuele structuur van belangen.

Gegeven de resultaten van zowel de interviews als de grootschalige meting, kunnen die gedeelde incentives worden ingericht op basis van de persoonlijke belangenstructuur van individuele medisch specialisten. Voor artsen die bijvoorbeeld de meeste waarde hechten aan werk-gerelateerde belangen zouden incentives elementen kunnen bevatten op het gebied van variëteit, specialisatie of onderzoek. Artsen die de werksetting belangrijk vinden zouden beloond kunnen worden door investeringen te bieden in faciliteiten of door het bieden van een rol bij het besturen van het ziekenhuis bij het realiseren van bepaalde organisatiebrede doelstellingen.

Verbeter het onderlinge begrip tussen artsen en ziekenhuismanagers door een proces te introduceren van socialisatie en sedimentatie voor (nieuwe) medisch specialisten en managers.

Betrokkenheid tijdens de oprichtingsfase en bij het bestuur van een ZBC is in essentie een sedimentatieproces dat medisch specialisten die zijn verankerd in de medische logica, in staat stelt om zich elementen uit de bedrijfsmatige logica eigen te maken. Hierdoor ontstaat een hybride logica die geheel of gedeeltelijk overlapt met de logica van het management. Op basis hiervan wordt veronderstelt dat een vergelijkbaar proces van sedimentatie voor medisch specialisten in ziekenhuizen kan bijdragen aan het verbeteren van de werkrelatie met het management binnen een ziekenhuis.

Recent onderzoek naar de transitie van arts in opleiding naar medisch specialist toont aan dat nieuwe specialisten vinden dat zij goed zijn voorbereid voor de klinische kennis en vaardigheden, maar dat zij zich onvoldoende voorbereid vinden op de benodigde meer generieke competenties zoals management en financiën (Westerman et al., 2013). Het bevorderen van sedimentatie door het bieden van een socialisatieprogamma door ziekenhuizen en ZBC's met aandacht voor onderwerpen als leiderschap, samenwerking met management, lean management en financiën, kan positief bijdragen aan de dialoog en samenwerking tussen medisch specialisten en managers.

Ook voor managers geldt dat zij hun effectiviteit in de samenwerking met medisch specialisten binnen ziekenhuizen kunnen vergoten door elementen uit de medische logica te adopteren zoals expliciet uitgesproken aandacht voor de leidende rol van medisch specialisten binnen het zorgproces om daarmee een meer hybride logica te ontwikkelen. 


\section{Implicaties voor medisch specialisten}

Vergroot het bewustzijn over de aanwezigheid van, en verankering in, institutionele logica's.

Bewustzijn over de eigen logica en die van collega medisch specialisten kan bijdragen aan het onderlinge begrip binnen maatschappen en vakgroepen. Daarnaast kunnen artsen die zijn verankerd in een hybride of bedrijfsmatige logica dienen als liaison zowel binnen medisch specialistische groepen als tussen artsen en het management. Het instrument dat in dit onderzoek is gevalideerd en gebruikt, kan worden toegepast om verschillen in logica's tussen medisch specialisten te identificeren.

Artsen die zijn verankerd in een hybride of bedrijfsmatige logica hebben de potentie om uit te groeien tot change agent.

Medisch specialisten die op grond van hun hybride of bedrijfsmatige logica in staat zijn om de verschillen tussen de medische logica en de bedrijfsmatige logica te overbruggen, hebben een potentie die acceptatie van de status-quo overstijgt. In plaats daarvan kunnen zij fungeren als change agents zowel binnen als buiten hun instelling. Voorbeeld hiervan zijn onder andere Gary Kaplan, directeur van het Virginia Mason Medical Center en Loek Winter, oprichter en directeur van DC Klinieken.

Gebruik logica's, belangen en motivationele behoeften als criteria bij het ontwerp van de toekomstige positie van medisch specialisten in ziekenhuizen.

In het kader van de huidige discussie over de positie van de medisch specialist na 2015, wijzen velen op de voordelen die verplicht dienstverband zou hebben voor de kosten van de gezondheidszorg en de bestuurbaarheid van ziekenhuizen (Dijl van et al., 2013; NRC, 2013). Dit onderzoek wees echter uit dat $80 \%$ van de artsen die op dit moment in maatschappen werken, dit verplichte dienstverband niet zien zitten (Orde van Medisch Specialisten, 2012). Op grond van deze en andere bevindingen uit dit onderzoek wordt aanbevolen om logica's, belangen en motivationele behoeften mee te nemen als criteria bij het ontwerpen van de toekomstige positie van medisch specialisten in ziekenhuizen. Dit kan onnodige frictie en een verlies van ervaren en ondernemende medisch specialisten uit ziekenhuizen voorkomen. 
De stap naar ondernemerschap brengt nieuwe afhankelijkheden die mogelijk additionele competenties of ondersteuning vereisen.

Zoals op grond van dit onderzoek kon worden geconcludeerd zijn de drijfveren van artsen om te gaan ondernemen complex. Voor artsen die zijn verankerd in de logica van het medisch professionalisme van wie de intentie om te gaan ondernemen is getriggerd door ontevredenheid en een behoefte aan autonomie, is het belangrijk te onderkennen dat ondernemerschap nieuwe en andere afhankelijkheden met zich meebrengt. Een ondernemer zal nieuwe afhankelijkheden ervaren, ditmaal ten aanzien van andere invloedrijke actoren buiten de ZBC zoals zorgverzekeraars en banken die vergelijkbaar met het ziekenhuismanagement, verankerd zijn in een bedrijfsmatige logica. Om als ondernemer succesvol te zijn in het omgaan met deze actoren, kan het waardevol zijn om hierbij ondersteuning te zoeken dan wel te investeren in eigen competenties op gebieden als bedrijfsvoering, financiën en onderhandelen. Dit laatste geldt ook voor artsen die verankerd zijn in een bedrijfsmatige of hybride logica aangezien ook voor hen geldt dat de geneeskunde opleiding artsen slechts beperkt toerust met bovengenoemde competenties (Westerman et al., 2013).

\section{Implicaties voor beleidsmakers en zorgverzekeraars}

Het is duidelijk dat ondernemerschap een moeilijk onderwerp is voor beleidsmakers die enerzijds trachten om verdere kostenstijgingen in de gezondheidszorg te beperken maar ook vernieuwing en innovatie willen stimuleren. Als onderdeel van gereguleerde marktwerking is het van belang om ruimte te bieden aan ondernemende artsen die als doel hebben de zorg te verbeteren met innovatieve concepten en behandelingen. Als marktmeester is de Nederlandse Zorg Autoriteit (NZA) verantwoordelijk voor het monitoren en veiligstellen van toegang en concurrentie. Vanuit die rol zou het suggesties kunnen doen met betrekking tot zorginkoopbeleid zoals dat wordt ontwikkeld door zorgverzekeraars. Eén van die suggesties zou de invoer van standaard reservering voor ondernemerschap en innovatie binnen de contracteerruimte kunnen zijn. Maar ook zonder interventie door de NZA, zouden zorgverzekeraars een geoormerkt percentage van het totale zorginkoopbudget kunnen alloceren aan innovatieve en snel groeiende ondernemende initiatieven. Selectie van deze initiatieven kan plaatsvinden op basis van transparante en objectieve criteria toegepast op een non-discriminatoire wijze. Deze criteria kunnen elementen bevatten zoals de mate van innovatie, verwachte kosteneffectiviteit en de bijdrage aan het welbevinden van patiënten. Transparante communicatie over deze criteria kan helpen om latent ondernemerschap van artsen te richten op belangrijke gebieden, terwijl simultaan ruimte wordt geboden aan innovatief ondernemerschap dat een bijdrage kan leveren aan het duurzaam verbeteren van de gezondheidszorg in het algemeen en de kwaliteit van zorg aan de patiënt in het bijzonder. 


\section{Referenties}

Andrews, R. (2010). Organizational social capital, structure and performance. Human Relations, 63, 583-608.

Calciolari, S., Cantu, E., \& Fattore, G. (2011). Performance management and goal ambiguity: Managerial implications in a single payer system. Health Care Management Review, 36, 164-174.

Chen, C.C., Greene, P.G., \& Crick, A. (1998). Does entrepreneurial self-efficacy distinguish entrepreneurs from managers? Journal of Business Venturing, 13, 295-316.

Dijl van, M., Schraverus, J., Linders, H., Bochove, K., Moors, M., \& Crijns, R. (2013). Onderzoek naar besturingsmodellen voor een duurzame relatie tussen ziekenhuis en specialist. Utrecht: PwC in opdracht van de NVZ.

Edwards, N. (2003). Doctors and managers: poor relationships may be damaging patients-what can be done? Quality and Safety in Health Care, 12, i21-i24.

Greenwood, R., \& Hinings, C.R. (1996). Understanding radical organizational change: Bringing together the old and the new institutionalism. Academy of Mangement Review, 21, 1022-1054.

Kim, T.Y., Shin, D., Oh, H., \& Jeong, Y.C. (2007). Inside the iron cage: Organizational political dynamics and institutional changes in presidential selection systems in Korean universities, 1985-2002. Administrative Science Quarterly, 52, 286-323.

Klopper-Kes, A.H.J., Meerdink, N., Wilderom, C.P.M., \& Van Harten, W.H. (2010). Effective cooperation influencing performance: a study in Dutch hospitals. International Journal for Quality in Health Care, 23, 94-99.

Mache, S., Vitzthum, K., Klapp, B.F., \& Groneberg, D.A. (2012). Improving quality of medical treatment and care: are surgeons' working conditions and job satisfaction associated to patient satisfaction? Langenbecks Archives of Surgery, 397, 973-982.

NRC. (2013). Goedkopere zorg hoeft niet ingewikkeld te zijn.

Ommen, O., Driller, E., Koehler, T., Kowalski, C., Ernstmann, N., Neumann, M., et al. (2009). The Relationship between Social Capital in Hospitals and Physician Job Satisfaction. BMC Health Services Research, 9.

Orde van Medisch Specialisten. (2012). Discussienota Positionering 2015.

Phillips, N., \& Tracey, P. (2007). Opportunity recognition, entrepreneurial capabilities and bricolage: connecting institutional theory and entrepreneurship in strategic organization. Strategic Organization, 5, 313.

Purdy, J.M., \& Gray, B. (2009). Conflicting logics, mechanisms of diffusion, and multilevel dynamics in emerging institutional fields. Academy of Management Journal, 52, 355-380.

Westerman, M., Teunissen, P.W., Fokkema, J.P.I., Van der Vleuten, C.P.M., Scherpbier, A.J.J.A., Siegert, C.E.H., et al. (2013). The transition to hospital consultant and the influence of preparedness, social support, and perception: A structural equation modelling approach. Medical Teacher, 35, 320-327.

Zhao, H., Seibert, S.E., \& Hills, G.E. (2005). The mediating role of self-efficacy in the development of entrepreneurial intentions. Journal of Applied Psychology, 90, 1265-1272. 



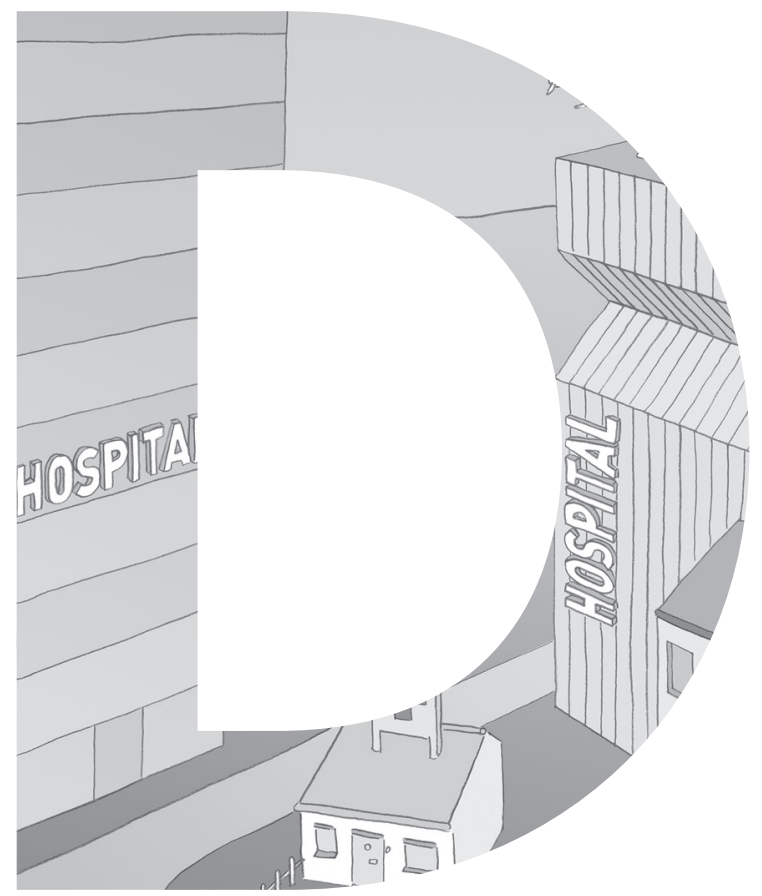

DANKWOORD 


\section{Dankwoord}

Een promotieonderzoek is als een verre reis: Vooraf lees je over - en luister je naar - de verhalen van hen die zo gelukkig waren om de gedroomde bestemming eerder te bereiken. Onderweg ontmoet je reisgenoten met wie je ontdekkingen deelt en met wie je ontberingen doorstaat om tenslotte samen te genieten als het einddoel is bereikt.

De wens om op reis te gaan was niet ontstaan zonder Jan Telgen. Jan, jij was en bent voor mij een inspiratiebron. Je inhoudelijke kennis waarmee je zonder opsmuk indruk maakte op onze klanten en collega's liet mij de waarde zien van echte verdieping. Jij wees me de weg naar de Universiteit Twente.

In Enschede aangekomen maakte ik kennis met Wim van Harten en Aard Groen. Hoewel wij elkaar tijdens het onderzoek niet altijd gezamenlijk ontmoetten, vormden we samen toch een team. Wim, jouw wetenschappelijke degelijkheid en ervaring als bestuurder in de zorg bleken van onschatbare waarde. Je verbaasde me regelmatig met je scherpzinnige vragen die mij aanzetten tot nieuw spitwerk. Aard, altijd kon ik een beroep doen op jouw kennis van ondernemerschap in combinatie met institutionele theorie en op je creativiteit hoe deze toe te passen. Als ik het even niet meer zag, schetste jij met enkele pennenstreken een wereld aan kansen en mogelijkheden. Dank daarvoor!

Michel Ehrenhard, jij was mijn dagelijkse reisgenoot. Onze gesprekken voerden van abstracte theoretische verhandelingen naar ervaringen met kerken en religies tot een dialoog over interne dynamieken binnen hier niet nader te definiëren organisaties. En dat alles vaak binnen vaak luttele ogenblikken.

Naast de directe reisgenoten waren er ook de collega's binnen HTSR bij wie het goed vertoeven was: De gezellige lunches, de vele koppen koffie en inspirerende onderzoeken gaven onderweg een thuisgevoel. Matthijs de Rover, dank voor de bijdrage die je aan het onderzoek hebt geleverd als onderdeel van je afstudeeropdracht. Karin Groothuis, dank voor je aanwijzingen bij mijn eerste verkenningen in 'statistiekland'. Eenmaal daar, heb ik veel gehad aan Anja Boevé (Universiteit Utrecht) en Max Aangenendt (Universiteit Leiden) zonder wie het structural equation modelling een stuk moeizamer zou zijn verlopen. 
Voor het maken van een uitdagende reis zijn soms helpende handen nodig. Door mijn toenmalige werkgever Significant werd ik gefaciliteerd bij het vinden van de benodigde onderzoekstijd. Amplixs stelde hun online meetapplicatie ter beschikking om doeltreffend de dataverzameling te kunnen uitvoeren. Op Clare Wilkinson kon ik altijd een beroep doen voor een laatste taalkundige check en tenslotte heeft Gerton Hermers zijn artistieke talent gebruikt om een ingewikkeld onderwerp te vatten in één beeld dat nu de cover van dit proefschrift vormt. Ook de vele tijd die je hebt gestoken in de opmaak van dit proefschrift wil ik niet onvermeld laten.

Tijdens de reis waren er momenten dat deuren geopend moesten worden. Ik ben dan ook buitengewoon dankbaar voor de hulp die ik daartoe mocht ontvangen van de Orde van Medisch Specialisten en de Nederlandse Vereniging van Ziekenhuizen. Bart Heesen, Janko de Jonge, Ernst Ziere, Carolien Meijer en Katrien Hendriks; jullie zagen snel de waarde van mijn onderzoek voor jullie achterban en hielpen mij daarbinnen te navigeren. Dit geldt ook voor Guus van Montfort en Margot van de Starre wiens hulp de weg effende naar ziekenhuisbestuurders. Veel leden van de Vrijgevestigde Specialisten Deventer (VSD) binnen het Deventer Ziekenhuis waren bereid om deel te nemen aan een eerste pilotmeting. Dankzij hen kon het onderzoeksinstrument worden getest en verbeterd. Dank aan de vele medisch specialisten en ziekenhuismanagers in diverse ziekenhuizen en ZBC's die vervolgens hebben deelgenomen aan het onderzoek. Zonder jullie deelname was dit onderzoek niet geslaagd.

Tenslotte, hoewel iedere verre reiziger het risico loopt ontworteld te raken bleken mijn kinderen Sifrah (5) en David (3) daartegen een zeer effectieve remedie. Ik prijs mijzelf gelukkig met Miranda, mijn vrouw. Samen hebben we veel doorstaan en de reis was helaas niet zonder tegenslagen. Als ik 'weer eens even wat ging doen', nam jij veel van de zorgtaken op je. Het is dan ook de hoogste tijd om ditmaal samen op reis te gaan: Naar het Beloofde Land! 



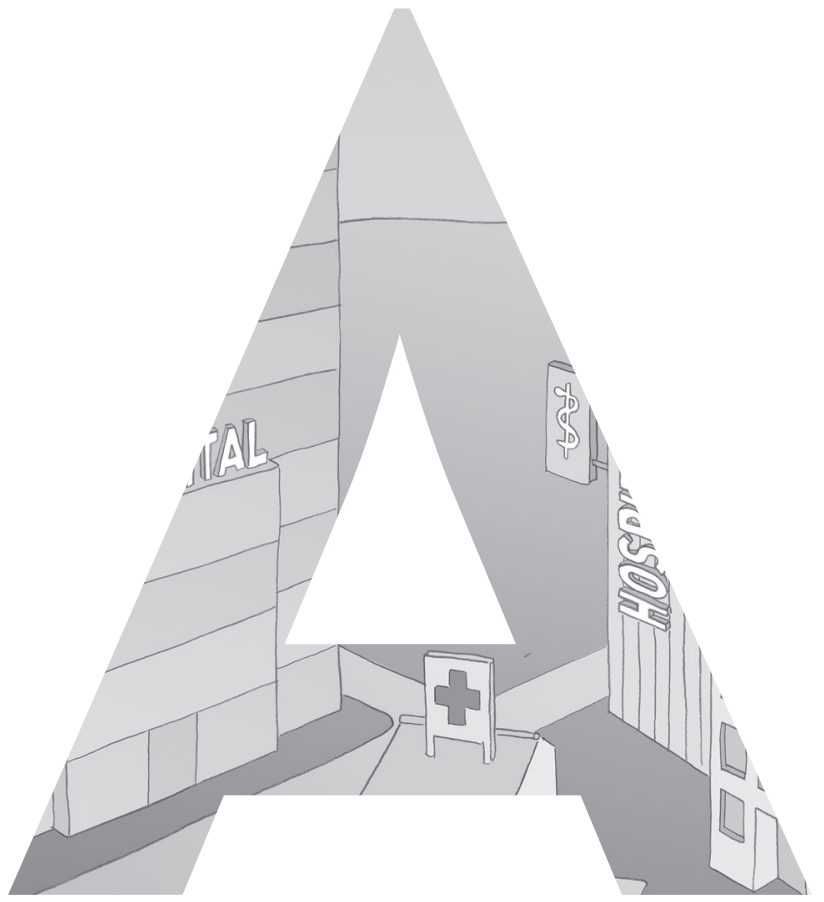

OVER DE AUTEUR 


\section{Over de auteur}

Wout Koelewijn is geboren op 28 maart 1976 in Amersfoort, waar hij ook zijn middelbare school heeft gevolgd. Na het behalen van zijn VWO diploma in 1994 woonde en werkte hij in kibboets Nes Ammim in Israel. In 1995 startte hij vervolgens met zijn studie Internationale Bedrijfskunde in Maastricht waarvoor hij tevens studeerde aan de Hebreeuwse Universiteit te Jeruzalem, Israel en Universidad del Pacifico in Lima, Peru. Ook deed hij werkervaring op bij Baan Business Innovation te Grand Rapids, VS. Na afronding van zijn opleiding ging hij werken bij ExxonMobil waar hij een kleine vier jaar werkzaam was in Brussel en Rotterdam. Op zoek naar meer maatschappelijke relevantie maakte hij de overstap naar de zorgsector. Als adviseur en interim manager was hij vervolgens actief bij zorgaanbieders, zorgverzekeraars en overheden. Zo werkte hij nauw samen met medisch specialisten en ziekenhuismanagers binnen diverse ziekenhuizen waaronder het Catharina Ziekenhuis in Eindhoven, het UMC St. Radboud te Nijmegen, het Medisch Centrum Leeuwarden en het Deventer Ziekenhuis. Momenteel is hij intensief betrokken bij de Beter Dichtbij-polis die is ontwikkeld vanuit de Samenwerkende Algemene Ziekenhuizen (SAZ) in samenwerking met a.s.r. en DSW. Gedreven door de wens om ondernemerschap door medisch specialisten te begrijpen en te ondersteunen, nam hij in mei 2009 het initiatief tot een parttime promotieonderzoek naar dit onderwerp binnen de Universiteit Twente. Het resultaat van dit onderzoek treft $u$ aan in dit proefschrift.

Wout is getrouwd met Miranda en vader van Sifrah (2008) en David (2010). 
